\title{
Heide Wüst
}

\section{Tradition und Innovation in der sowjetrussischen Dorfprosa der Sechziger und Siebziger Jahre \\ Zu Funktion, Darstellung und Gehalt des dörflichen Helden bei Vasilij Šukšin und Valentin Rasputin}

Verlag Otto Sagner München - Berlin - Washington D.C.

Digitalisiert im Rahmen der Kooperation mit dem DFG-Projekt „Digi20“

der Bayerischen Staatsbibliothek, München. OCR-Bearbeitung und Erstellung des eBooks durch den Verlag Otto Sagner:

http://verlag.kubon-sagner.de

( $)$ bei Verlag Otto Sagner. Eine Verwertung oder Weitergabe der Texte und Abbildungen, insbesondere durch Vervielfältigung, ist ohne vorherige schriftliche Genehmigung des Verlages unzulässig. 


\title{
SLAVISTISCHE BEITRÄGE
}

\author{
BEGRÜNDET VON \\ ALOIS SCHMAUS \\ HERAUSGEGEBEN VON \\ JOHANNES HOLTHUSEN · HEINRICH KUNSTMANN \\ PETER REHDER - JOSEF SCHRENK \\ REDAKTION \\ PETER REHDER \\ Band 178
}

\section{VERLAG OTTO SAGNER \\ MÜNCHEN}




\section{HEIDE WÜST}

\section{RADITION UND INNOVATION IN DER SOWJETRUSSISCHI DORFPROSA DER SECHZIGER UND SIEBZIGER JAHRE}

Zu Funktion, Darstellung und Gehalt des dörflichen Helden bei Vasilij Suksin und Valentin Rasputin

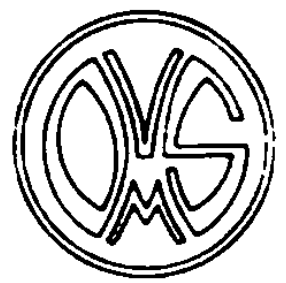

VERLAG OTTO SAGNER · MÜNCHEN 1984 
ISBN 3-87690-285-1

(C) Verlag Otto Sagner. München 1984

Abteilung der Firma Kubon \& Sagner, München

Druck: D. Grăbner. Altendorf 
$V \circ r w \circ r t$

Die vorliegende Untersuchung wurde im Wintersemester $1983 / 84$ vom Gemeinsamen Ausschus der Philosophischen Fakultaten der Albert-Ludwigs-Universitat Freiburg i.Br. als Dissertation angenommen.

Dank schulde ich Herrn Prof. Dr. Rolf-Dieter Kluge, der meine Arbeit betreute und ihren Fortgang stets mit Interesse verfolgte. Der Deutsche Akademische Austauschdienst (DAAD) ermbglichte mir in den Jahren $1979 / 80$ und 1980/81 zwei längere Forschungsaufenthalte in Leningrad und Moskau und forderte dadurch wesentlich meine Studien. Den Mitarbeitern des DAAD sei an dieser Stelle ebenfalls gedankt.

Mainz, April 1984 Heide wust 


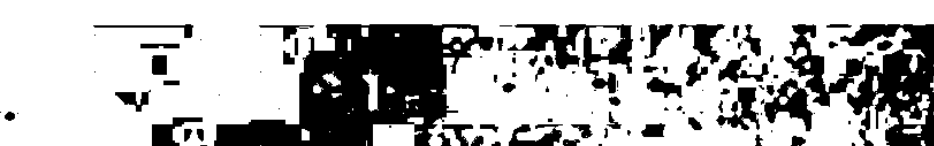

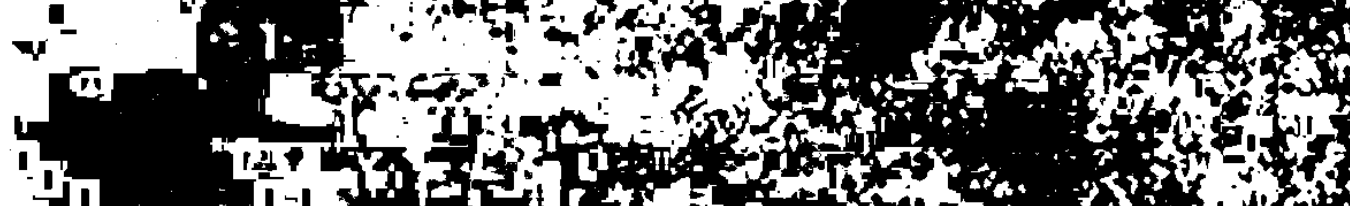

H

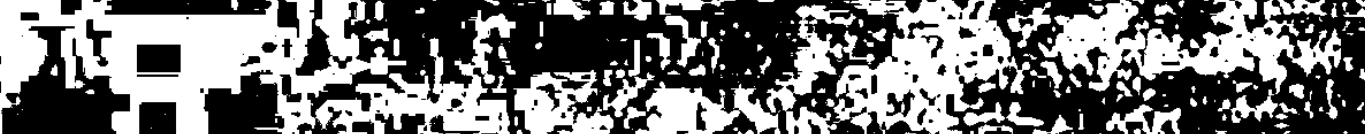

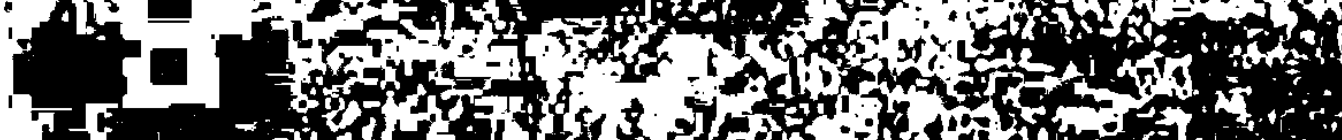

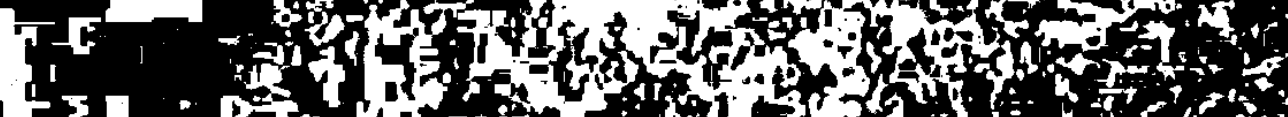

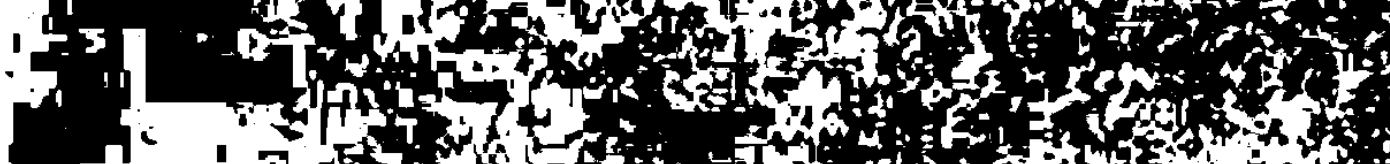
W.

Fin

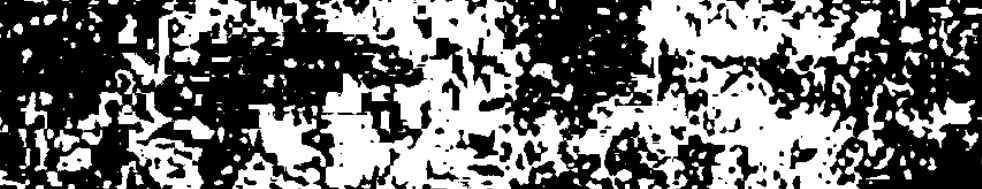

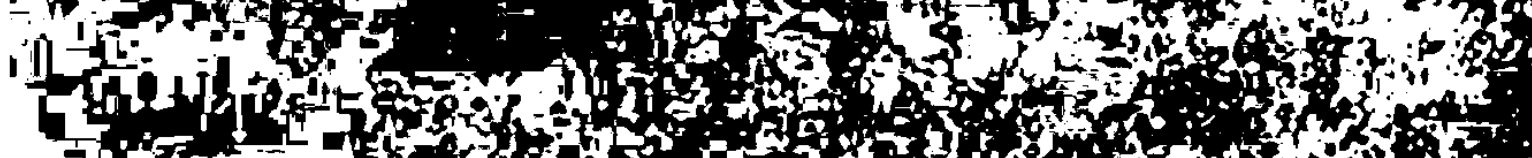
$3+$

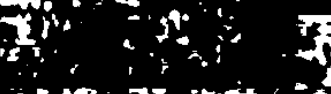

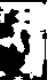

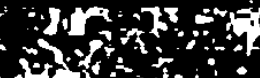

5

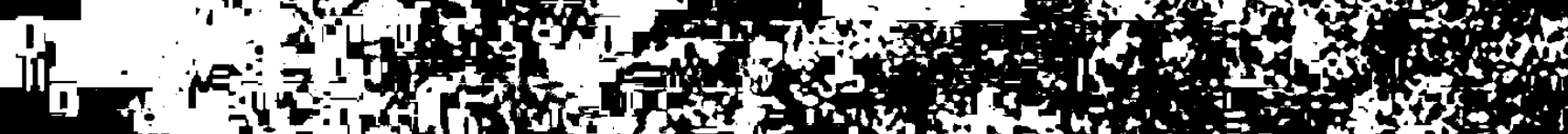
5.

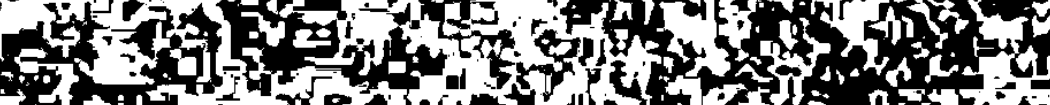

1.

215

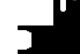

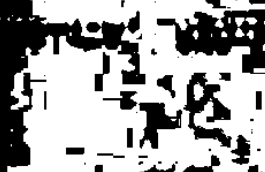

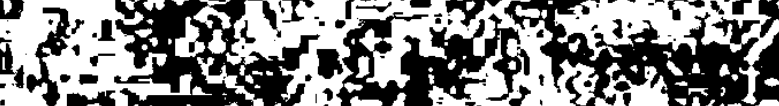
P.

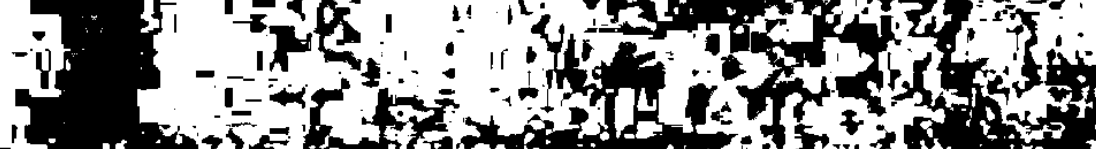

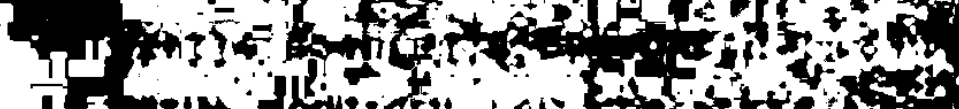

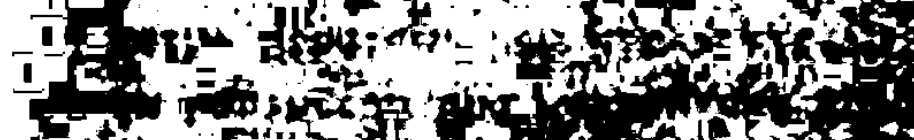

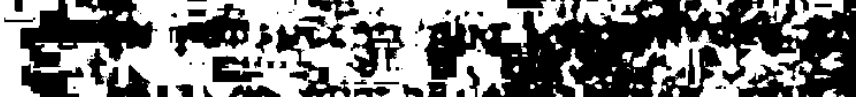

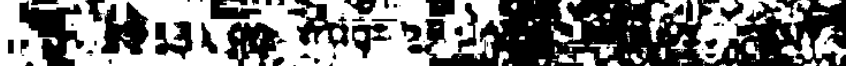
Th posa

W.

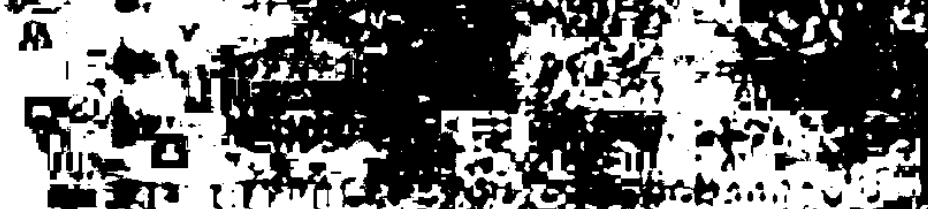

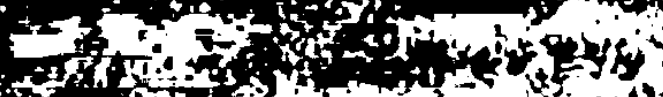

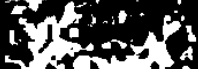

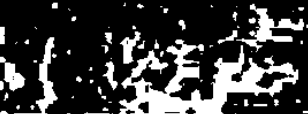
(n)

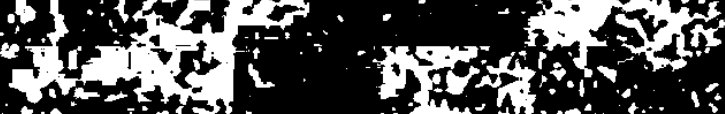

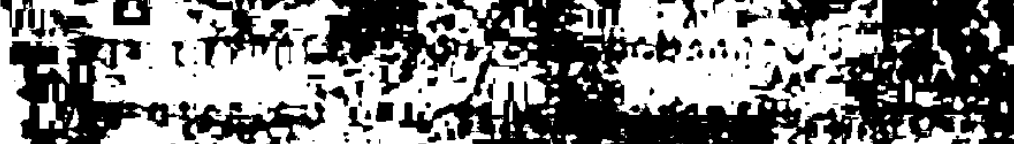

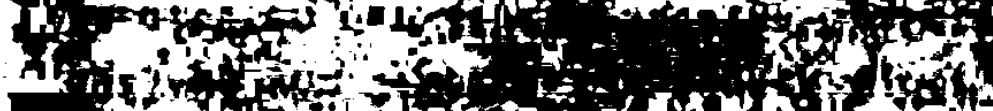

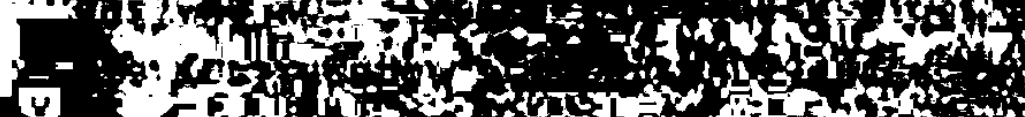

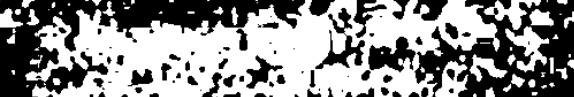

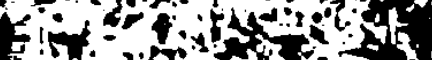
14. 1

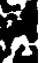

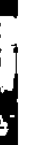

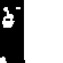


o. E $\quad$ in 1 e $i t u n g$

1. Aktualityt und Relevanz des Dorfes und des dorflichen Helden fur die

Literatur der sechziger und siebziger Jahre

1.1. Soziobkonomischer Wandel und Literatur 9

1.2. Die Problematisierung des technischen Fortschritts

1.3. Die "innerliterarischen" Faktoren

1.3.1. Das Interesse an der "narodnorazgovornaja rec."

1.3.2. Modifikation der "skaz"-Tradition. 27

1.3.3. Die Ablosung des literarischen Kanons 28

2. Vasilij Makarovic ś $u k$ s $i n$

2.1. Das Thema der zwei Kulturen 34

2.1.1. Zum Bezug von Biographie und literarischem Thema 34

2.1.2. Kontrast und Konfrontation als
thematisches und kunstierisches Prinzip 40

2.1.3. Die Darstellung des "naturlichen Menschen" 59

2.1.4. Der Ubergangstypus 65

2.1.4.1. "Ubergangspsychologie" und Entstehung
eines neuen Bewußtseins

2.1.4.2. Ethische und sozialkritische Aspekte der "Ubergangsproblematik" 74

2.2. Die Gestalt des Sonderlings 83

2.2.1. Der Drang nach Selbstdarstellung 86

2.2.2. Die Idee des Festtags : Das Feiern

2.2.3. Die Sonderlinge und ihre "Antiwelt" 102

2.2.3.1. Absonderlichkeit kontra Konvention 103

2.2.3.2. Absonderlichkeit als Abwehrhaltung 105

2.3. Der Aspekt des "Karnevalistischen" in Sukšins Prosa

2.4. Zusammenfassung 122 
3. Valentin Grigoreviz $R$ a $s$ p $t i n$

3.1. Charaktere und Bewubtseinstypen bei Valentin Rasputin

- Die Erzăhlung "Poslednij srok" -

3.1.1. Der traditionelle dorfliche Charakter - Die Gestalt Annas -

3.1.1.1. Erzăhlerische Verfahren und Sprache

3.1.1.2. Die geistige Welt Annas

3.1.2. Der moderne Mensch - Die Charaktere der Kinder -

3.1.3. Zus ammenfassung

3.2. Das Dorf und sein Charakter in der künstlerisch-philosophischen Konzeption Valentin Rasputins

- Die Novelle "Prošcanie s Matëroj" -

3.2.1. Die Einheit des Weltgebaudes und der Gedanke der "hobheren Ordnung"

3.2.1.1. Die Storung des "ewigen Kreislaufs"

3.2.2. Die Darstellung der Helden und inre Beziehung zu Matera

202

3.2.3. Die Einheit von Mensch und Natur als Grundlage der organischen Entwicklung des Lebens

3.2.3.1. Der fehlende Zusammenhang der Zeiten

3.2.3.2. Die negative Welt der "Fremden"

3.2.3.3. Die Beziehung zum Geschlecht

3.2.3.4. Die Bedeutung der Erinnerung

$3.2 \cdot 3.5$. Organisches Leben und Integritat der Personlichkeit

3.2.4. Zusammenfassung 
o. E i n l e i t u n 8

Der fast schon zum Schlagwort gewordene Begriff "Dorfprosa" (derevenskaja proza) bezeichnet einen Bereich der russischen Gegenwartsliteratur, der sich um die Mitte der sechziger Jahre zu entwickeln begann und seit Anfang der siebziger einen fuhrenden Platz in der modernen sowjetrussischen Literatur einnimmt. Von einigen Kritikern bereits zum Zeitpunkt ihres Entstehens als "die am meisten ernstzunehmende Richtung in der heutigen russischen Prosa" bezeichnet ${ }^{1)}$, wurde die sogenannte "derevenskaja proza" in mancherlei Hinsicht zum literarischen Ereignis, zu einer besonderen und zumindest anfänglich geradezu spektakulären Erscheinung, die wie keine andere die sowjetische Literaturkritik der letzten funfzehn Jahre bestimmte und immer wieder neue Diskussionen provozierte.

Ende der sechziger Jahre war es unter den sowjetischen Literaten zu einer wahren Bewegung zum russischen Dorf gekommen, das als thematisches Material eine Vielzahl von Autoren immer wieder aufs neue anzog. Im Laufe weniger Jahre entstand eine rast unuberschaubare Menge vorwiegend kurzerer Prosa zum Dorfthema, innerhalb derer sich zunehmend Autoren wie Vasilij Šukšn, Vasilij Belov, Sergej Zalygin, Viktor Astaf'ev, Valentin Rasputin und andere profilierten, die heute $z u$ den fuhrenden Reprăsentanten der russischen Gegenwartsliteratur zăhlen.

Frappierend waren zunăchst nicht nur Intensitat und Ausmas dieser literarischen Bewegung zum Dorf hin, sondern vor allem auch die besondere thematische orientierung der neuen Prosa. Wie wenig sich diese in die Tradition der sowjetischen Bauern- und Kolchosliteratur einfügen lieb, zeigt bereits das bei Forschern und Kritikern

1) $V_{g l}$. V. Gusev, 0 proze, derevre $i$ cel'nych ljudjach, in: Literaturnaja gazeta, 14.2 .1968 
lăngst zum Allgemeinplatz gewordene Unbehagen an dem Terminus "Dorfprosa":

Sowohl die Unzurriedenheit mit dem Terminus "Dorfprosa" als auch das gleichzeitige unverhohlene Bedürnis danach spiegeln eine reale und objektive Besonderheit der gegenwărtigen Literatur wider. Der Begriff "Dorfprosa" ist zweifellos für die auberst komplizierten und verschiedenartigen Erscheinungen, auf die er sich bezieht, zu eng und soziologisch zu geradiinig. Gleichzeitig umreist er, obgleich sehr bedingt und vergrobernd (aber vereinheitlichend), zahlreiche einander nicht ănnliche, selbständige kunstlerische Werke, indem er diese bunte Vielralt in einen literaturhistorischen Begriff fast, der gerade rur die sowjetische Prosa der sechziger Jahre charakteristisch ist. 2)

Gegenstand dieser neuen Dorfprosa war nămlich nicht der sowjetische Kolchos mit seinen wirtschartlichen und sozialen strukturen, und thematisiert wurden von ihr nicht die aktuellen Fragen des Dorfes und der sowjetischen Landwirtschaft, die die Autoren des Oveckin-Kreises in den funfziger und beginnenden sechziger Jahren mit so grobem Engagement in die Literatur und die literarische Diskussion eingefuhrt hatten, sondern im Mittelpunkt stand das alte russische Dorf mit seinem traditionellen "sel'skij byt" (dorfliche Lebensweise), von dessen mehr der Vergangenheit als der Gegenwart angehorenden Lebensund Wertvorstellungen die Autoren of rensichtlich rasziniert schienen. Gegenuber inren unmittelbaren Vorläufern, den "Očerkisten" um Valentin Oveckin, zeigten die Autoren der neuen Dorfprosa gănzlich andere Intentionen. ${ }^{3)}$ Die Kritik konstatierte eine Schwerpunktverlagerung "von soziobkonomischen und 8konomisch-organisatorischen Problemen hin zu moralischen, ethischen, psychologischen und

2) J. Starikowa, Der soziologische Aspekt der heutigen "Dorfprosa", in: Kunst und Literatur, 1973, Nr. 1, s, 43-65, s. 43

3) Zur Entwicklung vom "očerk" der rünfziger zur "Dorfprosa" der spáten sechziger Jahre vgl. auch die kürzlich vorgelegte strukturalistische Untersuchung von Georg Witte, Die sowjetische Kolchos- und Dorfprosa der funfziger und sechziger Jahre. Zur Evolution einer literarischen Unterreihe, Diss. Munchen 1983 
sogar philosophischen" Fragen ${ }^{4)}$, aber auch ein Interesse der Autoren an den "traditionellen geistigen Werten" des Dorfes und die Anerkennung seiner sittlichen Uberlegenheit gegenuber der Stadt:

Das Dorf wurde nun nicht mehr unter dem Aspekt der sich in ihm vollziehenden sozialbkonomischen Prozesse betrachtet, sondern als selbstăniger geistiger Wert, der sich in vielerlei Hinsicht vorteilhaft von der Stadt unterscheidet. Die Prosa der sechziger Jahre betrachtete das Dorf mit behutsamer und liebevoller Aufmerksamkeit, bestrebt, jene jahrhundertealten Grundlagen zu erfassen, auf denen das Leben der Bauern auch heute noch beruht. 5)

Am deutlichsten spiegelte sich das gewandelte literarische Interesse am Dorf in den neuen Helden der Dorfprosa. Nicht die verschiedenen Typen von Parteisekretaren und Kolchosvorsitzenden, die in der "očerk"-Literatur der funfziger Jahre eine so grobe Rolle gespielt hatten, traten hier auf, sondern einfache und bisweilen etwas merkwurdige dorfliche Gestalten onne besondere Bildung und geselischaftliche Stellung, mit gewornnlichem Schicksal und alltaglichen Lebenszusammenhăngen:

An die Stelle des nuchternen Wirtschafters traten nun der dörfiche Trăumer, das verschmitzte Băuerchen, der Spabvogel, der Weise, der alte Dorfgrobvater, der Bewahrer dorflicher Traditionen...6)

Es waren, fur das literarische Umfeld der Nachkriegszeit, ganz neue sozial-psychologische Typen, die hier in ihrem privaten Lebensbereich, mit ihrer eigenen Sprache, Psychologie und Weltsicht auftraten, und diese neuen Helden, die in inrer besonderen Beziehung zur Welt die "traditionellen moralischen und geistigen Werte" des russischen

4) V. Surganov, zit. bei Philippa Lewis, Peasant Nostalgia in Contemporary Russian Literature, in: Soviet Studies, 1976, XXVIII/4, S. 548-569, S. 550

5) Jelena Klepikowa, Fjodor Abramows Trilogie "Bruder und Schwestern", in: Kunst und Literatur, 1977, Nr. 6, S. $627-638$, S. 628

6) Lev Anninskij, zit. bei Feliks Kuznecov, Sud'by derevni $v$ proze i kritike, in: Novyj mir, 1973, Nr. 6, S. 233-250, S. 246 
Dorfes zu verkorpern schienen, wurden zum meistdiskutierten literarischen Typus der sechziger und siebziger Jahre. Im Mittelpunkt der anhaltenden und hăufig leidenschaftlich gefunrten Debatten, die einen ersten Hohepunkt in der von Ende 1967 bis April 1968 in der "Literaturnaja gazeta" (Literaturzeitung) publizierten Diskussion um die sogenannte "lyrische Prosa" erreichten" ${ }^{7}$, stand anfanglich die Frage nach Sinn und Inhalt jenes "Drangs zu den Quellen" (tjaga $k$ istokam), den man in der Hinwendung der Autoren zum alten Dorf zu erkennen glaubte, und die daraus abgeleitete Dichotomie Dorf versus Stadt. Das Interesse am Dorf wurde vor allem als Interesse an den, wie auch immer verstandenen, geistigen und moralischen Grundlagen der nationalen Vergangenheit gewertet sowie als Interesse am sogenannten "naturlichen Menschen", der sich in enger. Bindung an die Natur und im freien Austausch mit ihr eine Einheitlichkeit seiner Personlichkeit bewahrt habe, die als wahre Kultur der zerstorerischen $Z i v i l i s a t i o n$ der modernen Stadt gegenuberstehe. In seinem recht grundsatzlichen Artikel zu Vasilij Belov, einem der ersten und exponiertesten Vertreter der Dorfprosa, dessen 1968 erschienener Kurzroman "Privyčnoe delo" (Sind wir ja gewohnt) einen wesentlichen AnstoB fur die Diskussionen lieferte, setzt der Kritiker Lev Anninskij den Drang der modernen Literatur "zu den Quellen" in Bezug zu "der jahrhundertealten Tradition der russischen Literatur mit inrem Nachdenken uber den Menschen als Wanderer und uber den Boden (o celovekestrannike $i$ o počve)" und erklart inn als Reaktion

nicht auf die sozialen Umsiedlungen im Laufe von zwei bis drei Generationen, sondern auf die uber zwei bis drei Jahrhunderte hindurch sich vollziehende Entwicklung der analytischen Kultur der Neuzeit, die die heutige Zivilisation geschaffen und den Menschen in Funktionen aufgespalten hat.

7) $\mathrm{Zu}$ dieser Diskussion und ihrer Fortsetzung in den verschiedenen literarischen Zeitschriften vgl. die Untersuchung von Philippa Lewis, a.a.0. sowie den Beitrag von I. Dedkov, Stranicy derevenskoj żizni, in: Novyj mir, 1969, Nr. 3, S. 231-246 
Der Drang hin zur dorflichen Kindheit ist lediglich eine besondere Variante des Drangs nach geistiger Einheitlichkeit unter diesen Bedingungen. 8)

Auf der anderen Seite gab es indessen heftige Angriffe auf die Dorfprosa, deren Autoren man Idealisierung der "patriarchalischen" Vergangenheit und larmoyante Trauer uber das Verschwinden des alten "krest'janskij byt" (bauerliche Lebensweise) vorwarf und wurde der vor allem von einigen Kritikern beschworene "Drang zu den Quellen" als unhistorische und nationalistische Bewertung der Vergangenheit attackiert ${ }^{9)}$.

Der Streit um die "derevenstiki", wie die Autoren teils wohlwollend, teils ironisch genannt wurden, bewegte sich von Anfang an um Probleme, die weit uber den engeren literarischen Gegenstand hinausreichten, und in der bis in die achtziger Jahre anhaltenden Diskussion um einzelne Autoren und Werke spiegelt sich eine Fulle sozialer, philosophischer und literarischer Fragen, die die Dorfprosa als uberaus relevanten Faktor innerhalb der modernen russischen Literatur ausweisen.

Dies fand seinen Niederschlag auch in den Forschungsansătzen, die jungeren Untersuchungen zur Dorfprosa zugrundeliegen, welche zunehmend von einer Betrachtung des engen thematischen Aspekts dieser Literatur abrucken und sich der Vielschichtigkeit der in ihr behandelten

8) Lev Anninskij, Točka opory. Étičeskie problemy sovremennoj prozy, in: Don, 1968, Nr. 7, S. 178-187, S. 179

9) Zum Teil erwies sich die anfangliche Diskussion um die Dorfprosa als Kritikerstreit, bei dem die literarischen Werke lediglich den Aufhänger für die Darlegung der eigenen Position bildeten. Vgl. dazu Feliks Kuznecov, Literaturkritik: Mythos und Relitat der geistigen Werte, in: Kunst und Literatur, 1974, Nr. 10, S. 1087-1114; ders., Auf der Suche nach dem künftigen Helden, ebenda, 1973, Nr. 8, S. 778-792; B. Anaschenkow, Der "Mensch der Tat" und sein geistiges Potential: ebenda, 1975, Nr. 3, S. 273-299; Jurij Surovcev, O nacional'noj samobytnosti $i$ "fantastičeski vyčurnoj ljubvi" $k$ nej, in: Literaturnoe obozrenie, 1973, Nr. 2, S. 60-70; D.I. Tampej, Idejno-èstetičeskie problemy sovremennoj prozy o derevne i literaturnaja kritika, Avtoref. diss. ...kand.fil...., Moskva 1975; ders., Proza o derevne i sovremennaja literaturnaja kritika, in: Sovremennyj literaturnyj process i kritika, Moskva 1975, S. 77-104 
Probleme und ihren künstlerischen Besonderheiten zuwenden. Als allgemeiner Konsens hinsichtlich der Erklärung des Phănomens der Dorfprosa kann dabei gelten, was Anton Hiersche formuliert:

Die sowjetische Dorfprosa ist literarische Komponente eines komplexen gesellschaftlichen Prozesses, in dem sich küntlerische, okonomische und soziale, philosophische und historische, bkologische wie auch politisch-ideologische Faktoren zu einem heute noch schwer zu entwirrenden Entwicklungsstrang verflochten haben. Die Dorfprosa, so der sowjetische Kritiker Boris Anaschenkow, ist "nicht so sehr das Thema, als vielmehr eine Anschauung, ein Herangehen, eine Position, die künstlerisch găuBert werden. 10)

Die Beachtung, die die Dorfprosa in der westlichen Literatur fand, erfolgte bisher vorrangig unter dem Aspekt der "Wiederentdeckung des eigentlichen Dorflebens" und des "drevnij krest'janskij byt", die als Trăger nationaler Werte und starker sittlicher krafte der modernen sowjetischen Gesellschaft entgegengesetzt werden ${ }^{11)}$. Philippa Lewis beschreibt in ihrer Studie das Interesse am Dorf als Nostalgie der Autoren, die in ihrer Mehrheit selbst vom Dorf stammen und die auf diese Weise zu den Wurze in sowohl ihrer personlichen als auch der nationalen Identitat des russischen Volkes zurückkehren. Einer Identităt, die in der Turbulenz des sozialistischen Aurbaus und in der urbanen Sowjetgesellschaft verlorengegangen sei und nun in einer idealisierten traditionellen Welt der stabilen Werte wiedergefunden werde ${ }^{12}$ ). Die von Johann Meichel vorgelegte Arbeit zur Entfremdungsproblematik in der sowjetischen Gegenwartsprosa sieht in der Dorfprosa vor allem eine Ablehnung des

10) Anton Hiersche, Sowjetische Dorfprosa - ein literarisches Phanomen des entwickelten Sozialismus, in: Weimarer Beitrăge, 1980, Nr. 4, S. 5-28, S. 5

11) Vgl. Yves Perret-Gentil, Der Kolchosbauer in der heutigen russischen Dorf-Literatur, in: Osteuropa, 1978, Nr. 9, S. 794-810; Gerhard Hildebrandt, Ein Beitrag zur sowjetischen Dorfprosa der Gegenwart, in: Die Welt der Slaven, 1973, S. 190-200; Deming Brown, Soviet Russian Literature since Stalin, Cambridge 1978 , S. 218-252

12) Lewis, a.a.0. 
technischen Fortschritts und staatlichen Verwaltungsapparats und gelangt $z u$ der Auffassung, daB von den Autoren "eine im Gegensatz zur marxistischen Weltanschauung stehende patriarchalische Lebensordnung zum Ideal erhoben" werde ${ }^{13)}$.

Dem ist entgegenzuhalten, dab es sich bei den Autoren der Dorfprosa um sehr unterschiedliche Schriftsteller handelt, die am thematischen Material des Dorfes jeweils unterschiedliche ideelle wie literarisch-ăsthetische Probleme zu losen versuchen. Ausgangspunkt der vorliegenden Untersuchung ist dabei, dab als das gemeinsame, die verschiedenen Autoren und Werke verbindende und besonders charakterisierende Moment die Einfuhrung besonderer sozial-psychologischer Typen angesehen werden kann, die vornehmlich als Bewubtseinstypen auftreten: Einfache dorfliche Gestalten, die mit der ihnen eigenen Sprache und Weltsicht, den Besonderheiten ihres Denkens ganz in den Vordergrund treten. Verbunden ist dies mit erzählerischen Verfahren, die die fast durchgăngige Bindung der Erzăhlung an die Perspektive des Helden anstreben und sich dabei in starkem Maße auf dessen Sprachmaterial, die volkstumlich-umgangssprachliche Rede, stützen. Das Auftreten dieser neuen Helden war von Anfang an verbunden mit dem Aufzeigen neuer Problemkreise bzw. einer neuen Sicht "ewiger" Grundrragen menschlichen seins sowie mit der Suche nach neuartigen künstlerischen Lösungen, was der Dorfprosa innerhalb des aktuellen literarischen und geistesgeschichtlichen Prozesses in der Sowjetunion einen besonderen Platz zuweist.

Die vorliegende Arbeit will anhand ausgewahlter Texte zweier Autoren, Vasilij Suksins und Valentin Rasputins, die Darsteliung dieses Helden untersuchen und damit zugleich auch einen Beitrag zur Erforschung der "derevens-

13) Johann Meichel, Zur Entfremdungs- und Identitătsproblematik in der Sowjetprosa der 60er und 70 er Jahre, Diss. Munchen 1981, S. 196 
kaja proza" als literarischem Phănomen der sechziger und siebziger Jahre leisten.

In einem ersten Kapitel soll nach den Faktoren gefragt werden, die das außergewornnliche Interesse der modernen russischen Literatur an diesen dörflichen Helden und inrer geistigen Welt bewirkten und die Aktualitat und Relevanz des russischen Dorfes als literarisches Material begrulnden. Im Hauptteil der intersuchung wird dann anhand der Texte Sukşins und Rasputins zu zeigen sein, welcher Art die jeweils gestalteten Bewubtseinstypen sind und worin das Besondere und Neue besteht, das die Autoren an den dorflichen Helden und diesem fur die russische Literatur uberaus traditionellen Material entdecken. 
1. Aktualitat und Relevanz des Dorfes und des dorflichen Helden für die Literatur der sechziger und siebziger Jahre

\subsection{Sozioökonomischer Wandel und Literatur}

Die Frage nach den Faktoren, die das Dorf in den sechziger Jahren fur die Literatur wieder so interessant werden lieben, verweist zunachst auf die soziobkonomischen Verănderungen, die sich im sowjetischen Dorf wăhrend der letzten Jahrzehnte vollzogen und auch gegenwartig noch vollziehen. Das alte russische Dorf, wie es jahrhundertelang Geschichte und Kultur RuBlands mit geprägt hatte, verschwindet in der Gegenwart zusehends. An seine Stelle treten nun endgaltig modernisierte Kollektivwirtschaften, der traditionelle Charakter der băuerlichen Arbeit und Lebensweise verăndert sich und mit inm auch der russische Bauer selbst.

Dieser soziobkonomische und kulturhistorische Hintergrund mit seinen verschiedenen, zum Teil auch durch den problematischen Zustand der sowjetischen Landwirtschaft bedingten Nebenaspekten ${ }^{14}$ ) wurde in der Diskussion um die Dorfprosa immer wieder als erklärender Faktor herangezogen, und auch die Schriftsteller selbst stellten in ihren publizistischen Außerungen oft genug diesen Zusammenhang her. Der Dorfautor Fedor Abramov beschrieb inn in seiner Rede auf dem VI. Allunionskongreb der Schriftsteller:

14) Zum Beispiel das Problem der Landflucht, der Abwanderung vor allem der Jugend in die Stădte, die auch von den Schriftstellern hăurig beklagt wird. Zum soziobkonomischen und kulturellen wandel auf dem Lande vgl. Stephen B. und Ethel Dunn, Kulturwandel im sowjetischen Dorf, Berlin 1977; Starikowa, Der soziologische Aspekt, a.a.0.; G. Radov, Na novom étape (Sovremennoe selo $v$ literature), in: Literatura i sovremennost', $1970 / 71$, Nr. 11, Moskva 1972, S. 247274 ; I. Gusarova, Cuvstvo chozjaina zemli, in: Moskva, 1976, Nr. 2, S. 226-236; S. Vikulov, Ljubov' $k$ zemle? $\mathrm{Da}$ !, in: Naš sovremennik, 1969, Nr. 1, S. 110-115 
Das alte Dorf mit seiner tausendjăhrigen Geschichte hort heute auf zu existieren.

...Das aber heiBt, daß wesentliche Grundpfeiler zerstört werden, daß jener uralte Boden verschwindet, auf dem unsere ganze Nationalkultur gediehen ist ihre Ethik und Ásthetik, ihre Folklore und Literatur, inre wunderbare Sprache. Denn, die bekannten Worte Dostoevskijs abwandelnd, kann man sagen: Wir alle sind aus dem Dorf hervorgegangen. Dort ist unser Ursprung, sind unsere Wurze in. Das Dorf ist der Mutterschoß, der unseren Nationalcharakter gebar und der inn formte.

Und heute, da das alte Dorf seine letzten Tage beschliebt, betrachten wir mit besonderem, geschărftem Interesse jenen Menschentyp, den es hervorgebracht hat. 15)

Das Dorf als Mutter, deren Andenken es $2 u$ wurdigen und deren Vermachtnis es zu bewahren gilt, ist eine von den "derevenščiki" oft gebrauchte Metapher:

Das alte Dorf - das ist unsere Mutter, die unausweichlich von uns geht; aber man mub sich von ihr verabschieden, und man mub verstehen, worur sie gelebt una was sie uns hinterlassen hat. 16)

Die tiefgreifende Wirkung der soziobkonomischen Ablosungsprozesse und vor allem inre Unumkehrbarkeit weckte bei vielen Autoren, die selbst vom Dorf kamen, das Bedurfnis, innezuhalten und zuruckzublicken auf das, was war und was da unwiederbringlich $z$ verschwinden dronte. Das alte Dorf und seine Charaktere noch einmal einzurangen, in ihrer Bedeutung $z u$ würdigen und für die Nachwelt lebendig zu halten, solange es noch nicht zu spat war, erschien als vordringliche Aufgabe der Literatur:

Im Dorfthema sind wir, die Zeitgenossen, die letzten Zeugen und Teilnehmer jener Ereignisse, die sich im Dorf vollzogen und die seine jahrhundertealte Ordnung, die Lebensweise und die Psychologie des Dorfbewohners verăndert haben. Wenn diese Verănderungen,

15) Fedor Abramov, 0 chlebe nasušc̆nom i chlebe duchovnom, in: Nas sovremennik, 1976, Nr. 9, S. 170-172, S. 171

16) Valentin Rasputin, zit. bei E.I. Zacharova, Eto stanovitsja tradiciej (Valentin kasputin $v$ MGU), in: Vestnik Moskovskogo universiteta, 1977, ser. IX, filologija, Nr. 3, S. 79-86, S. 85 
diese jahe Wende in der Literatur nicht von uns bezeugt werden, wer wird es dann tun? 17)

Angesichts des rapiden Wandels in der modernen sowjetischen Gesellschaft muBte hier auch ein Nachholbedarf der russischen Literatur verstarkt ins Bewubtsein rücken:

Das traditionelle russische Dorf und seine Bewohner hatten als literarischer Stoff seit Esenin relativ wenig Beachtung erfahren ${ }^{18)}$. Die Literatur der zwanziger und dreiBiger Jahre uber das Dorf $\mathrm{sah}$ in ihm vor allem die Momente der Ruckstăndigkeit und Trăgheit, die es zu uberwinden galt. Ihr Thema war der Ausgleich von Stadt und Land auf dem Wege sozialistischer Kollektivierung, beschleunigter Industrialisierung und Urbanisierung. Besonders grob war der Nachholbedarf an authentischen bauerlichen Charakteren. Die Auffassung von der sozialen Determiniertheit des Charakters hatte gerade in diesem Bereich der Literatur hăufig zu einem Schematismus gefuhrt, der fur die individuellen Züge und nationalen Merkmale des menschlichen Charakters keinen Raum lieB. Der Kritiker A. Chvatov stellt hierzu treffend fest:

Die individuelle Expressivitat der Charaktere fand ihr MaB und ihre Form hauptsăchlich in der Sphäre der Klassenbeziehungen. Die Psychologie erhielt eine eintönige Fărbung: Sie war klassenmảiig bedingt, aber mitunter der individuellen Eigenart beraubt. Der Charakter verlor eine wichtige Seite, ohne die die Vorstellung vom Menschen unvollkommen war. Eine extreme Erscheinung dieser Tendenz waren die plakativen Gestalten der Kulaken mit der klassischen Garnitur an obligatorischen Merkmalen des Portrats und dynamischen Accessoires. 19)

17) S. Zalygin, Rasskaz i rasskazčik, in: Literatura i sovremennost', 1970/71, Nr. 11, Moskva 1972, S. 319$335, \mathrm{~S} .320$

18) Zum Traditionsfeld der Dorfprosa und zu ihren Anknüp fungspunkten innerhalb der verschiedenen Traditionslinien der russischen "Bauernliteratur" seit dem 19. Jahrhundert und der besonderen Bedeutung Esenins vgl. A. Hiersche, Die russische sowjetische Dorfprosa. Fragen ihrer Traditionen, in: Zeitschrift fur Slavistik, $1982, \mathrm{Nr} .4, \mathrm{~S} .568-575$

19) A. Chvatov, Poiski novych rešenij, in: V načale semidesjatych. Li teratura našich dnej, Leningrad 1973 , S. $24-54$, S. 30 
Noch weniger befriedigen konnte die idealisierende und

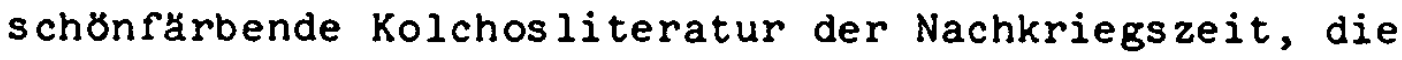
nichts mit dem realen Menschen des Dorfes gemein hatte und weit entfernt war von einem Verständnis seiner Psychologie und seines Schicksals ${ }^{20)}$. Zwar hatte es auch hier in der Periode des literarischen "Tauwetters" eine Wende gegeben, als sich Autoren wie Valentin Oveckin, Gavriil Troepol'skij, Efim Doroš und andere - vorwiegend in der Form des "očerk" (Skizze) und der publizistischen Prosa - der kritischen Darstellung der Kolchoswirklichkeit zuwandten. Inr Thema war jedoch die wirtschaftliche und soziale Situation auf dem Lande, die Kritik der MiBstände und Fehler in der-Landwirtschaft und im Leitungsstil der Kolchosen. Der Charakter des Bauern und seine Psychologie fanden auch in der Literatur des OvečkinKreises nur wenig Beachtung ${ }^{21}$ ).

Dennoch lebte bis in die jungste Vergangenheit die Mehrheit der sowjetischen Bevolkerung auf dem Lande ${ }^{22}$ ), und gerade dieser von der Literatur wie auch von der Gesel1schaft lange vernachlăssigte Bauer war es, der, wie es vielen Schriftstellern, die das Dorf der Kriegs- und Nachkriegszeit als Kinder oder junge Menschen erlebt hatten, schien,

die Hauptlast des Vaterländischen Krieges getragen hatte... und durch dessen Arbeit das Land nach dem Krieg wieder aufgebaut worden war. 23)

20) Zur Kolchosliteratur dieser Periode vgl. V.I. ProtCenko, Nekotorye voprosy razvitija "derevenskoj prozy", in: Problemy russkoj sovetskoj literatury 50 - 70-e gody, Leningrad 1976, S. 58-107, S. 58-66

21) Zum "oðerk" der funfziger und fruhen sechziger Jahre vgl. V. Surganov, Celovek na zemle, Moskva 1975, S. 285-312; V.I.Prot Cenko, Povest' $60-\mathrm{ch}$ - naxalo 70-ch godov, in: Sovremennaja russkaja sovetskaja povest', Leningrad 1975, S. 161-223; Helen von Ssachno, Der Aufstand der Person. Sowjetliteratur seit Stalins Tod, Berlin 1965, S. 171-173, 321-323; Brown, a.a.0., S. 223-233

22) $\mathrm{Vgl}_{\mathrm{g}}$. Starikowa, Der soziologische Aspekt, a.a.0., S.13ff.

23) Fedor Abramov, vgl. Po trebovaniju zizni (S IV plenuma vsesojuznogo soveta po kritike), in: Voprosy literatury, 1971 , Nr. 8, S. 26-39, S. 32 
Dem Dorf und seinen Bewohnern Gerechtigkeit widerfahren $\mathrm{zu}$ lassen, ihre Leistungen $z u$ wurdigen und ihnen ein literarisches Denkmal fur das Gedăchtnis der Nachwelt zu setzen, muß als eine der Intentionen der "derevenščiki" angesehen werden. Sie fand Anerkennung bei der Kritik, brachte ihnen aber auch den Vorwurf der einseitigen Rückwärtsgewand theit:

Zu leben, ohne dankbar der Vergangenheit zu gedenken ist uninteressant, unmoralisch und sogar gefăhrlich, das ist die Wahrheit, die bald als Entdeckung, bald als Mahnung in der "Dorfprosa" der sechziger Jahre laut zu vernehmen ist, und meines Erachtens liegen darin ihr Sinn und ihre progressive Bedeutung.

Aber man lebt nicht nur der Erinnerung und die Ruckwartsgewandtheit der "Dorfprosa", ihre Orientierung auf die Vergangenheit wird immer deutlicher als Einseitigkeit und Beschränktheit empfunden. 24)

Es war jedoch nicht nur diese Intention, die das Dorf fur die Literatur wieder so interessant werden lieb. Die soziobkonomischen Veränderungen enthalten noch einen weiteren Aspekt: Nicht nur, dab das alte Dorf unwiederbringlich verschwindet, beunruhigt, sondern dieser durch Technisierung und Urbanisierung bewirkte AblösungsprozeB erweist sich auch als kompliziert und vollzieht sich durchaus nicht problemlos. Auf dem Hintergrund dieser Problematik lassen sich im geistigen Bereich der modernen Sowjetgesellschaft Tendenzen aufzeigen, die in einem dialektischen Zusammenhang zum Phänomen der Dorfprosa stehen.

\subsection{Die Problematisierung des technischen Fortschritts}

Wie in anderen Industriegesellschaften läbt sich auch in der sowjetischen in den letzten Jahren ein wachsendes BewuBtsein fur die widerspruchlichkeit der modernen technischen Entwicklungen, die zunehmende Problematisierung der negativen Seiten der "wissenschaftlich-technischen Revolution", dieses "Emblems unserer gegenwartigen Epoche", 
wie Sergej Zalygin sie nennt ${ }^{25)}$, feststellen. In diesem Zusammenhang aufgeworfene bkologische, sozial- und kulturkritische Fragestellungen fanden ihren Niederschlag in den verschiedensten Bereichen. Besonders ausgeprăgt zeigt sich dieses neue Problembewubtsein in der Literatur und der literarischen Diskussion, wie sie von Kritikern, Wissenschaftlern und Schriftstellern gefuhrt wird ${ }^{26)}$. Seit den siebziger Jahren bewegt sich diese zunehmend um die negativen Aspekte einer Problematik, die mit "technischer Fortschritt und Mensch" umschrieben werden kann, wobei die moderne Literatur und in besonderem Maße die Dorfprosa nicht selten den AnstoB und das konkrete Material dafur lieferten:

Eine bedenkenswerte Auffassung des Problems rindet sich in der modernen Literatur, die mit der Entwicklung des Fortschritts die geistigen und sittlichen Aspekte des Seins verknüpft. Es ist ein Bewubtsein dafur entstanden, dab die Folgen des Fortschritts nicht eindeutig sein konnen. Die Probleme des Schutzes der Biosphäre, des menschlichen Organismus, die Gefahr eines Sauerstoffmangels und andere Fragen, mit denen sich jetzt Physiker, Biologen, Arzte und Soziologen beschartigen, treten in der Literatur als ethisches Signal, als soziales und sittliches Problem entgegen. 27)

Die aufgeworfenen Fragen sind vielfaltig, lassen aber eine Konzentration auf den ethischen und psychologischen Bereich erkennen. Negative Auswirkungen des technischen Fortschritts, der begleitet ist vom Anwachsen der Stadte und der Herausbildung einer besonderen stadtischen Kultur, der Erhøhung des materiellen Lebensstandards und

25) S. Zalygin, NTR i literatura, in: ders., Literaturnye zaboty, Moskva 1979 , S. 42-54, S. 42

26) Debatten uber Funktion und Aufgaben von Literatur im Zeitalter der "wissenschaftlich-technischen Revolution" spielen in der UdSSR seit Ende der funfiziger Jahre eine Rolle und wurden unter unterschiedlichen Vorzeichen gefunrt; vgl. hierzu Anton Hiersche, Sowjetliteratur und wissenschaftlich-technische Revolution, Berlin 1976; dort auch Literaturangaben $z u$ den einzelnen Diskussionen

27) N.S. Tenditnik, Otvetsvennost' talanta. O tvorcestve V. Rasputina, Irkutsk 1978, S. $81 \mathrm{f}$. 
des Lebenstempos, der "Informationsexplosion", der zunehmenden Loslösung des Menschen von der Natur, werden vor allem in der geistigen und sittlichen Entwicklung des modernen Menschen gesehen: In der Verarmung seiner geistigen Bedürfnisse, seiner Gefuhlswelt und zwischenmenschlichen Beziehungen. Die Gefahr eines Mibverhaltnisses von Materiellem und Geistigem in der modernen Gesellschaft labt sich als ein Grundtenor dieser Diskussionen feststellen. Der Schriftsteller Arkadij Strugackij spricht von einem neuen Typ des Massenmenschen, den die Epoche der wissenschaftlich-technischen Revolution hervorgebracht habe und von einer Massenpsychologie, die auf den Konsum als Ziel und Zweck menschlicher Existenz orientiert sei:

Ich meine den satten, schlecht erzogenen Massenmenschen (Massovogo Sytogo Nevospitannogo Čeloveka) - eine Krankheit, an der viele kapitalistische Länder leiden und deren Mikroben gegenuber wir ebenfalls nicht sorglos sein durfen. 28)

Die Ursachen dafür bestünden in der lange nicht erkannten Tatsache, daß eine gleichmabige Entwicklung von materiellen und geistigen Bedurfnissen sich nicht automatisch vollziehe:
In dem Schema "Arbeit - materielle Sătigung - geistiges Wachstum" wurde ein sehr wesentliches Moment versăumt (oder ignoriert). Das Problem be- steht darin, dab die Grenzen materieller Sattigung eine Funktion nicht nur und nicht so sehr der Phy- siologie, als vielmehr der Psychologie sind. Den Appetit auf materielle Guter bekommt der Mensch bei seiner Geburt. Der Appetit auf geistige Guter entsteht erst bei einer richtigen Erziehung. 29)

Der sinnvolle Umgang mit den neuen materiellen Lebensbedingungen und Mrglichkeiten des Menschen fordere ausgeprägte moralische Qualitaten und stelle erhohte Anforderungen an dessen geistige Erziehung, was im Tempo der gesellschaftlichen Verănderung oft vergessen $z u$ werden

28) A. Strugackij, Novye čelovečeskie tipy, in: Voprosy literatury, $1976, \mathrm{Nr} .11, \mathrm{~S} .16-18, \mathrm{~S} .17$

29) Ebenda 
drohe. Das technokratische, an kurzfristigem Nutzen orientierte Denken, das - so der Schriftsteller Daniil Granin - "mitunter, in gewissem Sinne zur Ideologie der wissenschaftlich-technischen Revolution wird" 30 , sei fern von solcher Erkenntnis und produziere seinerseits einen beschrănkten, selbstzufriedenen Menschen, der wirkliche geistige Kultur durch ein blob formales wissen ersetze:

Die Kultivierung des eindeutigen, eng verstandenen technischen Wissens kann dazu fuhren, daB die Sphäre der sinnlich-emotionalen Wahrnehmung des Menschen primitiv, unterentwickelt und durftig wird. Es reduziert sich in diesem Palle auch der Umfang an Werten, die der Mensch aus der jahrhundertealten Weltkultur noch aufnehmen kann. 31)

Einen Kermpunkt dieses wachsonden Problembewustseins hinsichtlich der Folgen und Begleiterscheinungen des technischen Fortschritts stellt auch die Prage nach der Beziehung des Menschen zur Natur dar. Die kritische Hinterfragung einer solchen Beziehung, in der die Natur lediglich als "Objekt der Untemerfung und Umgestaltung" 32) verstanden wird, erweist sich seit einigen Jahren als zentrales Anliegen vieler Literaten und wurde mehrfach auch zur Grundlage eines direkten Engagements in 8kologischen Fragen und bei Problemen des Naturschutzes. Valentin Rasputin spricht in einem Interview mit der Zeitschrift "Voprosy literatury" (Fragen der Literatur) von den brennenden Fragen Sibiriens, die ihn beschăfigen und mit denen sich zu befassen, er fur seine "staatsbürgerliche" und schriftstellerische Pflicht halt:

Vor allem beunruhigt mich, wie eigentlich alle, das Schicksal des Baikal. Schon heute ist Subwasser

30) D. Granin, Wissenschaftlich-technische Revolution, Personlichkeit, Literatur, in: Kunst und Literatur, $1978, \mathrm{Nr} .11, \mathrm{~S} .1123-1140, \mathrm{~S} .1128$

31) A. Arnol'dov, Socialisticeskij kul'turnyj progress i naučno-techničeskaja revoljucija, in: Voprosy literatury, $1981, \mathrm{Nr} .5, \mathrm{~S} .3-33$, S. $26 \mathrm{r}$.

32) Vgl. S. Zalygin, Pisatel' i Sibir', in: ders., Literaturnye zaboty, a.a.0., S. 19-41, S. 30 
eine ungeheure Kostbarkeit. Der Baikal ist ein SUBwasserreservoir von WeltmaBstab. Dieses Wasser zu behuten, ist unsere grobte Aufgabe. Wenn wir nicht ¿konomische Umsicht walten lassen, werden uns das unsere Nachkommen nicht verzeihen. 33)

Auch hier werden die Akzente vor allem im ethischen Bereich gesetzt, geht es nicht nur um eine kritik am einseitigen Rationalismus und Utilitarismus im Umgang mit der Natur, sondern um eine umfassende Aktualisierung der Beziehung Mensch/Natur als einer Grundbeziehung des Menschen zur Welt, die gerade in der gegenwartigen Epoche mit ihren gewaltigen Moglichkeiten der Einwirkung auf die Natur und den Menschen als Teil derselben einer Neubestimmung bedurfe ${ }^{34)}$. Daniil Granin spricht von einer Zeit "des Ubergangs vom Wildererbewubtsein zu einem neuen planetaren Bewubtsein", in der die Beziehungen zwischen Mensch und Natur eine neue Qualitat annehmen:

Wenn wir davon sprechen, was fur eine Personlichkeit wir erziehen wollen, wenn wir uns uber den konkreten Inhalt und den Begriff der sittlichen Personlichkeit Gedanken machen, dann gehbrt dazu unbedingt auch die Frage nach der Einstellung zur Natur. Mit dieser Einstellung wăchst das sittliche BewuBtsein des Menschen. 35)

Dem ethischen und asthetischen Inhalt des menschlichen Naturverhaltnisses, jenem "moralisch-psychologischen Komplex der menschlichen Seele, der mit der Wahrnehmung der Natur verbunden ist"36), wird zentrale Bedeutung fur die

33) zit. nach Valentin Rasputin, Das Leben ist das Wichtigste, in: Sowjetliteratur, 1978, Nr. 1, S. 150-157, S. 156

34) Zur Thematisierung dieser Problematik in der zeitgenossischen russischen Literatur vgl. I. Gutschke, Das Verhaltnis von Mensch und Natur in der sowjetischen Gegenwartsliteratur, in: Zeitschrift fur slavistik, 1975, Nr. 4, S. 526-531; G. Trefilova, Vremja vybora (Chudožestvennoe osmyšlenie vzaimootnošenij celoveka i prirody $v$ sovetskoj literature), in: Voprosy literatury, 1981, Nr. 12, S. 7-48; Hiersche, Sowjetilteratur und wissenschaftlich-technische Revolution, a.a.0., S. 140-153

35) Granin, a.a.0., S. 1132

36) C. Ajtmatov, Néizbežnost' garmonii, in: Literaturnaja gazeta, 1.1.1973 
geistige und sittliche Entwicklung des heutigen Menschen zugemessen. Die Entfremdung von der Natur erscheint als Wertverlust und Gefahr.

Weitere Erscheinungen, die im Zusammenhang mit dem technischen Fortschritt einer verstäkten Kritik unterzogen werden, sind die Vereinheitlichungs - und Nivellierungstendenzen in vielen Bereichen der modernen Gesellschaft:

..die wissenschaftlich-technische Revolution
bringt eine Flut von Standards mit sich: Eine
universelle Sprache, Massenproduktion, Repro-
duktion von Kunstwerken. Eine solche Standardi-
sierung erweist sich heute als historisch unver-
meidlich, aber sie bremst die schopferische Ent-
wicklung der Personlichkeit. 37 )

Diese Standardisierung vieler Lebensbereiche bringt nicht nur einen Verlust an Originalitat und Individualitat, sondern sie birgt in sich auch die Gefahr einer geistigen Niveliferung. Eine Befurchtung, die besonders in der Kritik an der gegenwărtigen Sprachentwicklung zum Ausdruck kommt. Sergej Zalygin stellt rest, dab unter dem Einflub der wissenschaftlich-technischen Revolution "die Sprache sich heute sehr stark verändert, in einem so gewaltigen AusmaB wie nie zuvor" ${ }^{38)}$. Der qualitative Unterschied $2 u$ fruheren Perioden intensivierten Sprachwandels, etwa der Zeit Peters des Großen oder Puškins, bestehe darin, daB in der Gegenwart sich nicht nur eine bestimmte Schicht der russischen Sprache - die offizielle Sprache oder die allgemeine Normsprache - verändere, sondern erstmals alle Sprachschichten von diesem Wandel errabt seien. Die sich dadurch vollziehende Nivellierung gehe vor allem auf Kosten der Volkssprache (narodnyj jazyk).

Anfangs war es die allgemeine Kenntis des Lesens und Schreibens, spater waren es dann Presse, Radio und Fernsehen, die allmăhlich zu den Massen vordrangen und diese Sprachen aufs auberste einander

37) Arnol'dov, a.a.0., S. 26

38) Zalygin, NTR i literatura, a.a.0., s. 49 
annäherten, sie nivellierten. Den stärksten Einflub ubten sie auf die Sprache aus, die bis heute die bestăndigste, ja, konservativste ist, auf die Volkssprache. 39)

Die zunehmende Verdrängung des volkssprachlichen Elements im modernen Sprachgebrauch zugunsten abstrakter, aus der Sprache von Wissenschaft und Technik entlehnter Begriffe und an Expressivităt armer Modeworter und Stereotypen wird als Zeichen der Verarmung empfunden:

Die mittlere städische Intelligenz besitzt heute einen ziemlich engen Wortschatz, der zudem in wenigen Bereichen konzentriert ist (Beruf; kulturelle "Zerstreuung" - Kino, Bücher; Alltag...). Die Mittel der volkstumlichen Anschaulichkeit (narodnoj obraznosti), die uberaus reiche Schicht der volkstumlichen Lexik - all dies ist fur sie in erheblichem MaBe verlorengegangen, und nicht nur aufgrund der Erziehung, der Lebensweise, sondern zum Teil auch durch Schuld der Literatur. 40)

Das "narodnoe slovo" (volkssprachliche Wort) verschwinde zunehmend aus allen Lebensbereichen und lasse sich somit immer schwerer aneignen. Die Kritikerin Marièta Cudakova verweist in diesem Zusammenhang auf das Fehlen der Grobmutter oder Amme in der modernen Gesellschaft, die in fruherer Zeit in lebendiger, anschaulicher Sprache Märchen erzăhlte und mit dieser Sprache auch die dahinter verborgene Vorstellungs- und Gefunlswelt mitvermittelte ${ }^{41}$ ). Die Kritik am modernen Sprachgebrauch richtet sich vor allem auch gegen die Verwendung sprachlicher Schablonen, gegen das gedankenlose Reproduzieren inhaltsleerer, stereotyper Formeln sowie auf die hinter einem solchen Umgang mit der Sprache sich verbergende Art des Denkens und des Verkehrs mit der menschlichen Umwelt.

Ist sich der moderne Mensch bewubt, daß das gesprochene oder geschriebene Wort ein sehr feines

39) Zalygin, NTR i literatura, a.a.0., S. 47

40) M. Cudakova, Zametki o jazyke sovremennoj prozy, in: Novy j mir, 1972, Nr. 1, S. 212-245, S. 236

41) Ebenda, S. $236 \mathrm{f}$. 
Werkzeug des menschlichen Gedankens, ein Mittel des Verkehrs und der Selbstauberung ist? Bisweilen scheint es, dab es in den Augen der Menschen nichts wert ist,... dab es nicht das Ergebnis angespannten Suchens ist, sondern einer Sprache der Schablonen und Stereotypen entnommen wird. Leider gehen dabei die Bedeutsamkeit des Wortes, seine Gewichtigkeit und Kraft verloren. In der Rede der Menschen wird die Flut abgegriffener, standardisierter worter, abgedroschener und banaler Bilder immer grober, die bei den Kommunizierenden eine bereits zur Gewohnheit gewordene Langeweile hervorrufen und inre geistige Wahrnehmung, ihre intellektuelle und emotionale Welt veramen lassen. 42)

Dieses vor allem im kulturellen Bereich der letzten Jahre zunehmend festzustellende Problembewubtsein hinsichtlich der Dialektik des Verhaltnisses von Mensch und technischem Fortschritt muB als ein wesentlicher Faktor fur das Interesse der modernen Literatur am Material des russischen Dorfes angesehen werden. Der dorfliche Held bot den Autoren in dieser schnellebigen Epoche, in der sich mit erhohter Geschwindigkeit nicht nur Umwelt und Lebensweise, sondern auch der Mensch selbst verăndern, die Moglichkeit zu verweilen, das Erreichte und den Proze $B$ der Verănderung kritisch zu betrachten. Mit seiner urwüchsigen, ausdrucksstarken Sprache, seinem konkretanschaulichen Denken, seiner Naturverbundenheit und seiner mehr oder minder starken Bindung an die traditionelle Lebensweise stellte er nicht nur ein Gegengewicht zum modernen Menschen dar, sondern gleichzeitig eine Art Schnittpunkt der Zeiten: In Psychologie und Denken dieses Helden vermochten der Zusammenstob von Altem und Neuem bzw. ihre Verknupfung ihren deutlichsten und unter Umstănden dramatischsten Ausdruck zu rinden.

In der besonderen Aurmerksamkeit für das Nationale und Volkstümliche, die mit dem Interesse am Dorf verknupft ist, spiegelt sich noch eine weitere Tendenz wider, die im gesamten kulturellen Bereich der Sowjetunion zu beobachten ist:

In den letzten Jahren labt sich in unserem Land ein verstărktes Interesse an den Architekturdenk- 
mălern der Vergangenheit, an Volksliedern, Volksbrăuchen, an der alten Malerei usw. beobachten. 43)

Die verstärkte Beschätigung mit den nationalen Traditionen, den asthetischen und ethischen Werten der eigenen Vergangenheit enthalt als eine wesentliche Komponente ein kultur- und zivilisationskritisches Moment, das von D.S. Lichačev wie folgt erklärt wird:

Die gegenwătige Kultur lost sich von jeglicher Entindividualisierung, die verbunden ist mit der Entwicklung von Standards und Schablonen; sie lost sich von dem einheitlichen "internationalen" stil in der Architektur, von der sich amerikanisierenden Lebensweise, von den allmahlich verschwindenden nationalen Grundlagen des Lebens. 44)

Und Fedor Abranov benennt dieses Problem konkret, wenn er feststellt:

Und welches Schonheitsgefuhl lebte im Volk! Was fur zauberhafte Dinge wurden aus Holz, aus Birkenrinde hergestellt! Die alten Hauser im Norden sind Paläste... Aber jetzt findet man vom WeiBen bis zum Schwarzen Meer nur noch ein Standardhaus. 45)

Die Dorfprosa labt sich somit in einen geistesgeschichtlichen Zusammenhang stellen zu Fragen, denen in unserer Zeit grundlegende Bedeutung zukommt, nicht nur in der Sowjetunion. Spatestens hierbei uberschreitet sie die Grenzen einer "Dorfprosa" im Wortsinne, indem das Dorf in ihr nicht Gegenstand der Darstellung ist, sondern als Material dient zur Gestaltung allgemeinmenschlicher und

43) Ju. Seleznev, Fantastičeskoe v sovremennoj proze, in: Moskva, 1977, Nr. 2, S. 198-206, S. 202;

vgl. auch den Artikel von Valentin Rasputin, "Irkutsk s nami" (Sovetskaja kul'tura, 14.9.1979), in dem sich der Autor gegen die leichtfertige Zerstorung alter Kulturdenkmaler in seiner Heimatstadt Irkutsk wendet, die einer standardisierten modernen Architektur und Stădteplanung weichen müssen.

44) D.S. Lichąev, zit. bei T. Napolova, Nacional'naja samobytnost' pisatelja i duchovnyj oblik geroja, in: Volga, 1972, Nr. 10, S. 147-177, S. 148

45) F. Abramov, Koe-cto o pisatel'skom trude, in: Voprosy literatury, $1974, \mathrm{Nr} .3, \mathrm{~S} .180-195, \mathrm{~S} .187 \mathrm{f}$. 
zudem uberaus aktueller, Gegenwart und Zukunft der menschlichen Gesellschaft betreffender Pragen. Die Wahl dieses Materials durch eine solche Vielzahl von Autoren erscheint verständich in einem Land, das von seiner băuerlichen Vergangenheit noch nicht allzu weit entfernt ist. Inwieweit es als literarischer stoff fur eine Bewaltigung der intendierten Problematik geeignet und fruchtbar sein konnte, muB als Frage an eine konkrete Textanalyse gestellt werden. Die Kritiker der Dorfprosa verneinen dies:

Wenn aber talentierte Schriftsteller nicht die Menschen sehen, die sich jetzt in vorderster Linie des wissenschaftlich-technischen Portschritts befinden, wenn sie sich auf Erscheinungen konzentrieren, die der Vergangenheit angehoren, so bewirkt das kaum ein künstlerisches Wachsen der Autoren. Um so gefahrlicher sind die Versuche, in der Zuwendung des Kunstlers zur Patriarchalitat die Quelle der Erneuerung zu finden. 46)

Auch Philippa Lewis sieht in der Wahl des Materials bei den Dorfautoren eher eine Flucht vor den Realităten der Gegenwart, denn eine produktive Auseinandersetzung mit ihnen, wenn sie schreibt:

Die Ambivalenz gegenuber dem ProzeB der Urbanisierung, die viele "derevenšciki" zum Ausdruck bringen, der Schmerz uber den Verlust einer stabilen, einfachen Welt der Tradition, muB als typisch angesehen werden für eine Geselischaft, in der Modernisierung neu ist und/oder noch immer in Gang ist. Der Sinn des Seins reiBt sich los von einem festen Beziehungssystem, undie daraus resultierende Suche nach Stabilität in einer sich schnell verăndernden Welt funrt zu einem nostalgischen Blick zuruck in eine idealisierte traditionelle Welt, die in Wirklichkeit keine Antwort geben kann auf die neuen Probleme und auf die Komplexitaten der modernen Welt. 47)

Der Vorwurf des Zivilisationspessimismus und der Fortschrittsfeindlichkeit wird von den Autoren selbst energisch zurückgewiesen. Bei einem Treffen mit Studenten

46) A. Met Zenko, Večnyj zov i pozyvnve veka, in: Moskva, 1972 , Nr. 4, S. 197-212, S. 203

47) Lewis, a.a.o., S. 568 
der Moskauer Universitat brachte Valentin Rasputin auf eine Formel, was von den "derevenšciki" immer wieder zu vernehmen ist:

Das Problem besteht nicht darin, ob es bei uns Wasserkraftwerke geben soll oder nicht. Wasserkraftwerke wird es naturlich geben. Und auch den hohen Geschwindigkeiten kann man nicht entkommen. Hier mag die Frage aurtauchen: "Sind Sie fur das Alte oder fur das Neue?" Aber ich bin gerade dafur, das Alte mit dem Neuen zu verbinden. Das Neue wird so oder so kommen. 48)

Indem sie Fragezeichen setzen, wo zuvor vor allem Ausrurezeichen zu sehen waren, wollen die Autoren konstruktiv, mit den Mitteln der Literatur, eingreifen in die geistigen Auseinandersetzungen der Zeit. Der Dorfautor Fedor Abramov gelangt in diesem Zusammenhang $z u$ einer uberaus positiven Bewertung der Leistungen dieser neuen Literatur:

DaB die Dorfprosa augenblicklich eine Blutezeit erlebt und in den Blickpunkt des Interesses ruckt, ist ein Zeichen von Reife, staatsburgerlicher und geistiger Reife unserer Literatur, zeugt davon, daB sie die tiefgreifendsten und wichtigsten Prozesse der Gegenwart erfabt und in der Lage ist, zu bedeutenden gesamtnationalen und allgemeinmenschlichen Problemen vorzudringen. 49)

\subsection{Die "innerliterarischen" Paktoren}

\subsubsection{Das Interesse an der "narodno-razgovornaja reć"'}

Das Interesse am dorflichen Helden manifestiert sich in der Dorfprosa in besonderer Weise auch als Interesse am "auBerliterarischen" Sprachmaterial dieses Helden. Die breite Verwendung der lebenden Umgangssprache, von "prostorecie", Jargon und Dialektwortern ist ein charakteristischer Stilzug dieser Literatur. Die besondere sprachliche Orientierung bestimmt in der Dorfprosa die gesamte Erzăhlstruktur in solch starkem Maße, dab in einem Teil der Forschung bei inrer Beurteilung den Stil- 
fragen kardinale Bedeutung zugemessen wird:

Eine Erbrterung der Prosa der siebziger Jahre ohne Berücksichtigung des Stilproblems ist unmöglich... In den werken der letzten Jahre lassen sich komplizierte Beziehungen aufdecken zwischen Stil und Wirklichkeit einerseits sowie zwischen Stil und kunstlerischer Sicht des Schriftstellers andererseits. Uberhaupt erweitert sich das System der Parameter, die als stilbildend gelten. 50)

Der auf die Sprache des Helden orientierten Prosa wird unter den verschiedenen Stiltendenzen der sowjetischen Gegenwartsliteratur die eigentliche innovatorische Kraft zuerkannt:

Als "modern" und "neu", vom Standpunkt der sich in der Literatursprache vollziehenden Prozesse, wird die Prosa bezeichnet, in der das Wort des Helden die fuhrende Rolle ubernimmt. 51)

Die Hinwendung zur lebenden Volkssprache hat in der russischen Literatur eine reiche, wenn auch ungleichmábig sich entwickelnde Tradition, die sich im 19. Jahrhundert herausbildete und in der nachrevolutionaren Literatur der zwanziger Jahre zu neuer Blute gelangte. Ihren Niederschlag fand sie vor allem im "skaz", in der in Form eines Augenzeugenberichts gegebenen Erzahlung, die den individuellen Sprachstil des Erzăhlers bewahrt und dessen unmittelbare Orientierung auf den Leser als "Ansprechpartner" beinhaltet. Dieses in den verschiedenen Periodenden oft "wellenartig" entstandene Interesse an der "narodno-razgovornaja reč" - nach Galina Belaja "eines der Geheimnisse der russischen Literatur" 52 ) - hat die

50) G.Belaja, Slovo $v$ jazyke i slovo $v$ stile, in: Literaturnoe obozrenie, 1980 , Nr. 2, S. 39-41, S. 39

51) N.V. Dragomireckaja, Slovo geroja kak prinzip organizacii stilevogo celogo, in: Mnogoobrazie stilej sovetskoj literatury. Voprosy tipologii, Moskva 1978, S. $446-459$, S. 446

52) G.A. Belaja, Roždenie novych stilevych form kak process preodolenija "nejtral'nogo" stilja, in: Mnogoobrazie stilej, a.a.0., S. 460-485, S. 460 
Forschung wiederholt beschartigt ${ }^{53)}$. Eine wichtige Punktion nimmt nach V.V. Vinogradov der "skaz" im ProzeB der Ablosung abgenutzter und uberlebter Pormen einer kanonisierten Prosa ein. Das Einströmen auberhalb der literarischen Norm stehender sprachlicher Elemente in den literarischen Text wird zum Mittel der Erneuerung einer erstarrten traditionellen Literatursprache, wobei der "skaz" als Vermittlungsinstanz fungiert

zwischen dem kunstlerischen Element des mündichen Sprachschaffens und der bestandigen Tradition des literarisch-stilistischen Kanons. 54)

In solchen Perioden

beginnen die Schriftsteller, neue Welten zu schaffen mit Hilfe des fremden, "außerliterarischen" Sprachmaterials. Den Worten folgen in die neuen Konstruktionstypen neue "Gegenstände". Auf der Grundlage der skaz-Formen werden nicht nur neue Typen von Wortkombinationen geschaffen, die auf dem Hintergrund des Umbruchs der gewohnten semantischen Beziehungen sehr deutlich wahrgenommen werden, sondern auch neue Methoden der künstlerischen Umgestaltung der Welt. 55)

Einen anderen Aspekt des "skaz" hebt Michail Bachtin hervor, indem er als das fuhrende funktionale Prinzip in diesem die Ausrichtung auf die "fremde Stimme" und damit auf eine fremde Sicht, einen fremden Standpunkt betont:

Uns scheint, daß der skaz in der Mehrzahl der Falle der "fremden Stimme" wegen einge fuhrt wird, einer sozial bestimmten Stimme, die eine Reihe von $\mathrm{Ge}-$ sichtspunkten und Wertungen mit sich bringt, deren der Autor bedarf. Es wird nämlich ein Erzähler ein-

53) Neben den "klassischen" Arbeiten von Boris Ėjchenbaum, V.V. Vinogradov und Michail Bachtin ist hier auf einige neuere Forschungen zur Entwicklung der skazTradition in der sowjetrussischen Literatur vor allem der zwanziger Jahre zu verweisen: G.A. Belaja, Zakonomernosti stilevogo razvitija sovetskoj prozy dvadcatych godov, Moskva 1977; N.A. Koževnikova, Rečevye raznovidnosti povestvovanija v russkoj sovetskoj proze, (Kandidatendissertation) Avtoref.diss...kand.fil..., Moskva 1973; dies., O tipach povestrovanija v sovetskoj proze, in: Voprosy jazyka sovremennoj russkoj literatury, Moskva 1971, S. 97-163

54) V.V. Vinogradov, 0 teorii chudožestvennoj reçi Moskva 1971 , S. 129

55) Ebenda, S. 127 
gefuhrt, ein Erzăhler aber ist kein literarisch gebildeter Mensch und gehort in der Mehrzahl der Fälle $z u$ den niederen sozialen Schichten, zum Volk (gerade das ist fur den Autor wichtig)... 56)

Unter diesen beiden Aspekten der "skaz"-Tradition in der russischen Literatur - der Ausnutzung des außerliterarischen Sprachmaterials bei der Destruktion erstarrter literarischer Kanons und der Einfuhrung des fremden Standpunkts wird in der Forschung auch die Orientierung der modernen Dorfprosa auf die lebende Umgangssprache betrachtet. Die verschiedenen Untersuchungen zu Fragen der Stilentwicklung und der innovatorischen Tendenzen in der Poetik der gegenwärtigen russischen Literatur, fur die unter anderem besonders die Dorfprosa das Material lieferte, ordnen diese in einen umfassenden literarischen AblosungsprozeB ein, der sich in Opposition $z u$ der vorangegangenen Literatur der vierziger und funfziger Jahre bzw. zu bestimmten Normen des sozialistischen Realisms vollzieht ${ }^{57)}$. Gestutzt auf diese Forschungsarbeiten soll im folgenden versucht werden, die "innerlitera-

56) Michail Bachtin, Probleme der Poetik Dostoevskijs, Munchen 1971, S. 214

57) Die wichtigsten Arbeiten sind hier der Sammelband "Jazykovye processy sovremennoj russkoj chudozestvennoj literatury. Proza", Moskva 1977; Belaja, Rozdenije novych stilevych form, a.a.0.; dies., Puti istinnye i mnimye, in: Literaturnaja učeba, 1978 , Nr. 4, S. 212217; dies., Slovo v jazyke, a.a.0.; dies., Istorizm kak nravstvennaja $i$ chudožestvennaja pozicija pisatelja, in: Zanrovo-stilevye iskanija sovremennoj sovetskoj prozy, Moskva 1971, S. 93-113; dies., Iskusstvo est' smysl, in: Voprosy literatury, $1973, \mathrm{Nr} .7, \mathrm{~S} .62-94$; Koževnikova, 0 tipach povestrovanija, a.a.0., dies., 0 nekotorych tendencijach razvitija jazyka sovremennoj russkoj prozy, in: Jazyk i stil' pisatelej v literaturno-kriticeskom analize chudożestvennogo proizvedenija, Kišinev 1977, S. 36-57; Dragomireckaja, a.a.0.; Wolf Schmid, Thesen zur innovatorischen Poetik der russischen Gegenwartsprosa, in: Wiener Slawistischer Almanach, Bd. 4, 1979, S. 55-93; V.V. Kožinov, Golos avtora i golos personažej, in: Problemy chudozestvennoj formy socialistićeskogo realizma, t. 2, Moskva 1971, S. 195-235; Ja.E. El'sberg, Izmenenija dejstvitel'nosti i razvitie stilej sovetskoj prozy, ebenda, t. 1, S. 179-234; E.Ju. Sidorov, K probleme stilevogo mnogoobrazija sovremennoj russkoj sovetskoj prozy (60 - 70-e g8.? (Kandidatendissertation), Avtoref. diss... kan. fil..., Moskva 1974 
rischen" Faktoren zu bestimmen, die eine besondere Relevanz des alten Dorfes als kunstlerisches Material fur die modernen Autoren $z u$ begrüden vermochten.

\subsubsection{Modifikation der "skaz"-Tradition}

In reiner Form tritt der "skaz" in der modernen Dorfprosa relativ selten auf. Man kann von einer "neuen Modifikation der skaz-Tradition" ${ }^{58)}$ sprechen, die sich als Annaherung der Sprache von Autor / fiktivem Erzăhler und Held charakterisieren labt, wobei die Orientierung auf das "Wort des Helden" bestimmend ist. Die Sprache der handelnden Personen findet auf allen Ebenen des Textes Eingang. Das charakterologische Erzăhlen, das seine Gestalten mittels ihrer eigenen "Stimmen" schafft59), verbindet sich dabei mit literatursprachlichen Formen der Wiedergabe, und der Text erhalt

jene komplizierte stilistische Zeichnung,... jene Zweiteilung $z w i s c h e n$ Alltagssprache und verallgemeinernder, das Leben erfassender Sprache, die den Bereich der handelnden Person in der modernen Prosa organisiert. 60)

Der "skaz" wird durch geschmeidigere Verfahren, die fur die Aufgaben der modernen Prosa tauglicher zu sein scheinen, verdrăngt, vor allem durch die "nesobstvennoprjamaja reč" ("erlebte Rede") und das "nesobstvennoavtorskoe povestvovanie"61).

58) Belaja, Roždenie novych stilevych form, a.a.0., S. 462

59) $\mathrm{Vgl}$. V.V. Vinogradov, 0 jazyke chudožestvennoj literatury, Moskva 1959 , S. 476

60) N.A. Kozevnikova, O' sootnošenii reci avtora i personaža, in: Jazykovye processy, a.a.0., S. 74

61) Der Begriff "nesobstvenno-avtorskoe povestvovanie" (NAP) stammt von N.A. Koževnikova; als deutsche Entsprechung bietet sich der von Holthusen geprăgte Begriff "uneigentliches Erzahlen" an (Johannes Holthusen, Stilistik des "uneigentlichen Erzăhlens" in der sowjetischen Gegenwartsliteratur, in: Die Welt der Slaven, 1968, S. 225-243). Er charakterisiert eine Erzahlweise, bei der in variabler Dichte sprachliche Besonderheiten und damit Wertung und Sichtweise des Helden in den Erzăhlbericht ubernommen werden.

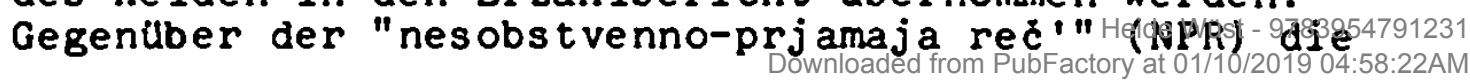


Mit der Sprache des dorflichen Helden rindet auch dessen Bewubtsein Eingang in die verschiedenen Textrragmente. Der "plan personaža", die Perspektive der handelnden Person und die Besonderheiten ihrer Weltwahrnehmung sind fast durchgăngig gegenwărtig und bestimmen die gesamte asthetische Struktur des Textes.

\subsubsection{Die Ablosung des literarischen Kanons}

Das bewubte und produktive Arbeiten mit dem "Wort des Helden" vollzieht sich in der modernen russischen Prosa auf dem Hintergrund einer Literatur und in Opposition zu einem Stil, die der "fremden stimme" und dem fremden standpunkt wenig Bedeutung beigemessen hatten. In den dreibiger Jahren war in der sowjetischen Literatur der "skaz" durch auktoriale Darbietungsformen abgelbst worden, in die Sprache und Perspektive des Helden nur noch bei einigen wenigen Autoren Eingang fanden ${ }^{62}$ ). Ein Vorgang, der nach Natal'ja Koževnikova wesentlich mit bedingt war durch den "Drang zum direkten und eindeutigen Ausdruck der Autorposition"63), was ja auch den Forderungen des sozialistischen Realismus entsprach. Dominierend wurde in der

als traditionelles Mittel der Wiedergabe der inneren Rede des Helden unmittelbar und unmiBverständich an dessen Perspektive gebunden ist, zeichnet $s i c h$ das NAP durch grobere Verselbständigung und Freineit bei der Kombination charakterologischer und literarischschriftsprachlicher Mittel aus und bewirkt die Uneindeutigkeit der Erzahlperspektiven und der dahinter verborgenen Nertungen. Die Ubergănge zwischen NPR und NAP sind fliebend und inre Unterscheidung ist vor allem aufgrund der Funktionserweiterung der NPR in der modernen Prosa oft schwierig. Zum Begriff des NAP und zur Unterscheidung der beiden Erzăhltypen vgl. auch Wolf Schmid, a.a.0., S. 83 r.

62) Nach Galina Belaja war dies u.a. bei Gor'kij, Leonov und Solochov der Fall, in deren Werk das Wort des Helden im objektiven Erzăhlbericht ein "Verhăltnis neuen Typs" mit dem Autorwort einging. Vgl. Belaja, Stil' i vremja, in: Mnogoobrazie stilej, a.a.0., S. 231-256; dies., Zakonomernosti stilevogo razvitija, a.a.0.

63) Koževnikova, Rečevye raznovionosti, a.a.0., S. 130 
Folgezeit ein Stil,

bei dem die vorherrschende Weltwahrnehmung des Autors die handelnden Personen vollstăndig unterdrückt und sie in die Bahn ihres Denkens, ihrer Weltsicht einschlieBt 64),

und der sich an der literatursprachlichen Norm orientierte. Die strenge monologische Ausrichtung des Textaufbaus, die keinen Zweifel an der Autorposition aufkommen lieb, fuhrte in der sozialistisch-realistischen Prosa der drei'Biger bis Mitte der funfiger Jahre zur Kanonisierung und schablonenmåigen Reproduktion auktorialer Erzăhltechniken und ging einher mit einer Vereinheitlichung der Sprache, was auch dem Streben nach leichter Verständichkeit und Transparenz des literarischen Wortes entsprach. In dieser Prosa

fuhren die erzăhlten Personen kein sprachliches

Eigenleben. Generell sprechen sie die gleiche Sprache wie der Erzăhler, und dieser lost sich nicht aus der Sprachsphäre des Autors. Auf allen Kommunikationsebenen des Erzăhlwerks spricht man in einem künstlich vereinheitlichten Stil, der seine mimetische Funktion gänzlich verloren hat. So dominierte das Prinzip der "odnostil'nost"". Ihre Grundlage war der neutrale, von sozialen, lokalen und charakterologischen Merkmalen gereinigte Stil der Buchsprache. 65)

Wie stark das Ungenugen an der Sprache dieser Literatur war, die in den funfziger Jahren einen recht hohen Grad der Verselbständigung gegenuber der lebenden Umgangssprache erreicht hatte, zeigt die Kritik, die in dieser Zeit unter den Literaten laut wurde und die sich vor allem gegen den publizistischen, mit fertigen Schablonen und abgegriffenen Wortklischees durchsetzten Stil richtete, der aus der offiziellen Sprache bereits allzu weit in die Literatur eingedrungen war ${ }^{66)}$.

Einen ersten Versuch, die "odnostil'nost'" der vorangegangenen Literatur $z u$ uberwinden, unternahm die "molodaja proza" (Junge Prosa) der spaten funfziger und fruhen

64) Belaja, Roždenie novych stilevych form, a.a.0., s. 469

65) Schmid, a.a.0., S. 73

66) $\mathrm{Vgl}$. die von Belaja gesammelten $\mathrm{Zitate}$ in: Roždenie novych stilevych form, a.a.0., S. 466 ff. 
sechziger Jahre 67), mit der Autoren wie Vasilij Aksenov, Anatolij Gladilin, Irina Grekova und andere die Sprache ihres jugendlichen, "antiautoritären" Helden in die Literatur einfuhrten: Den ironisch-lassigen Sprachstil und bunten Jargon des jugendlichen Intellektuellen aus der Grobstadt. Durch die Annaherung der fiktiven Sprache des Helden an die lebendige, gesprochene Sprache der Gegenwart strebte die "molodaja proza" wieder nach einer Verbindung

zwischen dem Wort und der psychologischen Verfassung der handelnden Person, zwischen der Welt inrer Gefuhle und Gedanken und dem hinter diesen stehenden Leben. 68)

In der saloppen Sprache dieses Helden spiegelten sich der Denkstil und die Bewubtseinshaltung des jugendlichen Großstadters. Gleichzeitig fuhrte die "molodaja proza" eine Polemik gegen die Schablonen der offiziellen und der literarischen Sprache, gegen den "kanceljarit", einer Stil,

in dem eine Sprache herrscht, die einst im System der neuen gesellschaftlichen Ideologie entstanden war, die aber spater erstarrte und verknocherte 69 ,

und der in inr zum Objekt parodistischer Verfremdung wurde.

67) Die Profilierung dieser literarischen Richtung beganr Ende der funfziger Jahre mit dem Aufstieg der Zeitschrift "Junost" (Jugend), in der die meisten Werke der "Jungen Prosa" veroffentlicht wurden. Die Bezeictnung erhielt sie nach ihrem Helden, dem jungen Menschen, von den Autoren und der Kritik seinerzeit auct als "negativer Held" heftig diskutiert. Die "molodaj proza" war wesentlicht beeinfluBt von westlichen Vorbildern, namentlich von Jerome $D$. Salingers "Catcher in the Rye" und wies Paralellen in anderen osteuropajschen Landern auf (vgl. hierzu Aleksandar Flaker, Modelle der Jeans-Prosa. Zur literarischen Oppositior bei Plenzdorf im os teuropäischen Kontext, Kronberg/Ts. 1975); zur "molodaja prcza" vgl. auch Brown, a.a.0., S. 180-217 sowie Ssachno, a.a.0., S. 268-299

68) Belaja, Puti istinnye, a.a.0., S. 214

69) Belaja, Rozdenie novych stilevych form, a.a.0., S. 473 
Diese "Junge Prosa" war ein wichtiger Schritt auf dem Weg zur uberwindung des monologischen Stils und bei der Suche nach neuen Ausdrucksformen. Um die Mitte der sechziger Jahre erwies sich inre innovatorische Kraft jedoch als erschöpft. Sie begann, auf der Stelle zu treten, sich $z u$ wiederholen. Der ironisch-parodistische Stil wurde seinerseits zur "durchschnittlichen literarischen Norm", was sich besonders deutlich daran zeigte, daB er bereits Eingang in die verschiedenen Genres der Publizistik gefunden hatte ${ }^{70)}$. Eine uberzeugende Erklärung fü den Abstieg der "molodaja proza" und ihre Ablosung auf dem fuhrenden Platz der Gegenwartsliteratur durch andere Autoren gibt Galina Belaja. Sie sieht die Begrenztheit der Mrglichkeiten dieser Prosa in der Begrenztheit ihres Helden und seiner Sprache angelegt. So wie der jugendliche Held in ihr nur als Reprăsentant eines engen sozialen Kreises auftrat, war auch seine Sprache nur auf eine begrenzte Problematik anwendbar: Die Wiedergabe der Gefuhle, Erfahrungen und geistigen Interessen eben dieses Kreises, die aber nur ein kleiner Ausschnitt des geistigen Lebens der Gesellschaft sein konnten ${ }^{71)}$. Der Stil der "molodaja proza"
war der Stil eines "Kreises" und nicht der Stil des "Ganzen". Die festen Sprachformeln, die Grell- heit, der Jugendjargon, die kuhne umgangssprachliche Manier - all dies war nur eine zentimeterdunne Schicht jener vielstimmigen und widerspruchsvollen Wirk- lichkeit, die uns umgibt. 72)

Mitte der sechziger Jahre wurde die "molodaja proza" von der Dorfprosa abgelost, die die Orientierung auf die gesprochene Umgangssprache und die Arbeit mit dem "Wort des Helden" fortsetzte und auf eine breitere Basis stellte. Indem sie sich mit der wahl inres Helden einer umfassenderen und ergiebigeren Sprachschicht zuwandte, modifizierte und vertiefte sie die bereits aufgeworfenen stilprobleme und strebte nach Verwirklichung neuer poetischer

70) Vgl. Čudakova, a.a.0., s. $218 \mathrm{ff}$.

71) Vgl. Belaja, Puti istinnye, a.a.0., S. 214

72) Belaja, Rozdenie novych stilevych form, a.a.o., S. 476 
Prinzipien, die den konventionellen literarischen Kanon endgultig abzulosen vermochten. Galina Belaja charakterisiert diese neuen Prinzipien:

Streben nach auberster Glaubwurdigkeit der Darstellung; Achtung der Souverănităt der handelnden Person; eine der fruheren Isoliertheit des Stils entgegengesetzte Verknupfung des Stils mit der Sprache des Helden;...ein Komplex von wechselseitig fest miteinander verbundenen Stilkoordinaten (Autor Held - Leser); die organische Aneignung des volkstumlich-umgangssprachlichen Baus der Sprache als Quelle fur die Aufdeckung des menschlichen Denkens und schlieblich das Heraustreten aus den Grenzen eines "Kreises" hin zum Ganzen, zum Volk - dieser Komplex charakterisiert heute die Stilentwicklung der sowjetischen Prosa. 73)

So scheint sich auch aus dem Prozeb der literarischen Evolution selbst ein Faktor zu ergeben, der ein besonderes Interesse der modernen Prosa am Material des Dorfes bewirken konnte. Die Sprache des Dorfbewohners, fur den Russen immer noch Verkorperung der "narodnyj jazyk", der Volkssprache, und das an diese Sprache gebundene "fremde" Bewubtsein wurden bedeutsam fur die Realisierung der neuen kunstlerischen Aufgaben, die die modernen Autoren sich stellten und die von der literarischen Entwicklung selbst auf die Tagesordnung gesetzt waren. Wie unterschiedlich auch hier die beschrittenen Wege und gefundenen Losungen waren, vermag die Textanalyse bei den beiden ausgewahlten Autoren zu zeigen.

73) Ebenda, S. 477 


\section{Vasilij Makarovic $\check{s} u k \dot{s} i n$}

Der 1929 im Ort Srostki im Altaj geborene und bereits 1974 verstorbene Autor kann als der erste bedeutende Vertreter der neuen Dorfprosa gelten. Das kunstlerische Schaffen Sukšins, der als Schriftsteller, Filmregisseur und Schauspieler gleichermaben bekannt wurde, fallt in die sechziger und siebziger Jahre. Sein vorwiegend aus Kurzprosa bestehendes erzahlerisches Werk war zu Lebzeiten des Autors in der sowjetischen Kritik heftig umstritten. Seit Mitte der siebziger Jahre wird Sukšin jedoch in der sowjetischen Forschung und Publizistik zunehmend als bedeutender vertreter der modernen russischen Literatur gewurdigt. Hinsichtlich der Leserschaft und der Popularitat seiner Prosa darf er zweifellos als einer der bekanntesten zeitgenossischen sowjetischen Autoren gelten.

Mit Ausnahme der beiden historischen Romane "Ljubaviny" (Die Ljubavins, 1965) und "Ja prišel dat' vam volju" (Ich kam, euch die Freiheit $2 u$ geben, 1971) sowie einigen groberen Erzăhlungen, unter denen besonders die Filmnovelle "Kalina krasnaja" (Roter Schneeballstrauch, 1973) sehr bekannt wurde ${ }^{74)}$, hat Sukšin vor allem kurze Erzăhlungen geschrieben, die in verschiedenen Zeitschriften und einer Reihe von Sammelbanden erschienen sind und den Kern seines schriftstellerischen Schaffens darstellen. Mit Ausnahme der Filmnovelle "Kalina krasnaja" wurden fur die vorliegende Untersuchung ausschlieblich kurze Erzăhlungen ausgewahlt, da sich in ihnen die ideelle Thematik sowie das besondere kunstlerische System des Autors am deutlichsten reprasentieren.

Eine Gesamtausgabe der Werke Suksins ist bisher noch nicht erschienen, und besonders die Erzăhlungen liegen vorläurig nur verstreut in einer Vielzahl von zeit-

74) Vor allem der gleichnamige Film, an dem Suksin als Drehbuchautor, Regisseur urd Hauptdarsteller mitwirkte, brachte ihm auch internationale Anerkennung und Bekanntheit 
schriften und meist kleineren Auswahlbănden vor, die zudem oft ungeschickt ediert sind und teilweise verschiedene Textvarianten aufweisen ${ }^{75)}$. Die für die Untersuchung ausgewăhlten Texte muBten deshalb verschiedenen Ausgaben entnommen werden, auf die im folgenden jeweils gesondert verwiesen wird. Redaktionelle Uberarbeitungen, die Sukšin bei seinen Erzăhlungen hăufig vorgenommen hat, werden nur in einigen wenigen, fur die Interpretation besonders relevanten Fallen berucksichtigt. Die Datierung der Erzahlungen in der vorliegenden Arbeit richtet sich nach dem Jahr der Erstveroffentlichung.

\subsection{Das Thema der zwei Kulturen}

\subsubsection{Zum Bezug von Biographie und literarischem Thema}

Šukšin nimmt innerhalb der Dorfprosa eine - allgemein anerkannte - Sonderstellung ein, die auf der Besonderheit seines Themas, seiner Helden und seiner kunstlerischen Methode beruht. Seine Erzahlungen gestalten eine Vielzahl verschiedenster dorflicher Charaktere, "wie es scheint, eine Galerie von Typen und Seltsamkeiten, die alle die gleiche Aufmerksamkeit des Autors genieben"76) und die sich schwerlich auf einen am traditionellen Bild des russischen Dorfes orientierten Typus reduzieren lassen. Stäker und mannigfaltiger als bei allen anderen "derevenšliki" begegnen und vermischen sich in dieser Prosa Dorf und Stadt, Elemente und Realien der alten bauerlichen Kultur mit solchen des modernen Lebens. Sukšin gilt denn auch vielen Kritikern als der Schriftsteller eines bestimmten Milieus, als

einzigartiger spezialist fur jene, in unserer Geschichte bisher unbekannte 2 wischenschicht, die jetzt, im letzten Drittel des Jahrhunderts, in Erscheinung getreten ist als Folge gewaltiger sozia-

75) Vgl. auch V. Gorn, Pereizdanijam V. Śukšina - podlinr.o naủnyj uroven', in: Voprosy literatury, 1977, $\mathrm{Nr} .1$, S. 248-252

76) Brown, a.a.0., S. 294 
ler Verănderungen, die das russische Dorf bis auf den Grund erschutterten. 77)

Es handelt sich um jene dorflich-stădtische Zwischenschicht, die noch vom Dorf geprăgt, gleichzeitig aber schon stärker von der stadtischen Kultur beruhrt ist und die den Nahrboden fur die Migration vom Land in die Stadte bildet. Die Problematik dieser Ubergangsituation in ihren psychologischen, kulturellen und ethischen Dimensionen beschaftigte den Regisseur und Schriftsteller bis zu seinem Tode, und zu ihrer Bedeutung in seinem Schaffen hat sich Sukßin mehrfach geăuBert:

In der Literatur wie im Film sind meine Vorlieben konstant: Ich erforsche die băuerliche Schicht und dabei auch das Schicksal der Menschen, die aus dem Balierntum hervorgegangen sind. Was beunruhigt mich? Vor allem das Schicksal des Menschen aus dem Dorf, der in neue Verhältnisse gerat, der abrupt sein gewohntes Milieu mit dem ihm eigenen System der Moral, mit den ihm eigenen Werten und Traditionen wechselt. 78)

Šuksin gehorte selbst dieser 2 wischenschicht an, und der ubergang von einem kulturellen zustand in einen anderen war eine Grunderfahrung des Autors, deren ganze Widersprüchlichkeit er schmerzlich und uberaus sensibel an sich selbst wie an seiner Umwelt wahrnahm.

Die verschiedenen $\mathrm{Zwischenstufen} \mathrm{dieses} \mathrm{Ubergangs} \mathrm{schei-}$ nen die Biographie Sukšins in besonderem MaBe $2 u$ kennzeichnen. Aufgewachsen auf dem Lande, wo er seit dem vierzehnten Lebensjahr im Kolchos arbeitete, hatte er in der Hungerzeit der Nachkriegsjahre seine sudsibirische Heimat verlassen, um sich als Gelegenheitsarbeiter in Fabriken und auf Baustellen an wechselnden Orten Zentralrublands zu verdingen. Wie viele junge Menschen des damaligen sowjetischen Dorfes war er aufgebrochen, "ein

77) Lev Anninskij, Put' Vasilija Šukšina, in: Vasilij Sukšin, Do tret'ich petuchov. Povesti. Rasskazy, Moskva 1976 , S. 638-666, S. 655

78) Vasilij Sukšin, zit. bei G.F. Pavlikov, Proza V. Suksina. Tvorćeskaja individual'nost' pisatelja i èvoljucija geroja (Kandidatendissertation), Diss... kand. fil..., Leningrad 1977, S. 72 
glulcklicheres Los zu suchen" ${ }^{79)}$. In Šukšins Biographie, den Besonderheiten seines Schicksals und seiner Personlichkeit, soweit sie sich aus seinen publizistischen Auberungen und Briefen erschlieben lassen, erinnert vieles an seine literarischen Helden. So zum Beispiel, wenn er in seinem "Lebenslauf" uber diese Jahre der Wanderschart von 1946 bis 1949 schreibt:

\begin{abstract}
Es "zu etwas zu bringen", gelang mir einfach nicht. Zweimal wollte mir fast das Gluck lachen. 1948 wurde $i c h$ als verstandiger und absolut gesunder Bursche vom Militarkommissariat der Stadt Vladimir zum Studium ans Luftrahrtinstitut des Tambover Gebiets delegiert. Alle meine Dokumente, und es waren viele, verschiedene Bescheinigungen, brachte ich selbst hir. Und verlor sie unterwegs. Im Institut zu erscheinen, waste $i c h$ nicht, und nach vladimir kehrte ich auch nicht zurück. Dort, im Militärkommissariat, waren gute Menschen, und es war mir unangenehm, ihnen verdrub zu bereiten dadurch, dab ich mich als solche "Schlafmütze" erwies. ...Und noch einmal, aus der Gegend von Moskau, schickte man mich an ein Militarinstitut, eine KfzSchule nach Rjazan. Dort fiel ich durchs Examen. In Mathematik. 80)
\end{abstract}

1949 bis 1952 diente Šukšin bei der Flotte in Leningrad und Sevastopol. Nach dem Militardienst kehrte er ins Altaj zurück, wo er als externer Schuler den Abschlub der Zehnklassenschule nachholte und darauf in seinem Heimatort ein Jahr lang als Lehrer an der Dorfschule fur Erwachsene arbeitete.

1954 gelang dem bereits 25jahrigen der Eintritt ins Uniorsinstitut für Filmwesen in Moskau. Mit dem Studium an der Fakultat fü Regisseure, das er 1960 abschloß, begann fü den Provinzler nicht nur die Konfrontation mit dem Leben und den Reizen der Hauptstadt, sondern zugleich auch ein Kamp $f$ um wissen und Bildung, um Anerkennung in einem Milieu, dessen Lebensformen und intellektuelle Gepflogenheiten ihm fremd waren, ein Kamp $f$ um "das Recht auf

79) Vasilij Śukšin, Tol'ko éto ne budet ékonomičeskaja stat'ja..., in: ders., Nravstvennost' est' pravda, Moskva 1979 , S. 40-50, S. 41

80) Vasilij Sukșin, Avtobiografija, in: Nravstvennost', a.a.0., s. 322 
die Kunst" 81$)$. Sukšin außerte spăter uber diese Zeit:

Ins Institut kam ich als zutiefst dorflicher Mensch, weit entfernt von der Kunst. Mir schien, daß das für alle sichtbar war. Ich kam viel zu spät ans Institut - mit 25 Jahren -, und meine Belesenheit wie auch meine Kenntnisse waren relativ. Das Studium fiel mir schwer, außerordentlich schwer. Mein Wissen eignete ich mir stückweise an und irgendwie mit Lücken. Auberdem mubte ich mir aneignen, was alle wissen, was ich aber im Leben versăumt hatte. Und da begann ich, bis zu einem bestimmten Zeitpunkt die gesammelte Kraft $z u$ verbergen. Und irgendwie gelang es mir, in den Leuten die Uberzeugung zu năhren, dab sie es sind, die sich mit der Kunst beschäfigen müssen und nicht ich. Aber ich wubte, dab ich den Augenblick abpassen würde, in dem ich... nun, mich als kompetenter erweisen wurde als sie mit ihren endlosen Erklarungen uber die Kunst. Die ganze Zeit uber verbarg ich in mir vor fremden Augen einen unbekannten Menschen, eine Art geheimen, verschlüsselten Kämpfer. 82)

Dem russischen Dorf des Altaj, zu dem es inn immer wieder hinzog, seinen Menschen und seiner Sprache blieb Šukšin bis zum Ende verpflichtet. Er bekannte sich nicht nur zu seiner dorflichen Herkunft ${ }^{83}$ ), sie war inm auch teuer als moralisches Fundament und Ruckhalt, aus dem er Lebensmut und neue schopferische kraft bezog. Aber nicht geringer war seine Bindung an die Stadt, in der er seit 1954 lebte und arbeitete, als Statte des Denkens, der geistigen Entwicklung und Vervollkommnung des Menschen ${ }^{84)}$. Um so stärker empfand er jenen Zwiespalt zwischen

81) Vgl. Vasilij Śuks̄in, Ešce raz vyverjaja svoju żizn', in: Nravstvennost', a.a.0., S. 266-284, S. 283

82) Ebenda, S. $281 \mathrm{f}$.

83) Obwohl er auch die andere Erfahrung gemacht hat te:

"Ich schamte mich lange, daß ich vom Dorf kam und daB mein Dorf weiB der Teufel wie weit entfernt war. Ich liebte es schweigend und sprach wenig." $\mathrm{V}_{\mathrm{gl}}$. Sukšin, Slovo o "maloj rodine", ebenda, S. 103-112, S.111f.

84) In "Monolog na lestnice" schreibt Sukšin: "Die Stadt, das ist auch das stille Hauschen von Ziolkovskij, wo die Arbeit nicht nach Ruhm strebte. Die Stadt, das ist dort, wo gewaltige hăuser stehen, und ir den Hăusern gibt es Bücher, und dort ist es feierlich still. In der Stadt wurde der einfache und geniale Gedanke geboren, dab alle Menschen Bruder sind. In die Stadt mub man gehen wie Glaubige in die Kirche - man muB glauben und nicht um Almosen bitten. Die Stadt, das sind auch die Fabriken mit ihrem: eigenen seltsamen, faszinierenden Reiz der Maschinen." Ebenda, S. 64 
dorflichen Wurzeln und städischer Existenz seiner Personlichkeit, ein Zwiespalt, den er vor allem in seiner Widerspruchlichkeit und vielschichtigkeit begriff und der sich fur ihn nicht auf eine einfache Dichotomie Stadt versus Dorf reduzieren lieb. In seinem beruhmten Aufsatz "Monolog na lestnice" schrieb Šukšin 1967:

So ergab es sich bei mir gegen mein vierzigstes Lebensjahr, dab ich nun kein städter von Grund auf, aber auch schon kein Dorfler mehr bin. Das ist eine Situation, nicht einmal zwischen zwei Stuhlen, sondern eher so: Ein Bein am Ufer, das andere im Boot. Und einerseits muB man losfahren, andererseits hat man aber Angst davor. Lange kann man in einem solchen Zustand nicht verharren. Ich weiB, man wird sturzen. Nicht den Sturz furchte ich (was fur ein Sturz? von wo?) - es ist wirklich einfach sehr unbequem. Aber diese meine Lage hat auch inr "Plus"... Vom Vergleichen, von all den "von dort nach hier" und "von hier nach dort" kommen einem unwillkülich Gedanken, nicht nur Uber "das Dorf" und "die Stadt", sondern Uber RuBland. 85)

Es gibt in Sukšins Publizistik sehr viele AuBerungen Uber das Dorf und die stadt, und sie sind in sich nicht immer frei von Widerspruchen. Uberhaupt zeigt diese Publizistik, die uberrascht durch inre offenheit und die Spontaneitat des Gedankens, eher eine vor allem fur die widerspruchlichkeit und Kompliziertheit der konkreten Lebenserscheinungen empfängliche Persornlichkeit, denn einen systematischen Denker, der zu logischen Schlubfolgerungen und ausformulierten Erkenntnissen neigt. Lev Anninskij hat Śkšin einen "Philosophen der russischen Tradition" genannt, dessen

Anschauungssystem in der "Färbung" des Lebensweges zum Vorschein kommt, wenn es aufgelost ist im SchaffensprozeB und diesen von innen her nahrt und durchdringt, ohne sich zu einem "professorenhaften"

System herauszukristallisieren. 86)

85) Sukšin, Nravstvennost', a.a.0., s. 51-75, s. 60

86) Lev Anninskij, Šukšin-publicist, Vorwort zum Sammelband "Nravstvennost' est' pravda", a.a.0., S. 3-20, S. 7 
Die innere Zerrissenheit des Menschen, der sich im Ubergang von einem zivilisatorischen Zustand in einen anderen befindet und die Suche nach einer Verbindung des in beiden Formationen als wertvoll Erkannten als einzige Chance, im Strudel des modernen Lebens nicht unterzugehen, kennzeichnen die Personlichkeit und das Denken Sukšins und fanden ihren Niederschlag in einem groben Teil seines künstlerischen Schaffens. Noch in seinem Todesjahr 1974 formulierte der Schriftsteller die Unabgeschlossenheit seiner Position in dieser Frage:
Uberhaupt mochte ich, daB der dorfliche Mensch, wenn er das Dorf verläbt, nichts verliert von dem Wertvollen, das inm die traditionelle Erziehung mitgegeben hat, von dem, was er einmal verstanden und geliebt hat; das er die Liebe zur Natur nicht verliert...
Aber ich und meine Wunsche als Autor sind eine Sache, eine andere ist der Mensch selbst: Ich verstehe die ganze Schwierigkeit dieses meines Helden, ja, mehr noch, ich verstehe auch meine eigene Schwierigkeit, denn $i c h$ weiB $j a$ selbst noch nicht sehr gut, was er eigentlich bewahren und was er lieben soll... I ch mochte nur sehr, dab dies nicht etwas Vorubergehen- des sei, sondern etwas so Pestes und Bestăndiges, wie es jahrhundertelang vor inm beständig gewesen war. 87)

Der Bezug zwischen Biographie und personlicher Problematik des Autors und der Besonderheit vieler seiner literarischen Helden hat bei einigen Kritikern den Begriff "šukšinskaja žizn"" (Śuks̄insches Leben) geprăgt, der das Schicksal jenes modernen Ubergangstypus der sowjetischen Gesellschaft zu bezeichnen sucht, den Suksin zum Teil selbst verkörperte und dessen Ausprăgung und geistige Evolution er in seiner Prosa wie in seinen Filmen immer wieder neu gestaltete ${ }^{88)}$.

In Śkšin nur den Autor des Ubergangs vom Dorf zur Stadt sehen zu wollen, wăre sicher verfehlt. Doch das Material des Dorfes gewinnt in seiner Prosa vor allem unter einem

87) Vasilij Śuksin, Ja rodom iz derevni..., Interview mit der italienischen Zeitung "Unita", in: Nravstvennost', a.a.0., S. 230-246, S. $236 \mathrm{f}$.

88) Vgl. Lév Anninskij, Śuksinskaja zizn', in: Literaturnoe obozrenie, $1974, \mathrm{Nr} .1$, S. 50-55 
zentralen thematischen Aspekt Bedeutung: Begegnung und Verflechtung verschiedener Formen der geistigen Kultur, verschiedener Lebenssphären - der des traditionellen russischen Dorfes und der der modernen Stadt - und die Auswirkungen dieses Prozesses auf Bewubtsein, Psychologie und Verhalten des Menschen sind ein Grundthema in dieser Prosa. Es zieht sich durch fast alle Erzählungen, auch dort, wo es nicht unmittelbar in der Fabel angelegt ist. Denn aus dieser soziokulturellen ubergangssituation schöpt der Autor seinen literarischen Stoff und in dem von ihr hervorgebrachten sozialpsychologischen Klima bewegen sich alle seine Helden.

Das Thema der beiden Kulturen ist für das Verstándnis der von Šukšin gestalteten Charaktere und Typen von zentraler Bedeutung und hat in ihnen eine originelle und eigenständige Note erhalten.

Im folgenden soll zunachst diese thematische Schicht in Zusammenhang mit einigen wesentlichen erzăhlerischen Besonderheiten der Prosa Sukšins untersucht werden.

\subsubsection{Kontrast und Konfrontation als thematisches und kunstlerisches Prinzip}

Šuks̄in begann zu schreiben, als die "Junge Prosa" im Mittelpunkt des literarischen Interesses stand und der jugendliche Held ausgesprochen urbaner Prăgung die Seiten der literarischen Journale beherrschte. Sein erster Erzăhlband, der 1963 erschien, mubte in dieser Zeit schon durch seinen Titel "Sel'skie ziteli" (Dorfbewohner) einen polemischen Klang erhalten ${ }^{89}$ ). Doch die Bedeutung, die das direkte Wort des Helden in der "Jungen Prosa" erlangt hatte, wurde in den Erzăhlungen des neuen Autors fortgefuhrt, und auch seine Helden waren, wenn auch auf ganz andere Weise und weniger auffallig, doch nicht minder als der Typus des "antiautoritaren" Großstädters ganz der

89) Vgl. B. Judalevič, O rasskazach V. Sukšina, in: Problemy literatury Sibiri, XVII - XX vv., Novosibirsk 1974 , S. 221-238, S. 221 
Gegerwart entnommene Charaktere, die den Stempel der zeit trugen.

Nichts zeigte dies deutlicher als die Sprache der neuen Helden, die in dieser Prosa ganz in den Vordergrund trat und den Autor ganz aus ihr "zu verdrängen" schien. In ihr ring Suksiin die Besonderheiten jenes Jargons ein,

jenes einzigartige lexikalisch-stilistische Durcheinander, in dem heute eine gewaltige 2 ahl von Menschen spricht, die an den sozialen und geographischen Schnittpunkten lebt. 90)

Diese Sprache, in der Śukšin bis ins Detail die Modifikationen der volkstümlich-dorflichen Umgangssprache unter dem Einflub der Sprachkultur der stadt verfolgt, die sich oft in schnell angeeigneten Forme in und Schablonen, in der witzigen und absurden Vermischung verschiedener Sprachstile und -schichten niederschlagen, ist kaum ubersetzbar, da deutsche Entsprechungen entweder fehlen oder dort, wo sie vorhanden sind, nicht die gleichen Assoziationen hervorrufen wie beim russischen Leser. Die Wirkung der Prosa Šukßins beruht aber unter anderem auch auf solchen Assoziationen des Lesers und ihrer Funktion bei der sprachlichen Selbstaufdeckung der Helden.

Die auf den ersten Blick so einfach erscheinenden Erzăhlungen von alltäglichen oder komischen, oft anekdotisch zugespitzten Begebenheiten erweisen sich bei genauerer Betrachtung als recht kompliziert und vielschichtig. Sie sind nicht durch Inhaltsangaben zu erfassen, da die helden vor allem in Bewubtseinszuständen und Denkvorgăngen dargestellt werden. Kernstück ist dabei der Dialog der agierenden Personen, deren Unterhaltungen indessen ebenso belanglos und kurios anmuten wie die geschilderten Begebenheiten und die Helden selbst, die der Autor aber mit fast stenographischer Genauigkeit wiedergibt:

...er gibt uns die Moglichkeit, alle Interjektionen, die diese Helden von sich geben, anzuhören, mit ihnen

90) B. Pankin, Vasilij Šukšin i ego "ćudiki", in: Junost', $1976, \mathrm{Nr} .6, \mathrm{~S} .74-80, \mathrm{~S} .79$ 
zusammen alle Gesprăchspausen abzuwarten - kurz, anwesend $z u$ sein bei ihrem privaten Gesprăch am Familientisch, am Flub, bei einem Gesprăch, das im übrigen meistens zu nichts funrt und unvermutet, nach Belieben des Autors, abgebrochen wird. Und es scheint, dab die Helden untereinander immer noch weiterreden in ihrer wunderlichen Sprache, wenn wir uns von ihnen bereits getrennt haben. 91)

Eire solch vollig alltagliche Geschichte uber ganz gewornnliche Menschen erzăhlt Sukšin in der fruhen Erzăhlung "Sel'skie żiteli" (Dorfbewohner, 1962) 92 ), die auch dem ersten Erzahlband des Autors den Titel verlieh.

Die alte Malan'ja erhălt von ihrem Sohn aus Moskau eine Einladung. Sie uberlegt, wie die Reise aus dem abgelegenen sibirischen Dorf in die Hauptstadt anzustellen sei und schreibt zusammen mit dem Enkel Šurka, der bei ihr lebt, ein Telegramm an den Sohn, daB sie mit Surka nach Neujahr kommen werde. Abends erzahlt der Nachbar Egor ausfuhrlich uber den Ablaur und die Gefahren einer Flugreise. Malan'ja bekommt Angst vor diesem Unternehmen und schreibt nun anstelle des Telegramms und sehr zum Verdrub Surkas dem Sohn einen Brief, daB sie vorerst doch nicht kommen werden.

Die Erzăhlung besteht hauptsăchlich aus dem Dialog zwischen Malan'ja und Šurka bzw. Malan'ja und Egor sowie den Schreiben der alten Frau an den Sohn, die sie dem Enkel, der schon die sechste Klasse besucht, diktiert. Der Anfang der Erzălung funrt - wie meistens bei Sukšin ohne weitere Vorbereitung in die Situation ein mit einem Zitat aus dem Brief des Sohnes. Die Vorstellung der Personen erfolgt erst spater, gleichsam nebenbei, wobei sich der Erzahler auf wenige aubere Fakten beschrankt und die Helden kaum portratiert und charakterisiert. Ein Blick in ihre Biographie erfolgt uberhaupt nicht. Dennoch liegt der Reiz der Erzahlung in der Darstellung der drei Charaktere, in denen der Autor, ganz gebunden

91) Ċudakova, a.a.o., S. 221

92) Im rolgenden zitiert nach: V.M.Sukšin, Rasskazy. Kniga dlja ctenija s kommentariem na russkom jazyke, Moskva 1979, S. 31-38; Seitenangaben in Klammern beziehen sich auf diese Ausgabe 
an die momentane Situation (die vorgestellte Reise nach Moskau), wesentliche Zuge aufdeckt. Die Begegnung der beiden Kulturen, von Altem und Neuem, hervorgerufen durch die im abgelegenen sibirischen Dorf eingetroffene Einladung nach Moskau, findet im Bewubtsein und Denken der Helden statt und erfahrt bei jeder der drei Gestalten inre eigene Ausprăgung. Dabei labt sich die Funktion des Kontrastes als zentrales kunstlerisches Prinzip in der Charaktergestaltung Sukšins bereits in dieser fruhen Erzăhlung aurzeigen.

Malan'ja wird durch die Vorstellung, nach Moskau zu fahren und die damit verbundenen Anforderungen v 811 ig aus ihrem gewohnten stabilen Lebensrhythmus und dem in dor $\mathbf{f -}$ lichen Alltagsleben gesicherten seelischen Gleichgewicht gebracht. Das Neue und Unbekannte, die Kompliziertheit der modernen Welt mit ihrer Technik und ihrem Tempo verunsichern sie und floben ihr Furcht ein. Gleichzeitig empfindet sie aber auch Freude und Stolz uber die Einladung und den Sohn.

Diese psychische Verfassung wird in den Auberungen der Heldin bis in feinste Nuancen wiedergegeben, wobei gleichzeitig Zuge inres ganz von der dorflichen Lebensweise gepragten Charakters deutlich werden. Sie kommen zum Ausdruck in der Art und Weise wie sie den Nachbarinnen von der Einladung erzăhlt, in der steten Wiederholung des Satzes:

- Зовет Павел-то к себе, в Москву. Прямо не знаю, что делать? (S. 32)

Ebenso in ihrem Telegramm an den Sohn, in der Umstandiichkeit und Ausfuhrlichkeit, mit der sie inre Gedanken auszudrucken sucht, wenn sie Surka schreiben labt:

\footnotetext{
- Доротоя сынок Паша, поговорила я тут с соседямн все советуют ехать. Конечно, мне на старости лет боязно маленько... (S. 32)
}

Auch inre obligatorische Abschweifung, wenn sie bei der Erwănnung Surkas die fur den Zweck des Telegramms vollig 
unnotige Bemerkung uber seine Grobe und sein Benehmen hinzurügt, verweist auf ihre Art des Denkens. Šukšin fangt hier typische Außerungen und Reaktionen ein, die beim Leser vertraute Assoziationen mit ähnlichen Charakteren und Situationen in der Wirklichkeit auslosen, wodurch mit äuBerst sparsamen Mitteln eine konkrete und authentische Vorstellung von der Gestalt erreicht wird. Wenn Malan'ja im Gesprach mit Egor auf dessen Hinweis, dab sie in Sverdlovsk umsteigen mussen, die Frage stellt,

Нам в Свердловске-то надо самнм попроситься, чтоб посадили, или там всех сажают? (S. 34),

so druckt diese Bemerkung mehr aus über ihren momentanen inneren Zustand, ihre Art $z u$ denken und ihren geistigen Horizont als dies eine ausfunrliche Beschreibung des Erzăhlers konnte.

Surka stellt auf seine Weise den Gegenpol zu Malan'ja dar. Die Aussicht auf die Reise fasziniert ihn. Er nimmt Moskau im Unterricht durch, und Technik und Tempo der neuen zeit Uben große Anziehungskraft auf ihn aus. Das Neue ist inm viel vertrauter als der Grobmutter, hat in sein Bewubtsein bereits Eingang gefunden (Begriffe, wie "Auspuffrohre" und "Schallgrenze" sind ihm längst vertraut), und die Begegnung damit verspricht ihm "viel Ungewohnliches". Die Ruckstăndigkeit der Grobmutter und inre Unerfahrenheit in modernen Dingen sind ihm bewubt, und der als "schüchtern bis zur Einfalt" und "bescheiden" charakterisierte Junge demonstriert angesichts der Verunsicherung Malan'jas sogar sein Gefuhl der Uberlegenheit, das BewuBtsein, klüger $z u$ sein als die Großmutter. Im Dialog zwischen Malan'ja und Surka begegnen sich zwei geistige Welten, zwei verschiedene Haltungen zu neuen Realien des Lebens, hinter denen sich unterschiedliche Lebensvorstellungen verbergen. Der Kontrast $z w i s c h e n$ beiden wird bereits im Streit um die Frage deutlich, wie ein Telegramm zu schreiben sei: 


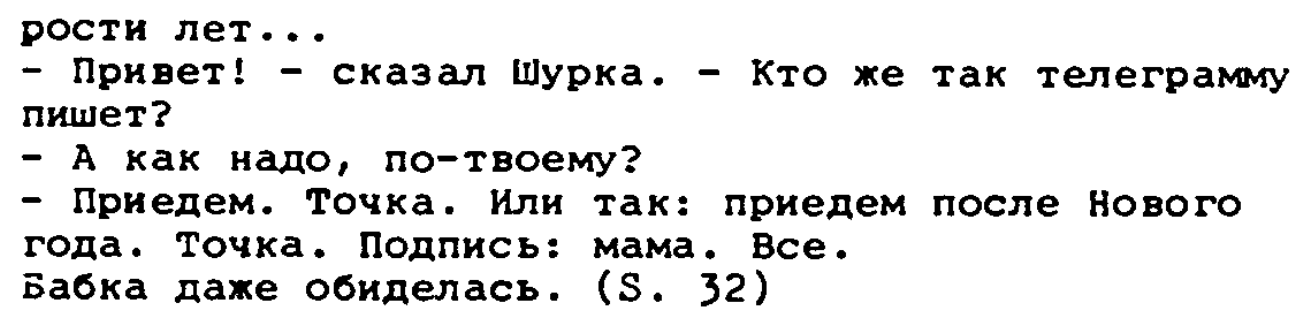

Beide Welten sind so verschieden, dab eine Verständigung auf rationaler Ebene unmoglich ist. Besonders deutlich wird dies an einem Detail, das zugleich die leichte Ironie, mit der der Dialog vom Autor dargeboten wird, verstärkt: Malan'ja făhrt auch nach Šurkas Belehrung uber den Telegrammstil fort, dieses auf inre Weise zu formulieren, aber sie ubernimmt Śurkas "tocka":

... Приедем после нового года. Точка. С Шуркоя. Он уж теперь большоя стал. Ничего, послушның паренъ... ...Ребятишек твонх хоть посмотрю. точка. Мама. (S. 33)

Besonders wirkungsvoll gestaltet Šukšin die Gegenuberstellung beider geistiger Welten beim Schreiben des Briefes nach Moskau. Wahrend Malan'ja ihren Brief diktiert, schreibt Surka seine Sicht der Dinge an den Onkel in Moskau nieder. Der Kontrast im Denken der Helden spiegelt sich dabei auch in ihrer Sprache wider. Wahrend die alte Frau Worte aus dem dorfilichen "prostorexie" gebraucht, wie "mne bojazno" (ich habe Angst), "sibko" (sehr), "znamo" (selbstverständich) und Wendungen, wie "strast' takaja" (schrecklich) und "poklon žene" (grübe deine Frau) wăhrend sie vom "Pilzesammeln", von "Eingesalzenem" und von "Sanddornmarmelade" spricht,schreibt Šurka uber "Auspuffrohre", "Fallschirme", von der "Schallgrenze" und "einem Zivilflugzeug" und gebraucht offiziell-schriftsprachliche Wendungen, die aus seinem Munde belustigend wirken, wie "privel takoj fakt" (er fuhrte folgende Tatsache an) und "éto uže šantaž" (das ist bereits Erpressung). Doch es geht bei dieser Konfrontation zweier geistiger Welten dem Autor nicht um das Fur und Wider des Themas Dorf-Stadt. Seine leichte Ironie sowohl gegenuber der altklugen Haltung Surkas wie auch gegenuber der naiven 
Furcht der alten Frau ist unverkennbar. Es ist jedoch keine die Helden abwertende Ironie, wie uberhaupt der die ganze Erzăhlung durchziehende Humor in den Gestalten einen Zug aufdeckt, der dem Autor besonders wichtig ist und auf dem seine Sympathie fulr sie beruht. Es ist dies ein naiv-kindliches Moment des Denkens, das nicht nur Šrka, sondern auch die alte Frau auszeichnet und das sehr deutlich darin zum Ausdruck kommt, wie sie den Brief an den Sohn adressiert:

\section{Герон Советского Союза Любавину Павлу Игнатьевичу.} От матери его из Сибири. (S. 38)

- Die Konfrontation der beiden BewuBtseinswelten ist frei von dramatischen Momenten. Sie dient vor allem der Charaktergestaltung mittels des Kontrastes. In diesem Zusammenhang ist auch die dritte Gestalt der Erzahlung zu betrachten, der Nachbar und Hausmeister der Schule Egor, den Malan'ja gebeten hat, uber das Fliegen Auskunft zu geben.

Aus der Perspektive der alten Prau erfährt der Leser, daB Egor "in seinem Leben viel herumgereist und mit Flugzeugen geflogen ist" und folglich zu den "Leuten, die Bescheid wissen" (znajušcie ljudi) gehørt.

Egor - eine nicht weniger farbenreiche und charakteristische Figur als die alte Malan'ja - stellt eine Art Verknupfung beider Bewubtseinshaltungen dar, in der sich eine Halbbildung, wie sie die Paktoren des modernen Lebens (Massenmedien, Reisen) mit sich bringen, mit provinzieller Rückstăndigkeit und dorflich geprăgten Denkgewohnheiten auf witzige und typische Weise vermischen. Dem entspricht die herablassend-souverăne Art, mit der Egor uber seine Flugerfahrungen erzăhlt, das unverhullte Prahlen mit seinen "Kenntnissen", der Gebrauch von Schablonen der offiziellen Sprache. Egors Sprache hebt sich von der urwüchsig-volkstümlichen Redeweise der einfachen und arglosen Malan'ja ab, was weniger in lexikalischen Besonderheiten seinen Niederschlag findet, als vielmehr im gesamten Bau seiner Rede, inrer Intonation, in der anders gearteten Umstandlichkeit und Anschaulichkeit des 
Ausdrucks, die den bei inm vorherrschenden Typ des Denkens nachzeichnen:

- На самолете лететь - это надо нервы да нервы! Вот он поднимается - тебе сраэу конфетку дают.. - КонФетку?

- А как же. Мол, забудься, не обрамая внимания... А на самом деле это самыя опаснья момент. Или тебе, допустим, говорят: "Привяхись ремнямя". - "Зачем?" - "Так положено". - "ХэХ...положено. Скамн прямо: можем навернуться, и всё. А то - полохено". (S. 35)

Но реактивные, те тохе опасные. Тот, если что сломалось, топором летит вниз. Тут ул сразу.... костея потом не соберут. триста грамм от человека остается. вместе с одехдоя. (S. $35 \mathrm{f.}$ )

Parallel zur kontrastiven Gegenuberstellung der drei Charaktere entwickelt sich in der Erzahlung ein weiterer Kontrast, in dem sich die Helden - jeder auf seine Weise bewegen: Zwischen dem Leben und Alltag des kleinen sibirischen Dorfes und dem Rhythmus des modernen Lebens. Aber auch hier ist es ein Kontrast ohne dramatische Momente, und eine Position des Autors ist lediglich in der Sympathie zu erkennen, die er fur seine Helden hegt. Eine Sympathie, die sich auf den Leser uberträgt, da der Autor es versteht, Reizvolles und sogar eine gewisse Poesie in seinen Gestalten zu entdecken.

In diesem Sinne ist die Erzahlung typisch fur die fruhe Prosa Šukšins, in der er im wesentlichen unkomplizierte Typen des dorflichen Milieus darstellt, die in einer konkreten, meist alltăglichen situation eingefangen werden. Es sind beschauliche, oft ein wenig naiv-ruhrende Gestalten, "svetlye duši" (heitere Seelen), wie der Titel einer Erzăhlung aus dem ersten Sammelband lautet. Der Leser lernt sie vor allem in ihrer merkwurdigen, etwas unbeholfenen Sprache kennen, und er wird zum Mithorer ihrer Gespräche, in die sich der Erzahler nicht einmischt. Die Darstellungen enthalten kaum dramatische Momente, die Konflikte sind deutlich abgeschwächt.

Die fruhen Erzăhlungen Sukšins haben in der Kritik widerspruchliche Reaktionen hervorgerufen, die von der erkennbaren Faszination einiger Kritiker durch den Śukšinschen 
nalitat dieses Autors reichen. Wăhrend die einen von "Cechovscher Feinsinnigkeit und psychologischer Tiefe" in seiner Prosa sprechen ${ }^{93)}$, sieht die schärfste Kritikerin Sukšins, Alla Marčenko, in seinen Erzahlungen eine "sentimentale Konfliktlosigkeit", lebensfremde "Idyllen" und erklärt den Erfolg des Schriftstellers mit der Mode des Dorfthemas und einem aktuellen "Bedurfnis nach Mythos und paradiesischen Hutten"94).

Das Paradoxon besteht darin, dab beide Seiten real vorhandene Momente in Šuksiins Prosa bewerten, und die in diesem Zusammenhang treffendste Beurteilung leistete Lev Anninskij, indem er die Besonderheit der fruhen Erzăhlungen Śukšins in der "Verbindung von Nuchternheit und Sentimentalităt" sieht 95). In der Tat ist diese "zweifache Beleuchtung"96) fur die fruhen Helden des Autors charakteristisch. Die Nulchternheit des Milieus, der Lebensumstănde, des Alltags, deren Darstellung frei ist von Ausschmulckung und idyllischen Farben und die den Helden den Stempel des Gew verbindet sich in diesen Erzăhlungen mit einer besonderen Art von seelischer Reinheit und Lauterkeit der Gefuhlsauberung bei den Gestalten, deren Abgleiten ins Sentimentale aber in den gelungensten Erzăhlungen durch den Humor der Darbietung und die leichte Ironie des Autors verhindert wird.

Aufzeigen läbt sich diese Besonderheit auch in der Erzăhlung "Kosmos, nervnaja sistema i šmat sala" (Der Kosmos, das Nervensystem und ein Stuck Speck, 1966) ${ }^{97}$ ). Auch hier gestaltet Šukšin die Konfrontation zweier geistiger Welten und gleichzeitig zweier Generationen im Dialog. Die Erzăhlung hat kaum Handlung und besteht im

93) V. Grigor'ev, zit. bei L.S. Śepeleva, Rasskazy Śukšina, in: Voprosy istorii i teorii literatury, vyp. 9-10, Celjabinsk 1972, S. 122-139, S. 122

94) A. Marćenko, Iz knižnogo raja..., in: Voprosy literatury, $1969, \mathrm{Nr} .4$, S. 48-71, S. 64^r.

95) Anninskij, Put' Vasilija Sukłina, a.a.0., S. 643

96) Ebenda

97) Im folgenden zitiert nach: Vasilij Šukšin, Rasskazy, Moskva 1979, S. 21-29 
wesentlichen aus dem Gesprăch zwischen dem alten Bauern Naum Evstigneic und dem Schuler Jurka, seinem Untermieter. Beide werden in einer ganz alltaglichen Situation gezeigt. Jurka sitzt an seinen Schularbeiten, der alte Naum quălt sich auf dem ofen mit seinem Katzenjammer vom vorabendiichen Rausch und sucht Ablenkung im Gespräch mit dem Jungen. Das Besondere, Ungewöhnliche an diesem Gespräch - der Streit der beiden uber Wissenschaft und Technik, Gott, Akademiemitglied Pavlov und die Zukunft der Menschheit - wirkt durch die Art wie es gefuhrt wird, beinahe ebenso alltăglich und gewönnlich, da die Diskussion der Helden in jedem Punkt an deren unmittelbaren Erfahrungsbereich und ihre Denkweise gebunden bleibt.

Es ist ein Streit uber Dorf und Stadt, uber das Alte und das Neue, der sich zwischen den beiden entspinnt, aber die Helden fungieren dabei nicht als Sprachrohr fur die Gedanken des Autors. Ihre engagierten Erorterungen erbffnen dem Leser keine "Weisheiten", und es gibt keine "Moral" der Geschichte, die sich als Quintessenz des Gesprächs formulieren ließe. Nicht die Argumente der Helden wirken auf den Leser, sondern die beiden Charaktere und Bewubtseinswelten, die sich in diesem streit aurdecken und dem Leser als in einer Gegenwart existierend bewubt werden. Dabei gibt es in der Erzahlung durchaus auch an den Leser gerichtete Aussagen uber Dorf und Stadt, aber sie werden vermittelt uber die Charaktere und mussen zwischen den Zeilen, im "podtekst", aurgedeckt werden.

Naum als Vertreter des Alten, des Dorfes, des Bauerlichen, ahnelt der Figur Malan'jas aus "Derevenskie i̇iteli". Mit ihr teilt er die Purcht vor den "iraplany", wie er die Plugzeuge bezeichnet, ebenso wie die Haltung zur Arbeit, die gut bestellte Wirtschaft. Seine Bemerkungen zur Herstellung des Specks erinnern an Malan'jas Erklarung, wie man gutes Honigbier zu brauen hat, und verweisen auf einen charakteristischen Zug dieses Typus, namlich auf die positive Einstellung und Fanigkeit zu ordentlicher Arbeit. Aber in Naum untersucht Sukšin diesen Typus eingehender, zeigt er weitere Momente seiner Psyche und geistigen Welt 
und gibt damit Einblick nicht nur in einen weitgehend der Vergangenheit angehorenden Charakter, sondern zugleich auch in eine vergangene Generation und zeit.

Die kulturelle Ruckstăndigkeit und geistige Enge des alten Dorfes, die harten und dunklen Seiten seiner Lebensweise treten in dem Charakter des Alten deutlich hervor. Naum und mit inm das Alte werden hier in keinem Punkt idealisiert. Der Held past nicht in das Bild des "naturlichen Menschen". Mit seiner Gewohnheit, sich einmal im Monat gehorig vollaufen zu lassen, wust zu fluchen und der Beschrănkung seines Pflichtbewubtseins und Verantwortungsgefuhls auf das eigene Haus und personliche Interesse werden eher gegenlăufige Charakterzüge in den Vordergrund geruckt. Auch seine negative Haltung zur Stadt, zu Wissenschaft und technischem Fortschritt bleibt unbegrundet. Sie stellt sich als Vorurteil dar, das aus seiner mangelnden Bildung und konservativen Lebensanschauung erwachst und unterstreicht, daB Naum hinter seiner Zeit zuruckgeblieben ist. Aber mit allen diesen Zugen ist Naum auch keine unsympathische Pigur. Sie erweisen sich gleichsam als integraler Bestandteil nicht nur seiner geistigen Welt, sondern auch seines Milieus, einer Form der băuerlich-dorflichen Kultur, die mit den "modernen" Kriterien Jurkas nicht zu messen ist. So zum Beispiel, wenn der Alte seinen Hang zum Alkohol erklart:

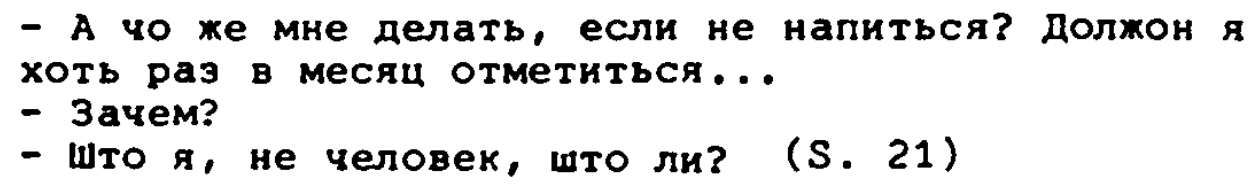

Oder seine einfache Logik, mit der er sein gotteslăsterliches Pluchen begründet:

$$
\begin{aligned}
& \text { - я, што ли, один так лажсь? Раз его все вспомннают, } \\
& \text { стало быть, и мне можно. (S. 24) }
\end{aligned}
$$

Der Alte liebt es, Jurka zuzuhøren, er hat Freude an dem Jungen, und die Art der Wirkung, die dessen Erzăhlungen 
bisweilen auf den Alten ausuben, deckt in diesem sympathische Züge auf. Dies gilt besonders fur den Eindruck, den Jurkas Bericht uber das Sterben von Akademiemitglied Pavlov bei Naum hinterlabt. Weder die medizinischen Prognosen Jurkas, noch die von inm angefuhrten Perspektiven, die die Erschliebung des Kosmos der Menschheit bieten wird, vermögen dem Alten zu imponieren. Sie liegen fern seines personlichen Erfahrungsbereichs und seiner Weltvorstellung. Nicht so das Sterben eines alten Menschen, das bei Naum Anteilnahme und Achtung gegenuber dem fremden Schicksal hervorrufen muB. Bemerkenswert ist die besondere Form, in der Šukšin diese Anteilnahme seines Helden zum Ausdruck kommen läbt:

А у его чо-же, родных-то никого, што ли, не было?

- спросил вдруг старик.

- у кого? - не понял Dрка.

- У того академкка-то. Одни студенты стояли?

- У Павлова-то? Были наверно. Я точно не знаю.

Завтра спроау в школе.

- Дети-то били, подн?

- Наверно. Завтра уэная.

- Были, конечно. Никого еслив бы не было родных-то, немного надиктуешь. Одному-то плохо. (S. 29)

Diese Stelle bringt nicht nur zum Ausdruck, daB Naum sich den Tod eines alten Menschen auBerhalb seiner Familie (nur mit studenten!) nicht vorstellen kann, sondern bezeichnet auch eine besondere, fur das Denken Naums charakteristische Weise der Anteilnahme am Schicksal des Wissenschaftlers: Hat er sein Leben wüdig beschlieben und auf ein erfulltes Dasein zurulckblicken können? Diese Frage ist fur den Alten untrennbar verbunden mit der Frage nach den Kindern und fur ihn - ganz im Unterschied zu Jurka - sehr viel wichtiger als die wissenschaftlichen Leistungen Pavlovs und die Liebe seiner Studenten. Das er diese Frage stellt, verweist auf den Grad seiner Anteilnahme an dem fremden Schicksal. Sukšin deckt hier künstlerisch uberzeugend ein wichtiges Moment des bauerlich-patriarchalischen Denkens im allgemeinen sowie einen "sehr russischen Zug" im besonderen auf, der darin 
besteht, das "zărtliche Zuneigung fü einen Menschen sich darin aubert, daß er Verwandte hat"98).

Diese Stelle am SchluB der Erzahlung macht Naum dem Leser sympathisch, deckt eine neue Dimension seines Charakters auf: Einen weichen, sehr menschlichen und rürenden Zug, der in der sehr konkret zum Ausdruck gebrachten Anteilnahme an einem fremden Schicksal - auch die Bekðstigung Jurkas ist ein Ausdruck dafür - seinen Niederschlag findet. Gleichzeitig erhellt diese Passage Naums eigene Situation, seine Probleme mit den Kindern und seinen Zorn auf den "Drang zur Stadt". Die moderne Entwicklung ist dem Alten nicht nur verdachtig wegen ihrer Hektik, Gefahrlichkeit und der abstrakten Besserwisserei der Jungen, sie beruhrt inn auch ganz personlich, indem sie die Săulen seiner Lebensauffassung umzusturzen droht: Die Bindung $z u$ den Kindern, die Achtung des Alters und seiner Erfahrung.

In Jurka gestaltet der Autor abermals den bereits aus "Sel'skie ziteli" bekannten Typ des altklugen Schuljungen, der nun aber als aktiver Verfechter des Neuen auftritt. Die Punkte, an denen die Konfrontation der beiden Bewubtseinswelten und Generationen stattfindet, sind Wissenschaft und Technik, rationales Denken, das selbst Alltagsprobleme wie Naums Katzenjammer auf abstrakte Forme In zurulckfuhrt ("Vergiftung des Organismus"), aber auch der Idealismus und die Begeisterung Jurkas fur nichtmaterielle Werte, denen die pragmatisch-nulchterne orientierung des Alten am Bewahrten und Gesicherten gegenuberstent.

Bewubtseinshaltung und Psychologie der beiden Gestalten kommen ausgezeichnet in ihrer Sprache zum Ausdruck. Jurkas Denken spiegelt sich in der wenig reflektierten, schulerhaften Aneignung moderner wissenschaftlich-technischer Terminologie und erlernter Schablonen, die sich bei inm mit lebendiger Umgangssprache, volkstumlichen Wendungen, grammatikalisch fehlerhaften Konstruktionen

98) J.S. Lichačev, Zametki o russkom, in: Novyj mir, $1980, \mathrm{Nr} .3, \mathrm{~S} .10-38$, S. 12; vgl. hierzu besonders die Aus funrungen Lichačevs $S .11 f$. 
etc., die seinem Alter und seiner Sozialisation entsprechen, vermischen. In diesem Sprachstil seines Helden gelingt Sukšin die anschauliche Wiedergabe der noch kindlich-naiven Denkweise und Psychologie sowie typischer Momente einer bewubtseinsmäBigen Entwicklungsstufe moderner Bildungsaneignung, in der sich angelesenes und erlerntes, aber gedanklich noch schlecht verarbeitetes Wissen mit naiver Begeisterung fur das Neue und einem kămpferisch-optimistischen Glauben verbinden. Kennzeichnend dafur sind in der Sprache des Helden Konstruktionen, in denen sich lexikalische und syntaktische Besonderheiten verschiedener Sprachebenen vermischen und in deutlichem Kontrast zueinander stehen:

- Ну, во-первых, освоение космоса - э프._.봉...

...И веэде қивут сумества. (S. 25)

Derartige Konstruktionen wirken belustigend und lenken die Aufmerksamkeit des Lesers vor allem auf die Art zu sprechen. Sie decken dabei ein psychologisches Moment auf, nămlich das Orientiertsein des Sprechenden auf Autoritaten (Bücher, Lehrer), das in dem Bemulhen um sprachliche Nachahmung seinen Niederschlag findet. Dies zeigt sich bei Jurka auch in der Ubernahme rhetorischer Formein vom Typ

- я говорю - в смысле образования! (S. 25)

oder in fehlerhaften Konstruktionen, wie

- Никому до этого не касается. (S. 23) 99 ),

in denen sich sein Streben nach literatursprachlichem Ausdruck kundtut.

Jurkas Sprache ist voller solcher belustigender Effekte. Seine ganze Verteidigung des Neuen stellt im Grunde eine

99) Die Konstruktion stellt eine grammatikalisch falsche Verknupfung aus den beiden literatursprachlichen Wendungen "èto nikogo ne kasaetsja" und "èto nikomu ne do dela" dar. 
Aneinanderreihung găngiger Vorstellungen und Argumentationen dar, die allerdings durch das Bewubtsein und den Gesichtskreis dieses Typus gebrochen sind. Besonders deutlich wird dies in Jurkas Ausfuhrungen zur ErschlieBung des Kosmos und seiner Beschreibung der Moglichkeiten des "Videozeitalters". Ein gängiges utopisches Klischee wird hier in der gedanklichen Aufbereitung und lebendigen Umgangssprache eines Schuljungen wiedergegeben:

Вот и получится тогда то самое царство бохие, которое религия называет - рая. Или ты, допустим, захотел своих сыновея повидать прямо с печки - пожалуяста, включил видеоприемник, настронлся на определенную волну - они здесь, разговарнвая. захотелось слетать к дочери, внука понянчить - лезешь на крыпу, заводишь небольшон вертолет - и через какое-то время икс ты у дочери... (S. 25)

Die ăsthetische Funktion dieser durch den Sprachstil der Person bewirkten "Brechung" besteht vor allem darin, dab durch die Art des Sprechens die Aufmerksamkeit des Lesers vom Inhalt des Gesprochenen auf eine andere Schicht des Textes gelenkt wird, namlich auf den sich hinter dieser Sprache verbergenden Bewubtseinstyp.

Die Sprache Jurkas steht in deutlichem Kontrast zur Sprache des Alten. Naum verwendet keine abstrakten Begriffe und modernen Termini, dafur begegnen in seiner Rede sehr viel hăuriger als bei Jurka "prostoretie" (iß̌o, malost', sibko, baška, svovo, pomirat') und volkssprachlich-dörfliche wrrter und Formen, wie "majat'sja", "zapolosnilat", "robit"", "končajus"", "ponadelali", "bog miloval", "podi", "dak", "kopyt'jami" und andere. Wăhrend in Jurkas Rede lediglich das dialektale, aber bereits in der stadtischen Umgangssprache verbreitete "no" (statt "da") auftritt, weist die Sprache Naums eine etwas stärkere Dialektfarbung auf, bleibt aber dennoch auf wenige, aus dem Kontext muhelos zu erschließende worter beschränkt ("Aposlja" privezes' - a posle privezes; "sèstol"" stol'ko; "esliv" - esli; "spominajut" - pominajut). Die mangelnde Bildung des Helden wird hervorgehoben durch die phonetische Aurzeichnung einzelner worter an- 
stelle der orthographisch exakten ( z.B. das bei Śukšin sehr hăufig auftretende "što" anstelle von "čto") sowie durch den bisweilen fehlerhaften Gebrauch der Verbendung ("tolkut" statt "tolkajut"; "ucut" statt "učat"; "ljubjut" statt "ljubjat").

Das Vorhandensein derartiger volkssprachlicher Elemente, die in Škšins Prosa immer wieder auftreten, dient wesentlich der sozialen und lokalen Charakterisierung der Gestalten und des Milieus und erhoht die Authentizitat der Darstellung ${ }^{100 \text { ) }}$.

Nicht weniger bedeutsam fü die Wiedergabe des ganzen Kolorits der Gestalt sind die Besonderheiten in Syntax und Phraseologie des Helden. Naum spricht in kurzen, im Bau unkomplizierten, manchmal etwas schwerfalligen Satzen und einer gegenständichen, bilderreichen Sprache, in der sich die langsame, umständiche Art und die Anschaulichkeit des băuerlichen Denkens widerspiegeln:

- Ноги вытянешь, пока доядешь до хирурга-то...

- дак на коя ке шут тогда хнты из себя тянуть столько лет?

- Сбили вас с толку этим ученьем - вот и мотаетесь nо белому свету, как...

- Жили раньше без всякого ученья - ничо, бог миловал: без хлебушка не сидели. (S. 23)

100) Zu den volkssprachlichen Besonderheiten in der Prosa Suksiins und ihrer Funktion vgl. L.L. Salagaeva, Funkcii narodno-razgovornych èlementov $v$ proze V.M. Sukšina, in: Formirovanie stilističeskich navykov ućaścichsja $v$ processe raboty nad grammatičeskoj temoj, Alma Ata 1977, S. 62-67; dies, Vneliteraturnaja leksika $v$ proizvedenijach V.M. Sukš̉ina, in: Stilističeskij aspekt izučenija russkogo jazyka v skole i vuze, Alma Ata 1978, S. 53-60;

I.A. Ossovetskij, Dialektnaja leksika v proizvedenijach sovetskoj chudoźestvennoj literatury 50 - 60-ch g8., in: Voprosy jazyka sovremennoj russkoj literatury, a.a.0., S. 301-385; vgl. auch das vorwort von A.E. Balichin zur kommentierten Ausgabe der Erzăhlungen Sukśins, in: Sukšin, Rasskazy. Kniga dlja ctenija, a.a.0., S. 5-30, S. $27 \mathrm{fr}$. sowie die Kommentare im Anhang $S .237-374$ 
Bildhafte, der konkreten Alltagswelt entnommene VerGleiche sind für die Sprache des Alten ebenso charakteristisch wie der Gebrauch von Sprichwortern und volkstumlichen Redensarten:

.... то башка, как этот...как бачок из-под самогона. (S. 26)

... Тебе всего-то от горшка два верика. (S. 21)

- Непроненыя гость хуже татарина. (S. 25)

Der durch die Gegenuberstellung im Dialog bewirkte Kontrast zwischen den beiden Charakteren und Bewubtseinsweiten tritt besonders deutlich hervor in Passagen, in denen Altes und Neues unmittelbar sprachlich konfrontiert werden, wobei das Gesprach gleichsam auf zwei Ebenen verlauft: Auf der "abstrakt-wissenschaftlichen" Jurkas einerseits und der konkret-anschaulichen, dem Erfahrungsbereich der Alltagswelt verhafteten Ebene Naums. So zum Beispiel, wenn Jurka von der Erschliebung des Kosmos und den Zukunftsperspektiven der Menschheit spricht und der Alte Bemerkungen dazu macht, wie:

- Ишо драться кинутся.

- Жениться, што ли, друг на дружке будете? (S. 25)

Das Prinzip der Wiedergabe der Gestalten und des Milieus mittels ihrer elgenen "Stimmen" wird auch in dieser Erzăhlung vor allem durch den Dialog realisiert. Der Autor selbst hat der besonderen Ausdruckskraft der direkten Rede bei der Aufdeckung des Charakters grobe Bedeutung zugemessen:

Die direkte Rede ermoglicht es mir, den beschreibenden Teil stark zu reduzieren: Was fur ein Mensch? Wie denkt er? Was will er? Letzten Endes machen wir uns doch auch auf diese Weise eine Vorstellung vom Menschen, indem wir inm zuhorren. Hierbei lügt er nicht, kann er nicht lügen, selbst wenn er mochte. ${ }^{101}$

101) Vasilij Šukšin, otvet na anketu "Voprosov literatury" "Literatura i jazyk", in: Voprosy literatury, 1967, Nr. 6, S. 148-150, S. 149 
In dieser Prosa dominiert das Wort des Helden, das "sich als derart aktiv erweist, dab es rast die ganze Last des Inhalts auf sich nimmt" 102 und den auktorialen Erzahler vollig zu verdrängen scheint. Zwischen den Repliken des Dialogs ist der Erzăhlertext weitgehend auf knappe satze und Hinweise beschrănkt, die einer Art "Regieanweisungen" ăhneln oder die Funktion haben, die einzelnen "Szenen" miteinander $z u$ verknüpren:

Пауза. Юрка поскритывает пером. (S. 21)

ьрка откинулся на спннку венского стула... (S. 21) По утрам беседуют у печки. (S. 22)

Die Kritik hat in diesem Zusammenhang wiederholt auf den EinfluB von Stilelementen des Films und Dramas in Sukšins Erzăhlungen hingewiesen. Viktor Calmaev bezeichnet sie als "Inszenierungen von Mikrosituationen des Alltags" ${ }^{103,}$ und V.A. Kuz'muk spricht von "erzahlten Szenen" (rasskazyscenki) und verweist dabei auf den Bezug dieser Prosa zur Poetik Čechovs 104.

Auch Abschnitte des Erzahlertextes, die auf den ersten Blick auktoriale Wertungen zu enthalten scheinen, erweisen sich bei năherer Betrachtung als orientiert an der "fremden Stimme". So etwa die Beschreibung der Lebensverhaltnisse des Alten und Jurkas. Die Schilderung der wirtschaftlichen Situation Naums, die detaillierte Aufzăhlung

102) Belaja, Iskusstvo est' smysl, a.a.0., s. 67

103) Viktor Calmaev, Ukrepit'sja i iit'... (Molodye geroi $i$ novellističskoe iskusstvo Vasilija Sukšina), in: ders., Obnovlenie perspektivy, Moskva 1978, S. $113-164$, S. 154

104) V. Kuz'muk, V. Sukšin i rannij Čchov, in: Russkaja literatura, 1977 , Nr. 3, S. 198-205, S. 199; zum EinfluB von Stilelementen des Films in Suksins Prosa vgl. auch B.M. Judalevic, Idejno-chudożestvennoe svoeobrazie povesti i rasskaza 60-ch godov, (Kandidatendissertation), Avtoref. diss... kand. fil..., Irkutsk 1975, S. 13;

V.K. Pudożgorskij, Priemy raskrytija avtorskoj pozicii $v$ rasskazach $V$. Sukšina, in: Problemy realizma, Vologda 1979, S. 122-134 
seiner Vorrate, weist eine Anlehnung an die Denkstruktur des dörflichen Milieus auf und enthalt Wertungen, die dem Bewußtsein der Dorfbewohner entstammen:

\begin{abstract}
Он вообще скряга отменныя. Живет справно, пенсия неплохая, сыновья и дочь помогајт из города. В погребе у него чего только нет - сало еще проилогоднее, соленые огуриы, капуста, арбузы, грузды... ...Когда он не хворает, он встает до света и весь день, до темноты, возится по хозяяству. (S, 22)
\end{abstract}

Kurze Sătze und einfache Formen, die Spuren der direkten Rede bewahren, nähern diesen ganzen Abschnitt des Erzăhlertextes der Sprache des Milieus an, in dem sich die Helden bewegen.

Отца нет. А у матери, кроме него, еще трое. Отец утонул на лесосплаве...

...А варят - старик себе отдельно, юрка себе. (S. 22)

Nach demselben Prinzip sind vereinzelte kommentierende Einschube zwischen den Repliken des Dialogs gestaltet:

\footnotetext{
Но работать - это значнт только для себя, на своея пашне, на своем огороде. Как раньше. В колхозе Он давно не работает, хотя старики в его гощы еще колупаются помаленьку - кто на пасеке, кто объездным на полях, кто в сторохах. (S. 23f.)
}

Hier handelt es sich nicht um den Kommentar eines uber die Situation und die Helden erhobenen Erzahlers, sondern um eine Wertung, die aus der Perspektive der Dorfbewohner in den Erzăhlbericht projiziert ist.

Der "dialogische Streit"105), in dem sich in der Erzahlung zwei unterschiedliche geistige Welten begegnen, bleibt frei von auktorialer Einmischung. Die beiden Thesen, die sich in der Aufdeckung dieser zwei BewuBtseinstypen formulieren, werden als Gegenstand der Reflexion an den Leser weitergegeben, der aufgefordert ist, aus dem dargebotenen Wirklichkeitsausschnitt seine eigenen Schlubrolgerungen zu ziehen. 
2.1.3. Die Darstellung des "naturlichen Menschen"

Auch bei Šukšin gibt es das Thema des "natürlichen Menschen", der aus der engen Bindung an Natur und Heimaterde eine innere Stabilităt bezieht, die dem modernen Stadtmenschen fehlt. Es ist allerdings bezeichnend für die künstlerische Eigenart dieses Autors, dab jener fur die gesamte Dorfprosa geradezu obligatorische Typus in seinem Werk sehr bald eine besondere und eigenstăndige Evolution erfăhrt.

In der fruhen, im Sammelband "Sel'skie žiteli" erschienenen Erzăhlung "Solnce, starik i devuśka" (Die Sonne, der alte Mann und das Mădchen) wirkt dieser Typus noch deklarativ, und seine Darstellung verbleibt ganz im Rahmen eines modischen Klischees der Dorfprosa. Eine Studentin aus Moskau begegnet auf dem Lande einem Greis, von dem sie eine Zeichenstudie anfertigt. Sie kommt mit inm ins Gespräch und ist tief beeindruckt von der inneren Ruhe und Ausgeglichenheit, die der alte Mann gerade auch im Hinblick auf sein gelebtes Leben ausstrahlt. Als sie von seinem plotzlichen Tod erfahrt, ist die Moskauerin tief erschuttert und bedauert, nichts uber das Leben dieses Menschen erzăhlen zu können.

Die Darstellung in dieser Erzahlung ist lyrisch-sentimental, die Sinnintention des Autors unverhullt und deklarativ. Doch die Frage nach dem Geheimnis dieses der Vergangenheit angehorenden Lebens und im Zusammenhang damit nach dem Sinn des menschlichen Lebens uberhaupt beschartigte suksin auch weiterhin und kann als wichtiges Moment in seiner geistesgeschichtlichen und kunstlerischen Entwicklung angesehen werden:

Alle Probleme, die Śukšin in seinen Erzăhlungen aufwirft, sind letztendich mit der Frage nach der Einstellung zum Leben verknupft, nämlich: Versteht der Held das Leben als komplizierten, aber zugleich auch interessanten ProzeB, oder aber betrachtet er es als eine hochst einfache 
Sache und besteht die Weisheit fur inn im Streben nach dieser Einfachheit. 106)

In der Anfang der siebziger Jahre entstandenen autobiographischen Erzahlung "Djadja Ermolaj" (Onkel Ermolaj) gestaltet Sukšin eine Episode aus seiner Kindheit, in deren Mittelpunkt der Dorfbrigadier Ermolaj steht. Die Erzahlung endet mit einer lyrischen Reflexion des IchErzahlers am Grabe des langst verstorbenen Brigadiers, die beinahe wortlich an die Gedanken der Heldin aus "Solnce, starik i devuška" anknupft:
...стою над могилоя, думан. И дума моя о нем простая: вечныя был труженик, добрыя, честныя человек. Как, врочем, все тут, как дед моя, бабка. Простая дума. только додумать я ее не умею, со всеми своими инсти- тутамн и книхками. Например: чтб, был в этом, в их жнзни, какоя-то большоя смысл: В тсм именно, как они ее прохили. Или не было никакого смысла, а была одна работа, работа... Работали да детеи рохали. Видел же я потом других тодея... Вовсе не лодырея, нет, но... Свор хизнь они понимахт иначе. Да сам $я$ ее понимах теперь иначеl но талько, когда смотрю на эти холмяки, я не знар: кто из нас прав, кто умнее? 107)

Aus der fruheren Prosa Sukśins ist in diesem Zusammenhang die Erzahlung "Zemljaki" (Landsleute, 1968) 108) interessant, in der der Autor die in der Schlubpassage von "Djadja Ermolaj" dargelegten Gedanken kunstlerisch $2 u$ gestalten sucht.

Auch in dieser Erzahlung begegnen sich Stadt und Land, diesmal in Gestalt zweier Bruder an ihrem Lebensabend. Der eine lebte ein gewohnliches Bauernleben, der andere, seit dem Kriege verschollen, hatte sich in der Stadt eine neue Existenz aufgebaut. Vor seinem Tod besucht er noch einmal sein Heimatdorf, um vom Bruder Abschied zu nehmen, dem er sich jedoch nicht zu erkennen gibt.

106) O.A. Kamyševa, Nekotorye osobennosti poétiki rasskazov Vasilija Śukšina, in: Problemy istorii kritiki i poètiki realizma, Kujbyṡev 1977, vyp. 2, S. 163176 , S. 166

107) Šuks̉in, Rasskazy, a.a.0., S. 381

108) Im folgenden zitiert nach: Śukšin, Rasskazy. Kniga dlja ctenija, a.a.0., S. 39-47 
Der Erzăhlung liegt ein für die Dorfprosa typisches Motiv zugrunde: Die Begegnung naher Verwandter, deren Dasein von unterschiedlichen Lebensverhaltnissen und deren jeweiliger kultureller Einbettung gepragt ist. Ein Motiv, das ein aus der Dorfprosa vertrautes Lbsungsklischee geradezu aufdränt und welches in den Worten des Alten aus der Stadt auch seine Bestatigung zu finden scheint:

- у тебя болит, что ли, чего?

- Душа. Немного. Жалко... не нахился, не устал...

...жалко покоя вот этого... Суетился много. (S. 44)

Der "suetlivyj človek", der unruhige, hastende Mensch der Stadt wird als negatives Pendant dem "naturlichen Menschen" des Dorfes gegenubergestellt. Doch selbst an dieser Erzahlung, die in ihrer lyrischen Tonalitat an der Position des Autors wenig Zweifel labt, wird deutlich, wie sich Sukśins Texte einer klischeehaften Deutung entziehen und wie wenig sie sich auf die zunăchst in der thematischen Schicht vermutete Aussage reduzieren lassen.

Der Aufbau der Erzahlung labt drei Teile erkennen. Der erste gestaltet den Weg des alten Anisim zur Heumahd, seine Gedanken, Beobachtungen und Erinnerungen auf diesem Weg und wahrend der Arbeit. Der zweite Teil enthalt die Begegnung mit dem unerkannt bleibenden Bruder aus der stadt, die vorwiegend als Dialog gestaltet ist. Der dritte Teil schlieblich bringt die Losung des im vorangegangenen leicht angedeuteten Rätsels der Begegnung.

Eine besondere Verknüpfung von Erzăhlerrede und "erlebter Rede" charakterisiert den ersten Teil der Erzahlung. Der Gedanke des Abschieds vom Leben, der sich durch alle drei Teile zieht, wird eingefuhrt vom Erzahler noch vor der Einfuhrung des Helden:

Стариковское дело - спокояно думать о смерти. И тогда-то и открывается человеку вся сокрытая, изумнтельная, вечная красота Жнзни. Кто-то хочет, чтобы человек напоследок с болью насытился ею. И ушел. И уходят. И тихим медленным звоном, как звенят 
теплые удила усталых конея, отдают шаги уходяиих. Хорошо, мучительно хорошо бшло жить. Не уходил бы!

(S. 39)

Im weiteren Verlauf erfärt diese verallgemeinernde Erzăhlerreflexion inre Konkretisierung in der Gestalt des Alten, in seinem Denken und gefuhlsmabigen Emp finden des $z u$ Ende gehenden Lebens. Anisims Situation ist die, von der der Erzahler spricht. Dies wird deutlich, ohne das ein besonderer Hinweis darauf erfolgt, in der "erlebten Rede" des Helden, die an die Reflexion des Erzăhlers anknupft:

Конечно есть люди, которым не все равно: есть ты или нет... (S. 39)

Der nahtlose Ubergang von Erzahlerrede und "erlebter Rede" des Helden wird hier bewirkt durch die lyrische Tonalitat, in die beide eingebettet sind und die Korrelation zwischen der Naturbeschreibung des Erzăhlers in der Einleitung und dem in "erlebter Rede" wiedergegebenen Naturempfinden des Helden:

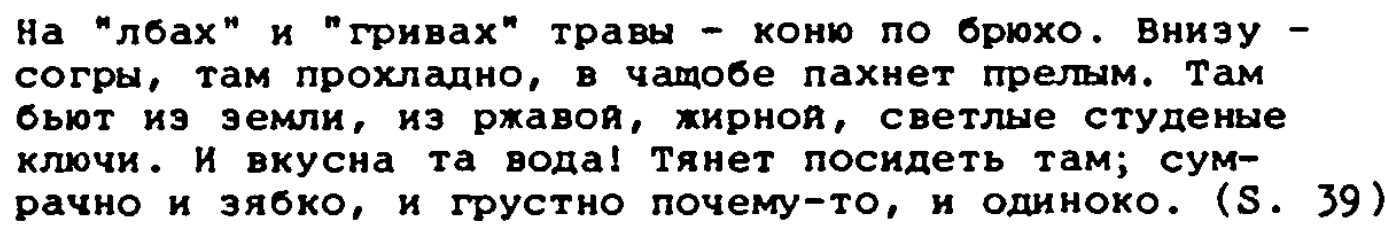

Die Auktorialitat der Erzăhlerreflexion wird auf diese Weise geschwächt, und letztere fungiert als Heranfuhrung an die innere Welt und Stimmung des Helden.

Der Gedanke, bald vom Leben Abschied nehmen zu müssen, verknüpt sich für Anisim mit der Frage nach dessen Sinn. Dabei sind seine Reflexionen nicht abstrakt, nicht intellektueller Art, sondern an den geistigen Horizont und die Gefuhlswelt des bauerlichen Charakters gebunden:

Но ведь... что же? Тут сам не поямешь: зачем дана была эта непосильная красота? Что с нея было делать?.. Ведь чего и жалко-то: прошел мимо - торопился, не глядел. (S. 39) 
Der erste Teil der Erzăhlung gestaltet diese "unfabbare Schonheit" (neposil'naja krasota) wie sie sich dem Helden eroffnet. Die "verborgene, wundersame, ewige Schønheit des Lebens", von der der Erzahler spricht, wird aufgedeckt in den Emprindungen des Helden, die die Schonheit der naturlichen Umwelt, die Wahrnehmung der Verănderung und Bewegung in ihr, die Bindung an die Heimaterde und die Erinnerungen an das verflossene Leben auslosen.

Wir haben eine Ode in Bildern (obraz-oda) vor uns an das "unmerkliche" ("nezametnomu") und gewaltige Leben... Sie wurde hervorgebracht, um mit den Worten des Helden zu sprechen, in der "Rückschau" des Menschen an seinem Lebensabend, wenn dieser - "als weiBhaariger Greis" - "sein Leben gelebt hat". 109)

In deutlichem Kontrast zu dieser "Ode in Bilderr" steht der zweite Teil der Erzahlung, was bereits formal - durch den Dialog - ins Auge fallt. Auch das Gesprăch der beiden Alten durchzieht der Gedanke des Abschieds vom Leben, und den Stadter bewegen dieselben Gedanken wie Anisim:

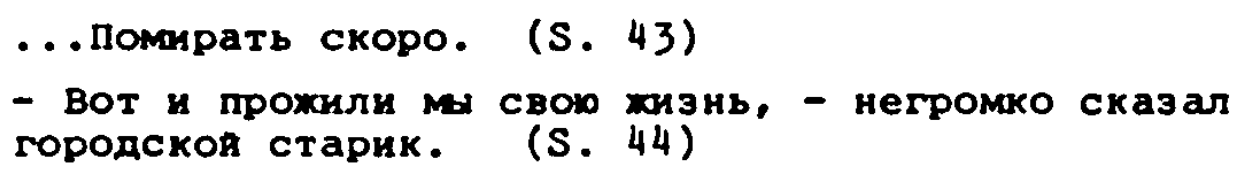

Aber es fehlt ihm die innere Ruhe, die diesen auszeichnet. Den Gedanken an den Tod kann er nicht dasselbe entgegensetzen wie Anisim, sie rufen in ihm nicht die Emprindung der Schonheit des Lebens hervor, sondern Bedauern, Unruhe, das Gefuhl, nicht richtig gelebt zu haben.

Die kontrastive Beziehung zwischen den beiden Teilen der Erzahlung ist allerdings noch subtiler und verweist auf eine weitere Erzahlebene des Textes. Auffallend ist der Kontrast zwischen der "erlebten Rede" Anisims im ersten Teil und der direkten Rede im Dialog. Auf die Frage des Bruders, ob inm nicht traurig zumute sei, antwortet er nur:

109) Dragomireckaja, a.a.0., S. 457 
- Грусти не грусти - что толку? (S. 44)

In seiner "inneren Rede" zu Beginn der Erzăhlung war hingegen gerade diese Traurigkeit hervorgehoben worden. Der Alte aus der stadt spricht mit Bedauern von der Hast und Hektik, die sein Leben bestimmten ("suetilsja mnogo"). Derselbe Gedanke hatte zuvor noch Anisim bewegt:

Ведь чего и жалко-то: прошел мимо - торопился, не глядел. (S. 39)

Aber die AuBerung des Stadters lost keine Erwiderung bei Anisim aus. Er spricht iberhaupt nicht von seinen Gedanken und Gefunlen, die ihn vor der Begegnung so beschătigt hatten, und seine AuBerungen im Dialog stehen in deutlichem Kontrast zu seiner inneren Welt, wie sie der erste Teil der Erzahlung aufdeckt. Uber die Erinnerungen, die Anisim zuvor noch so teuer waren, aubert er plotzlich:

...а я беспречь назад оглядварсь - тохе плохо. Расстрояство одно. (S. 45)

Und die Arbeit, die er so liebt ("Net milee raboty kos'by", S. 41), bezeichnet er nun dem Fremden gegenuber als "notwendig" (S. 42).

In diesem feinen Kontrast zwischen "erlebter Rede" und direkter Rede des Helden zeigt sich das Gefül sukśins für den Charakter und die künstlerische Authentizităt. Der Dialog der beiden Alten ist vollig "gewornlich", gleichsam der Realitat abgeschaut. Die Besonderheit der inneren Welt des Helden, wie sie im ersten Teil aufgedeckt wird, wird gerade durch diese im Dialog dargestellte Gewohnlichkeit der Gestalt als etwas Besonderes deutlich und uberzeugend. Der Held ist weit davon entfernt zu "philosophieren", seine innere Welt dem Gesprăchspartner zu offnen. Und nicht nur, weil dieser ein Fremder ist, sondern weil es seinem Wesen und dem Bewubtseinstyp, den er verkorpert, nicht entspricht. 
Es ist eine Innenwelt, die von dem Helden nicht bewubt reflektiert und intellektuell-begrifflich erfabt wird, sondern ein Weltempfinden, das sich vornehmlich auf der Ebene der Gefuhle und der sinnlichen Wahrnehmung realisiert.

Der Gedanke von der zentralen Bedeutung der "rodnaja zemlja" (Heimaterde) für das Empfinden der Sch⿰丿nheit des Lebens und letztendlich auch fur dessen Sinn wird in der Erzahlung uberlagert und zum Teil relativiert durch die Gestaltung eines Bewubtseinstyps, in dem der Autor vor allem mit den Mitteln des Stils ein Stuck Wirklichkeit in ihrer Besonderheit und Widersprüchlichkeit einfängt.

\subsubsection{Der Ubergangstypus}

Das Thema der zwei Kulturen, der Begegnung von Dorf und Stadt, fand in den Erzăhlungen S̆ukšins seine besondere Ausprăgung in der Darstellung jenes Ubergangstypus, in dessen Bewubtsein und Psychologie sich beide Formen geistiger Kultur vermischen und verflechten. Es ist ein moderner, ganz der Gegenwart entnommener Typus, den der Autor in immer wieder neuen Varianten zeigt und in dem eine Reihe von Erscheinungen und Widersprüchen der Zeit ihren künstlerischen Ausdruck finden.

Das Bewubtsein des modernen Menschen weist eine komplizierte Dialektik auf, die bestimmt wird durch die "Informationsexplosion" in der modernen Gesellschaft und das zunehmende Eindringen von Wissenschaft und Technik in den Alltag.

Es labst sich feststellen, dab in der modernen Welt die Rolle der geistigen Wechselbeziehungen auBerordentlich gewachsen ist, die Rolle der Ereignisse, die, obgleich sie vom Menschen nicht personlich erlebt wurden, dennoch fur inn zu einer unverrückbaren psychologischen Realitat geworden sind. Die Generation, die Hiroshima und Chatyn' nicht erlebt hat, weib dennoch heute sehr viel daruber. Dasselbe gilt für die Helden von Stalingrad oder die eisernen Nachte Leningrads. Auch dies ist psychologisch real, 
sind seelisch von allen aufgenommene Fakten. Und der Kosmos, die Oberflache des Mondes? Alles, was andere durch inre Arbeit und inren Willen erreicht haben, ist auch fur uns Realitat geworden, vor allem eine visuelle Realitat und zum Teil auch eine psychologische. Die geistige Welt des Zeitgenossen besteht in vielerlei Hinsicht aus solchen psychologischen Realitäten... 110)

Šukšin fangt diese Dialektik der geistigen Welt des zeitgenossen dort ein, wo sie sich am schwierigsten und verworrensten gestaltet: In der halbbăuerlichen, halbproletarischen Ubergangsschicht der heutigen sowjetischen Gesellschaft, in der die materiellen und geistigen Paktoren des modernen Lebens mit traditionellen bauerlichen Denkweisen und Lebensformen eine Symbiose besonderer Art eingehen.

\subsubsection{1. "Ubergangspsychologie" und Entstehung eines neuen Bewubtseins}

Eine Variante dieses Ubergangstypus gestaltet die Erzahlung "V profil' i anfas" (Im Profil und en face, 1967)111). Der Held Ivan, Kraft fahrer auf einem Kolchos, steht nach dem Verlust seiner Pahrerlaubnis vor der Wahl, die inm angebotene Arbeit im Viehstall anzunehmen oder das Dorf $z u$ verlassen und anderswo Arbeit $z u$ suchen. Er entschliebt sich zu letzterem, obwohl inm der Abschied schwer fallt und der Mutter deswegen fast das Herz bricht.

Kernstuck der Erzahlung ist der Dialog zwischen Ivan und dem alten Nachbarn. Es ist ein Gespräch uber Ivans Situation und über die Frage, wie und wofur der Mensch leben soll. Auch hier stellt Sukšin zwei geistige Welten gegenuber, deren jede mit ihrer eigenen "Wahrheit" ausgestattet ist.

110) Ćalmaev, a.a.0., S. $158 \mathrm{f}$.

111) Im folgenden zitiert nach: Vasilij Sukšin, Tam, vdali. Rasskazy. Povest', Moskva 1968, S. $231-243$ 
Die Welt des Alten ist traditionell, klar und einfach. Fur die Vorstellung des Lesers von diesem Typus genugen wenige Striche: Seine ruhige, gemessene Haltung gegenuber dem Gerede und Gesang Ivans, seine moralisierenden Vorhaltungen, aber auch die Anteilnahme an der Situation des jungen Burschen und seiner Mutter. Die Lebensauffassung des Alten berunt ganz auf den traditionelien Grundpfeilern des Dorflebens: Arbeit, Pamilie, Dorfgemeinschaft (einschlieblich des Respekts vor der Obrigkeit).

Ivan ist demgegenuber ein neuer Typus, in dem sich traditionelle Wurzeln mit neuen Lebensgewohnheiten und Erfahrungen verknüpfen. Seinem inneren moralischen Empfinden nach gehort er noch starker dem Dorf an. Mit diesem verbindet inn seine Kindheit, hier ist inm alles vertraut, mit inm ist er emotional verwachsen. Nicht minder erfabt hat ihn aber auch das Neue. Eine moderne Schulbildung, drei erlernte Berufe, Arbeitserfahrung im Fernen Osten haben ihn mit einem neuen Arbeits- und Lebensrhythmus konfrontiert. Zudem hat er Erfahrungen gemacht, die mit seinen dorflichen Wurzeln im Widerstreit stehen: Die gescheiterte Ehe mit einer Leningraderin, der Verlust der Fahrerlaubnis und damit der Arbeit, die Zusammenst४be mit den "fraery", von denen er spricht. Das Fundament des alten Dorfes ist fur inn durchbrochen, weshalb inn auch dessen traditionelle moralische Pfeiler nicht mehr voll stutzen können. Die Wirklichkeit stellt sich fur Ivan sehr viel komplizierter dar als für den alten Nachbarn, und um sich in ihr zurechtzufinden, bedarf es neuer Kenntnisse und MaBstabe. Die Lebensauffassung des Alten ("In deinem Alter habe ich nicht so gedacht...Da habe ich fü drei gearbeitet", S. 236; "Heirate, dann horst du auf, dich zu plagen", S. 238), die diesem noch innere stabilitat verschaffen konnte, reicht fur Ivan nicht mehr aus:

Ну, нажрался. А дальше что?...

... Мне чего-то больше надо. (S. 236)

...я должен сгорать от люовн. (S. 238) 
Ivan und das Neue, das in seiner Lebenshaltung entstanden ist, erfahren in der Erzahlung eine zweifache Charakterisierung. Die eine erfolgt aus dem Munde des alten Nachbarn, der das Verhalten Ivans nach seinen Kriterien beurteilt, was in Worten zum Ausdruck kommt, wie "unvertrăglicher Kerl", "Schwatzer", "Dummkopr", "Faulenzer", "Tausendrubler". Parallel zu dieser Charakterisierungslinie und gleichzeitig ihr entgegen latuft die der "Selbstaufdeckung" Ivans im Dialog. Die Windigkeit und Unvertrăglichkeit seines Charakters, vor allem in seiner Haltung gegenuber der obrigkeit, die sich hierbei zeigt, korrespondiert mit der Charakterisierung des Alten, macht diese glaubwurdig und verstandlich. Ivan deckt im Dialog jedoch noch ein psychologisches Moment auf, das dem Urteilsvermbgen des Nachbarn verschlossen bleibt, dem Leser aber eine Begrundung fur das Verhalten des Helden liefert: Das Gefuhl Ivans, dab inm Unrecht getan wurde, dab man seine wurde verletzt hat. Eine Empfindung, auf die er mit Trotz und Verachtung reagiert.

Noch deutlicher treten beide Charakterisierungslinien im zweiten Teil des Dialogs hervor, im Streit der beiden Helden um die Frage, wie der Mensch leben soll. Das Neue, das in Ivans Haltung zum Leben zum Ausdruck kommt, erfahrt aus dem Munde des Alten eine Charakterisierung nach den Kriterien der alten Lebensweise:

\section{- Заелись...}

- Суетитесь на земле - туда-сюда, туда-сюда, а толку никакого... Скоро детея рохать разучитесь..(S.236) ...а все хорохорятся...

... Только по клубам засвистывать... (S. 237)

Dem Leser eroffnet sich demgegenuber noch eine psychologische Dimension der neuen Lebenseinstellung. Ivans Verlorenheit auf dem Dorf, seine Ruhelosigkeit und Suche nach Verănderung dieses Zustandes beruhen auf der Sehnsucht nach einem irgendwie gearteten anderen, unruhigeren und komplizierteren Leben als jenem, welches inm der Alte empriehlt : 
- Я тебе говорю: наелся. Что дальше? Я не знаю. но я знаю, что это меня не устраивает. Я не могу только на один желудок работать. (S. 238)

In Ivan gibt es eine Vorstellung von Gluck, die uber die seines Gesprăchspartners hinausreicht. Sie labt sich nicht als konkret-praktische Gegebenheit formulieren, wie das der Alte mit seinen Xußerungen uber die Moglichkeiten des Geldverdienens tut, sondern verlangt nach einer erweiterten, abstrakten Begrifflichkeit, die Ivan aber fehlt. Sukšin deckt hier ein wesentliches Moment im Bewubtsein seines Helden auf: Den Ansatz einer neuen Vorstellung vom Leben, die sich psychologisch vorbereitet und $z u$ quălender "Denkarbeit" füht, aber von Ivan (noch) nicht zu Ende gedacht werden kann. Die Darstellung des Helden aus zwei Perspektiven labt dieses Neue in seinem Bewubtsein besonders deutlich hervortreten und lenkt die Aufmerksamkeit des Lesers auf die komplizierte, widerspruchliche Innenwelt Ivans, der sich "im Profil" vollig anders darstellt als "en race".

In der Erzăhlung "Mikroskop" (Das Mikroskop, 1969)112) kauft der Tischler Andrej Erin fur 120 Rubel von seinem Sparbuch ein Mikroskop. Seiner Frau erzahlt er, das Geld habe er verloren, das Mikroskop vom Betrieb als Pramie erhalten. Eine Woche lang untersucht Andrej unter dem Mikroskop "Mikroben". Als der Schwindel mit der Prămie schlieblich ans Tageslicht kommt, verkauft seine Frau das Mikroskop und Andrej beskuft sich.

Die aubergewohnliche Bedeutung des Ereignisses fur den Helden wird gleich im ersten Satz der Erzăhlung unterstrichen:

На это надо было решиться. Он реиился. (S. 99)

Bevor der Held vorgestellt wird (wer er ist und wozu er sich eigentlich entschlieben muBte, erfahrt der Leser erst auf der dritten Seite), wird der Leser in dessen seelischen zustand eingeruhrt und erhalt durch den voran-

112) Im folgenden zitiert nach: Śukšin, Rasskazy, a.a.o., S. $99-106$ 
gestellten Dialog zwischen den Eheleuten bereits eine Vorstellung von dessen Charakter und Lebensverhăltnissen. Andrej nimmt die Szene mit seiner streitsuchtigen Frau in Kauf, steckt Schlage ein, schiebt Uberstunden und fült sich eine Woche lang "abscheulich" - alles um des Kaufes eines Mikroskops willen. Dieses verăndert ihn völlig, macht aus inm geradezu eine neue Personlichkeit. Er hort auf zu trinken, beginnt, sich gegenuber seiner Frau zu behaupten, scherzt und lacht uber sie, zeigt ein uberraschendes Selbstbewubtsein, kurz:

становился крикливым хозяяном в доме. (S. 102)

Eine Woche lang lebt Andrej "wie im Traum". Die Untersuchung der "Mikroben" unter dem Mikroskop nimmt seine ganze Freizeit in Anspruch. Er stellt eine "Theorie" uber die Lebenserwartung des Menschen und die Funktion der "Mikroben" dabei aur. Letztere $z u$ vernichten, ist sein "Porschungsziel".

Das kuriose Verhalten des Helden wird voller Humor dargeboten, der sich aus der Art seines Denkens und aus seiner Sprache ergibt. Andrejs Auberungen Uber seine Experimente und der "wissenschaftliche" Disput mit seinem Sohn sind durchsetzt mit "prostorečie", Slang und Vulgärausdrücken. Sie finden in seiner gewohnten Sprache statt, die in witzigem Gegensatz steht zur Wissenschaftlichkeit des Gegenstands und des Anliegens:

- Мнкробов ты пьёшь, голубунка, микробов. С водоя-то. Миллиончика два тяпнешь - и порядок. (S.101)

Сеичас их там сам организм начнет колоиматить. Он-то с имя управляется! (S. 103)

Микробы Они, сволочи, укорачивают век человеку. (S.103)

Andrejs Gedankengănge weisen kindlich-naive, in ihrer Spontaneitat und Aufrichtigkeit rührende Zugge auf:

Ночью Андрея два раза вставал, захнгал свет, смотрел в мнкроскоп и шептал:

- От же ж собаки!... Што вытворяют. Што они только вытворя:т! Н не спится им! (S. 103) 
- Скипндаром?.. Не возьмет. Водка-то небось покрепче... я п пью, а вон видел, што делается в крове-то! (S. 104)

Die Personlichkeit des Helden wird nicht beschrieben und nicht analysiert. Es gibt keine Uberlegungen des Erzăhlers uber sein Verhalten. Was der Leser uber Denken und Psyche des Helden erfahrt, wird im Dialog und durch dessen Handlungen aufgedeckt. Der Erzăhler registriert dabei, in der Art eines objektiven Beobachters, fast nur ăuBerlich wahrnehmbare Gegebenheiten:

Отец уступил место у микроскопа и взволнованно стал ходить по комнате. Думал о чем-то. (S. 102)

Dennoch gibt es im Erzăhlertext Stellen, die das Licht, in dem der Held dargeboten wird, mitbestimmen und für die Haltung des Autors zu seinem Helden von Bedeutung sind. So enthalt die ironische Passage des Erzăhlers Uber die Erschaffung der Prau (S. 103) gleichsam eine Abschwăchung der Hărte des ehelichen Loses und der hăuslichen Szenen fur den Helden. Ihre Plazierung im Text ermoglicht den Schlub, dab hier auf eine mogliche Einstellung Andrejs zu seiner Frau hingewiesen wird, in der sich der Erzahler mit dem Helden verbundet.

Auf die Sympathie des Autors fur seine Gestalt verweist auch der lyrische Unterton einer anderen Stelle des Erzăhlertextes :

Руки его, натруженные за много лет - большие, пропахиие смольем... чуть дрожали на коленях. (S. 104)

Sie deutet zudem auf einen wichtigen $\mathrm{Zug}$ des Helden hin, der auch an anderer Stelle deutlich wird: Andrej ist im ubrigen ein vollig "normaler" Mensch, ein fleibiger, redicher Arbeiter, der ein gewohnliches Leben fuhrt. Suksin greift in dieser v૪llig durchschnittlichen Gestalt lediglich ein Moment heraus, das das alltägliche Bild von inr verăndert, es plotzlich kurios und widersprichlich, aber auch komplizierter und interessanter ers sheinen labt. Was zunachst als spleen, Verrulcktheit 
des Helden erscheint, erweist sich bei năherem Hinsehen als ein Stuck Innenwelt, das im normalen Alltag nicht zum Vorschein kommt, das aber dem Helden etwas verleint, was inn gegenuber dem Gewohnten und Durchschnittlichen auszeichnet.

Gerade im Kontrast zur inneren Welt seiner Frau - die ja nur als Spleen sieht, was dem Leser zunăchst ebenso erscheint - wird dieses Besondere im Helden als etwas Positives deutlich. Es ist ein Drang nach "hoheren", ideellen Werten, nach Vollbringung einer aubergewohnlichen Tat, einer Leistung von allgemeinem Nutzen, der in Andrejs Begeisterung fur das Mikroskop zum Ausdruck kommt. Es ist dies ein Bedurfnis, das in den realen Lebensverhăltnissen des Helden keine Befriedigung findet, das aber fur sein Lebens- und Selbstwertgefuhl von ausschlaggebender Bedeutung is $t$.

In Suksiins Prosa gibt es die vorgestellte Verwirklichung des Traums: Wenn es unmöglich ist, den Traum zu verwirklichen, dann soll es so sein, als ob er Wirklichkeit geworden sei, die erwunschte, naturliche und notwendige Wirklichkeit. Das ist etwas Kindliches. 113)

Auch hier ist es ein Moment der "Ubergangspsychologie", das S̆uks̆in einfăngt, der Entstehung eines neuen BewuBtseins am Schnittpunkt zweier Kulturen. Auch Andrej kann in den traditionellen Grundpfeilern des Alten aus "V proril' i anras" keine Berriedigung mehr rinden, sie vermtgen ihm nicht mehr Geschlossenheit des Weltbildes und der Lebensvorstellung $z u$ vermitteln. Sein Gesichtskreis ist weiter geworden. Er weib von Entdeckungen des "Atomzeitalters", dab es Gelehrte gibt, die sich mit wichtigen Fragen beschaftigen, neue Realien und Begriffe ("mikroby", "mikroskop", "organizm") sind in sein Gesichtsfeld getreten. Die Aneignung des Neuen hat begonnen, hat unumkehrbare Spuren im Bewubtsein hinterlassen. Aber die "Verarbeitung" des Neuen erfolgt bei Andrej auf der Grundlage

113) W. Kawerin, Die Erzăhlungen Wassili Schukschins, in: Kunst und Literatur, 1977, Nr. 12, S. 1283-1290, S. 1288 
der alten Kultur und vermischt sich mit inr zu einer seltsame und kuriose Züge annehmenden Form von Halbkultur. Das Dilemma des Helden besteht darin, nicht mehr leben zu kơnnen wie dif Alten, aber auch zu einem Aufgehen im Neuen nicht in der Lage zu sein, weil die Einfachheit der aus der alten Kultur ubernommenen Masstabe - wie die schlichte Vorstellung von gut und borse, nutzlich und schädich etc., von der sich der Held bei seinen "Untersuchungen" leiten labbt - auf die Kompliziertheit der modernen Welt nicht anwendbar sind.

Šuksin făngt mit diesem BewuBtseinstyp eine Erscheinung ein, die der aktuellen Gegenwart angehort und die neue Fragen aufwirft. Das Neue an seinem Ubergangstypus besteht vor allem in dem gewaltigen Kontrast zwischen den beiden Kulturen, die hier aufeinandertreffen und der neuen, mit fruheren Epochen nicht vergleichbaren Qualitat und Breitenwirkung, mit der die "Epoche der wissenschaftlichtechnischen Revolution" auf Bewubtsein und Psychologie des Menschen einwirkt. Šukšin "erforscht" diesen ProzeB in einer Vielzahl seiner Helden, wobei er immer wieder neue Aspekte und Nuancen entdeckt und eine neuartige und wunderliche Welt menschlichen Bewubtseins zeigt, die den Stempel der Zeit trăgt: Einer immer komplizierter werdenden Gegenwart, in der sich auch die Frage nach dem Sinn des Lebens und den geistigen Moglichkeiten des Menschen fur den einzelnen auf neue Weise stellt.

Im Begreifen der Kompliziertheit der inneren Welt des Menschen wie auch ihrer Wechselbeziehung mit der sie umgebenden Wirklichkeit werden Erfahrung und Vernunft der Menschheit erworben. Nicht zufallig hat die Kunst aller Zeiten aufmerksam die Verwirrungen der Seele (smjatenija dusi) beobachtet und - unbedingt - nach einem Ausweg aus diesen Verwirrungen und $Z$ weifein gesucht. 114)

Diese "smjatenija duši" und die Suche nach einem Ausweg kennzeichnen fast alle Ubergangstypen Sukšins, wobei der Autor eine eigene Sprache fur den besonderen seelischen

114) Vasilij Śukšin, zit. bei V. Korobov, Vasilij Šukšin: Trorčestvo. Ličnost', Moskva 1977, S. 138 
Zustand dieses Helden und in der Aufdeckung des Sonderbaren und Paradoxen im scheinbar Alltagglichen und Gewornlichen zugleich einen besonderen künstlerischen Ausdruck fulr das moderne "Ubergangsbewubtsein" findet:

Das zentrale Material Suksins ist das Alltagsleben (byt), der Alltag im Rayonmabstab. Aber das ist nur die Faktur, der Hintergrund, und Sukśin liebt es, innerhalb dieser Faktur Sonderbares, Ungewbhnliches zu finden, sein Material zu "verseltsamen" (ostranit'). 115)

Diese "Verseltsammg" des Materials, von der Gusev spricht, erhalt in den Erzăhlungen des reifen Sukšin eine zunehmende und vielschichtige Bedeutung, die im folgenden noch ausfuhrlich $z u$ betrachten sein wird. Im Zusammenhang mit dem tbergangstypus wird sie zu einem zentralen Mittel fur die Gestaltung psychologischer und bewubtseinsmabiger vorgănge.

\subsubsection{Ethische und sozialkritische Aspekte der "Ubergangsprob lematik"}

Einen Ubergangstypus und Sonderling besonderer Art gestaltet Sukšin in "Srezal" (Reingelegt, 1970) 116). Auch in dieser Erzăhlung scheint ein typisches Handlungsschema der modernen Dorfprosa zugrundezuliegen. Ein städtischer Intellektueller, Kandidat der Wissenschaften, kommt zu Besuch in sein Heimatdorf. Nach alter Tradition versamme in sich am Abend die Männer des Dorfes, um den Ankommling zu begrüben. Im Gesprăch, das sich zwischen den Dorflern und dem Stadter entspannt, stellt sich heraus, das sie einander nicht verstehen, und der dorfliche Kontrahent des Kandidaten "beweist" diesem, daß er der Unterlegene und zu einem Gesprăch "mit dem Volk" nicht in der Lage ist.

115) V. Gusev, Imenno zizn', a ne cto drugoe..., in:

Literaturnoe obozrenie, $1974, \mathrm{Nr} .1, \mathrm{~S} .50-55, \mathrm{~S} .50$

116) Im folgenden zitiert nach: Suksin, Rasskazy, a.a.0., S. $165-171$ 
Die Erzăhlung beginnt mit der Peststellung, dab zur alten Agaf'ja Zuravleva der Sohn mit Prau und Tochter zu Besuch gekommen ist. Im năchsten Absatz erfahrt der Leser aus der Perspektive der Dorfbewohner die năheren Umstande der Ankunft:

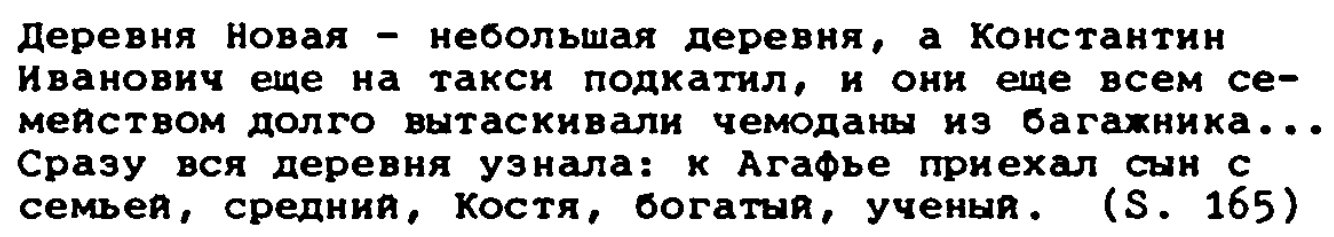

Im AnschluB daran wird die eigentliche Hauptgestalt eingefuhrt: Gleb Kapustin, charakterisiert als "vierzigjahriges Mannsbild, hellbland, mit dicken Lippen, belesen und boshaft". Gleb ist im Dorf dafur bekannt, das er die "znatnye ljudi", die zu Bildung und Ansehen gelangten ehemaligen Dorfler, bei ihrem Besuch zu Hause einer Prufung unterzieht, der diese in aller Regel nicht standhalten. Die Dorfbewohner zollen Gleb Respekt ob dieser seiner Fahigkeit und warten jedes Mal mit Spannung, wie auf ein Schauspiel, wenn dieser sich anschickt, den Besucher "reinzulegen" (srezat').

Durch diese Einleitung der Erzahlung und den das Ergebnis der Aktion bereits vorwegnehmenden Titel ist der Leser eingestimmt auf einen am vertrauten Dorf-Stadt-Schema der Dorfprosa orientierten Handlungsverlauf, in dem sich der "Mann aus dem Volk" und damit das positive sittliche Element des Dorfes der modernen Bildung und Zivilisiertheit des stadters uberlegen erweist.

Gleb geht denn auch tatsachlich aus dem Disput mit dem Kandidaten als Sieger hervor, aber dennoch entwickelt sich die Geschichte der Erwartungshaltung des Lesers entgegen, und nur eine oberflachliche Betrachtung mag dazu verleiten, in den Worten Gleb Kapustins, mit denen dieser uber die Intelligenzler den stab bricht, die Position des Autors sehen zu wollen ${ }^{117}$ ):

117) Gerhard Hildebrandt interpretiert die Erzahlung in dieser Weise, vgl. Hildebrandt, a.a.0., S. 198 
Можно сотни раз писать во всех статьях слово "народ", но знания от этого не прибавится. Так что когда уж выеэжаете в этот самыя народ, то будьте немного собраннея. Подготовленнея, что ли. А то легко можно в дураках очутиться. До свидания. Приятно провести отпуск... среди народа. (S. 171)

Im Kontext der Erzăhlung erweisen sich diese Worte als Demagogie, und "Srezal" belegt ein weiteres Mal, wie wenig der Dialog bei Śukšin der Erorterung von "Wahrheiten", hinter denen sich die Position des Autors verbirgt, dient, sondern vor allem der Aufdeckung der agierenden Charaktere und Bewustseinstypen.

In "Srezal" geht es um den Bewubtseinstyp, den Gleb Kapustin verkorpert. Die fur den Leser uberraschende Wende im Handlungsverlauf setzt dort ein, wo die Konfusitat der Kapustinschen Argumentation in der Diskussion mit dem Kandidaten deutlich wird:

\footnotetext{
...Как сеячас философия определяет понятие невесомости?

- Как всегда определяла. Почему - сеячас?

- но явление-то открыто недавно. - Глеб улыбнулся прямо в глаза кандндату. - Поэтому я н спрашиваю. Натурфилософия, допустим, определит это так, стратегическая фитософия - совершенно иначе... (S. 167)
}

Was Kapustin hier und im folgenden an Belesenheit und bruchstuckhaftem Wissen demonstriert, ist ebenfalls eine Form von Halbkultur, wie sie das "Informationszeitalter" erzeugt. Alles, was die modernen Massenmedien an populărwissenschaftlichen und eingăngigen Informationen bis ins abgelegenste Dorf $z u$ befordern vermochten, scheint Kapustin aufgenommen $z u$ haben, und die geradezu exaltierte Form seines Disputs mit dem Kandidaten bringt die ganze Widerspruchlichkeit dieser Aufnahme bestens zum Ausdruck:

Dieser Dialog... hilft, all das Verworrene und das chaotische Durcheinander der Kenntnisse wiederzugeben, die sich durch diesen "gleichmäbig verbreiteten Informationsstrom" in Glebs Kopf festgesetzt haben. Gleb ist Gefangener einer pervertierten Informationsaufnahme, Gefangener jeglicher Art billi- 
ger Journale und Unterhaltungssendungen des Fernsehens. 118)

Aber Kapustin wird nicht nur als Opfer der modernen "Informationsexplosion" gezeigt. Die Form von Halbbildung, die hier aufgedeckt wird, verbindet sich bei inm mit bestimmten Charaktereigenschaften, die im Text mit der Charakterisierung seiner Gestalt als "echidnyj" (boshaft, tückisch) und "žestokij" (hart, grausam) angedeutet sind. Die Belesenheit Kapustins ist nicht vornehmlich Ausdruck eines Bedürfnisses nach wissen und Bildung, eines Strebens nach geistigen Werten, sondern resultiert aus dem selbstsulchtigen Wunsch, sich "in Szene zu setzen", zu beeindrucken, indem er andere herabsetzt und diskreditiert. Er ist ein "krasnobaj", ein Schwatzer und Wichtigtuer 19). Die Beruhrung mit dem Neuen, das durch Presse, Radio, Fernsehen und Bucher in sein Leben eindrang, hat auch bei inm eine innere Unruhe erzeugt, einen besonderen psychologischen Zustand, der sich jedoch nicht - wie bei Ivan aus "V profil' i anfas" - in der unbestimmten Suche nach einem neuen Lebensinhalt oder - wie bei dem Helden aus "Mikroskop" - im Wunsch nach Vollbringung einer groben Leistung niederschlägt. Im Vergleich $z$ jenen Helden ist der Typus, den Kapustin verkorpert, innerlich viel leerer und ärmer. Was ihn auszeichnet, sind vor allem Bosheit und Neid sowie der Wunsch,

sich dafur zu răchen, daß er sozusagen beim allgemeinen Festschmaus leer ausgegangen ist. 120)

Was Kapustin in seinem Disput mit dem Kandidaten betreibt, ist Hochstapelei und Demagogie, und der Dialog spiegelt

118) ¿almaev, a.a.o., s. 162

119) So wird der Held in einer fruheren Variante der Erzăhlung, die auch in die zweibandige Ausgabe der Prosa Sukşins aufgenommen wurde, charakterisiert: "tolstogubyj, belobrysyj muzik let soroka, derevenskij krasnobaj, nacitanny $j$ echidny $j^{\prime \prime}$. Vgl. hierzu auch Gorn, a.a.0., S. 249

120) Sukšin, Ja rodom iz deréni, a.a.o., S. 245 ; Sukšin deutet hier selbst die Gestalt Gleb Kapustins in dieser Weise 
ausgezeichnet die Methoden wider, die der Held dabei anwendet.

Kapustin verfugt über ein ganzes Arsenal an auswendig gelernten Begriffen und gängigen Schablonen, die populärwissenschaftlichen Darstellungen und der Zeitungsprache entnommen sind. So spricht er von der "Prioritat von Geist und Materie", vom "Begriff der Schwerelosigkeit", vom "Problem des Schamanismus in einzelnen Gebieten des Nordens" und ähnlichem und kleidet seine verworrenen Gedanken in "wohlklingende" Formeln, wie: "weit entfernt von den gesellschaftlichen Zentren"; "das Problem als solches"; "es handelt sich naturlich nicht um eine globale Frage"; "in der gegenwartigen Etappe" usw. Ganze Absatze in seiner Rede stellen eine einzige Aneinanderreihung solcher Schablonen aus der wissenschaftlichen und publizistischen Terminologie dar:

\begin{abstract}
- Где ваши расчеты естественных траектория? Куда вообме вся космнческая наука может быть приложена? Мухики внимательно слупали Глеба.

- допуская мысль, что человечество все чаме будет посещать нану, так сказать, соседку по космосу, можно допустить также, что в один прекрасния момент раэумные существа не выдержат и вылезут к нам навстречу. Готовы мы, чтобы понять друг друга?
\end{abstract}

Die Ausfuhrungen Kapustins enthalten weder einen rechten Sinn noch richtige Informationen, und auf seine Fragen zu antworten, ist unmoglich. Aber er benutzt "avtoritetnye slova"121), autoritative Begriffe und Formeln, und die Art und Weise wie er diese einzusetzen versteht, labt dem verblufften Kontrahenten keine Chance, so dab

aus der Sicht des gebildeten Betrachters die Wahrheit von der Ignoranz an die Wand gedrängt wird. 122)

Gleb Kapustin "arbeitet" mit solchen Formeln auf allen Ebenen. Er benutzt nicht nur stereotypen der populär-

121) V. Kantorovic, Novye tipy, novyj slovar', novye otnošenija, in: Sibirskie ogni, 1971, Nr. 9, S. 176180, S. 178

122) Ebenda 
wissenschaftlichen Literatur, sondern operiert auch mit einer Reihe von Schablonen, die Grundpositionen der offiziellen Ideologie bezeichnen: Die Frage nach dem Verhaltnis von Geist und Materie, die "Dialektik der Natur", die Beziehung zwischen Volk und Intelligenz. Das scheinbare Nicht-Standhalten des Kandidaten Eegenuber diesen "autoritativen" Fragen muB inn in den Augen der Zuhorer gleich in zweifacher Hinsicht - intellektuell und ideologisch diskreditieren.

Und schlieblich versucht Kapustin durch den demagogischen Einsatz von Phrasen und gedanklichen Klischees jeder Art und letztlich durch das unverfrorene Ausspielen seiner Position als "Vertreter des Volkes", den Gegner auch moralisch zu diskreditieren:

- Нет, можно, конечно, сделать вид, что такоя проблема нету. Я с удовольствием тохе посмеюсь вместе с вамн... Но от этого проблема как таковая не перестанет сумествовать. Верно? (S. 168)

...кандидатство - это ведь не костюм, которыя купил

- и раз и навсегда. (S. 169)

...Так что этот харгон мохет... плохо кончиться, товарищ кандидат. Не все средства хороши, уверяю вас, не все. (S. 170)

Im Dialog zwischen Kapustin und dem Kandidaten deckt Sukšin die Hohlheit und Verlogenheit solcher stereotyper Forme in und sprachlicher Klischees auf, zeigt aber zugleich die Gefahrlichkeit dieses Phănomens im modernen Sprachgebrauch. Hinter der bizarren Figur des Helden aus "Srezal" verbirgt sich ein sozialpsychologischer Typus, dessen Problematik und Gefăhrlichkeit besonders deutlich wird, wenn man ihn auf einen breiteren gesellschaftlichen Kontext Uberträgt, wie dies der Kritiker A. Urban tut:

Die Figur Glebs ist nur auf den ersten Blick anekdotisch. In Wirklichkeit kann so ein Gleb auch Kandidat der Wissenschaften sein, der sich auf dem Boden der "Gegenwart" $z u$ beweisen sucht, indem er mit modischen Begriffen jongliert. Er kann auch ein findiger Publizist sein, der aus schlecht verarbeiteten Fakten künstlich wissenschaftliche Sensationen produziert. Oder ein kleiner Beamter, der sich Autorităt $z u$ verschaffen sucht, indem er Reklame 
macht fur phantastische Liebhaberprojekte. Kurz, das ist nicht einfach ein komischer Kauz. Gleb steht stellvertretend fur eine ganze Reihe von eitlen Schwatzern, die von dem schmarotzen, was Informationsexplosion genannt wird. 123)

Auch in dieser Erzăhlung enthalt sich der Autor direkter moralisierender Wertungen, wird der Held "objektiv" vor allem im Dialog - dem Leser vorgefuhrt, der aufgefordert ist, sich uber das seltsame Verhalten Kapustins sein eigenes Urteil zu bilden. Lediglich der abschlieBende Kommentar des Erzăhlers uber die Erbarmungslosigkeit des Helden verweist auf eine Position des Autors:

Глеб же Капустин по-прежнему неизменно удивлял. изумлял. Восхинал даже. Хоть любви, положнм, тут не было. Нет, любви не было. Глеб жесток, а жестокость никто, никогда, нигде не любил еще. (S. 171)

Auch fehlt in Bezug auf Gleb Kapustin der wohlwollende Humor, der Šukšins Helden meist ungibt. Die Hauptfigur in "Srezal" trăgt eher satirische Zuge, die aber durch die Darstellung der Gleb umgebenden Bauern des Dorfes hier ist der Humor vorhanden - etwas abgeschwăcht werden. Trotz alledem ist Gleb Kapustin keine ganz eindeutige Figur. Die Absonderlichkeit dieser Gestalt ruft beim Leser zwiespaltige Gefuhle hervor, was mit der Struktur der Erzahlung und dem Arrangement der handelnden Personen zusammenhangt, die bewirken, daß der Leser mehrfach zum Nachdenken und zur Uberprufung seines Urteils gezwungen wird.

Wesentlich sind hierfür die verschiedenen in der Erzăhlung vertretenen standpunkte in Bezug auf das Verhaiten Kapustins, deren Wiedergabe im Text dergestalt ist, dab sich aus ihnen keine eindeutigen Schlubfolgerungen uber den Helden ziehen lassen.

Die Gestalt des Kandidaten ist nicht - wie Hildebrandt meint ${ }^{124)}$ - negativ gezeichnet. Sie entspricht nicht dem

123) A. Urban, S podlinnym verno, in: Zvezda, 1974, $\mathrm{Nr} .4, \mathrm{~S} .213-215, \mathrm{~S} .214$

124) Hildebrandt, a.a.0., S. 214 
Bild des uberheblichen, vom einfachen Volk entfremdeten Intellektuellen, das Kapustin ihm entgegenhalt. Der Kandidat verhalt sich vielmehr "normal", der situation entsprechend. Aber der Autor hat in ihm auch nicht einen echten Konkurrenten seines sonderbaren Helden geschaffen oder gar eine Identifikationsfigur fur den Leser, und das Urteil des Kandidaten uber seinen Gegenspieler ("Ein typischer Demagoge und Intrigant", S. 170) bleibt im Textzusammenhang ohne rechte Uberzeugungskraft.

Auch die nicht einheitliche Haltung der Dorfbewohner gegenuber dem Helden zeigt diesen in einem unterschiedlichen Licht. Da sind einerseits die Bauern, deren Verschmitztheit und Schläue vom Autor mit deutlicher Sympathie wiedergegeben werden, die den Disput der beiden Gegenspieler mit hoher Aufmerksamkeit und offenkundigem Respekt vor Gleb Kapustin verfolgen. Andererseits ist von einem Teil der Dorfbewohner die Rede, der mit Gleb unzurrieden ist, und es gibt die nicht onne Ironie erfolgende Feststellung, dab

\section{Все матери энатных людея в деревне не любили} Глеба. Oпасались. (S. 166)

Diese unterschiedlichen Wertungen hinsichtlich der Person Kapustins steigern noch die bereits durch den Gang der Erzăhlung und das merkwüdige Verhalten des Helden bewirkte Uneindeutigkeit seiner Gestalt, was den Leser $z u$ verstărktem Nachdenken zwingt. Gleichzeitig erscheint hierdurch das Problem der Beziehung von Volk und Intelligenz, das als gedankliches Klischee vom Autor schon durch den Aufbau der Erzăhlung "entgegen der Erwartungshaltung des Lesers" einer Polemik unterzogen wird, auf einer anderen Ebene als reales Problem neu: Nămlich als Errahrungswert der Bauern und Gleb Kapustins aus dem Umgang mit den "angesehenen Leuten" und als seelisches Problem des Helden, das sich in seinem Auftritt gegenuber dem Kandidaten als eine Art Minderwertigkeitskomplex offenbart, als Furcht vor einer herablassenden Haltung des Inteliigenzlers, die von sich abzuwehren, er am besten im Angriff gewahrleistet sieht. 
Die Orfenheit und Mehrdeutigkeit der Gestalt des Helden, wie sie sich in "Srezal" zeigt, ist kennzeichnend für viele Texte Śukšins. Inr liegt eine küntlerische Position zugrunde, die sich auch in den publizistischen XuBerungen des Autors rindet:

Ich halte nicht viel vom Sujet. Meiner Ansicht nach birgt ein Sujet zwangsläufig eine moralische Belehrung in sich. Wenn eine Geschichte in sich geschlossen ist, wenn sie zu einem bestimmten Zweck erzăhlt und voliendet wurde, dann bedeutet das, dab der Autor ein bestimmtes $Z i e l$ verfolgt, etwa dieser Art: Handle nicht so, sondern so. Oder: Das ist gut, aber das ist schlecht. So etwas sollte es in der Kunst nicht geben.

Wenn ich auf die Wahrheit stoBe, die Wahrheit einer Darstellung oder Beschreibung, dann beginne ich ganz von selbst, Schlubrolgerungen zu ziehen. Und zwar vollig richtige SchluBfolgerungen, denn ich bin ein lebendiger und normaler Mensch. Warum vertraut man denn dieser meiner Fahigkeit... bisweilen nicht? Diese Arbeit muB man mir selbst uberlassen. Belehrungen in der Kunst machen mich sehr hellhorig. Ich furchte sie, und ich traue innen nie. 125)

Die Ablehnung jeglichen Moralisierens und auktorialer Wertungen in der Literatur wird hier verbunden mit der Forderung nach dem aktiven Leser, der selbstăndig uber das Dargestellte urteilt und durch die Art der Darstellung, ihre Authentizitat, auch dazu befăhigt wird. Die von Suksin in "Srezal" angewandten Verfahren dienen denn auch vor allem der Aktivierung des Lesers, indem sie diesen in besonderem MaBe zum Nachdenken und Weiterdenken uber das Erzahlte hinaus auffordern und ihn damit zugleich an die Komplexitat des dargebotenen Wirklichkeitsausschnittes heranfuhren.

Zweifellos labt sich in dieser, auch fur andere werke der modernen russischen Prosa kennzeichnenden Erzahlhaltung $^{126)}$, eine Reaktion auf den Normenkanon des sozialistischen Realismus mit seiner Forderung nach Eindeutig-

125) Vasilij Śuks̉in, Es̉ce raz vyverjaja svoju zizn'..., Beseda s korrespondentom "Literaturnoj gazety", in: ders., Nravstvennost', a.a.0., S. 266- 284, S. 278 r.

126) Vgl. Schmid, a.a.0., S. $66 \mathrm{fr}$. 
keit des Autorstandpunktes und Belehrung des Lesers erkennen. Sie steht jedoch bei Sukšin auch in engem $\mathrm{Zu-}$ sammenhang mit der besonderen Auseinandersetzung, die der Autor mit dem Klischee, dem Schematismus und der Eingleisigkeit im Denken als einem Grundproblem moderner Geisteshaltung funrt.

\subsection{Die Gestalt des Sonderlings}

Die Vorliebe Śukšins fur das Kuriose, Exzentrische, $A b-$ sonderliche, auf die im vorangehenden bereits aufmerksam genacht wurde, hat ihren konzentrierten Ausdruck in der Gestalt des Sonderlings gefunden, der in Prosa und Film vor allem des spăteren Šukšin zentrale Bedeutung zukommt. Zuge dieses Sonderlings wurden bereits im Zusammenhang mit dem Ubergangstypus untersucht, wobei auf inre Funktion bei der Wiedergabe psychologischer und bewubtseinsmäbiger Vorgănge hingewiesen wurde.

Alle Sukšinschen Sonderlinge lassen sich ihren sozialpsychologischen Merkmalen nach dem Ubergangstypus zuordnen und weisen Bewubtseinsstrukturen auf, die in mehr oder minder starkem Mabe jene merkwurdige Verknupfung von Altem und Neuem erkennen lassen, die als "Halbkultur" bezeichnet wurde. Dennoch labt sich die Gestalt des Sonderlings bei Sukšin nicht auf den Ubergangstypus und das an inm realisierte Thema der zwei Kulturen reduzieren, sondern trăgt daruberhinaus eigenstăndige Bedeutung. Mit inr hat Śuksin eine literarische Gestalt in die moderne russische Prosa eingefunrt, die ihn nicht nur innerhalb der Dorfprosa als sehr eigenstăndigen Autor hervorhebt. Uber die "čudiki" und "strannye ljudi"127) Sukšins wurde in Forschung und Kritik viel geratselt, wobei vor allem

127) Eine seiner Erzăhlungen heiBt "Cudik" (Zärtlichkeitsform von "cudak" - Sonderling, komischer Kauz); "strannye ljudi" (seltsame Menschen) ist der Titel eines Films von Šukśin (1969), dem die Erzăhlungen "Ćudik", "Dumy" und "Mil' pardon, madam!" zugrunde liegen 
die Widersprüchlichkeit dieser Helden und die ihrer Darstellung innewohnenden Paradoxa immer wieder Schwierigkeiten bereiteten.

AuBerlich sind diese Sonderlinge einfache dörfliche Gestalten mit durchschnittlichem Leben und Schicksal, aber hinter ihrer Absonderlichkeit verbirgt sich ein komplizierter Charakter. Das Seltsame an ihnen ruhrt aus ihren merkwürdigen, scheinbar unerklärlichen, von den allgemeinen Normen und Konventionen abweichenden Verhalten, das sie in einen ständigen oder partiellen Konflikt mit der Umwelt führt.

$\mathrm{Da}$ ist Bron'ka Pupkov aus der Erzahlung "Mil' pardon, madam!", der den Besuchern aus der Stadt, die er als Funrer auf ihre Jagdausfluge begleitet, die Geschichte eines miBgluckten Attentats auf Hitler zu erzahlen prlegt, in der er selbst die Hauptrolle spielt. Oder Monja Kvasov aus "Upornyj" (Der Hartnăckige), Kraftfahrer auf einem Kolchos, der ganz von dem Gedanken besessen ist, ein Perpetuum Mobile zu konstruieren und sich durch nichts und niemanden von der Undurchfuhrbarkeit seines Vorhabens uberzeugen 1aBt. Der Held der Erzahlung "Štrichi k portretu" (Striche zu einem Portrăt), ein Handwerker, der Fernsehgerate repariert, schreibt in seiner Freizeit an einem umfassenden und seltsamen Traktat uber den Staat, den Sinn des Lebens und das Problem der Freiheit, weil inm "sonst der Kopf zerspringt vor Anspannung". Auch der Viehhirte Kostja Valikov, genannt "Aleša Beskonvojnyj" (Widerspenstiger Aleza) gilt im Dorf als un- / verbesserlicher Kauz, weil er sich kategorisch weigert, an Wochenenden irgendwelche Arbeiten $z u$ verrichten. Den Samstag hat sich der Held selbst als Badetag verordnet, und an diesem Tag beschaftigt er sich ausschlieblich damit, im Dampfbad zu schwitzen und seinen Gedanken nachzuhăngen. Und "Čudik" (Sonderling) aus der gleichnamigen Erzăhlung ist einfach deshalb ein Sonderling, weil "mit inm stăndig irgendetwas passiert", weil er mit seinem kindlichen Wesen überall aneckt und für seine Umwelt zur komischen Pigur wird. 
Im Auftreten dieser bunten Palette komischer und kauziger Figuren in Sukšins Prosa gegen Ende der sechziger Jahre wird in Forschung und Kritik ein Wendepunkt im Schaffen des Autors gesehen, ein Ubergang zu groberer gedanklicher Tiefe seiner Erzăhlungen und zur Gestaltung komplizierterer Typen und Charaktere.
"Seltsame Menschen" ist der "seltsamste" Film V. Sukśins. In ihm spiegelt sich, wie auch in den Erzăhlungen, die dem Film zugrunde liegen, ein ver- stärktes Nachdenken des Autors wider, das Paradoxe, das er in der Welt und den Menschen entdeckt, wel- che inm fruher so klar und einfach erschienen waren in der Bekraftigung inrer sitten und Bräuche und inrer Vorstellungen. 128)

Lev Anninskij konstatiert einen grundlegenden Wandel des literarischen Helden und damit den Schaffensbeginn eines "neuen", des "echten" Sukšin bereits zu einem fruheren Zeitpunkt, nämlich mit dem Erscheinen der Erzăhlung "Kritiki" (Kritiker) in der Zeitschrift "Iskusstvo kino" (Filmkunst) im Februar 1964129). Und bei seinem Versuch, einen gemeinsamen Nenner für die merkwürdigen und in inrer Merkwurdigkeit sich so unahnlichen Helden zu finden, der das Interesse des Autors an diesem Typus erklaren konnte, gelangt Anninskij zu der auch von anderen Kritikern ubernommenen These, daB Šukšin "einen jeden Menschen begreifen will" und deutet die kunstlerische Entwicklung des Autors vor allem als Versuch,

die entstellte Seele zu begreifen, im Brsen das Gute $z u$ wecken, Verständnis dem entgegenzubringen, der im Unrecht is $t$. 130)

128) Balichin, a.a.0, S. 18; zur kunstlerischen Evolution der Prosa Sukšins vgl. auch $A$. Andrianov, Ešce raz o "strannych gerojach" v. Sukśina, in: Molodaja gvardija, 1973, Nr. 10, S. 308-312; AI. Ovcarenko, Rasskazy Vasilija Šukšina, in: Don, $1976, \mathrm{Nr} .1$, S. 155-166; Ivaj 10 Petrov Ivanov, Proza Vasilija Śukšina. Chudožestvennyj mir pisatelja (Kandidatendissertation), Diss...kand. fil..., Leningrad 1979

129) Anninskij, Put' Vasilija Śuksina, a.a.0., S. 645

130) Ebenda, S. 663, S. 665; zu dieser Auffassung des Kritikers vgl. auch ders., Sukšinskaja žizn', a.a.o. 
Hinter der Rătselhaftigkeit der Śukšinschen Sonderlinge verbirgt sich jedoch eine Vielschichtigkeit dieser literarischen Gestalt, die mit der Formel Anninskijs nicht zu erfassen ist, und die Konzeption des Kritikers stieB bei anderen Autoren zu Recht auf Kritik ${ }^{131)}$. Es handelt sich bei den Sonderlingen vor allem um eine besondere Form der Wirklichkeitsdarbietung, die nach neuen Ausdrucksmbglichkeiten strebt und dem Autor ermbglicht, verschiedenartige Probleme und Erscheinungen künstlerisch zu gestalten.

\subsubsection{Der Drang nach Selbstdarstellung}

Die Helden erscheinen vor allem dadurch als Sonderlinge, dab sie niemandem in ihrer Umgebung gleichen, sich von dem Gewohnten, Ublichen, von keinem in Frage Gestellten unterscheiden durch ein Verhalten, das bei der Umwelt MiBbilligung, Spott oder Kopfschutteln hervorruft.

Bei Bron'ka Pupkov, dem Helden aus "Mil' pardon, madam!" $(1968)^{132)}$, der als ortskundiger und geschickter Jager die in sein Dorf kommenden stadter auf die Jagd begleitet, besteht dieses ungew konstanter Regelmăbigkeit den Fremden die Geschichte seines Attentats auf Hitler erzahlt. Der Held wartet auf diese Jagdausfluge "wie auf einen Feiertag" und besonders den letzten $\mathrm{Tag}$, an dem er beim Abschlubfest am Lagerfeuer gewohnlich seinen Auftritt inszeniert, erwartet er "mit grobter Ungeduld":

...изо всех сил крепился... К когда он наступал, желанныя, с утра сладко нело под сершем, и Бронька торжественно молчал. (S. 88)

131) Vgl. Galina Belaja, Antimiry Vasilija Śukšina, in: Literatura i sovremennost', $\mathrm{Nr}$. 16, Moskva 1978, S. 269-279; Leonard Emljanov, Vtoroe prodtenie. K 50-letiju so dnja rożdenija V.M. Suksina, in: Naś sovremennik, 1979, Nr. 7, S. 162-170, S. 169; Gusev, Imenno żizn', a.a.o.

132) Im rolgenden zitiert nach: Suksin, Rasskazy, a.a.0., S. $37-93$ 
Bron'ka hat aufgrund dieser merkwurdigen Geschichte viel auszustehen. Im Dorf gilt er als komischer Kauz und wird als solcher auch den ankommenden städtern empfohlen. Seine Frau bereitet inm regelmäbig unertrăgliche Szenen, und mehrmals ist er schon seines Verhaltens wegen vor den Dorfsowjet zitiert worden. Der Held leidet unter dieser Situation und fluchtet sich in den Alkohol:

Зря она говорила, что Броньке - все равно. Нет. Он тяжело перехнвал, страдал, элился...и дня два пил дома... (S. 93)

Bereits dieser Umstand verweist auf den seelischen Konflikt, in dem sich der Held befindet, darauf, dab sein Bedürnis nach Erzăhlen dieser Geschichte nicht auf eitlem und verantwortungs losem Schwatzertum beruht, wie inm das seine Frau vorwirft, sondern eine tiefergehende, kompliziertere Ursache hat.

Die Art und Weise wie Bron'ka die selbst erfundene Geschichte erzahlt ist bemerkenswert. In allen Einzelheiten und mit grober Anschaulichkeit schildert er den Tag seiner Begegnung mit dem Generalmajor im Lazarett, das Gesprăch mit diesem, die Ubertragung des ehrenvollen Auftrags, Hitler zu erschieBen aufgrund seiner Ahnlichkeit mit einem gefangengenommenen deutschen Spion. Er berichtet geheimnisvoll von der Spezialausbildung, die er erhielt, malt genublich die Details seiner Sonderbehandlung aus, schildert mit Pathos seine innere Einstellung zu dem Auftrag und gelangt schlieblich zum Hohepunkt der Geschichte, seinem Vordringen in Hitlers Bunker und der miBgluckten Ausfürung des Attentats. Bron'kas ganze Geschichte

gleicht einem verworrenen Traum, unklar und voller Widersprulche. Doch Bron'ka fuhrt sie so eindringlich vor, mit solch einer wahrhaftigen, poetischen Begeisterung, dab man ihn weder unterbrechen noch uberfuhren kann... Das ist die Poesie der Luge. Wir sehen einen Dichter vor uns, einen Improvisator. Was sollen da Unstimmigkeiten, Unklarheiten, Widerspruche? Er fliegt, 
inm wachsen Flügel, er glaubt unerschutterlich, dab alles, was er erzahlt, die reine Wahrheit ist. 133)

Von Bedeutung ist die im Text enthaltene Charakteristik des Helden, die diesen als komische und tragische Figur zugleich darstellt:

Бронька /Бронислав/ Пупков, еще крепкия, ладно скроенныя мужнк, голубоглазыя, ульбчивы, легкия на ногу и на слово. (S. 87)

An der Front war er als Sanitater. Wie der Erzăhler feststellt, hat Bron'ka in seinem Leben "viel randaliert", sich hăufig auf Schlägereien eingelassen, aber:

...зла ни на кого не таил. Легко жил. (S. 87)

Der Held ist bekannt als geschickter und erfahrener Funrer und Jager und als ausgezeichneter Schltze. Diese ganze Charakteristik verweist auf die Widerspruchlichkeit seiner Personlichkeit und Lebenssituation, in der sich komische Momente mit tragischen zugen verknupfen. Die komische Seite Bron'kas wird noch unterstrichen durch die eingeflochtene Anekdote uber den Verlust seiner Finger, durch seinen auffalligen Namen Bronislav Pupkov 134) und die Geschichte mit dem Popen. Die Betonung seiner Făhigkeiten, die nicht zuletzt auch in der Art wie er seine Geschichte erzahlt zum Ausdruck kommen, vor allem aber der Tatsache, daB er ein ausgezeichneter Schutze ist, was vom Erzahler im SchluBsatz noch einmal ausdrücklich und mit Ernst vermerkt wird, verleinen seiner Gestalt eine tragische Note.

Bron'ka hat seine Păhigkeiten nicht entfalten und in einer entsprechenden Tatigkeit und gesellschaftlichen Stellung zur Anwendung bringen konnen. Die Tatsache, daB er als hervorragender Schutze - aufgrund seiner fehlenden Finger - an der Front nur als Sanitater eingesetzt war,

133) Kawerin, a.a.0., S. 1289

134) Der Familienname Pupkov wird assoziiert mit russ. "pup", "pupok" (Nabe 1), was in witzigem Gegensatz steht zu dem vornehmen und seltenen Vornamen Bronislav 
scheint dies besonders $z u$ unterstreichen. Seine reale Lebenssituation steht in krassem Gegensatz zu seinen eigentlichen Lebensvorstellungen, zu dem Reichtum an Phantasie, uber den er verfugt, und sie ist nicht dazu angetan, seinen seelischen Bedurfnissen Rechnung zu tragen.

Auch Bron'ka fluchtet sich in den Traum, in das "Als ob", das er gefuhlsmäbig so intensiv durchlebt, dab es fur inn schon zur Realităt wird. Das Losziehen mit den Stădtern auf die Jagd ist fur inn ein Ausbruch aus der Enge des dorflichen Alltags und Milieus, in dem sein Versuch, dem seelischen Verlangen Befriedigung $z u$ verschaffen, nur als Spleen gilt und der Lăcherlichkeit preisgegeben ist. In seiner Vorstellung braucht er gerade das stadtische Publikum fur diesen Ausbruch, wie der an Perspektive und Lexik Bron'kas orientierte Erzălertext belegt:

Ходили дня по три, по четыре, по неделе. Было хорошо. Городские лоди - увахительне, с нимн не манило подраться, дахе когда выпивали. (S. 87)

Wie fur Andrej Erin aus "Mikroskop" ist das Erzahlen seiner Geschichte fur Bron'ka ein Versuch der Selbstaußerung, der Versuch, eine Seite seiner Personlichkeit zu zeigen, die fur gewornlich im Verborgenen bleibt, ein Akt der Selbstdarstellung mit dem Ziel, dem alltäglichen, gewohnten Bild des Bron'ka Pupkov, das alle von inm haben, ein anderes Bild, das des wirklichen Pupkov, entgegenzustellen. Und wie bei Andrej Erin vollzieht sich auch bei Bron'ka eine Verwandlung, wenn er seine Geschichte erzathlt. Er ist in diesem Augenblick ein anderer Mensch, der, der er in seiner Vorstellung sein mochte. Und entsprechend dieser - widersprulchlichen und verworrenen Lebensvorstellung des Helden zeigt der "verwandelte" Bron'ka sowohl Züge, die inn der Lăcherlichkeit preisgeben als auch eine eigene innere Schonheit, die inm etwas Besonderes, Bemerkenswertes verleint.

Bron'ka spielt nicht, obwohl es erstaunlich ist, wie er "in seine Rolle schlupft". Diese merkwurdige, erfundene Geschichte ist ein offentliches Bekenntnis 
eine nach außen drängende Herzensqual, eine Beichte und Selbstzuchtigung. Nur auf diesem Wege verschafft er sich fur kurze Zeit eine gewisse seelische Erleichterung. 135)

Wiederum ist es der Traum von einer bedeutenden Leistung, einer Heldentat, die das reale Leben dem Helden nicht gewăhrt hat, und in der Geschichte, die er sich ausgedacht hat, erlebt er mit aller Intensitat die Grobse und Erhabenheit eines vorstellbaren und die Tragik seines realen Schicksals gleichermaben, die in seiner Geschichte darin zum Ausdruck kommt, dab er als vortrefflicher Schutze vorbeischiebt.

Hinter diesem Drang nach SelbstzuBerung und "Befriedigung der Seele" verbirgt sich ein seelischer zustand, zu dem Šukšin anlăblich seines 1970 angelaufenen Films "Strannye ljudi" Stellung genommen hat. Der Film selbst lief ohne Erfolg, aber die XuBerung Šukšins behalt Aussagekraft auch für die Erzăhlungen, die dem Film zugrundeliegen und fur die Gestalt des Sonderlings bei Śuksin im allgemeinen:

Ich wollte mit diesem Film zum Ausdruck bringen, dab die Seele des Menschen von Unruhe und Sehnsucht gequalt wird, wenn sie nie in Jubel ausbrechen konnte, nie die Begeisterung verspurt hat, die uns zu großen Taten drängt, wenn sie nie ein erfulltes Leben gelebt, nie geliebt hat und nie von echter Leidenschaft ergriffen war. 136)

Indem Śukšin dieses seelische Moment ganz in den Vordergrund ruckt und unter Verzicht auf eine eingehende Individualisierung des Helden umfassend und in seiner ganzen Widerspruchlichkeit analysiert, gelingt es ihm, im Charakter des Saufers und Schwätzers Bron'ka Pupkov, den das ganze Dorf als wunderlichen Kauz verspottet, die Fahigkeit zum Traum als Gegengewicht zur Nichtigkeit der eigenen Existenz aufzudecken, die Sehnsucht nach der Verwirklichung eines Ideals, den Wunsch, dem Leben einen 
tieferen Sinn abzugewinnen und nicht zuletzt, in dieser scheinbar hoffnungs losen und unbedeutenden Natur schopferische Făhigkeiten sichtbar werden zu lassen.

Durch die bewubte Begrenzung der Darstellung auf einen Charakterzug bzw. ein psychologisches Moment und die hieraus resultierende Uberzeichnung der Gestalt, die als künstlerisches Prinzip für Śukšins Prosa überhaupt kennzeichnend ist, erreicht der Autor einen besonderen ass thetischen Effekt und bemerkenswerte Møglichkeiten der Charaktergestaltung in der kleinen Form ${ }^{137}$ ).

Von zentraler Bedeutung ist dabei auch die Sprache des Helden, in der uns der Autor einen Bewubtseinstyp zeigt, in dem sich wesentliche Erscheinungen und Widerspruche der Zeit spiegeln.

Der Drang des Helden nach Selbstdarstellung nimmt eine Form an, die seinem Bewustsein entspricht und die einen geistigen Horizont of fenbart, der wiederum mit dem Begriff der modernen Halbkultur bezeichnet werden kann. In der Geschichte, die Bron'ka erzahlt, spiegelt sich die Vemorrenheit seiner Lebensvorstellung, in der šukšin das Einwirken der verschiedensten geistigen und kulturellen Spharen auf das moderne Bewubtsein aufspurt. Dies kommt zum Ausdruck in der deutlichen Anlehnung der Geschichte Bron'kas an die Klischees ansprucholoser Abenteuerfilme und an das ubersteigerte Pathos offizieller Darstellungen vom Heldentum des 2 weiten Weltkrieges, besonders aber in der Sprache des Helden, auf der die asthetische Wirkung der Erzăhlung und des Charakters ganz wesentlich beruht.

Die Sprache Bron'kas stellt ein buntes Konglomerat von "prostorečie", Slang, Umgangssprache und lexikalischen

137) Die Forschung hat in diesem Zusammenhang zu Recht auf den Bezug der Prosa Sukšins zur Poetik des fruhen Cechov hingewiesen; vgl. V. Gusev, C̈echov i stilevye poiski sovremennoj sovetskoj prozy, in: $v$ tvorčeskoj laboratorii Cechova, Moskva 1974, S. 354-366; ders., Prostranstvo slova. O dvuch stilevych tendencijach sovremennoj prozy, in: Literatura i sovremennost', Nr. 17, Moskva 1980, S. 121-130; V.A. Kuz'muk, Svoeobrazie geroja rasskazov Vasilija Sukšina, in: Vestnik Moskovskogo universiteta, ser. IX, filologija, 1978, Nr. 2, S. 14-2d4 Wüst-978395479123 
Elementen und Schablonen, die anderen Sprachstilen entnommen sind, dar. Kennzeichnend fur seine Rede im Gesprach mit den stadtern und beim Erzăhlen seiner Geschichte ist die Kombination unterschiedlichster Stilelemente und der haurig falsche Gebrauch von idiomatischen Wendungen, Schablonen der offiziellen Rede und einzelnen wortern, die er aus den verschiedensten Quellen aufgenommen hat und die inm fur seine Zwecke besonders dienlich erscheinen. Deutlichster Ausdruck hierfur ist die Floskel "Mil' pardon, madam", eine in Bron'kas Mund völlig unpassende Wendung, die er irgendwo aufgeschnappt und die inn offensichtlich besonders beeindruckt hat. Ebenso die witzige Wendung "prošcu plesnut", in der der Held das vornehme, seine Achtung gegenuber den stadtern zum Ausdruck bringende "prošcu" (ich bitte) mit dem seiner eigenen Sprache entstammenden slangwort "plesnut" " (wortlich: "verspritzen") kombiniert.

Diese Besonderheit der Sprache Bron'kas zeigt deutlich, wie der Held in seinem Streben nach Selbstdarstellung aus verschiedenen, ihm zugänglichen kulturellen und geistigen Spharen das ergreift und nutzt, was inm richtig und wichtig erscheint und $d a b$ seine Vorstellung vom Leben selbst aus solchen verschiedenen bruchstuckhaften Einflussen zusammengesetzt ist. Sprachlich fuhrt das zu ganz eigenen Konstruktionen, die auf den Leser uberaus belustigend wirken und anschaulich zeigen, wie bei Bron'ka einfache, unkomplizierte Denkstrukturen des bauerlichen Milieus auf andere Bereiche ubertragen werden:

Честное партияное (S. 89) - Bron'ka Ubertragt hier die aus der Kindersprache ubernommene Wendung "честное пионерское" in den "ernsthafteren" Kontext der Erwachsenenwelt.

Где будем отвальную coобрахать? Hа бережку? (S. 88) Ein sehr witziger Efrekt wird hier erreicht durch die Kombination des Slangwortes "отвальная" mit dem Verb "coo6paxaтb" (hier ergibt sich zudem eine Assoziation zu der unubersetzbaren, der niederen Umgangssprache 
angehorenden Wendung "cooбрахать на троих") und im

Zusammenhang damit das folkloristisch-dorfliche

"на берехкy".

Dasselbe gilt fur die Verbindung des sehr offiziellen

"cneu-" mit dem mehr umgangssprachlichen Ausdruck

"выучка" in Bron'kas Wortsch8pfung "cпецвъучка" (S. 91)

Beim Erzăhlen findet bei Bron'ka ein ständiger Wechsel statt zwischen seiner Umgangssprache, die mit "prostorečie", verschiedensten Bereichen entstammenden Slangausdrucken und Vulgärlexik durchsetzt ist, und dem Streben nach offizieller, formlicher Rede, die in der Verwendung von găngigen Forme in und Wendungen zum Ausdruck kommt, wie:

$\begin{array}{ll}\text { дорогие товарими } & (\mathrm{S} .88) \\ \text { искахение история } & (\mathrm{S} .89) \\ \text { покрыто моаком } & (\mathrm{S} .89)\end{array}$

Готов, Говорю, к выолненшо задания! (S.91)

...за намн страдания!.. 3а напн раны За кровь советских лодея!.. За раэрушенные города и села! За слеэь намих жен и матерея!.. (S.92)

Heftige Stilbrüche kennzeichnen dabei ganze Absätze seiner Rede:

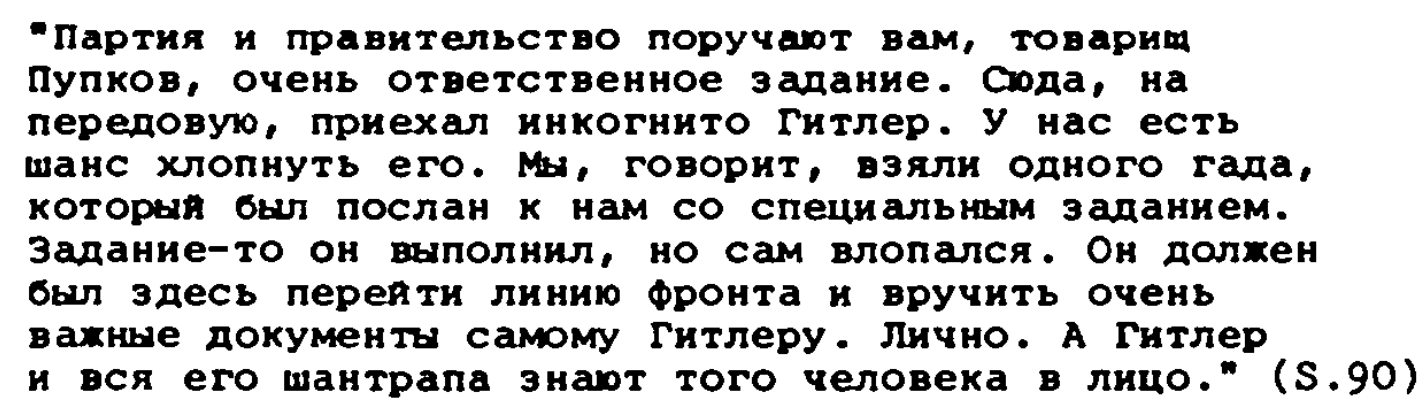

Sie treten innerhalb einzelner satze auf sowie in den fur die Sprache des Helden so typischen Wendungen, wie "prošcu plesnut" .

Auf dieser sprachlichen Besonderheit beruht der Humor der Erzăhlung, die besondere Eindringlichkeit des Charakters und die Sympathie, die dieser hervorruft. 


\subsubsection{Die Idee des Festtags: Das Feiern des eigenen Ich}

Nicht besondere Menschen, sondern das Besondere im Menschen, das oft dem Blick der Umwelt verschlossen bleibt, interessiere Šukšin, stellt der Kritiker Boris Pankin fest :
Dieses Besondere in den Helden Škšins ist in der Regel verbunden mit dem Bestreben, irgendwie aus dem Teufelskreis der alltăglichen Sorgen und Prlich- ten, der gewbhnlichen, banalen Notwendigkeiten aus- zubrechen. Es ist verbunden mit dem Bestreben, der ein fur allemal festgelegten Gang der Dinge etwas entgegenzusetzen, sich zu zeigen, sich und der Um- welt etwas zu beweisen, kurz, sich zu erheben und uber die Gewohnlichkeit und Alltăglichkeit zu triumphieren. 138)

Dieser Ausbruch ist fur die Sonderlinge Sukšins von ratselhaft-zentraler Bedeutung. Ohne ihn gilt ihnen das Leben nichts. Nicht zufaliig wird in "Mil' pardon, madam!" erwăhnt, dab Bron'ka "auf die Jager aus der stadt wie auf einen Festtag wartete" (S. 83). Der Gedanke des Festtags (prazdnik) tritt auch in anderen Erzahlungen auf, und das Verlangen nach inm verspüren alle Sonderlinge Sukšins. "Ein Fest ist notig", wiederholt Egor Prokudin, der aus dem Gefăngnis entlassene Held in der Pilmnovelle "Kalina krasnaja" immer wieder auf seinem scheinbar ziellosen Streifzug zwischen seiner dorflichen Brieffreundin Ljuba und der stadt mit der "malina", dem Gaunermilieu, und ihren Vergnugungsmoglichkeiten, und alle seine Unternehmungen sind Versuche, seiner "kranken Seele" dieses Fest zu organisieren. Eine ausgezeichnete Charakteristik dessen, was der Gedanke des "prazdnik" im Werk Šukšins bedeutet, gibt Galina Belaja:

Die Idee des Festtags ist die Lieblingsidee des Schriftstellers. In seinen Helden und seinem Werk 
erscheint diese Idee fast irrational. Sie ist nicht zerlegbar in Ursachen und Wirkungen und labt sich nicht in eine logische Erklarung fassen. Der Festtag ist das Beste, was in der menschlichen Seele existiert, er ist der Widerhall des Lebens in ihr, der Beweis, daB noch nicht alles Pulver verschossen ist, dab unter einer Schicht von Unrat und Staub die Idee von Gerechtigkeit, Gluck und Freiheit noch lebendig ist. Der Drang nach einem Festtag ist ein Signal der nicht ermatteten, unzerstorten Lebensfreude, der Fahigkeit, sich zu ihr aufzuschwingen, ein Signal fur die Diskrepanz zwischen dem Leben, wie es ist und wie es sein konnte. Sukšin vermochte nie genau zu bestimmen, was das ist, der Festtag. Aber er verlieh diesem Rausch den höchsten Rang, beschrieb dieses Spiel der Kräte und schuf ein Bild von diesem gewaltigen Element. 139)

Es ist die Idee vom Peiern des eigenen Ich, von der freudigen Bewubtwerdung der eigenen menschlichen Substanz und des Selbstwertes, die Śukšin in der suche seiner Sonderlinge nach einem "Festtag der Seele" gestaltet. Bron'ka Pupkov erlebt inn im Erzahlen seiner Geschichte, das ihn aus der beengenden Alltăglichkeit seiner realen Existenz ausbrechen labt und inm erst das Gefuhl, wirklich zu leben, verschaff.

Seinen besonderen Pesttag organisiert sich auch der Held der Erzahlung "Aleša Beskonvojny.j" (1973) ${ }^{140)}$, der seinen Spitznamen "widerspenstiger Aleša" wegen seiner "in der heutigen Zeit seltenen Verantwortungslosigkeit und Widerspenstigkeit" erhielt. Diese besteht darin, daB er an Wochenenden grundsatzlich nicht arbeitet, als ob er "in der Fabrik" und nicht "in der Landwirtschaft" tatig ware. Man hat versucht, Aleša von dieser Gewohnheit abzubringen, hat ihm gedroht, man bedauert seine funf Kinder - alles ohne Erfolg, bis man schlieblich einsah, daB Aleśa "von Geburt an so" ist. An den Werktagen hutet Aleša das Vieh des Kolchoses, fur das Wochenende hat er sich seine eigene Ordnung installiert, und besonders der Samstag, sein Badetag, ist inm heilig:

139) Galina Belaja, Fars ili tragèdija?, in: Literaturnoe obozrenie, 1979, Nr. 3, S. 58-60, S. 59

140) Im folgenden zitiert nach: Sukšin, Rasskazy, a.a.0., S. $335-346$ 
В субботу он топил бано. Все. Больше ничего. Накалял бано, мылся и начинал париться. Парился как ненормальныя, как паровоз, - по пять часов парился! (S.335)

Der Badetag ist für den Helden ein Fest, dem er sich mit ganzer Hingabe widmet. An diesem Tag lebt er nur fur die Seele und uberzeugt sich dabei immer wieder davon, daB das Leben herrlich ist.

Der Leser wird Zeuge und Teilnehmer eines solchen Badetages des Helden, den Suk\$in bis ins Detail schildert: Das Auswăhlen und Hacken des Holzes, das Wasserholen und Anheizen, die Vorbereitung des Rutenbesens, den Vorgang des Waschens und Schwitzens, die Gerulche, die Aleša dabei wahrnimmt, seine Empfindungen, Gedanken und Erinnerungen. Aleša braucht und liebt den Badetag zum Nachdenken uber das Leben und den Tod, inren Sinn, uber die Menschen, die Natur. Und er braucht ihn, um das eigentliche Leben zu spuren, die Empfindung fur das Leben wachzuhalten, zu erneuern und $\mathrm{zu}$ vertiefen:

Последнее время Алеша стал замечать, что он вполне осознанно любит. Любит степь за селом, зарю, летния день... То есть он вполне понимал, что он - любит. Стал случаться покоя в дупе - стал любить. (S.344)

Und noch eine Funktion hat der wochentliche Badetag fur den Helden. Beim Baden und Schwitzen in der "banja", dem russischen Dampfbad, schirmt sich Alesa gegenuber den Widrigkeiten der Welt und des Alltags ab, errichtet sich seine eigene sittliche Welt, "eine richtige Festung, die Stabilitat und Naturlichkeit des Daseins garantiert"141):

Всякое вредное напряжение совсем отпустило Алешу, мелкие мысли покинули голову, вселилась в душу некая цельность, крупность, ясность - жизнь стала понятноя. То есть она была рядом, за окошечком бани, но Алеша стал недосягаем пля нее, для ее суетни и злости, Он стал большоя и снисходительныя. (S.343)

141) ¿̇almaev, a.a.0., S. 134 
Der Samstag im Damproad ist der Pesttag, den Aleśa sich organisiert, um die Schonheit und das Gluck des Lebens zu empfinden. Die Erzăhlung zeigt einen glucklichen Menschen und frappiert den an eine komplizierte Gluckssuche in der modernen Welt gewohnten Leser durch die Einfachheit, mit der der Viehhirte Aleßa sich dieses Gluck verschafft. Er

ist ein Sonderling, wenn man darunter einen Men$s$ chen versteht, der frei von mechanischem Denken und Handeln ist, der sich vom allgemeinen Trott distanziert. Darin liegt ja gerade die Starke, dab der einfache Mensch, durchaus kein Sonderling, die Kunst, die Wissenschaft und schlieblich eine Arbeit braucht, die er liebt, damit er das Gluck zu leben schătzen kann. Aleša Beskonvojnyj braucht dazu fast gar nichts: Er braucht nur das Dampfoad. 142)

DaB es die alte russische "banja" ist, die wie wohl keine andere Realie mit dem traditionellen russischen Dorf und seinem Leben verbunden ist, die fur den Helden eine solche Bedeutung gewinnt, ist naturlich kein Zufall, und nicht umsonst vergleicht sie Alesa mit dem neuen Gemeinschaftsbad im Dorf, das fur ihn "kein Dampfbad, sondern irgend so ein Mibverstăndnis" darstellt. In den Uberlegungen des Helden wird denn auch ständig das Dampfbad und die mit ihm verbundene Ruhe (pokoj) der Hektik (sueta) des Lebens draußen gegenubergestelit. Das Dampfbad erhalt hier eine doppelte Bedeutung, die sich auch in anderen Werken der Dorfprosa findet: Die konkrete Bedeutung, die es fur Alesa hat, dem es das ist, was Kunst, Wissenschaft und schopferische Tatigkeit dem "einfachen Menschen", von dem Kaverin spricht, bedeuten mbgen, nämlich Quelle der Kraft, Lebensfreude und sittlichen Stabilitat. Und eine symbolische, als Sinnbild der geistigen und moralischen Werte des alten Dorfes:

Bei solch modernen Prosaikern, wie V. Belov und v. Sukß̧in, "wăscht" das dorrfliche Dampfoad im direkten Sinne und verschafft, wiederum im direkten

142) Kawerin, a.a.0., S. 1286 
Sinne, dem Menschen ein "freies" Atmen...

In der Darstellung sind alle Details des dorflichen Badevorgangs enthalten: Das Hacken des Holzes, das Anheizen des Ofens usw. Aber in dieser "Genre"Beschreibung verbirgt sich ein tieferer Sinngehalt. Hinter dieser vordergrundigen und scheinbar einzigen Erzăhlschicht steht ein veraligemeinerndes Sinnmotiv: Die Problematik der geistigen und sittlichen Auslotung des Menschen durch Hinwendung zu den Wurzeln des Volkstums. 143)

Auch bei diesem Helden ist das Bedurfnis nach einem Pesttag Ausdruck des Wunsches, den Alltag mit seinen Widrigkeiten und zwangen abzustreifen und sich uber seine Gleichrormigkeit zu erheben. Und auch hier bffnet der Festtag ein Ventil fur das Verborgene, Unterschwellige, das im gewobnlichen Leben des Helden nicht zum Tragen kommt. An seinem Badetag, von der Umwelt nur wahrgenommen als Spleen, offenbart Aleša Eigenschaften und eine Innenwe 1t, die, wie auch der Erzahler und Aleśa selbst feststellen, niemand in ihm vermutet hatte:

Никто бы не поверил, но Алеша серьезно вдумывался в хизнь... (S.339)

Алеша лобил детея, но никто бы никогда так и не подумал, что он любит детея: он не показывал. (S.338)

никому никогда не рассказввал Алеша про тот случая, а он ее тобил, Ато-то. Вот как. (S.341)

Hinter dem unkonventionellen Verhalten des Helden verbirgt sich ein unkonventionelles Denken, eine unkonventionelle Beziehung zum Leben, die uberrascht durch die Einfachheit und Naturlichkeit, mit der es inm gelingt, sich Lebensgenub $z u$ verschaffen. Einfachste Beobachtungen lobsen in ihm grundsătzliche Gedanken aus:

Алеша всегда много думал, глядя на огонь. Например... он сделал открытие: человек, помнрая - в конце в самом, - так вдруг захочет жить, так обнадеется, так возрадуется какому-нибудь лекарству!.. Это знают. Но точно так и палка любая: догорая, так вдруг вспьхнет, так озарится вся, такую выкинет шапку огня, что диву даешься: откуда такая последняя сила? (S.337f.) 
Diese "Verwandlung" des Helden manifestiert sich in der Erzăhlung auch auf der Ebene des stils, indem Śuksin das direkte und das "innere" Wort des Helden kontrastiv gegenuberstellt und auf diese Weise gleichsam zwei Alesas dem Leser vorfunrt.

Šukšin unterscheidet zwei Formen des "Heldenwortes" und fuhrt sie auf zwei verschiedenen Ebenen in den Text ein. Das charakteristische Wort des Helden, das alle von ihm kennen, wird in die Erzahlerrede eingefuhrt. Das nicht gesprochene, "innere" Wort des Helden tritt dagegen selbständig auf... 144)

Vom Erzahler eingefuhrt, ist ein Alesa zu vernehmen, der sich von dem im Dampfoad deutlich unterscheidet:

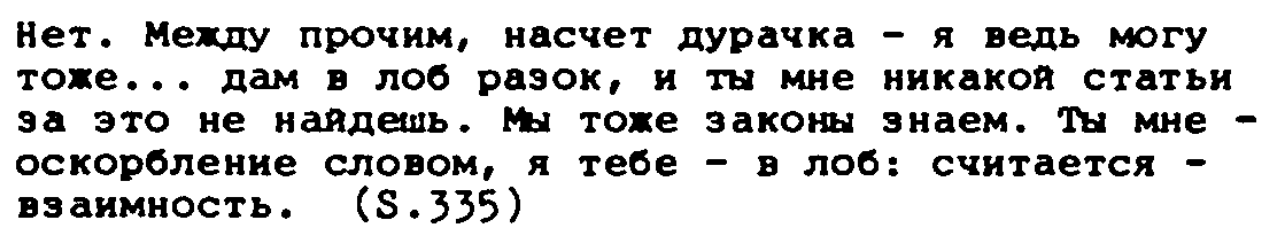

Die Innenwelt des Helden wird in dieser Erzahlung nicht im Dialog, in der unmittelbaren Konfrontation mit einem Gegenuber aufgedeckt, sondern in der "erlebten Rede" Alešas, die wahrend der Beschreibung des Badetages ganz in den Vordergrund ruckt und durch die sich das vorab gegebene $B i l d$ des Helden zunehmend verăndert. Der Anfang der Erzăhlung führt unmittelbar in die Situation Alesas im Dorf ein. In der stimme des Erzahlers

ist eine Spur Mitgefuhl, sogar moralischer tberlegenheit gegenuber dem Helden zu erkennen. Doch zunehmend erhalt der Erzăhlbericht eine folkloristische und zärtiche Note. Wenn der Erzăhler schlieblich dazu ubergeht, ... einen "Badesamstag" Alešas zu beschreiben, "stimmt" sich die Erzahlerrede auf die Stimme Alešas ein, verschmilzt mit inr und vollzieht der Erzahler einen Wechsel von der eigeren Perspektive zur Perspektive Alešas. 145)

In dem Wechsel der "Stimmen" in der Erzahlung ist ein polemisches Moment enthalten. Die Innenwelt des Helden tritt in Kontrast zu den Denkstrukturen seiner Umwelt, 
zu deren Lebenseinstellung und inrer Meinung uber inn. Der Anfang der Erzăhlung enthălt die "Stimmen" der Dorfbewohner, eingeführt durch den vom Erzăhler wiedergegebenen Dialog bzw. durch die Annăherung des Erzăhlers an die Perspektive und Wertmasstăbe des Dorfes:

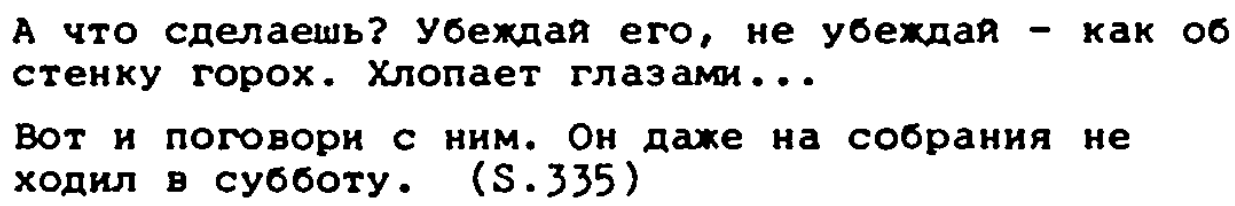

Die Dorfbewohner sind gegen Aleša eingestellt, schimpfen mit ihm, schutteln uber ihn den Kopf, bemitleiden ihn. Dieser durch die Autorităt des Erzăhlers zunăchst gestutzten "allgemeinen Wahrheit" wird im folgenden die "Wahrheit" Alešas gegenubergestellt, und ohne daß der Erzăhler kommentierend eingreift, entspannt sich in der Erzăhlung ein dialogischer Streit zwischen dem kollektiven Standpunkt der Dorfbewohner und dem Standpunkt des Helden. Das Wort des "einfachen Menschen", das Šukšin mit soviel Nachdruck in die Literatur einfuhrt, erscheint gerade in dieser Erzăhlung als selbstăndiger Blick auf die Welt, der die allgemeine Sicht der Dinge - die Meinung der Dorfbewohner und im weiteren Sinne die allgemeine Auffassung vom "kleinen Mann" - relativiert.

Die Idee vom Feiern des eigenen Ich enthălt bei Šukšin ein spezifisch russisches Moment, das in den traditioneilen und in Folklore, Literatur und Kunst immer wieder zum Ausdruck gekommenen Vorstellungen vom russischen Nationalcharakter wurzelt. Ivan Bunin schreibt in "Žizn" Arsen'eva" (Das Leben Arsenevs) uber diesen, auch an die Sonderlinge Šukšins erinnernden Zug:

Ach, dieses ewige russische Verlangen nach der Feiertäglichkeit! Wie gefuhlsbestimmt wir doch sind, wie sehr wir nach dem GenuB des Lebens dursten - und nicht nur nach seinem Genuß, sondern geradezu nach einem Taumel; wie sehr uns doch der stăndige Rausch, ja die Trunkenheit lockt, wie 
langweilig uns der Alltag und die planmäBige Arbeit dunken! 146)

Und D.S. Lichačev untersucht in seinem Aufsatz "Zametki - russkom" (Bemerkungen uber das Russische) anhand des Inhalts der russischen Begriffe "volja", "udal"", "podvig", für die es in anderen Sprachen nur unzulängliche Entsprechungen gibt, diese Besonderheit in Weltempfinden und Lebensgefuhl der Russen:

\begin{abstract}
"Volja" (Freiheit, Unabhăngigkeit) - das ist das Fehlen der Sorge um den morgigen Tag, die sorglose Unbekümmertheit, das freudige, gănzliche Aufgehen im Heute.

..."Volja" - das ist der weite Raum, durch den man immerzu gehen kann, in dem man auf măchtigen stromen grobe Entfernungen durchmessen und freie Luft atmen kann..., der die Moglichkeit bietet, sich in verschiedene Richtungen $z u$ bewegen, wie es einem gerade gefällt. 147)
\end{abstract}

Und als Gegenpol $z u$ dieser von einem besonderen Freiheitsgefuhl durchdrungenen Beziehung zur Welt setzt Lichacev den ebenso russischen Begriff der "toska" (Sehnsucht, Schwermut), der verbunden sei mit der Empfindung der Enge, der Beschränktheit des Raumes und der Bewegungsfreiheit.

Der Bezug zu diesem nationalen Moment des Volkscharakters ist in Sukšins Prosa evident ${ }^{148)}$, und er hilft, das Wesen der Helden und ihres unklaren Strebens, den "UberschuB an Kraft, Gefuhl und Wollen"149), der dabei freigesetzt

146) Iwan Bunin, Das Leben Arsenjews, Berlin und Weimar 1979, S. 109; vgl. auch Korobov, a.a.0., S. 168

147) Lichacev, a.a.0., S. $12 \mathrm{f}$.

148) Zum Problem des Nationalcharakters bei Šukšin vgl. auch E. Gromov, Poetika dobroty, in: Moskva, 1978, $\mathrm{Nr} .12, \mathrm{~S} .204-208$

149) Ju.I. Seleznev, Većnoe dvizenie. Iskanija prozy 60-ch - naćala 70-ch 8g., Moskva 1976, S. 151. Interessant ist in diesem Zusammenhang auch eine AuBerung V. Rasputins uber Suksin, den er einen "russischen Volksschriftsteller" nennt: "Die Volkstümlichkeit Sukšins besteht darin, daB er den heutigen Zustand des russischen nationalen Charakters nicht nur mit seinen $Z$ weifein und seiner Uberspannung, sondern auch mit seiner Fahigkeit gezeigt hat, sich aufzurichten und seine besten Eigenschaften zu

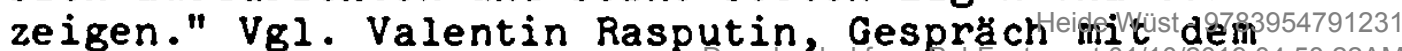
Autor, in: Sowjetunion heute, 1983, Nr.4, S. 37 3 free access 
wird, besser $2 u$ verstehen. Im Verlangen der Helden nach einem "Festtag der Seele" bricht sich dieses Lebensgefühl Bahn, und in ihren ganz verschiedenen Versuchen es zu realisieren, gestaltet Sukšin, aktualisiert an den komplexen Erscheinungen der Epoche mit ihrer Tendenz zu Rationalisierung und Standardisierung, ihrer Hektik und ihren Entfremdungserscheinungen, ein Grundproblem des Menschen: Das Nichtzusammenfallen innerer menschlicher Bedürfnisse mit der Realitat des ăuBeren Lebens und den hieraus resultierenden Verlust des inneren Gleichgewichts, das Fehlen der Harmonie zwischen Mensch und Welt und das individuelle Streben nach Herbeifuhrung dieser Harmonie.

\subsubsection{Die Sonderlinge und inre "Antiwelt"}

Das Streben der Helden nach einem "prazdnik" tritt in den Erzăhlungen in vielfăltigen Gegensatz zu der "normalen", "richtigen" Lebenshaltung der Umwelt, der ein solches streben fremd ist. Dabei erhalt nicht nur der Konflikt

zwischen Menschen mit einem hohen MaB an Erwartungen, Bestrebungen und Hoffnungen, mit ewig "unabgeschlossenem" Schicksal, die nach einem komplizierten Gluck suchen, und Menschen mit einem begrenzten MaB an Bestrebungen und Gefuhlen 150)

einen besonderen künstlerischen Ausdruck, sondern auch die Auseinandersetzung, die Šukšin mit dem Abgeklărten und Konventionellen, dem Standard und dem Klischee vor allem in Denken und Geisteshaltung des modernen Menschen fürt, erreicht eine besondere Schärfe. Das von den allgemein anerkannten Normen und Konventionen abweichende Verhalten der Helden erweist sich aus der dem Leser dargebotenen Perspektive als besondere, hăfig inhaltsreiche Beziehung des Helden zur Welt, die diesen vorteilhaft von seiner Umgebung abhebt. 


\subsubsection{Absonderlichkeit kontra Konvention}

Vasilij Knjazev, der Held der Erzăhlung "Čudik" (von "cudak" - Sonderling, 1967)151), wie er von seiner Frau zärtich genannt wird, zeigt Eigenschaften, die ihn in seinem Leben und Verkehr mit den Menschen ständig anecken oder zu einer komischen Figur werden lassen. Aus der Perspektive des Lesers erhalt die Komik seiner Gestalt jedoch eine etwas andere Bedeutung und erweist sich gerade das "normale" Verhalten der Umwelt als seltsam, kalt, starr und unmenschlich.

Die Erzăhlung baut wiederum auf auf dem Gegensatz $z w i s c h e n$ dem sogenannten gesunden Menschenverstand und jener Kindlichkeit der Wahrnehmung, die naturlichen Menschen eigen ist... 152)

Die ganze Reise des Helden zu seinem Bruder, die in der Erzahlung geschildert wird, sein stăndiges Anecken an den Gepflogenheiten und Verkehrsformen der Umwelt, gestaltet den Kontrast zwischen der Spontaneitat und Naturlichkeit seines Wesens, seiner Aufrichtigkeit und Arglosigkeit und dem Abgeklarten, Standardisierten und Berechnenden.

"Ćudik" liebt die Geselligkeit, das Gesprăch mit Menschen, das er jederzeit anzuknupfen bereit ist. Er hat das Bedurfnis, seine Gedanken mitzuteilen. Aber alle seine Versuche in dieser Hinsicht scheitern an dem durchaus im Rahmen der Konvention verbleibenden Verhalten seiner Umgebung. Sowohl der "intelligente Genosse" im Zug als auch der "Leser" im Flugzeug reagieren auf seine seltsamen Pragen mit Befremden. "Cudik" mochte witzig und originell sein, Frohlichkeit verbreiten und seinem Gefuhl Ausdruck verleihen, aber auch damit scheitert er an den vorgegebenen Normen der Realitat. Das unkonventionelle Telegramm, das er seiner Prau schicken will, stชBt bei dem Frăulein vom Amt auf kühles Unverstăndnis,

151) Im folgenden zitiert nach: Sukšin, Rasskazy, a.a.0., S. $79-86$

152) Șepeleva, Rasskazy Suksina, a.a.0., S. 129 
und als er den Kinderwagen seines Neffen bemalt, zieht er den Zorn der Schwägerin auf sich, die - wie "Ćudik" es sieht - keinen Sinn fur das "Volksschaffen" hat.

Bei aller Komik, mit der das Verhalten des Helden behaftet ist, unterscheidet inn dieses vorteilhaft von seiner Umgebung. Das betrifft auch sein Denken. "Cudik" ist neugierig, empfänglich für Eindrucke, er nimmt alles um sich herum intensiv wahr und stellt eigenständige Gedanken daruber an:

Стал смотреть вниз. Горы облаков внизу. Чудик почемуто не мог определенно сказать: красиво это или нет? А кругом говорили, что "ах, какая красота!". Он только опутил вдруг глупеяшее желание: упасть в них, в облака, как в вату. Еце он подумал: "Почему же я не удивляюсь?... (S. 81f.)

DaB all dies im Kindlich-Naiven verbleibt entspricht dem geistigen Horizont "Cudiks", doch das Wesen des Helden, das sich dabei offenbart, seine naturlich-spontane Beziehung zur Welt stehen in positivem Gegensatz zur kuhlen Nuchternheit der sich "normal" verhaltenden Umwelt.

Es gibt viele solcher "Čudiks" bei Šukšin... Inre "Holprigkeit" beruht nicht auf charakterlichen Mängeln, sondern auf dem deutlichen Kontrast, in dem sie zu anderen Menschen stehen, die sich in den Grenzen einer eng gefabten Alltagsmoral bewegen. Die Zwischenfalle, die sich mit den "Cudiks" ereignen, sind fast anekdotisch, und humoristisches Material gibt es hier reichlich. Aber es ist ein Humor, der den Helden meistens nicht herabsetzt, sondern inn positiv heraushebt, denn sehr viel kläglicher und manchmal geradezu verwerflich erscheinen die, mit denen das Schicksal den Helden konfrontiert. 153)

Die Gestalt "Cudiks" erinnert an eine Xußerung Šukšins zum Problem des positiven Helden in der Literatur des sozialistischen Realismus:

Wie soll der moderne positive Held sein? Man weiB, dab er rechtschaffen sein soll, klug, dab er ein

153) I. Éventov, Nakazanie smechom. O sovremennom jumore, in: Zvezda, 1977, Nr. 1, S. 198-207, S. 200 
guter Mensch und prinzipienfest sein soll usw. Man weib noch mehr: Der positive Held kann auch gewisse negative Seiten, Schwăchen haben. Uberhaupt wissen alle, wie der positive Held sein soll. Und hier liegt meiner Ansicht nach der Fehler: Es ist nicht notig zu wissen, wie der positive Held sein soll, man muB wissen, wie er im Leben ist. 154)

Und weiter fügt der Autor hinzu:

Mir scheint, der Sinn der sozialistischen Kunst besteht nicht darin, das man sich bemunt, ideale positive Helden zu schaffen..., sondern darin, das Positive - das heibt gute, menschliche Eigenschaften herauszufinden und aufzudecken und dies als das Schone im Menschen zu zeigen. 155)

\subsubsection{Absonderlichkeit als Abwehrhaltung}

Der ZusammenstoB der Sonderlinge mit Vertretern aus inrer "Antiwelt" ist für die Helden quallend und dramatisch. Was in "Čudik" noch in humoristischer Weise dargeboten wird, støBt in anderen Erzăhlungen in tiefere Dimensionen vor und wird - hinter dem nie fehlenden Humor der Darbietung und der Komik der Helden - als sittliche Position des Autors erkennbar.

Sehr interessant ist in diesem Zusammenhang die fruhe Erzăhlung "Kritiki" (Kritiker, 1964)156), in der sich ein erster Ubergang Suksins zur Gestaltung komplizierterer sozialer Typen manifestierte. Der erste Teil der Erzăhlung erinnert noch stark an die beschaulichen Gestalten des fruhen Sukšin: Großvater und Enkel - beide leidenschaftliche Kinobesucher - erortern den gesehenen Film. Das Streitgesprăch der beiden dient, wie in den Erzăhlungen "Derevenskie ziteli" und "Kosmos, nervnaja sistema i smat sala", vor allem der Aufdeckung der geistigen

154) Vasilij Sukšin, Voprosy samomu sebe, in: ders., Nravstvennost', a.a.0., S. 23-39, S. 36f.

155) Ebenda, S. $37 \mathrm{f}$ :

156) Im folgenden zitiert nach: Suksin, Rasskazy, a.a.o., S. $10-16$ 
Welt der beiden Helden. Es zeigt zwei Bewubtseinstypen, wie sie aus den genannten Erzăhlungen bereits bekannt sind. Der geistige Horizont des Alten mit seiner konkretanschaulichen, der praktischen Lebenserfahrung eng verhafteten Denkweise spiegelt sich in seiner Kritik an dem gesehenen Film wider. Alles im Film Gesehene wird von inm gleichsam als unmittelbare Realitat aufgenommen und aus dem ganz konkreten Lebens- und Erfahrungsbereich heraus beurteilt:

- Хреновина, ...Так не бывает.

- Да его бы давно на смех подняли, такого! Ему бы проходу не было. Он пюбнт... Когда пюбют, то стыдятся. А этот треэвонит ходит по всея деревне... Какая же дура поядет за него! Он же несурьезныя парень. вын, помню: поглянется девка, так ты ее за две улищы обходншь - потому что совестно. Любнт... Ну и люби на эдоровье, но эачем же... (S. 11)

Seine Leidenschaft furs Kino und fur Diskussionen uber Filme ("ob iskusstve") unterscheidet den Helden allerdings von den dorflichen Alten aus Sukšins anderen fruhen Erzahlungen. Bezeichnend ist, dab sich Grobvater und Enkel in dieser Leidenschaft zusammenfinden und sich darin in der Erzählung gerade von der Welt der "Erwachsenen", "Reifen" positiv unterscheiden.

Со вэрослыми дед редко спорил об нскусстве - не умел. начинал сраэу нервничать, обэнвался. (S. 13)

Von den "Erwachsenen", den Eltern Pet'kas, wird die Leidenschaft der beiden nachsichtig belachelt:

\footnotetext{
- Они у нас критики с Петькоя... (S. 12)

- Тебе ведь трудно угоднть, тять, - сказал Петькин отец. - иди луше к Петьке, помоги ему. - Склонился к городскому человеку и негромко пояснил: - Помогает моему сыну уроки учить, а сам ни в зуб ногоя. Спорят друг с другом. Умора! (S. 13)
}

Die kleine Erzählung gestaltet einen ZusammenstoB des Alten mit den "Erwachsenen" in Fragen der Kunst, der mit einem exzentrischen Auftritt des Grobvaters vor dem 
Fernsehapparat und seiner schlieblichen Festnahme durch den Dorfmilizionăr endet. Die Reaktion der "Erwachsenen", vor allem des Besuchs aus der Stadt, auf seine Kritik an dem Film uber das Dorf, der im Fernsehen gezeigt wird und in dem der Zimmermann "noch nicht einmal das Bejl richtig halten kann", erbost den Alten so sehr, daB er sich betrinkt und schlieblich mit dem stiefel den Fernsehapparat zertrummert .

Die Kritik des Alten an dem dorflichen Zimmermann im Film erfolgt nicht ohne Sachkenntnis. Schlieblich hat er sein Leben lang selbst als Zimmermann gearbeitet und im Dorf gelebt. Im Dialog mit dem Alten wirken denn auch die wohlgesetzten Worte der Găste aus der Stadt fade und inhalts leer:

- Любопытно,.... А почему вы решили, что он топор неправильно дерхит?

- Да потому, что я сам всю хизнь плотничал. "Почему решили?"

- дедушка, - встряла в разговор Петькина тетя,

- а разве в этом дело?

- В чем?

- А мне вот гораздо интереснее сам человек. Понимaете? Я знах, что это не настоямия плотник, - это актер, но мне инте... мне гораздо интереснее... (S.13)

Die Erzahlung erschien erstmals in der Zeitschrift "Iskusstvo kino" (Filmkunst), und es ging Sukšin mit ihr sicher auch, wie Korobov meint, um eine Kritik an den Mode gewordenen zeitgenossischen Rilmen uber das Dorf, die "schön und ergreifend" hochstens für einige stadter waren sowie um eine Kritik an "Primitivitát, Banalitat und Kitsch" in der Kunst ${ }^{157)}$. Von groberer Bedeutung ist in "Kritiki" jedoch die Konfrontation des Helden mit einer Geisteshaltung, die in Sukšins Erzăhlungen als "Antiwelt" der Sonderlinge und des Autors deutlich wird ${ }^{158)}$. Der Alte wird besonders von den stadtern nach einem kompletten schema beurteilt und in ein fertiges

157) Korobov, a.a.0., S. 107

158) Vgl. hierzu den Aufsatz von Galina Belaja, Antimiry Vasilija Šukśina, a.a.o. 
Bild eingeordnet, in dem für die Individualităt seiner Personlichkeit kein Platz ist. Die "Erwachsenen" machen sich gar nicht die Muhe, inn verstehen $z u$ wollen und von inm vielleicht etwas Neues, nicht in ihr vorgefertigtes Bild Passendes zu erfahren. "Interessant" ist das Gesprăch mit dem Alten fur sie nur deshalb, weil es Gelegenheit bietet, Uberlegenheit $z u$ demonstrieren und sich uber den seltsamen dörflichen Kauz $z u$ amusieren. Im Dialog wird diese Haltung, die in Kontrast steht zu dem echten inneren Engagement des Alten, deutlich und noch verstärkt durch den Erzăhler, der teilweise die Position des Großvaters bzw. Pet'jas einzunehmen scheint: ...А как бывает? - громко повторил городскоя муж-
чнна, заранее почему-то улыбаясь. (
Он.12)
ен мыли очень умные и все знали - Петькина тетя и
мни улыбались, когда разговаривали с дедом.

(S.13)

Der Alte spurt diese Haltung, vor allem die fremde Vorstellung von seiner Person, gegen die er machtlos ist. Sie versetzt ihn in Rage, und da er keine "normale" Moglichkeit sieht, gegen sie angehen zu konnen, inszeniert er schlieblich seinen jahzornigen Auftritt vor dem Fernsehapparat. In der Szene, die sich dabei abspielt, fehlt den "Erwachsenen" - ganz im Unterschied zu Pet'ja - jegliches Verständnis fur das exzentrische Verhalten des Alten, und sie erweisen sich als unfahig, die situation $z u$ erfassen.

Die Haltung, einen Menschen mit Hilfe vorgefertigter Urteile $z u$ bewerten, sein Innenleben auf ein fertiges, allseits bekanntes Schema $z$ u reduzieren, wird in "Kritiki" als geistige "Antiwelt" des Sonderlings deutlich und das absonderliche Verhalten des Helden als Form der Gegenwehr gegen diese fremde Vorstellung von der eigenen Person, als einzig moglich erscheinender Ausweg, sich ihr gegenuber $z u$ behaupten.

Mit dem Protokoll des Dorfmilizionärs uber den Vorfall wird diese fremde Beurteilung auf die Spitze und durch den komisch-orfiziellen Stil, in dem es abgehalten ist, ad absurdum gefuhrt: 


\begin{abstract}
... Выпеуказанныя Тимофея двадцать пятого сентября сего года заявился домоя в состоянии крепкого алкоголя. В это время семья смотрела телевизор. И гости еме были...

Тимофея тоже стал смотреть телевизор. Потом он сказал: "Таких плотников не бывает". Все попросили Тимофея оправиться. Но он продолжал возбужденное состояние. Опять сказал, что таких плотников не бывает, вранье, дескать. "Руки, Говорит, у плотников совсем не такие". И стал совать свои руки. Его еще раз попросили оправиться. Тогда Тимофей снял с ноги правыя сапог /размер 43-45, яловыя/ и произвел удар по телевизору. Само собоя, выниб все на свете, то есть там, где обычно бывает видно. (S. 15f.)
\end{abstract}

Der von dem Milizionăr nicht beherschte, aber um so mehr durchgängig angestrebte offizielle Stil wirkt wie eine Parodie auf die Inhaltslosigkeit und Verlogenheit offizieller Schablonen und abgegriffener Phrasen und deckt die Entfremdung dieses Sprachgebrauchs und der mit inm verbundenen Denkform von der Realităt auf, $z$ deren adăquaten Erfassung sie unbrauchbar und unfăhig sind.

Ein ZusammenstoB zweier "Antiwelten" findet auch in der Erzăhlung "Daeš' serdce!" (1970) ${ }^{159)}$ statt. Ein ungewornlicher Vorfall trug sich in dem Dorf Nikolaevka zu. Mitten in der Nacht ertunten dort zwei Schusse und der Schrei eines Menschen: "Daeš' serdce!". Es stellt sich heraus, dab der unauffallige, trăge, bisher von keinem besonders beachtete Veterinarfeldscher Kozulin geschossen hat. Alle sind ăuberst erstaunt uber diese unerklărliche Tat, besonders der Dorfmilizionăr und der Vorsitzende des Dorfsowjets, vor die Kozulin zur Aufklärung des Falls geladen wird. Es erweist sich schlieb-

159) Der Titel der Erzăhlung ist ins Deutsche nicht zu Ubertragen. Der Ausruf "Daes' serdce!" (wortlich: Du gibst das Herz) ist analog gebildet zu umgangssprachlichen Wendungen vom Typ "Daes' plan!", "Daes' pjatiletku!" (Aufruf zur erfolgreichen Planerfullung). Er bringt die Begeisterung des Helden uber die erste gelungene Herztransplantation zum Ausdruck und ist zugleich ein Appell zu weiteren Leistungen auf diesem Gebiet.

Im folgenden zitiert nach: Sukšin, Rasskazy. Kniga dlja ćtenija, a.a.0., S. 97-101 
lich, daB Kozulin Salut geschossen hat aus Freude uber einen Sieg der Wissenschaft: Die erstmalige Transplantation eines menschlichen Herzens im fernen Afrika.

Das Ereignis versetzte den Helden in einen Zustand freudiger Erregung, der ihn dazu drăngte, seinen Gefuhlen auf solch spontane Weise Luft zu machen. Fur seine beiden Gesprächspartner ist dieser Seelenzustand Kozulins unbegreiflich:

- Я не вижу прямоя связи между этим... патологическим случаем и двумя выстрелами в ночное время, строго заметил председатель.

- Я обрадовался... Я был ошеломлен, когда усльлал, мне попалось на глаза ружье, я выбежал во двор и выстрелил..

- В ночное время.

- A что тут такого?

- Что? Наружение общественного порядка трудящихся. (S. 99)

Der Dialog zwischen Kozulin und dem Vorsitzenden des Dorfsowjets deckt zwei gegensatzliche geistige Welten auf, die im unterschiedlichen Sprachgebrauch der Helden zum Ausdruck kommen. Das formalisierte Denken des Bürokraten wird in den Worthulsen und Phrasen des Vorsitzenden deutlich, die in diametralem Gegensatz stehen zu der naturlichen, vom spontanen Gefuhl gelenkten Ausdrucksweise Kozulins 160).

Nachdem Kozulin sich davon uberzeugt hat, daß von Seiten seiner Gesprachspartner kein Verständnis zu erwarten ist, vollzieht sich mit inm eine Verwandlung:

- Простите, не подумал в тот момент... Я - шизя.

- Кто? - не понял милиционер.

- Шизя. На меня, знаете, находит... Теряю самоконтроль. - Фельдшер как бы в раздумье потрогал лоб, потом глаза - пальцамн. - ширво коло ширво... Зубноя порошок и прочее. (S. 99)

Der Held stulpt sich die Maske des Schizophrenen uber und entschuldigt seine Tat mit dem zeitweiligen Verlust der Selbstkontrolle.

160) $V_{g l}$. auch Belaja, Roždenie novych stilevych form, a.a.o., S. 480 f. 
Galina Belaja hat auf das Moment der "Verwandlung" bej Škšins Sonderlingen hingewiesen, das auch für die struktur vieler seiner Erzăhlungen bestimmend ist.

Das gemeinsame Merkmal in ihrem Verhalten besteht lediglich in den "Verwandlungen", in dem Ablegen der gewohnten Hullen, in den abrupten Ubergängen, die die Diskrepanz zwischen dem Leben, wie es ist und dem Leben, wie es möglich wäre, deutlich werden lassen. 161)

In der Fimnovelle "Kalina krasnaja" (Roter Schneeballstrauch, 1973) 162) gibt es eine Episode, in der der Held, Egor Prokudin, einen geradezu frappierenden Rollenwechsel inszeniert. Bei seinem ersten Besuch im Hause seiner Briefbekanntschaft Ljuba Bajkalova ist der Held gezwungen, ein Gesprăch mit den alten Bajkalovs zu fuhren, die ihn mibtrauisch und voller Vorurteile nach seiner Vergangenheit ausfragen. Prokudin, der zunăchst versucht, sich als Buchhalter auszugeben, läBt plotzlich, sobald er merkt, dab die beiden Alten den wahren Grund seines Aufenthalts im Gefängnis erraten, diese Rolle fallen und gent zum Angriff uber:

- Дак какое, говоришь, недораэумение-то вьшло? Метил кому-нибудь по лбу, а угодил в лоб? - как бы между делом спросил дед.

Егор посмотрел на смекалистого старика.

- да... - неопределенно сказал он. - Семерых в одном месте зарезали, а восьмого не углядели ушел. Вот и попались... (S. 414)

Der ganze Dialog zwischen Egor und den alten Bajkalovs stellt ein mit schauspielerischem konnen inszeniertes Possenspiel dar, in dessen Verlauf der Held in verschiedene Rollen schlüpt. Von der Rolle des Buchhalters geht Egor zu der des Kriminellen uber, darauf zu der des politischen Kommissars, des Untersuchungsrichters und schlieblich zu der Rolle des Politruks:

161) Belaja, Antimiry, a.a.0., S. 275; vgl. auch dies., Rożdenie novych stilevych form, a.a.0., S. 482

162) Im folgenden zitiert nach: Vasilij Sukśin, Do tret'ich petuchov, a.a.0., S. 393-467 
Ну, поставим вопрос несколько иначе, по-домашнему, что ли: на собраниях часто выступал?...

- Видите, как мы славно пристронлись жнть!...

- Страна производит электричество, паравозы, миллионы тонн чугуна... Люди напрягают все силы. Люди буквально падают от напряжения, ликвидируют все остатки разгильдяяства и слабоумяя, люди, мохно сказать, заккаются от напряхения,.... люди покрываются моршинами на Краянем Севере и вынухдены вставлять себе золотые зубы... А в это самое время находятся другие лица, которье из всех достижения человечества облюбовали себе печку! (S. 415f.)

Der Rollenwechsel, der hier vorgefuhrt wird, manifestiert sich ganz auf der sprachlichen Ebene und zeigt die Beherrschung des "fremden Wortes" durch den Autor, die Beherrschung sozial determinierter Sprachstile von hoher charakterologischer und assoziativer Wirkung.

Die einzelnen Verwandlungen des Helden sind Masken aus wortern, die er nacheinander aufsetzt. Masken, die mit Hilfe bestimmter "Wortblocke" gebildet sind, wie sie jeweils charakteristisch sind fur das soziale Denken, das - in der Vorstellung der beiden Alten und Egor Prokudins - den Buchhalter, den Dieb, den Sonderbevollmächtigten und den politischen Kommissar auszeichnet. 163)

Doch der Auftritt Egor Prokudins, sein Spiel mit Sprachklischees, sind für den Helden nicht Selbstzweck, sondern resultieren aus der besonderen psychischen situation, in der er sich befindet: Einem Zustand innerer Anspannung, der vor allem durch die Furcht gekennzeichnet ist, aurgrund seiner kriminellen Vergangenheit in ein bestimmtes Bild gepresst $z$ werden, das inm keine Chance mehr gibt, als der erkannt zu werden, der er wirklich ist.

Die Posse Egor Prokudins enthalt eine offene Polemik. Sie ist gegen den Versuch gerichtet, das Innenleben eines Menschen schnell und mit Hilfe standardisierter Vorstellungen zu entschlusseln, genauer, das Geheimnis dieses Innenlebens zu banalisieren, es zu reduzieren auf Bekanntes und Gewohntes, was keine Anstrengung des Verstandes und keine Storung des inneren Gleichgewichts erfordert. 164)

163) Belaja, Roždenie novych stilevych form, a.a.0., S.482 164) Ebenda 
Auch hier ist das Rollenspiel des Helden eine Form der Abwehr fremder Vorstellungen von sich und fremder Denkhaltungen, die als Angriff auf das eigene Gefuhlsleben und die Individualitat begriffen werden. Vom Standpunkt des "zdravyj smysl", des in konventionellen Bahnen und Normen verlaufenden Denkens, erscheint das Verhalten Prokudins wie auch des Veterinarfeldschers Kozulin exzentrisch und kurios und sogar moralisch fragwurdig. Durch die Art der Darstellung, die den Blick auf die Vorgänge im Innern des Helden frei macht, wird jedoch gerade dieser "zdravyj smysl" als formalisiertes, vom eigentlichen Menschen losgelostes Denken und damit als die eigentlich pervertierte Form des Denkens entlarvt. So werden durch Prokudins Posse gleichzeitig zwei Schichten der Realitat, die Existenz zweier "Wirklichkeiten" aufgedeckt: Eine außere, durch Normen und Konventionen verbindlich geordnete, den Menschen rollenmäBig und funktionell determinierende Welt und die innere, in ihren Bedurfnissen und inrer Einzigartigkeit durch jene eingeeng,te Welt des Menschen, wobei die erste durch die Aufdeckung der letzteren relativiert und in ihrer verbindlichkeit und Gultigkeit in Prage gestellt wird.

Die besondere Form der Weltdarbietung in den Erzăhlungen Uber die Sonderlinge, die wesentlich auf der "Verseltsamung" des Materials, der Exzentrizitat des Helden und der Sujetsituation berunt, ermoglicht es Šukšin, Momente in den Charakteren und im Bereich der seelischen Befindlichkeiten aufzuzeigen, die im gewohnlichen Leben verborgen bleiben. Sie beinhaltet zugleich eine besondere kunstlerische sicht der Welt, die fur das Verstănanis dieser Prosa von wesentlicher Bedeutung ist und eine gesonderte Betrachtung verdient.

\subsection{Der Aspekt des "Karnevalistischen" in Śkśins Prosa}

Galina Belaja hat auf den Bezug dieser Prosa zu den - von Michail Bachtin erforschten - Traditionen der mittelalterlichen Lachkultur und ihrer spezifischen Ausprăgung in 
der russischen Polklore aufmerksam gemacht. Am Beispiel der Posse Egor Prokudins vor den alten Bajkalovs stellt sie fest:

Dieses Spiel Šukšins mit Wortklischees ahnelt der Kombdiantenposse, ihrer "tănzelnden" Stilistik, wie auch die Fragen des Alten und die Repliken seiner Prau an die Rolle erinnern, die dem Spasvogel zukommt: Man liefert inm "zundstoff", und er wird, wie D.S. Lichacev feststellte, "gleichsam zum Akteir in einem Theater, in dem auch die Zuschauer mitspielen." 165)

Die Sonderlinge Śukšins erinnern an den Typ des "durak" (Dummkopf), jene - der Pigur des Hanswursts bzw. des Kaspers der deutschen Buhne vergleichbare - Gestalt aus der Schaubudenvorstellung der Jahrmarkte, dem russischen Märchen und dem "rajok", den billigen Răngen der Theate:, und es ist sicher kein Zufall, dab ir. Šukšins letztem Werk, dem satirischen Marchen "Do tret'ich petuchov" (Bis zum dritten Hahnenschrei), als Hauptheld "Ivanuškaduračok", der meist nur vermeintlich dumne und wunderliche Volksheld des russischen Marchens auftritt.

Was hat es mit dem "Sonderling" im russischen Mărchen auf sich? In der Regel handelt es sich doch bei dieser Gestalt um eine unterschwellige Polemik mit dem engstirnigen, nur auf den eigenen Vorteil bedachten Denken, mit der auf Gewohnheit beruhenden Trăgheit, die dazu verleitet, lieber die beiden normalen Prerde $2 u$ wahlen als das habliche, bucklige Pferdchen. Der "Sonderling" verkorpert das Vertrauen in den Zufall, den Glauben an das Gelingen der Sache und an das aufrichtige Gefuhl des Herzens . 166)

Šuksin selbst hat diesem Typus die Bedeutung eines "Helden unserer Zeit" beigemessen:

Es gibt in RuBland noch einen Menschentyp, in dem sich die Zeit, die Wahrheit der Zeit ebenso sturmisch kundtut wie im Genie, ebenso ungeduldig wie im talentierten Menschen und ebenso unauffaliig

165) Belaja, Antimiry, a.a.0., S. 274

166) Ċalmaev, a.a.0., s. 140 
und unausloschlich wie im Denker... Dieser Mensch ist der "Dummkopf". Das weib man nicht erst seit heute (die Narren in Christo, die religiosen Dulder und Gotteswanderer - wie zahlreich waren sie doch in der russischen Literatur, in Volkssagen und Marrchen)...

Der Held unserer Zeit ist immer ein "Dummkop $f^{\text {", in }}$ dem seine Zeit, die Wahrheit dieser Zeit am deutlichsten zum Ausdruck kommt. 167)

Mit der Gestalt des Sonderling knupft Šukšin an diesen, in der Kultur und Weltvorstellung des Volkes fruherer Zeiten wurzelnden Typus und die hierin enthaltenen ăs thetischen Moglichkeiten an. Die Exzentrizitat seiner Helden und der Sujetsituationen, die plotzlichen Verwandlungen, die unerwarteten Umschwunge im Verhalten der Helden und im Handlungsverlauf, das Spiel mit Worten und schroffen Kontrasten in seinen Erzahlungen - all dies sind zentrale Momente der Poetik jener Lachkultur des Volkes und ihres "karnevalistischen Weltemprindens" (Bachtin). Michail Bachtin beschreibt das Wesen des Karneval als "ein grobes, das ganze Volk erfassendes Weltemprinden vergangener Jahrtausende ${ }^{168)}$ :

Im Karneval entsteht in konkret-sinnlicher, halb als real, halb als gespielt erlebter Form ein neuer Modus menschlicher Beziehungen, der den allmächtigen, sozial-hierarchischen Beziehungen des nicht karnevalistischen Lebens gegenubergestellt wird. Das Verhalten, die Geste und das Wort des Menschen befreien sich aus der Gewalt jeder hierarchischen Ordnung (des Standes, Ranges, Alters, der Besitzverhaltnisse), die sie auBerhalb des karnevalistischen Lebens vollig bestimmt, und werden, mit der Logik des gew $6 h n l i c h e n$, nicht karnevalistischen Lebens betrachtet, exzentrisch und unangemessen. Die Exzentrizitat ist eine besondere Kategorie des karnevalistischen Weltempfindens, die mit der Kategorie des familiaren Kontakts organisch verbunden ist; sie erlaubt den verborgenen Seiten der menschlichen Natur, sich in konkret-sinnlicher Form zu zeigen und auszudrucken. 169)

167) Vasilij Šukšin, Nravstvennost' est' pravda, in: ders., Nravstvennost', a.a.0., S. 76-94, S. $76 \mathrm{f}$.

168) Bachtin, a.a.0., S. 180

169) Ebenda, S. $137 \mathrm{f}$. 
Das Pathos des Wechsels und der Veränderung, des Todes und der Erneuerung als - nach Bachtin - Kern des karnevalistischen Weltempfindens bestimmt auch die ambivalente Natur der karnevalistischen Gestalten und des karnevalistischen Lachens. Es schliebt jede einseitige dogmatische Ernsthaftigkeit des Lebens und Denkens aus und bezeugt die Relativitat einer jeden Ordnung, die Unabgeschlossenheit alles Gewordenen. Hierin bestehen auch Sinn und Bedeutung dieses Weltempfindens,
das von Angst befreit, das in hochstem Mabe die Welt dem Menschen und die Menschen einander annahert (alles wird in den Bereich des freien, familiaren Kontaktes einbezogen), das mit seiner Preude am Wech- sel und seiner froblichen Relativitat dem nur ein- seitigen und dusteren of fiziellen Ernst gegenuber- steht, der durch Angst hervorgerufen, dogmatisch, dem Werden und Wechsel feindlich ist und den be- stehenden Zustand des Seins und der Gesellschafts- ordnung $z u$ verabsolutieren sucht. Gerade von diesem Ernst befreite das karnevalistische Weltempfin- den. 170)

Die Momente des Karnevalistischen im Bachtinschen Sinne in Šukšins Erzahlungen sind vielfaltig und fur das kunstlerische System des Autors von zentraler Bedeutung. Sie bestimmen die besondere Form des kunstlerischen Sehens, das in dieser Prosa die Welt organisiert und erklaren die Ambivalenz der Helden und der dargebotenen Wirklichkeit, die ihnen innewohnenden Paradoxa. Der Verstob gegen das Gewohnte und allgemein Anerkannte, das auf kuriose und dadurch die Aufmerksamkeit in besonderem MaBe erregende Weise aus seinem gewohnten Gleis und seiner festgefugten Ordnung herausgehobene Leben, das die Sonderlinge verkઠrpern, ermઠglicht es Šukšin, die verborgenen Seiten der menschlichen Natur aufzudecken: Die seelische Problematik eines in seinen Moglichkeiten nicht voll ausgeschoprten Lebens, der Drang nach Selbstverwirklichung und individueller selbstauberung in einer diese behindernden Umwelt, das Verlangen und die Suche nach einer Har-

170) Bachtin, a.a.0., S. 180 
monie von Mensch und Welt, aber auch Elementares und Irrationales im menschlichen Charakter, jene "unausgegorene elementare Kraft", die in seinen Erzăhlungen auch als "destruktives Element" auftritt ${ }^{171) .}$

Gleichzeitig enthalt diese Form der Weltdarbietung eine ideologiekritische Dimension, indem sie die Relativitat des Gewordenen, scheinbar Festgefugten und Gultigen hervorhebt und durch die Polemik mit dem auberlich Starren und Abgeklarten Einseitigkeit und dogmatische Engstirnigkeit bekămprt.

Die Sonderlinge bei Šukšin sind, wie ihre Betrachtung gezeigt hat, moderne Gestalten, die sich ungeachtet aller Merkwurdigkeit ihres Charakters, Verhaltens und Denkens im geistigen Klima der Gegenwart bewegen und von diesem geprăgt sind. Das besondere Verhaltnis von Gestalt und Wort zur Wirklichkeit, das nach Bachtin das karnevalistische Weltempinden vermittelt ${ }^{172)}$ und das in Suksins Prosa evident ist, steht in Zusammenhang mit der besonderen Beziehung des Autors zur Gegenwart mit inren gewaltigen sozialen Umwalzungen und ihrer komplexen Einwirkung auf Geist und Psyche des Menschen, die den Blick verstărkt auf die offenheit und Unabgeschlossenheit allen Werdens, auf die ambivalente und unvollendbare Natur des Menschen und des menschlichen Denkens orientieren.

Besonders deutlich tritt dies in der an Elementen des Komischen und Karnevalistischen reichen Erzahlung "Veruju!" (Ich glaube!, 1971) 173) hervor. Der Held, Maksim Jarikov, leidet unter Anfallen von Schwermut. Besonders sonntags, wenn andere "sich kulturvoll erholen", wie seine verstandnislose Frau sich beschwert, uberkommt inn diese Stimmung. Er qualt sich und weis nichts mit sich anzufangen. Maksim spricht aus, was viele Helden Śukšins kennzeichnet: "duša bolit" (die Seele tut weh) und er beschreibt diesen zustand:

171) Belaja, Istorizm, a.a.0., S. 114

172) Bachtin, a.a.0., S. 119

173) Im folgenden zitiert nach: Śukšin, Rasskazy, Kniga dlja ctenija, a.a.0., S.110-118 
- "ну и что? - сердито думал Максим. - Так же было сто лет назад. Что нового-то? И всегда так будет. Вон парнишка идет, Ваньки Малофеева сын... А я помно самого Ваньку, когда он вот такоя же ходил, и я сам такоя был. Потом у этих - свон такие же будут. А у тех - свон... И все? А зачем?" (S. 112)

Dieses "wozu?", die Frage nach dem Sinn dieses Lebens, bewegt Maksim besonders. Als er erfahrt, dab ein Pope zu Besuch ins Dorf gekommen sei, sucht er diesen auf, um inn zu fragen, ob "den Glaubigen auch die Seele weh tut oder nicht". Zwischen dem Popen und Maksim entspannt sich ein Gesprach, in dessen Verlauf der Pope den aufrichtig interessierten Maksim auf seine Weise in Dialektik unterweist:

- Как только появился род человеческия, так появилось зло. Как появилось зло, так появилось желание бороться с ним, со злом то есть. Появилось добро. Значит, добро появилось только тогда, когда появилось зло. Другими словами, есть зло - есть добро, нет зла - нет добра...

... Итак, идея Христа возникла из желания победить зло. Иначе - зачем? Представь себе: победило добро. Победил Христос... Но тогда - зачем он нужен? Надобность в нем отпадает. Значит, это - не есть нечтс вечное, непреходянее, а есть временное средство, как диктатура пролетариата. (S. 113)

Maksim erfahrt, dab auch dem Popen die "Seele weh tut", weil "es Gott nicht gibt". Und gleichzeitig behauptet der Pope :

... бог - есть. Имя ему - Жизнь. В этого бога я верую. Это - суровыя, могучия бог. Он предлагает добро и эло, вместе, - это, собственно, и есть рая.

(S. 114 )

Fur den Popen ist der Seelenschmerz Maksims Ausdruck eines Strebens nach Wahrheit und des Nicht-Verharrens in der Trăgheit eines "seelischen Gleichgewichts", und er lehrt diesen, an das Leben zu glauben:

Поэтому, в соответствин С этим монм богом, я Говорю: душа болит? Хорошо. Хорошо! Ты хоть зашевелился, ядрена мать! А то бы тебя с печки не стащить с рав- 
новесием-то душевным. Живи, сын моя, плачь и приплясывая. Не бояся, что будешв языком сковородки лизать на том свете, потому что ты уже эдесь, на этом свете, получишь сполна и рая и ад... Верь в Кизнь. Чем все это кончится, не знаю. Куда все устремилось, тохе не знаю. Но мне краяне интересно бежать со всемн вместе, а если удастся, то и обогнать других... (S. 115)

Der Autor läbt das Gespräch der beiden schlieblich in einem wilden, trunkenen Gesang und Tanz enden, in dem sich das "ich glaube" des Popen, skandiert von Maksim, bis zur Ekstase steigert:

- Громче! Торжественно: ве-рую! Вместе: ве-ру-ю-у!... - В авиацию, в химнзацию, в механизацию сельского хозяяства, в научнуш революцию-у! В космос и невесомость! - ибо это объективно-о! вместе! За мноя!..

(S. $116 f$. )

Die dargestellte Situation ist extrem, in einer Weise ungewohnlich und absonderlich, die rast ans Groteske grenzt. Desgleichen die Figuren der Erzăhlung, vor allem die Gestalt des Popen. Allein schon der Auftritt eines Popen im Kontext des modernen sowjetischen Dorfes stellt ein Kuriosum dar, und Šukł̌ins Pope erweist sich zudem noch als ganz besonderes Exemplar. Seine Charakteristik ist voller Paradoxa: Er ist lungenkrank und ins Dorf gekommen, um sich mit "Dachsspeck" zu kurieren. Ungeachtet seiner Krankheit ist er ein KOlOB von einem Kerl, trinkt Sprit in beachtlichen Mengen, lacht und schreit mit voller Lautstărke. Es ist eine Pope, der zu fluchen und zu schimpfen weib, souverăn mit den Geboten der Bibel umgeht ("Nichts da mit 'halte auch die rechte hin'. Ich geb inm eine in die Fresse und basta", S. 115), der Esenin liebt und beim Singen seiner Verse zu weinen anfänt. Kurz, er bestatigt ganz den Eindruck, den er beim ersten Anblick aur Maksim macht:

такому - не кадилом махать, а от алиментов скрываться. (S. 113)

Auch Maksim ist nicht rrei von Komik. Mit der Erwăhnung seiner merkwürdigen Gewohnheit, sich im betrunkenen $\mathrm{Zu}$ - 
stand aller moglichen Vergehen zu bezichtigen, was ihn einmal zu dem "Gestăndnis" vor der Miliz verleitete, "ein wissenschaftlicher Vlasov" zu sein, verleint der Autor seinem Charakter jene Verknüpfung von tragischen und komischen Zügen, wie sie Bron'ka Pupkov aus "Mil' pardon, Madam" und andere Sonderlinge Sukšins aufweisen. Kurios und scheinbar unsinnig gestaltet sich dann auch das Gesprăch der beiden Helden. Der Pope spricht uber die Dialektik von Gut und Böse, von Christus, der "Diktatur des Proletariats", vom "Sprit" und von seiner "zuverlässigen Faust", vom Glauben an das Leben und meint: "Wie das alles enden wird, weis ich nicht".

Abrupte Ubergănge von einem Thema zum anderen und schnelle Wechsel vom Konkreten zum Abstrakten kennzeichnen seine Rede :

- Я болен, друг мо. Я пробехал только половнну дистанции и захромал. Ты самолетем летал?...

В самолет верую. Вообие в жияни много справедливого. Вот, жалеют: Есенин мало прохил. Ровно - с песню. Будь она, эта песня, плиннея, она не была бы такоя мемямея. длинных песен не бывает. (S. 116)

Ebenso die bunte Abfolge und Vermischung verschiedenartiger und scheinbar vollig unvereinbarer Dinge und Bereiche, die in der Rede des Popen auftreten. Seinen Hohepunkt erreicht dieses Spiel mit Worten, Begriffen und Kontrasten in der ekstatischen SchluBszene. Suksin selbst erklarte den Sinn dieses Spiels:

In der Erzăhlung "Ich glaube!" erschien es mir verlockend, ganz verschiedenartige Vorstellungen vom Leben miteinander in Verbindung $2 u$ bringen, um damit folgendes zu zeigen: Wir bekommen heutzutage viele Informationen, unser Verstand erhält sehr viel Nahrung, aber wir schaffen es nicht, all dies richtig zu verdauen, und daraus resultiert ein volliges Durcheinander in unseren Kopfen. Ubrigens resultiert daraus auch eine ernst zu nehmende Schwermut. 174)

174) Šukšin, Ja rodom iz derevni, a.a.0., S. 246 
Die Karnevalisierung des Sujets und der Gestalten ermbglicht dem Autor nicht nur, einen besonderen künstlerischen Ausdruck fur dieses "vollige Durcheinander" im Bewustsein des modernen Menschen und das Streben nach einer Synthese der verschiedensten Seinssphären als Antwort auf die die Seele qualende Frage "wofur?" zu finden. Sie ermbglicht vor allem die Transponierung der "letzten Fragen des Lebens und des Todes" aus der abstrakt-philosophischen Sphare "in den konkret-sinnlichen Bereich der (nach karnevalistischer Art) dynamischen, vielfătigen und grellen Bilder und Ereignisse" und l8st sie damit "nicht auf abstrakt-philosophischem oder dogmatisch-religibsem Wege, sondern spielt sie in der konkret-sinnlichen Form karnevalistischer Handlungen und Bilder durch"175). Die fur Suksiin so charakteristische kontrastive Verflechtung verschiedenster Sphären des materiellen und geistigen Lebens erreicht in "Veruju!" einen kunstlerischen Ausdruck von besonderer Eindringlichkeit.

Kuhner wohl als in irgendeinem anderen seiner Werke verknupft Suksin hier nicht nur unterschiedliche Lebensbereiche und kulturelle Spháren (den Alltag in seinen verschiedenen Erscheinungen, die kirchliche Zeremonie, den Aufruhr der Instinkte, wissenschaftliche Vorstellungen, Poesie), sondern auch die mit diesen verbundenen Sprachstile zu einer Synthese, die in der Apotheose, der Tanzszene, einen merkwurdig farbenreichen und in ihrer grotesken, hyperbolischen Form sogar gespenstischen Charakter annimmt. 176)

Das Besondere an der Gestalt des Popen und ihre asthetische Funktion beruhen auf der in inr zur schau gesteliten Aufhebung der Trennung von Denken und Sein, von der Realitat der Welt und des Lebens und der Vorstellung von ihnen. Der Pope verkorpert selbst auf bizarre Weise und in hyperbolischer Ausprăgung die in seinen KuBerungen

175) Bachțin, a.a.0., S. 150

176) Ja. El'sberg, Smena stilej v sovetskom rasskaze 1950-1960-ch godov. Sergej Antonov - Jurij Kazakov - Vasilij Suksin, in: Smena literaturnych stilej, Moskva 1974, S. 178-198, S. 196 
angestrebte Synthese, wie sie auch in seiner Devise zum Ausdruck kommt, die er Maksim ans Herz legt: "Lebe, mein Sohn, und weine und tanze dazu" (S. 115). Alle relevanten Faktoren des Seins haben in seine Gestalt Eingang gefunden: Intellekt und Instinkt, Rationales und Irrationales; in inr haben Wissenschaft, Poesie und Religion ebenso ihren Platz wie materieller LebensgenuB, Sinnesfreude und elementarer Daseinskampr.

\subsection{Zusammenf assung}

Die Beschăftigung mit der Prosa Sukšins stðBt auf eine Reihe von Schwierigkeiten, die in der Besonderheit des literarischen Helden dieses Autors und seines kunstlerischen Systems, in der Kompaktheit und Vielschichtigkeit seiner Erzăhlungen begrundet liegen, welche in auffäligem Gegensatz stehen $z u$ der scheinbaren Unkompliziertheit und Anspruchslosigkeit der oft humoristisch und anekdotisch anmutenden Geschichten. V. Gusev beschreibt diese in Forschung und Kritik begegnende Verlegenheit:

Mit Šukšin wuBte man bei uns im Grunde lange nichts anzurangen. Er ist ein Dorfautor und doch wieder auch nicht, er "mokiert sich" mal uber die Dorfler, mal Uber die Stadter, seine Helden sind. "Sonderlinge"... Bei inm hält ein Dorfphilosoph die angereisten Intelligenzler zum Narren, aber auch der Philosoph selbst erweist sich nicht als Krone der Schbpfung. Bei inm ist der Autor versteckt hinter dem Helden, gibt es "erlebte Rede" und "skaz"... 177)

Und Galina Belaja stellt fest:

In der allgemeinen Wertschătzung, die Šukš in geniebt, gibt es ein trugerisches Moment: Es scheint, als ob den Schriftsteller alle verstehen. Die unerhorte Popularităt Sukšins gilt als Zeichen und Beweis seiner Gemeinverstăndichkeit.

Die Zeit korrigiert diesen Irrtum zusehends, und es zeigt sich, dab es schwierig ist, den Schrift-

177) Gusev, Prostranstvo slova, a.a.0., S. 125 
steller zu interpretieren und noch schwieriger $z u$ erklaren, warum man ihn liebt und schatzt. 178)

Die Fulle von Charakteren und BewuBtseinstypen, die in Škšins Erzăhlungen ganz in den Vordergrund treten, die Vielzahl "unterschiedlicher, der Literatur fast unbekannter Schicksale"179), die hier begegnet, bereitet der Orientierung des Lesers und einer Standortbestimmung des Autors in dieser bunten und wunderlichen Welt Schwierigkeiten. Auch die eigenartige sprachliche Struktur dieser Prosa, die durch die Dominanz der "Stimme" des Helden sowie durch den Wechsel und die Vermischung der verschiedensten Sprachebenen und -stile bewirkt wird, hat hieran inren Anteil und hat dem Autor mehrfach den Vorwurf der Uneinheitlichkeit seines Stils eingebracht. Marietta Cudakova stellt in einigen Erzăhlungen eine zu grobe Diskrepanz zwischen den "neuen Stimmen" der Helden und dem Autorwort fest und sieht in der hohen Selbständigkeit der vor allem im Dialog dargestellten Charaktere eine die künstlerische Entwicklung Šukšins hemmende "Selbstverleugnung" des "von seinem Material erdruckten" Autors ${ }^{180}$ ). Auch Wolf Schmid betont, anknupfend an Čudakova, daß sich Sukšin allzusehr damit begnüge, statische Charaktere lediglich zu demonstrieren und wüdigt seine Prosa vor allem als Entwicklungsschritt innerhalb des Innovationsprozesses der modernen russischen Prosa:

Die Fulle von "strannye ljudi" und "čudiki", die Buntheit der Personenlandschaft... war naturlich ein uberaus wichtiger Schritt in Richtung auf eine tiefere und vollere Realitatserfassung. Gegenuber der flachen Personentypisierung und dem engen Wirklichkeitsspektrum des sozialistischen Realismus und auch gegenuber der jugendlich stilisierten Welt der "molodaja proza" bedeutete sie eine wesentliche Vertiefung und Präzisierung der charakterologisch authentischen Personendarstellung sowie eine weite offnung der Literatur für neue Weltbereiche. 181)

178) Belaja, Antimiry, a.a.0., S. 269

179) Cudakova, a.a.0., S. 233

180) Ebenda, S. 233; vgl. auch S. $220 \mathrm{r}$.

181) Schmid, a.a.0., s. 77 
Die obige Betrachtung der Erzahlungen hat allerdings gezeigt, daB sich besonders der spatere Šukšin durchaus nicht darauf beschränkt, "den Leser durch ein Panoptikum von kauzigen Figuren zu fuhren"182), und Galina Belaja hat in diesem Zusammenhang zu Recht auf den konzeptionellen Gehalt der Charaktere Šukšins ningewiesen ${ }^{183)}$. Mit dem Ubergang zur Gestaltung komplizierterer Typen und Charaktere, mit der Entdeckung des Ubergangstypus und des Sonderlings, ist in Śukšins Prosa auch eine tiefere gedankliche Konzeption des Autors verbunden, in der vermittelt uber die Charaktere und die Konfrontation verschiedener Bewubtseinswelten - die aktive Auseinandersetzung mit all dem, "was der Autor gesehen und beobachtet hat und was in den Stimmen seiner Helden zum Ausdruck kommt"184), sehr wohl deutlich wird. Die Charaktere Šukšins sind moderne Gestalten, die in vielfaltiger Weise den Stempel der Zeit tragen und in denen es dem Autor gelingt, wesentliche zuge und Grundbefindlichkeiten nicht nur des modernen Russen, sondern des Menschen der Gegenwart uberhaupt einzufangen und in innen zugleich die Verăderungen und Bewegungen der zeit kunstlerisch zu erfassen.

Die Prage nach der Besonderheit des kunstlerischen Systems bei diesem Autor verweist vor allem auf die grobe Bedeutung des dargesteliten Wortes in seiner Prosa, namentlich auf die besondere Punktion, die in ihr das "auberliterarische" Sprachmaterial einnimt. Die zentrale Rolle des Heldenwortes fur die Selbstaufdeckung des Charakters sowie die wirkungsasthetischen Besonderheiten, die dem Bemuhen um Authentizitat und Glaubwürigkeit der Darstellung zugrundeliegen, wurden im vorhergehenden ausfuhrlich untersucht. Eine besondere Wirkung und die "Verdichtung" des dargestellten Wirklichkeitsausschnittes wird dabei dadurch erzielt, daB der Autor

182) Schmid, a.a.0., s. 77

183) $\mathrm{Vgl}$. die Kritik Belajas an der Konzeption von Marietta Cudakova in: Belaja, Iskusstvo est'

184) Cudakova, a.a.o., S. 233 


\begin{abstract}
"kompakte" Formen ("znatnyj", "srezal" u.a.) verwendet, Wörter, die als Signale fungieren und bewirken, daB im Bewubtsein des Lesers unzahlige Vorstellungen und vertraute Bedeutungen hervorgerufen werden. Dieses Gelaufige, Allgemeine ist bereits etwas fest in der Psyche Verwurzeltes. Deshalb wird es nicht beschrieben, sondern lediglich durch Andeutungen, durch Wortsignale bezeichnet. 185)
\end{abstract}

Im bewusten Streben des Autors nach Authentizitat und Glaubwurdigkeit der Darstellung, in seiner Orientierung auf den aktiven und emanzipierten Leser, die mit dem erhohten Gewicht der "fremden stimme" und des "fremden Standpunktes" in seinen Erzăhlungen verbunden sind, druckt sich eine allgemeine Tendenz der modernen russischen Prosa aus, die sich von alten literarischen Normen befreit. Die besondere Verwendung der "fremden Stimme" in den Erzăhlungen Śukšins führte jedoch bei diesem Autor zur Herausbildung eines besonderen Stilsystems, das in Anknupfung an die Poetik der karnevalistischen Lachkultur vielfaltige kunstlerische Ausdrucksmbglichkeiten erreichte und die eingangs angefuhrte These Vinogradovs von den produktiven Făhigkeiten des "auBerliterarischen" Sprachmaterials fur die Schaffung "neuer Methoden der kunstlerischen Umgestaltung der Welt" eindrucksvoll bestatigt. Belaja spricht von einer "sich sprachlich zur Schau stellenden Form" (s lovesno-zreliščnaja forma) 186) dieser Prosa, die durch den Stilwechsel in der Sprache der Helden, die sich sprachlich manifestierende "Verwandlung" der Gestalten bewirkt wird. Aufbauend auf dem Gegensatz zwischen dem lebendigen, sinntrăchtigen, mit dem realen Leben eng verbundenen umgangssprachlichen Wort und dem "kanceljarit", der erstarrten, abgegriffenen, sinnentleerten Schablone, ermbglicht dieses Stilsystem Śukšin eine besondere kunstlerische Auseinandersetzung mit der Wirklichkeit und der modernen Gegenwart auf der Ebene des Stils, die durch andere Elemente der Erzahlstruktur (antithetischer Aufbau, Handlungsverlauf "entgegen der Erwartung des Lesers") verstarkt wird: Die Bloßstellung und Bekămpfung der verschiedenen Formen des standardisier-

185) Belaja, Roždenie novych stilevych form, a.a.0., S. 480 186) Ebenda, S. 484 
ten, klischeehaften Denkens und die Aufdeckung der Vielschichtigkeit dieses Phänomens in der modernen Welt. Indem er den formalisierten und pervertierten Ausprägungen des Lebens und Denkens das Bedurfnis des Menschen nach freier und naturlicher Gefuhlsbekundung, individueller Selbstăußerung und Selbstverwirklichung, nach einer Annăherung von Mensch und Mensch und Mensch und Welt gegenuberstellt, dringt Sukšin in einen ethischen Bereich vor, dessen Bedeutung und Aktualitat gerade fur den Menschen der Gegenwart in seiner Prosa besonders deutlich werden. Die besondere Form, in der sich die Helden dieser Prosa sprachlich zur Schau stellen, hilft auch, den Einflub des Filmemachers und Schauspielers zu erklăren, der in ihr wirksam wurde sowie das gleichzeitige küstlerische Interesse an Literatur und Film, das Vasilij Šukšin auszeichnete ${ }^{187)}$.

187) Vgl. ebenda; zum Zusammenspiel von Film, Schauspielkunst und Prosa im künstlerischen Schaffen des Autors vgl. auch das Vorwort zur zweibăndigen Ausgabe von Sergej Zalygin, "Geroj v kirzovych sapogach. $K$ tvorcestvu Vasilija Suksina, abgedruckt auch im Sammelband: Sergej Zalygin, Literaturnye zaboty, a.a.0., S. 156-162 


\section{Valentin Grigorevič $R$ as $p u t i n$}

1937 in dem ostsibirischen Dorf Ust'-Uda an der Angara geboren, gehort Valentin Rasputin zur jungeren Generation der Sowjetautoren. Dem in Irkutsk lebenden Schriftsteller gelang der Durchbruch zu literarischem Erfolg relativ schnell, und ungeachtet der nicht unerheblichen Schwierigkeiten, die die Sprache seiner Prosa dem Ubersetzer bereitet, gehort er zu den auch im westlichen Ausland viel ubersetzten und beachteten Autoren ${ }^{188)}$.

Wie viele seiner sowjetischen Kollegen arbeitete Rasputin nach Abschlub seines Studiums an der Philologischen $\mathrm{Pa}-$ kultat der Universităt Irkutsk 1959 als Journalist fur verschiedene Jugendzeitschriften in Irkutsk und Krasnojarsk, eine Tătigkeit, die ihn in die entlegensten. Gegenden und auf alle groben Baustellen seiner sibirischen Heimat fuhrte. Bereits in dieser zeit schrieb er kleine Erzahlungen, die in verschiedenen Zeitschriften und literarischen Almanachen erschienen. 1966 gab er den Journalistenberuf auf, um sich als freischaffender schriftsteller in Irkutsk niederzulassen. Im selben Jahr veroffentlichte er zwei Bändchen mit Skizzen uber seine journalistischen Reisen und ein Jahr spater den Erzăhlband "Čelovek s ètogo sueta" (Ein Mensch von dieser Welt), der den eigentlichen Beginn seiner schriftstellerischen Laufbahn markierte ${ }^{189)}$.

188) Zu den Ubersetzungss chwierigkeiten der Prosa Rasputins vgl. die Diskussion der DDR-Ubersetzer Thomas Reschke, Eckhard Thiele und Werner Creutziger um Elena Panzigs Ubersetzung von "Prošcanie s Matëroj": Ubersetzung im Disput, in: Neue deutsche Literatur, $1980, \mathrm{Nr} .7$, S. 102-117

189) Zur Biographie Rasputins und den frühen Arbeiten des Autors vgl. die Monographien von Tenditnik, a.a.o. und V.N. Sapošnikov, Valent in Rasputin, Novosibirsk 1978 , sowie Vadim Baranov, Formula tvorcestva. 0 tvorčstve pisatelja V. Rasputina, in: Literaturnoe obozrenie, 1975, Nr. 12, S. 65-69; B.M. Judaleviz,, "Dialektika dusi" $v$ rannich proizvedenijach Valentina Rasputina, in: Oxerki literatury i kritiki Sibiri (XVII-XX vv.), Novosibirsk 1976, S. 255-273; Wolfgang Kasack, Walentin Rasputin, in: Osteuropa, 1975, Nr. 7, S. 489 r. 
Einen ersten großen Erfolg brachte Rasputin die 1967 erschienene grobere Erzăhlung "Den'gi dlja Marii" (Geld für Maria), die inm bereits uber Sibirien hinaus Bekanntheit verschaffte. Mit der Romanerzahlung "Poslednij srok" (Die letzte Frist), 1970 in "Naš sovremennik" (Unser Zeitgenosse) veröffentlicht, gelang schlieblich der endgültige Durchbruch, der Rasputin als bedeutenden Erzăhler und exponierten Vertreter der Dorfprosa profilierte.

Die bedeutendsten Arbeiten des Autors sind neben den beiden genannten die Romanerzăhlung "Živi i pomni" (Leb und vergib nicht, 1974), fur die Rasputin 1977 mit dem Staatspreis der UdSSR ausgezeichnet wurde, und die Novelle "Prošcanie s Materroj" (Abschied von Matera, 1976), das bisher letzte grọbere Werk des Schriftstellers. Ungeachtet der allgemeinen Anerkennung des großen erzahlerischen Talents gehort Valentin Rasputin zu den umstrittensten Autoren der sowjetischen Gegenwartsliteratur, dessen Werk in den Auseinandersetzungen um die Dorfprosa mit im Mittelpunkt stand und dabei nicht wenigen Angriffen ausgesetzt war. Besonders gilt dies fur das letzte Buch des Autors, "Prošcanie s Matëroj", das bis in die achtziger Jahre Gegenstand heftiger Debatten der Kritiker war und dem Autor mehrfach den Vorwurf der Fortschrittsfeindlichkeit und der Idealisierung der patriarchalischen Vergangenheit eingebracht hatte.

Fur die rolgende Untersuchung wurden die Romanerzăhlung "Poslednij srok" und die Novelle "Prošcanie s Matëroj" ausgewăhlt, die innerhalb des bisher vorliegenden Werks des Autors sowohl thematisch als auch hinsichtlich des zentralen Charakters, den sie gestalten, eine Einheit aufweisen und in denen sich die ideell-kunstlerische Problematik und Entwicklung des Autors besonders deutlich aufzeigen labt. 
3.1. Charaktere und Bewustseinstypen bei Valentin Rasputin - Die Erzălung "Poslednij srok" -

Das vorrangige Interesse Rasputins gilt dem traditionellen băuerlichen Charakter, wie ihn das alte russische Dorf hervorgebracht und geprägt hat und wie inn der Autor in den kleinen, fernabgelegenen sibirischen Dorfern, in denen die Handlung seiner Erzahlungen meistens angesiedelt ist, vor allem unter der alteren Generation noch $z u$ entdecken weiB. Die Aufdeckung eines solchen Charakters und der Innenwelt einer Gestalt, in deren Bewubtsein, Sprache, moralischem und ăsthetischem Bezugssystem sich die in sich geschlossene Welt des alten Dorfes und bauerliche Kultur widerspiegeln, steht im Mittelpunkt der drei großen Erzahlungen Rasputins und hat dem Autor den Ruf eines "Verkünders der sittlichen Grundlagen des russischen Menschen"190) eingebracht. Die Hauptfiguren sind Prauen - die achtzigjahrige Băuerin Anna in "Poslednij srok", dre junge Nastêna in "živi $i$ pomni" und die Greisin Dar'ja in "Prošcanie s Matëroj" -, und in den drej Heldinnen lassen sich Abwandlungen eines Charaktertyps erkennen, eines Typus, der zudem fur Millionen russischer Frauen der gleichen Generation stehen kann. Rasputin hat selbst auf die Verwandtschaft seiner Heldinnen hingewiesen und seine beiden letzten Bucher als Fortsetzung des bereits in "Poslednij srok" aufgeworfenen Themas bezeichnet ${ }^{191)}$. Das Erzăhlen uber diese bescheidenen, von der Literatur lange nicht beachteten Menschen und Schicksale und ihr unauffalliges, von der groben Welt abgeschiedenes Leben sieht Rasputin als sein personliches schriftstellerisches Metier an, das er bewubt der Dynamik des modernen Lebens und dem Sibirien der Pioniere, uber das alle schreiben, entgegenstellt:

190) P.V. Zabelin, Russkij čelovek v proze V. Rasputina, in: ders., Literaturnyj raz-ezd. Razmyšlenija o tvorcestve irkutskich pisatelej, Irkutsk 1974, S. 62-86, S. 83

191) Vgl. Zacharova, a.a.0., S. 85 
Uber Baustellen und die Bauleute habe ich viel und mit aufrichtiger Anteilnahme geschrieben, für die Presse. Als Schriftsteller aber wollte $i c h$ von dem erzăhlen, was nur ich weib.

Das Leben unserer Gegenwart ist auberordentlich dynamisch, alles eilt dahin, und so beschlob ich, uber ein ruhiges Leben zu berichten. 192)

Und uber die Anziehungskraft, die die Frauengestalten des Dorfes auf inn ausuben, fügt der Autor hinzu:

Besonders haben mich die Frauengestalten angezogen. Die alten Dorfbewohnerinnen sind voll innerer Anmut und Schonheit; sie wissen viel und sprechen eine ausdrucksstarke Sprache. 1970 habe ich die Erzăhlung "Die letzte Frist" veroffentlicht, die meines Erachtens das zum Ausdruck bringt, was andere, wenn uberhaupt, dann von einem voliig anderen Blickpunkt aus sagen. 193)

Rasputin zeigt seine Heldinnen im privaten Bereich des ihnen vertrauten Milieus, in inren familiăren Bindungen und personlichen Beziehungen zu den Menschen und Dingen inrer Umgebung. Die Handlung bleibt dabei auf den engen răumlichen Rahmen des abgelegenen sibirischen Dorfes beschränkt. Der Autor stellt seine Figuren jedoch stets in eine besondere Situation, in aubergewohnliche Umstände, die sie einer Prufung ihres Charakters und allseitigen moralischen Bewahrungsprobe aussetzen. Diese besondere Situation wird zur Grundlage des Sujets, das seine dramatische Zuspitzung weniger durch aubere Ereignisse als vielmehr durch das Verhalten der handelnden Personen und die sich in innen vollziehenden Bewustseinsprozesse erfăhrt.

Rasputin beginnt seine Erzăhlungen mit einem ungewöhnlichen Vorkommnis, das die festgefugte Ordnung im Leben der Helden stort und den gewohnten Lauf der Dinge unterbricht. In "Poslednij srok" ist es der bevorstehende Tod der Hauptgestalt, der sich unerwartet um wenige Tage verzoggert. Die Romanerzăhlung weist kaum Handlung auf. Die

192) Rasputin, Das Leben ist das Wichtigste, a.a.0., S.153

193) Ebenda 
Băuerin Anna liegt im Sterben, und nach langen Jahren der Trennung versammeln sich die Kinder wieder im Elternhaus, um von der Mutter Abschied zu nehmen und ihr das letzte Geleit zu geben. Da geschieht etwas Onerwartetes: Die Preude uber die Ankunft der Kinder bewirkt im Zustand der alten Frau eine Besserung, verlangert ihr Leben um unverhoffte drei Tage. Anna ist dankbar und glllcklich uber diese inr gewahrte "letzte Frist", die es ihr ermbglicht, sich von den Kindern $z u$ verabschieden und auf den Tod vorzubereiten. Sie wartet nur noch auf die jungste Tochter Tan'cora, die aus Kiev erwartet wird. Tan'cora bleibt jedoch aus, und bei den versammelten Kindern ruft die entstandene Situation Verwirrung, Bestürzung und schlieblich Arger daruber hervor, umsonst gekommen zu sein. Es kommt zum Streit zwischen den Geschwistern, und sie reisen vorzeitig ab im Giauben, dab es der Mutter wieder besser gehe. Die Erzahlung endet mit der lapidaren Peststellung: "In der Nacht starb die alte Prau." Die Handlung umfaBt die drei letzten Tage im Leben Annas, beginnend mit der Ankunft der Kinder und endend mit deren Abreise und der Peststellung des Erzahlers vom Tod der alten Prau in der folgenden Nacht. Der an außeren Ereignissen arme Verlauf der Erzahlung unterstreicht die Situation des Wartens und der aufgendtigten Untatigkeit, in der sich alle Beteiligten befinden. AuBere Handlungsmomente sind lediglich durch die verschiedenen Beschätigungen gegeben, denen sich die aus ihrem gewohnten Tagesablauf herausgerissenen und in eine verănderte Umgebung gestellten Personen, je nach ihrem Charakter, widmen: Der Spaziergang Ljusjas, die Zecherei der Brlder Michail und Il'ja in der Badestube, das Umherlaufen und Jammern der hilflosen Varvara, das Zusammenkommen der Pamilie bei Tisch oder am Bett Annas. Die eigentliche Bewegung des Sujets erfolgt in den Dialogen und Reflexionen der Gestalten, in denen sich ihre Charaktere und Denkhaltungen dem Leser eroffnen. Mit der unverhofften letzten Frist kann nur Anna etwas anfangen. Fur diese ist sie Anlaß zum Nachdenken ubber ihre Kinder und ihr Leben und zur be- 
wubten Vorbereitung auf den Tod. Sie ist die zentrale Gestalt der Erzahlung. Inrem Charakter und dem BewuBtseinstyp, den sie verkbrpert, sind fünf der elf Kapitel des Buches gewidmet.

\subsubsection{Der traditionelle dorfliche Charakter - Die Gestalt Annas -}

Im Unterschied zu den modernen Ubergangstypen Šukšins wie auch $z u$ den jugendlichen stadtischen Helden der "Jungen Prosa" handelt es sich bei den zentralen Charakteren in der Prosa Rasputins nicht um neue literarische Gestalten. Mit der ernsthaften Hinwendung zur Lebenswelt des alten russischen Dorfes und zum bauerlichen Volkscharakter betrat der Autor - und mit inm die Mehrheit der modernen "derevenşiki" - einen recht traditionsreichen Pfad der russischen Literatur, was die gestellte Aufgabe angesichts der hier bereits vorliegenden Leistungen nicht leicht erscheinen labt. Das Wesen dieser neu aufgegriffenen traditionellen Helden, ihre Unauffalligkeit und Bescheidenheit, mubte kunstlerische Probleme aufwerfen, die fur das aktuelle literarische Umfeld der sechziger Jahre neu waren:

Die Autoren, die sich dem Dorfthema zuwandten, standen vor Aurgaben, die ihren Vorgungern unbekannt waren. Die von ihnen gewăhlten Helden waren nicht so leicht zu erfassen, lieben sich nicht durch fluchtige Betrachtung begreifen. In der Lebenssphare, die ihren Alltag bildete, gab es keine schnellen und auffalligen Veränderungen, die sich im $\mathrm{Nu}$ erfassen lieben. Ihre Stimmen waren leise, man mubte sich in sie hineinhoren. Zwei oder drei Satze, die bei den Helden der vorangegangenen Autoren als Erkennungszeichen eines ganzen Charakters dienen konnten, waren hier nicht ausreichend. Es war notwendig, zu der "alten" Aufgabe der umfassenden und in sich geschlossenen Darstellung des Helden zurulckzukehren. 194)

194) Ćudakova, a.a.0., S. 229 r. 
Dieser Aufgabe der ganzheitlichen Darstellung seiner Gestalt, der volligen Ausschbpfung eines in sich geschlossenen Charakters stellt sich Rasputin in allen seinen Erzăhlungen. Die auBergewornnliche Beobachtungsgabe des Autors sowie die besonderen sprachlichen und erzăhlerischen Mittel, die er bei der Wiedergabe seiner Gestalten, ihrer Wahrnehmungen und inneren Regungen einzusetzen versteht, erscheinen dabei als das hervorstechende Merkmal dieser Prosa. Die von der Kritik hăufig bewunderte Păhigkeit Rasputins,

sich in seine Gestalt hineinzuversetzen, Schicksale und Charaktere von Menschen darzustellen, die inm "fernstehen", die inrem Alter, ihrer Lebenserfahrung und ihren rein menschlichen Eigenschaften nach wenig mit ihm gemeinsam haben... 195)

gilt in besonderem MaBe fur die Gestalt der Anna in "Poslednij srok".

\subsubsection{Erzăhlerische Verfahren und Sprache}

Das Bild der alten Anna erwăchst langsam, gleichsam zogernd aus dem Verlauf der Erzahlung. Es entsteht und verdichtet sich behutsam in dem MaBe, wie die Heldin aus der Bewubtlosigkeit ins Leben zuruckkehrt und sich ihrer Umgebung und ihrer selbst bewubt wird. Der Autor labt sich Zeit mit seiner Gestalt, eilt nicht mit Beschreibungen und Informationen und zeigt sich stattdessen vor allem als inr aufmerksamer Beobachter.

Anna sind funf Kapitel gewidmet: Das dritte, in dem sie aus der BewuBtlosigkeit erwacht und inre Kinder erkennt, das vierte, das den Morgen des zweiten Tages und das Gesprăch mit den Tochtern umfaßt, das siebte, das die unterhaltung mit der Freundin Mironicha gestaltet sowie das neunte und zehnte, in denen im Erwarten Tan'coras, in den Erinnerungen an die Kinder und die eigene Jugend und

195) Šapošnikov, a.a.0., S. 7 
schlieblich in der Vorbereitung auf den Tod ein umfassender Blick in die Innenwelt der Heldin und die Kulmination des Charakters erfolgen. Die beiden ersten Kapitel sind vornehmlich den Kindern gewidmet: Ihrem Wiedersehen nach langer Zeit der Trennung, ihrer Begegnung mit der bewustlosen Anna, ihren Empfindungen und Vorbereitungen in Erwartung des bevorstehenden Todes der Mutter. Uber die alte Frau erfahrt der Leser hier nur, dab sie an die achtzig Jahre alt ist, daß der Tod nicht uberraschend kommt, sondern sich schon seit geraumer Zeit angekundigt hat durch Bettlăgerigkeit und zunehmende Schwăche, dab Anna viele Kinder zur Welt gebracht hat, aber nur funf am Leben geblieben sind und dab sie bei ihrem Sohn Michail, der als einziger der Kinder nicht aus dem Dorf weggegangen ist, inr Leben zu Ende gelebt hat.

Alles an diesem bevorstehenden Tod ist so selbstverstandlich und naturlich, so ganz und gar nicht unerwartet, wie es bei einem achtzigjahrigen, bis zur Neige ausgeschopften Leben nur sein kann. Und dennoch haftet der in keiner Weise als ungewohnlich charakterisierten Gestalt Annas und ihrem nahen Tod bereits in den ersten beiden Kapiteln etwas Besonderes an, das die Aufmerksamkeit und das Inresse des Lesers auf sich lenkt und Anna als Mittelpunkt und zentrale Figur der Erzăhlung ausweist. Dieses Besondere beruht nicht auf der Einstellung der Kinder zur Mutter, nicht auf der Fursorge oder den Gedanken und Gefuhlen, die sie der sterbenden Mutter gegenuber zeigen, sondern auf der Haltung, die der Autor seiner Heldin gegenuber einnimmt, der auBergewohnlichen Aufmerksamkeit und Sorgfalt, mit der jedes Detail an inr Beachtung findet.

Bereits die ersten Satze der Romanerzăhlung spiegeln diese besondere Haltung des Autors wider, die dieser keiner anderen Gestalt zuteil werden läbt. Auch die Sprache des Erzăhlers nimmt eine eigene, besonders warme und teilnehmende Farbung an, wenn er die Gebrechlichkeit und Schwäche der alten Prau beschreibt:

Она долго пересиливала себя н держалась на ногах, но три года назад, оставиись совсем без силенок, 


\begin{abstract}
сдалась и слегла. Летом ер будто легчало, и она выползала во двор, грелась на солньлке, а то и лереходила с роздыхом через улицу к старухе Миронихе; но к осени, перед снегом, последняя мочь оставляла ее, и она по утрам не в состоянии была даже вынести эа собов горшок, доставшияся еи от внучки Нинки. А после того как старуха два или три раза подряд завалилась у крыльца, еи и вовсе приказали не подниматься, и вся ее жизнь осталась в том, чтобы сесть, посидеть, опустив на пол ноги, а потом опять лечь и лежать. 196)
\end{abstract}

Diese besondere Aufmerksamkeit gegenuber der Gestalt Annas steigert sich zu einer ăuBerst konzentrierten und minuziosen Betrachtung ihrer Gestalt, sobald diese in das Blickfeld des Erzăhlers gerăt. Am Ende des zweiten Kapitels stehen die Kinder am Bett der Mutter, die erste, noch ganz schwache Lebenszeichen gibt. Sie offnet die Augen, erblickt ihre kinder und nennt schlieblich mit zitternder Stimme ihre Namen. Diesen Vorgang gibt der Erzăhler auf eineinhalb Seiten wieder, wobei keine Regung und Verănderung an der Gestalt und kein Moment der Anstrengung und Muhe, die sie das kostet, seiner Aufmerksamkeit entgeht:

\begin{abstract}
Что-то стало биться в старухнны глаза, шевелить их, и глаза не сразу, не легко, но открылись, попробовали пояматься за свет и не смогли, сорвались. Несколько мннут они лежали спокоино, затем опять пришли в движение и разомкнулись, на этот раз силы в них было больше, и они в своем ненадежном свете что-то увидали... (S. $417 f$.
\end{abstract}

Rasputins erklärte Absicht, mit seinen Gestalten uber ein "ruhiges Leben" zu erzăhlen, setzt Ruhe und Geduld des Betrachters voraus, ohne die ein solches Leben nicht $2 u$ erfassen ist. Diese Ruhe und Bereitschaft zum Verweilen fordert der Autor auch von seinem Leser. Ganz anders als Šukšin, der beim Schreiben bewubt von der Zeitknappheit des modernen Lesers auszugehen pflegte und das Wesen der Erzăhlung in Kürze und Prăgnanz sowie im Vermeiden überflussiger Beschreibung sah ${ }^{197}$ ), ruckt bei Rasputin nier

196) Valentin Rasputin, Poslednij srok, in: ders., Povesti, Moskva ("Molodaja gvardija") 1978, S. 395-555, S. 397. Alle Zitate im folgenden nach dieser Ausgabe

197) Vgl. Vasilij Šukšin, Kak ja ponimaju rasskaz, in: ders., Riravstvennost', a.a.0., S. 120-125eide Wüst-9783954791231 
ein gegenteiliges Moment rast programmatisch in den Vordergrund. Er will gegen Tempo und Hektik des modernen Menschen und Lebens und die damit verbundene Plüchtigkeit und Ungenauigkeit der Wahrnehmung anschreiben:

Bei unserem modernen Tempo gibt es moglicherweise nur noch zwei Kräte, die geeignet sind, sich diesem Tempo zu widersetzen und den Menschen zum Nachdenken zu veranlassen: Die Natur und die Literatur. Ich weiB nicht, ob es uberhaupt moglich ist, sich diesem modernen Tempo $z u$ widersetzen, aber $i c h$ meine dennoch, das man es tun mub. Denn wenn man sich inm unterwirft, wenn man immerzu nur in Eile ist, wird man zu einem gedankenlosen Leser, der nie die "Anna Karenina" zu Ende lesen wird. 198)

Und befragt nach der Bedeutung der Sprache in der Literatur, außert Rasputin an anderer Stelle:

Die Sprache muß vor allem genau sein. Gerade an $\mathrm{Ge}-$ nauigkeit rehlt es bei uns leider hăurig. Die Dinge nur ungefahr zu benennen (priblizitel'nost'), ist ein verbreitetes Ubel. 199)

Diese Bereitschaft zum Verweilen und sorgfaltigen Betrachten kennzeichnet alle der Gestalt Annas gewidmeten Kapitel. Dabei eilt der Autor seiner Heldin in keinem Punkt vorán, nimmt nichts vorweg, sondern gibt nur das wieder, was allmăhlich, nach und nach in den Gesichtskreis und das Bewustsein der Greisin tritt, und entwickelt der Logik dieses Bewubtseins gemab seine Gestalt vor dem Leser. Das dritte Kapitel gestaltet das erste Gesprăch der Mutter mit den lange nicht gesehenen Kindern. Anna ist noch schwach, das Sprechen fällt ihr schwer, aber es drängt sie $z$ u reden, und der Autor gibt jedes Wort dieses von der Heldin mit Mühe und Preude zugleich gefuhrten, von Pausen der Ersch bp fung unterbrochenen Gesprăchs wieder.

198) Valentin Rasputin, zit. bei Zacharova, a.a.0., S.80; vgl. auch Nyota Thun, Dialog mit Rasputin, in: Sinn und Form, 1980, Nr. 1, S. 197-207, S. $204 f$.

199) Valentin Rasputin, Byt' samim soboj, in: Voprosy itteratury, $1976, \mathrm{Nr} .9, \mathrm{~S} .142-150$, S. 148 
Der Autor Uberlabt das Wort seiner Heldin. Er hort ihr zu, ohne sie zu unterbrechen, ohne Eile und ohne ihre Worte auf das zu konzentrieren, was inm selbst wichtig und wesentlich erscheint. Was sie zu sagen hat, steht in Ubereinstimmung mit ihren eigenen WertmaBstaben. Man kann sich beim Lesen des sonderbaren Eindrucks nicht erwehren, dab der Autor nicht "Schopfer" der Rede seiner Heldin, sondern inr Zuhbrer ist, dab er zusammen mit dem Leser dieser Rede mit unverminderter Aufmerksamkeit folgt... 200)

Alle Belanglosigkeiten und unständichen Aus fürungen Annas werden in diesem Dialog wiedergegeben, der nicht stilisiert ist, sondern die lebendige, volkstumliche, dialektgefarbte Umgangssprache des alten sibirischen Dorfes widerspiegelt:

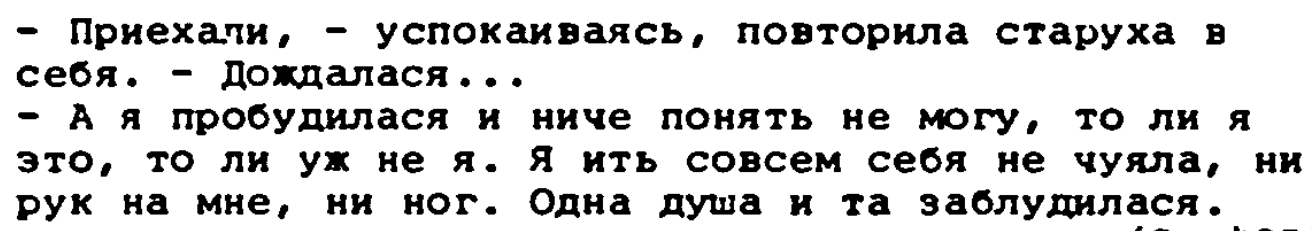

Rasputin zeigt seine Heldin in diesem Kapitel vor allem mit ihrer eigenen Sprache, deren charakterologische Moglichkeiten er fur die Aufdeckung der Gestalt bis zum aubersten nutzt. Diese Sprache Annas wirkt auffallend und uberraschend nicht nur durch die erheblichen Abweichungen von der schriftsprachlichen Norm ${ }^{201)}$, sondern

200) Čudakova, a.a.0., S. 232

201) Wie neu und ungewbhnlich für die Literatur diese Sprache, in der dialektale und lokale Lexik vom Typ "pokul'" (poka), "Zdrja" (zrja), "sedni" (segodnja), "moit"" (možt byt'), "k mine" (ko mne), "zist'" (zizn') usw. breiten Raum einnehmen, in den Dialogen der alten Frauen und Mănner bei Rasputin erschien, zeigt schon deren zum Teil vollig unterschiedliche Bewertung durch die Kritik, die dem Autor bald eine Uberfrachtung seiner Prosa mit "rein ethnischen Elementen" (Zabelin, a.a.0., S. 82) zum Vorwurf macht, bald inm bescheinigt, daB diese frei sei "von jenem Ubermaß an Archaismen und regionaler Lexik, zu dem sich fast alle Dorfautoren verleiten lassen" (Boris Pankin, Prošcanija i vstreci s Matëroj, in: ders., Strogaja literatura. Literaturno-kriticeskie stat'i i ocerki, Moskva 1980, S. 58-85, S. 72);

Marietta Cudakova hat im Zusammenhang mit diesem breiten Einflieben des volkssprachlichen Elements, 
auch durch die besonderen Möglichkeiten des Ausdrucks, die sie beinhaltet. Die bildhaft-anschauliche Art, mit der Anna uber alles, auch die belanglosesten, alltăglichen Dinge und Vorgănge spricht, deckt die konkret-gegerständiche Denkweise dieses BewuBtseinstyps auf, dem eine eigene Poesie anhaftet:

\footnotetext{
- Животишко-то уж в узелок завязался, - с горькоя радостыю повторила старуха. - думал, па-е-хали, Анна Степанна, на новую фатеру. Па-е-ехали с орехамн. (S. 421)
}

Die Wiedergabe der Empfindungen Annas mit ihrer eigenen merkwurdigen Sprache offnet zugleich einen Ausschnitt der Innenwelt der Gestalt und ihres geistigen Horizonts :

- А я ить, Варвара, слыхала, как ты вчерась надо мноя ревела... только я-то подумала, что это ты надо мноя над мертвоя ук ревешь. Ну. Я ишо раныше, как в памяти была, леху и думаю: "Вот помру, приедет варвара, обголосит меня, и то ладно". Так на тебя и надеялась. А тут сльлу: ты. Вот я и посчитала, что это я тебя скрозь смерть сльпу - не иначе...

- А кто скажет, мокть, оне потом ншо сколько данить сльшат,... Кто скакет? Никто не скажет. Глаза-то им закрокт, а уши открытые. (S. 428)

das in "Poslednij srok" seinen Hơhepunkt in dem farbenreichen Dialog $z w i s c h e n$ Anna und Mironicha erreicht, auf ein wirkungsăsthetisches Problem aufmerksam gemacht: "Das Bestreben, alles 'ganz neu' zu schreiben, ohne sich dabei auf eine feste Tradition der Literatursprache stutzen zu konnen, vermochte sich noch nicht in makelloser Form niederzuschlagen. Die Gespräche der alten Frau mit ihrer Freundin sind bei Rasputin noch ungenugend ausgearbeitet ("ozvuceny"), ihre Wirkung ist nur bedingt. Sie setzen einen Leser voraus, der diese Sprache kennt, dem sie seit langem vertraut ist, der sich in sie hineinhoren konnte. Und in inm vor allem wird die Sprache der Heldin Rasputins eine Wirkung auslosen... Wem jedoch diese Sprache nicht allzu vertraut ist, der lauft Gefahr, sie gar nicht in inrer ganzen Ausdruckskraft zu vernehmen." (Cudakova, a.a.0., S. 234);

Zur Sprache Rasputins vgl. auch Nikolaj Kotenko, Prežde vsego - točnost'. O tvorcestve V. Rasputina, in: Literaturnaja uceba, 1978, Nr. 4, S. 127-133 
Bei der Beschreibung ihres Zustandes erreichen die Worte der Heldin bisweilen einen Grad an Genauigkeit und Anschaulichkeit, die den Leser jenen fast physisch nachemprinden lassen:

Я от рук, от ног последнее отыму, а голосу добавлю. А он и сам идет, без меня. Я только зачну, а дальше он сам, покуль не устанет. От начать, правда что, тяжело. Вроде сперва на вышину надо эапрыгнуть. И одынка ишо берет... (S. 426)

Bisweilen gibt der Autor seiner Heldin Raum zu langen Monologen:

\begin{abstract}
Ночь сильно длинная мне показалась, с целья год. О6 чем я только не передумала? И с мамкоя со своея поговорела, сказалась, что вскорости буду. И про таньчору богу помолилась, чтоб пропустил он ее к мнне, когда видал где. Только б она седни приехала, а то ить я могу и не дохдаться. Я уж по себе вижу, что я не своея жистью живу, что это бог мне эа-ради вас добавку дал, а у ей, подимте, тоже конец есть. (S. 442)
\end{abstract}

Die Naturlichkeit und Lebendigkeit dieser Sprache, in der das innere, gefuhlsmăbige Beteiligtsein der Heldin an dem Gesagten deutlich zum Ausdruck kommt, sowie der Reichtum an Schattierungen und Nuancen, uber den sie bei der Wiedergabe von Gedanken und Gefuhlen verfugt, steht in merklichem Kontrast zur Sprache der Kinder, vor allem zu der geschlifrenen, städtischen Rede Ljusjas.

- Вы самя-то покуль не уезжаяте от меня, побудьте Со мно маненько...

- Никто пока и не собирается уезжать.

- Побудьте. Я не стану вам надоедать, я тихонько. Лежу и лежу...

- Что это еще эа "надоедать" да "молчком"?... - Как тебе не стыдно, мама! Что ты выдумываешь?... (S.429)

Eine Bewegung des Sujets erfolgt in diesem dritten Kapitel nur im Dialog: Ljusja entdeckt die schmutzigen Laken im Bett der Mutter und macht dem Bruder deswegen Vorwurfe; Anna erkundigt sich nach ihrer Freundin Mironicha, die Brüder beschlieben, auf das Wohl der Mutter zu trinken usw. Der Erzăhler bleibt dabei unaufdringlich im Hinter- 
grund, mischt sich nicht kommentierend in das Gesprăch ein. Aber dennoch ist seine Funktion hier eine andere und bedeutsamere als in der vor allem auf dem Dialog aurbauenden Prosa Śukšins. Rasputins Erzăhler übernimmt in den Gesprachspausen immer wieder die Aufgabe des aufmerksamen Beobachters der Hauptgestalt und vollzieht dabei eine erste, behutsame Annăherung an die Innenwelt der Heldin. Er verfolgt jede Bewegung inres Gesichts und K४rpers, jedes Zittern, die Zeichen von Anstrengung, die Bewegung ihres Blicks und dringt daruber langsam zu dem vor, was in ihrem Innern vorgeht.

Dieses wird zunăchst ganz bestimmt von den Kindern und der Wiedersehensfreude. Anna laBt ihren Blick vom einen zum andern schweifen, und die Gedanken, die jedes von ihnen in ihr auslost, stellen weniger eine Charakteristik der Kinder dar, als daß sie vielmehr züge ihres eigenen Charakters aufdecken. Die Gedanken Annas gleiten vom AuBeren der Kinder, ihrer auberlichen Verănderung uber zur Frage nach ihrer inneren Entwicklung und ihrem Leben und berüren das Problem der Loslosung von Mutter und Elternhaus und bewegen sich schlieblich um die Bedeutung der Kinder fur Annas eigenes Leben. Die Betrachtungen der Heldin uberschreiten dabei nicht den Horizont der alten Frau, und indem das, was ihr wichtig erscheint, in den Vordergrund rückt, offenbaren sich dem Leser bestimmte Momente ihrer Vorstellungswelt. Die konkret-anschauliche Sprache, in der diese Gedankenwiedergabe erfolgt, die Verwendung von Bildern und Vergleichen, die Einflechtung von volkstumlichen Redensarten vor allem beim Ubergang $z$ abstrakten Reflexionen spiegeln die Anschauungsweise der Heldin und die băuerlich-volkstümliche Art inres Denkens wider ${ }^{202)}$ :

Столько нового мясо наросло на нем, столько всяких людея без нее ходило с ним рядом, что она верила и не верила, что это он, будто ее илью, как малую рыбешку, заглотила рыбина побольше да порасторопнея, и теперь они живут в одном теле. (S. 422f.)

202) Zur Verwendung und Funktion von Sprichwortern, Redensarten und anderen Elementen der Folklore in der Sprache der Helden vgl. T.V. Krivoščapova, Idejnochudožestvennye runkcii fol'klora $v$ proze Valentina Rasputina, in: Fol'klor i litenatura sibinielde Wust-9/83954791231

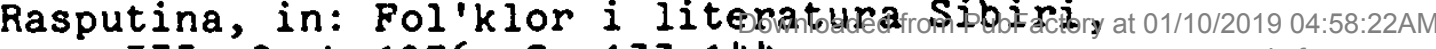
vyp. III, Omsk 1976, S. 133-144 
Она часто вспомннала поговорку стариков: первыя сын богу, второя царю, третьия себе на пропитание. (S.424)

Die Besonderheiten der Kinder werden so wiedergegeben, wie Anna sie sieht, und nahezu mit ihren eigenen Worten:

Ея казалось, что и дочь тоже должна стыдиться ее вон какая она красивая, грамотная, даже говорит не так, как говорят здесь: слова вроде те же, но, чтобы понять их, надо слушать изо всех сил. (S. 425)

Die Beziehung Annas $z u$ ihren Kindern und deren Bedeutung fur sie und ihr Leben werden nicht vom Erzähler beschrieben oder gar einer Wertung unterzogen, sondern sie werden deutlich, indem der Autor die Emprindungen und Gedanken wiedergibt, die die Anwesenheit der Kinder bei der Greisin auslost. Dabei findet er besondere Ausdrucksformen, die Mutterschaft und Mutterliebe als zentrales Merkmal dieses Charakters deutlich werden lassen:

\footnotetext{
Илья, Јиося, Варвара, Таньчора для того, казалось, и уезхали от матери, чтобы она потом заметила, как они иэменились, они привоэили ея себя как заботливое напомннание о годах: с последнея встречи прошло столько-то времени, столько-то, столько-то, и с кажшым таким приездом старуха, спохватываясь, перебегала вперед сразу на несколько лет. Получалось, что она старела годами, которые они привозили ей от себя, а не своими собственнымя, сама она неэаметно копошилась да копошилась бы на одном месте, покуда не придет ее час. (S. 424)
}

Diese im oritten Kapitel einsetzende Annăherung des Erzăhlers an die Perspektive und Innenwelt der Heldin setzt sich im folgenden Kapitel fort und steigert sich in den weiteren, Anna gewidmeten Teilen zu ausfunrlicher Bewubtseinsdarstellung, die die organisierende Funktion des Erzahlers zunehmend schwăcht. Je mehr die alte Anna zu Bewubtsein und Kraften gelangt, um so mehr und bereitwilliger tritt der Erzăhler zuruck und uberlabt ihr das Wort.

Das Eingenommensein Rasputins von seiner Gestalt, die Faszination, die dieser Charakter und dieses gelebte Leben auf inn ausuben, sind offensichtlich. Aber die innere 
Hingabe des Autors an seinen Stoff wird nicht deklarativ, nicht in auktorialen Kommentaren und Reflexionen zum Ausdruck gebracht, sondern zeigt sich in dem Bestreben, die Gestalt bis zum Ende auszuschopfen, bis zur aubersten Grenze dessen vorzudringen, was diesen Charakter ausmacht. Auf dieser Verlagerung des Erzăhlvorgangs

aus der Sphäre rein auktorialer Reflexionen in eine Sphăre der völligen Durchdringung des Gegenstandes (dosledovanija), die vorst8Bt zu etwas, das auBerhalb jenes Komplexes von Gefuhlen und Gedanken liegt, der dem Leser bereits wohlbekannt ist 203)

beruht die Eigentumlichkeit der Gestaltung des traditionellen dorflichen Charakters bei Rasputin und die hohe Authentizitat der Darstellung.

Diese bereits bei Vasilij Šukšin festgestellte radikale Verănderung des Verhaltnisses von Autor und Held wird auch von Rasputin bewubt reflektiert und nicht ohne Polemik mit der Frage der Glaubwurdigkeit und ăs thetischen Wirksamkeit von Literatur in Zusammenhang gestellt:

Mit der literarischen Gestalt, genauer: mit dem Charakter, den man zeigen mochte, beginnt eigentlich jede Geschichte, mit ihm kommt sie in Bewegung. So war es mit "Die letzte Frist" und auch mit "Leb und vergib nicht". Hier haben nicht die Probleme die Helden ausgewăhlt, sondern die Alte und Nastëna, die zur vollen Entfaltung inrer Charaktere in bestimmte Umstände gestelit sind, haben fur ihr Leben ganz natürliche Probleme. Ich möchte betonen: naturliche. Sie entstehen normalerweise aus der Philosophie und der Lebenserfahrung der Helden, aus der Situation und den Umstănden, in denen sie handeln. Und so sehr ein Autor mitunter verleitet wird, die Helden als ein Vermittlungsglied $z u$ benutzen, um die eigenen Gedanken auszusprechen, die ihm so wichtig erscheinen und die, unausgesprochen von den Helden, vom Leser dann unbemerkt blieben - ein wirkliches Problem wird auf diese Weise dann nicht entstehen. Das heibt, auber Willkur des Autors gegenuber seinen Helden kommt dabei nichts heraus. 204)

203) Cudakova, a.a.0., S. 232

204) Valentin Rasputin, Ich muBte mich von Matjora verabschieden, in: ders., Die letzte Frist. Leb und vergib nicht, Leipzig 1980, S. 444-446, S. 445 
Nur eine solch ernsthafte Haltung des sich nicht uber seine Gestalten erhebenden Autors bringe lebendige Helden hervor und nicht solche, die sich "wie Marionetten an Drăhten bewegen" 205).

Die Realisierung dieses Prinzips kommt in der Prosa Rasputins nicht nur in der quantitativen Reduktion des Erzăhlertextes und der entsprechenden Ausweitung und hohen Autonomie der Personentexte zum Ausdruck, sondern fuhrt $z u$ einer Personalisierung des gesamten Erzăhlvorgangs, in dem die Interferenz von Erzăhlertext und Personentext als strukturprăgendes Merkmal kardinale Bedeutung erhălt 206). Bereits bei Śukšin wurde auf das Einfließen der "fremden Stimme" in den Erzăhlertext hingewiesen. Wăhrend jedoch in seinen Erzăhlungen von einer Dominanz des Heldenwortes und einer weitgehenden Reduktion des Erzahlertextes auf "Regieanweisungen" gesprochen werden kann, ist fur die sprachliche Struktur der Prosa Rasputins die Annaherung von Erzahler- und Personenrede kennzeichnend, was einem hohen Anteil des Erzăhlens in "nesobstvenno-prjamaja reć" und "nesobstvenno-avtorskoe povestvovanie" entspricht. Gegenuber Šuǩin stellt dies einen weiteren Schritt des Autors in der Bewaltigung des neuen Sprachmaterials und auf dem Wege einer Erneuerung der Literatursprache durch Hinwendung zur lebenden Volkssprache dar, ein Schritt, der gerade im Hinblick auf die gestellte Aufgabe der ganzheitlichen Darstellung des traditionellen dorflichen Charakters von zentraler Bedeutung ist. Mariètta Čudakova beschreibt diese sprachliche Annăherung des Autors an seine Gestalt:

Bedachtig und mit noch groberer Schwierigkeit gestaltet Rasputin die Erzăhlerrede, die natülich nicht mit der Personenrede der alten Frau verschmilzt, aber doch auch nicht von dieser durch die gewohnte Wand der schriftsprachlichen Tradition getrennt ist. Wenn der Erzahler berichtet, was

205) Ebenda

206) Zum Problem der Textinterferenz in der innovatorischen Gegenwartsprosa und den inr zugrundeliegenden, bereits bei Dostoevskij entwickelten Verfahren vgl. Schmid, a.a.0, S. $79 \mathrm{fr}$. 
die alte Frau denkt, wie sie sich mit Muhe bewegt, so schimmern dabei immer wieder nicht nur die Empfindungen der Greisin, sondern auch ihre eigenen Worte durch. Nicht das dialektgefärbte, lokale Wort, mit dem ihre direkte Rede durchsetzt ist..., sondern jenes, noch schwieriger ausfindig zu machende, durchaus literatursprachliche Wort, das lediglich durch seinen besonderen Gebrauch die volkstumliche Gefuhls- und Sprachstruktur aufdeckt...20')

Die Kritikerin verweist auch auf die Schwierigkeiten ditses Versuchs, alles "neu" zu schreiben, bei dem der Autcr sich nicht auf eine bereits herausgebildete literatursprachliche Tradition stutzen kam, und zugleich auf im stilistischen Gefuge des Textes auftretende Mangel, wobei sie jedoch vor allem den produktiv-schrpferischen Gehali dieser Bemuhungen betont:

Aber diese Unbeholfenheit ist derzeit wertvoller als perfektes konnen. Wir haben es mit einer Prosa zu tun, die gleichsam lernt, komplizierte und einfache Dinge, vergessene Details auf neue Weise zu beschreiben, mit einer Prosa, die sich noch nicht von der Erde losgerissen hat und sich noch schwerez Schrittes fortbewegt. Dafur gibt es in ihr auch nicht das schnelle, aber trugerische Hingleiten an der Oberflache, sondern sie ist fest verkettet mit inrem Material. 208)

Der Anfang des vierten Kapitels zeigt deutlich diese Annăherung des Autors an Bewubtsein und Sehweise der alter Anna. Bereits der erste Satz. ("Und wieder erblickte die alte Frau den Morgen", S. 439), in dem Zabelin Anklänge an den biblischen Vers $z u$ erkennen glaubt ${ }^{209)}$, fuhrt an die besondere Situation und die Innenwelt der Heldin heran. Was im folgenden auf den ersten Blick als Deskription und Narration eines wertenden Erzăhlers erscheinen mag, erweist sich bei naherer Betrachtung als durchsetzt mit Benennungen und Wertungen, die dem Bewubtsein Annas entstammen. In die Beschreibung Annas, die auf das Licht wartet, flieben Momente inrer Sehweise ein, die dem Tex eine volkstumlich-poetische Fărbung verleihen:

207) Ćudakova, a.a.0., s. 234

208) Ebenda, S. 235

209) Zabelin, a.a.0., s. 82 
Наконец окошко, которое было олике к утру, стало очнщаться от темноты, и сквозь него глаза увидали дальше, потом проступило на своем месте и второе окоико, и с двух сторон в комнату потекли ранние и холодные, прехде солнца, сумерки. (S. 439)

Die Ubergănge von Erzăhler- und Personenperspektive sind hier fliebend, die Formen des "nesobstvenno-avtorskoe povestvovanie" und der "nesobstvenno-prjamaja rec'" vermischen sich und lassen sich in ihren sprachlichen Merkmalen kaum noch unterscheiden:

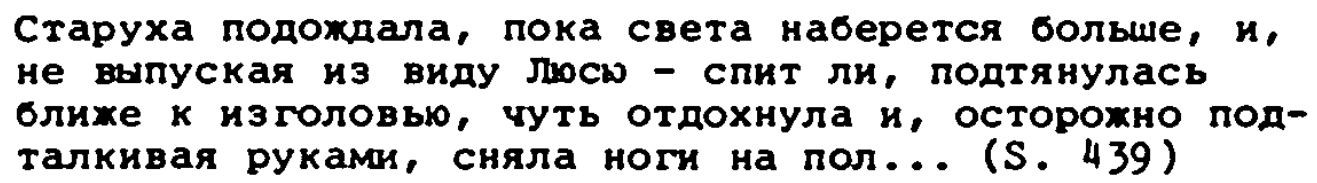

Die besondere sprachliche Form erlaubt hier die minuziose Wiedergabe des Zustandes der neu zum Leben zurückkehrenden Anna und die nahezu vollständige Erfassung der Gestalt in ihrer Einheit von ăuberen und inneren, physischen und psychischen Vorgăngen und Befindlichkeiten. In ihr spiegelt sich die enge und lebendige Beziehung Annas zu den Dingen und der Bewegung um sie herum, zu den Teilen inres eigenen Korpers ebenso wie zum anbrechenden Morgen und der durch inn hervorgerufenen Veränderung im Raum, zum Licht, zur Sonne. Die Wiedergabe dieser Beziehung und der damit verbundenen Empfindungen wirkt durch die Sprache authentisch und verleint der Gestalt eine besondere Poesie:

Глазам так легче было смотреть... ...Вот и ноги совсем не омертвели, кровь до них еие достанет. (S. 439 )

Солнце по утрам не попадало в избу, но, когда оно взошло, старуха узнала и без окошек: воздух вокруг нее заходил, заиграл, будто на него что дохнуло со стороны. Она подняла глаза и увидала, что, как лесенки, перекинутые через небо, по которым мохно ступать только босиком, поверху бъот суматошные от радости, еме не нашедияе земшо солнечные лучи. (S.439r.)

Dies ist nicht die Sprache Annas, aber der Autor vollzieht hier eine deutliche Annăherung an die gemăchliche und 
bildhafte Art des Denkens seiner Gestalt, was den lyrischen Ton angebracht und gerechtfertigt erscheinen labst. Bezeichnend fur die Unaufdringlichkeit des Autors und sein Gefunl fur das MaB ist der unmittelbare Ubergang von diesem poetischen Absatz $z u$ den "banalen" Dingen des Alltags ("Die alte Frau horte die Kuh im Stall brullen..." S.440), den morgendlichen Gerauschen des Hauses, deren vertraute Wahrnehmung ganz aus der Perspektive Annas wiedergegeben wird.

Die Vereinigung von realistischer Zeichnung der außeren Gegebenheiten - die Schwăche und Hinfalligkeit der Heldin, ihr abgezehrter Korper, das Brülien der Kuh, das Klappern der Tur, die Erwăhnung von Ninkas "Topf" usw. und lyrisch-poetischer Wiedergabe der Innenwelt Annas 210) und ihrer Beziehung $z u$ all diesen Gegebenheiten, die den ganzen ersten Teil des vierten Kapitels kennzeichnet, ist ein fur die Gestaltung des Charakters der Heldin zentrales Verfahren, das die Authentizitat der Darstellung wesentlich mitbewirkt und einer Erhohung und Idealisierung der Gestalt entgegenwirkt.

Die Annäherung von Erzăhler- und Personenrede in den Formen der "nesobstvenno-prjamaja rec'" und des "nesobstvenno-avtorskoe povestvovanie" ermoglicht in "Poslednij srok" eine Aufdeckung und kunstlerische Verdichtung des Charakters und BewuBtseinstyps, wie sie, gestutzt allein auf die Sprachmittel der Person und die ihnen innewohnenden charakterologischen Eigenschaften, nicht moglich ware, die aber dennoch eine Darstellung des Charakters "von innen heraus" gestattet und die "Illusion" seiner Unabhängigkeit vom Autor (Belaja) bewirkt.

Ihren Hohepunkt erreicht diese Art der Darstellung in den beiden letzten der Gestalt Annas gewidmeten Kapiteln, in denen der Autor zu ausfunrlicher BewuBtseinsdarstellung ubergeht und in den Erinnerungen und Reflexionen der Hel-

210) Zur Funktion des Lyrischen bei der Wiedergabe der Psychologie der Gestalt in "Poslednij srok" vgl. V. Kamjanov, Zemlja - émpirei - obratno, in: Družba narodov, 1974, Nr. 3, S. 255-267 
din ein ganzes Leben und die Philosophie dieses Lebens entstehen labt.

Das neunte Kapitel beginnt mit der Feststellung, daB nur noch Anna auf Tan'cora wartet. Die Reflexion des ersten Absatzes uber das ungehorige Verhalten der Tochter, die nicht angereist ist, erfolgt, gleichsam im Kontrast $2 u$ der anschliebend wiedergegebenen Haltung Annas, aus der Perspektive der Kinder. Die Peststellung, daß "nur noch die alte Prau ununterbrochen wartete" (S. 504), leitet uber zur Sehweise der Hauptgestalt, und obwohl der Erzăhlbericht im folgenden weitgehend durch den Erzăhler gestaltet wird, druckt sich in inm doch vor allem die Person aus und kaum ein wertender und den Erzăhlvorgang organisierender Erzahler. Aufgrund der Durchsetzung des Erzahlberichts mit Wertungen und Wendungen, die der Perspektive der Heldin entstammen oder sich ihr annthern, gibt dieser vornehmlich Bewubtsein und Bewustseinstatigkeit der Person wieder:

Глаза у старухн бил хороше, при ее годах грех жаловаться, но и они уставали смотреть в одно место, будто им приходилось дерхать тяжелую заборку на весу, на себе. Старуха не давала им пован, заставляла смотреть - на что еи теперь их бло беречь, для Kakoh нухmе? (S. 505)

Die Bewubtseinstătigkeit der Heldin organisiert auch die Bewegung des Sujets. In der Auswahl der ăuberen Wirklichkeitsausschnitte folgt der Erzahler dem Horizont der wahrnehmenden Anna:
И правда, посльшались шаги, зашевелилась занавеска - вошла Варвара. Своим горячим, несмиривиимся умом старуха подумала, что Варвара пришла известить ее - Таньчоре, но та, будто нарочно, чтобы подразнить мать, стала рассказывать, кто что в деревне говорит про ее сон. (S. 505)

Auch die Wiedergabe der inneren Vorgănge folgt der Bewegung des Bewubtseins der alten Prau nach dessen innerer Logik. Vom Erzăhler wird nur das mitgeteilt, was Anna bereits selbst bewubt geworden ist: 
В конце концов старуха почувствовала, что устала и больше не в состоянии сидеть, а от беспрерывного слушания в голове у нее начался гуд. Она припомнила, что и радость и нерадость любят являться нечаянно, как снег на голову, и упрекнуло себя за то, что ждала черезчур сильно... (S. 506)

Den Zustand sehnsllchtigen Erwartens der Tochter, in dem Anna sich befindet, versteht der Autor, bis in die feinsten psychischen Regungen wiederzugeben, wobei die fast suggestive Art des Erzahlens ein unmittelbares Mitemprinden des Lesers erzeugt.

Erst nachdem Anna fur sich eine Erklarung dafur gefunden hat, warum die Ankunft der Tochter sich so lange verzogert, wird sie ruhiger, weicht die innere Anspannung, und es beginnen Erinnerungen in ihr wach $z u$ werden an fruhere Situationen des Wartens auf Tan'cora, an die Briefe der Tochter und uberhaupt an die unterschiedliche Art der Kinder, Briefe zu schreiben. Und Annas Gedanken und Erinnerungen gleiten von den Briefen uber zu den unterschiedlichen Charakteren der Kinder und weiter zuruck zu deren Jugendzeit im Elternhaus. Diese Erinnerungen Annas, die im zehnten Kapitel fortgesetzt werden, veranschaulichen nicht nur die Art und Weise, wie die im Sterben liegende Greisin auf ihr Leben zuruckblickt und es Uberdenkt, sondern geben zugleich einen Einblick in dieses vergangene Leben und tragen zur Vervollständigung und Verdichtung des von inm hervorgebrachten Charakters bei. Anna erinnert sich nicht nur an aubere, sondern vor allem an innere Situationen, so daB in der Retrospektive vornehmlich Bewubtseinszustände und -vorgănge aus der Vergangenheit der Heldin wiedergegeben werden:

Эти письма были специально для старухи - специально для нее таньчора собиралась их писать и писала, специально для нее их везли и несли, а чтобы не потерялись, на конвертах, на которых рукоя таньчоры было выведено имя матери, ставили вахные печати. То, что Таньчора хотела сказать ея, она говорила не через кого-то, а прямо, как бы видя перед собоя мать, она не писала "скажите маме", она писала: "мама моя", и это ласково-призывное и одинокое "мама моя!" заставляло старуху замнрать от счастья и страха... 
Die hier anwesende personale Perspektive ist nicht die der im Sterben liegenden Anna der Erzăhlgegenwart, sondern die einer fruheren Anna, mit deren Wiedergabe der Autor einen zentralen Zug ihres Charakters - Mutterschaft und Mutterliebe - in der Vergangenheit beleuchtet. Durch die Verknupfung und Uberlagerung verschiedener Zeitebenen in der Retrospektive werden auf diese Weise Psychologie und Bewubtseinstyp Annas auch in der Zeit erfabt, was den Einblick in inre Gestalt vertieft und die Vorstellung von diesem Charakter erweitert.

\subsubsection{Die geistige Welt Annas}

Ein besonderer Reiz des Charakters der alten Anna ergibt sich aus der Verbindung von auberer Schlichtheit und Durchschnittlichkeit ihrer Gestalt und ungewohnlicher Schonheit und Poesie ihrer inneren Welt. Nichts an dem Leben und Schicksal der Heldin, als deren Prototyp dem Autor die eigene crobmutter diente ${ }^{211}$ ), ist ausgefalien. Ein gewohnliches Bauernleben, das vor allem in harter Arbeit und der Aufzucht der vielen Kinder bestand und in dessen Bedingungen sich die historischen stationen des russischen Dorfes widerspiegeln: Kollektivierung, Krieg, die Not der schweren Nachkriegszeit, die Ruckstandigkeit und Abgeschiedenheit von den groben Zentren und Bewegungen des modernen Lebens.
А старуха хила нехитро: рохала, работала, ненадолго падала перед новым днем в постель, снова вскакивала, старела - и все это там же, где родилась, никуда не отлучаясь, как дерево в лесу, и справляя те же че- ловеческие надобности, что и ее мать. (S. 531)

Auch die geistige Welt Annas, die weder lesen noch schreiben kann, ist ganz in diesem dörflichen Leben befangen. Eine Beruhrung mit der Welt drauben und dem modernen Leben hat sie nur durch die Kinder, und selbst diese ist

211) Vgl. Zacharova, a.a.0., S. 84 
sehr flüchtig. Das gegenwärtige Leben der Kinder wird von Anna nur wenig reflektiert, von ihren Lebensbedingungen hat sie kaum eine Vorstellung:

у Люси была какая-то другая, непонятная, неизвестная старухе жизнь, в котороя многое делается поновому, может, дахе умирают по-другому - старуха не знала. (S. 425)

Poesie und Schönheit dieses Charakters erwachsen aus der Geschlossenheit und inneren Harmonie, die ihn auszeichnen, und indem der Autor bis in die feinsten Nuancen das aufdeckt, was das Leben der Heldin ausmachte und es so in sich geschlossen und stabil hat sein lassen, zeigt er Neues und Besonderes in diesem so traditionellen und so gar nicht ungew ohnlichen Charakter. Die Gestalt Annas labst an die Frage erinnern, die der Ich-Erzahler in Šukšins "Djadja Ermolaj" sich am Grabe des Dorfbrigadiers stellt:

...gab es in diesem inrem Leben einen tieferen Sinn? Lag er gerade darin, wie ste inr Leben lebten oder gab es uberhaupt keinen Sinn, gab es da allein Arbeit, Arbeit... Haben sie nur gearbeitet und Kinder zur Welt gebracht... 212)

Rasputin, so scheint es, hat mit seiner Heldin hier eine küntlerisch uberzeugende Antwort gegeben.

Annas Vorstellungen von der Welt und inrem Leben wurze in tief in den uberlieferten Traditionen, in den auf der Grundlage jahrhundertelanger Erfahrung herausgebildeten und von Generation $z u$ Generation weitergegebenen Anschauungen und Maßstaben des Volkes. Es sind dies nicht abstrakte Leitsatze, sondern verinnerlichte, in Fleisch und Blut ubergegangene und sich in der Beziehung Annas $z u$ den Dingen und Erscheinungen ausdrückende Vorstellungen, wie der Mensch zu leben hat. Dieses Eingebundensein der Heldin in die Tradition ist dementsprechend auch nicht Gegenstand der Reflexion weder des Erzahlers noch der Personen, sondern wird konkret und fur den Leser erfahrbar

212) Sukśin, Rasskazy, a.a.0., S. 381 
wiedergegeben, vermittelt uber das Empfinden Annas, ihre Art, die Welt wahrzunehmen.

Kennzeichnend ist hier zunăchst die Bildhaftigkeit der Sprache und Gegenstăndlichkeit der Wahrnehmung, die Uberall im Text die Anwesenheit der Perspektive Annas signalisieren:
...старуха знала, что теперь иэба - как поставленная на печку посудина с варевом, которое вот-вот эахо- дит, заговорит. (S. 440)

Volkstumlichkeit des Denkens spiegelt sich in solchen Bildern ebenso wie die Nahe und geradezu intim-familiăre Beziehung der Heldin zu allem, was ihren Lebensbereich ausmacht, was vom Autor besonders feinfuhlig in inrer Art, Zwiegesprăche mit den Dingen und Erscheinungen zu fuhren, wiedergegeben wird:

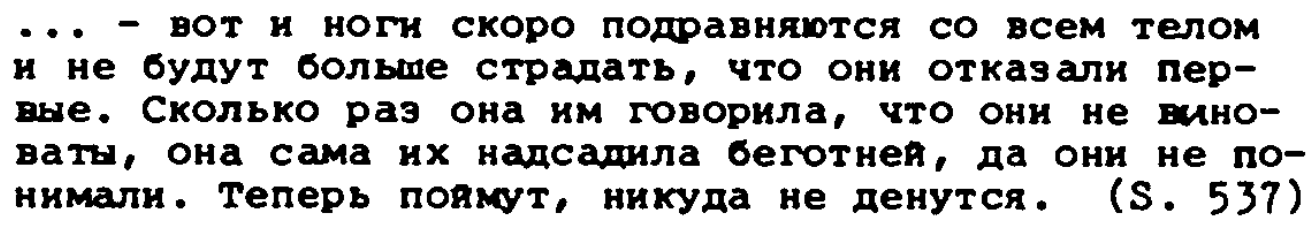
вые. Сколько раз она им говорила, что они не виноваты, она сама их надсаднла беготнея, да они не понимали. Теперь поямут, никуда не денутся. (S. 537)

Auch in der personifizierten Haltung Annas zum Schlaf, der nicht kommen will, wird diese naiv-anschauliche, an volkspoetische Betrachtungsweisen anklingende Weltbeziehung aufgedeckt:

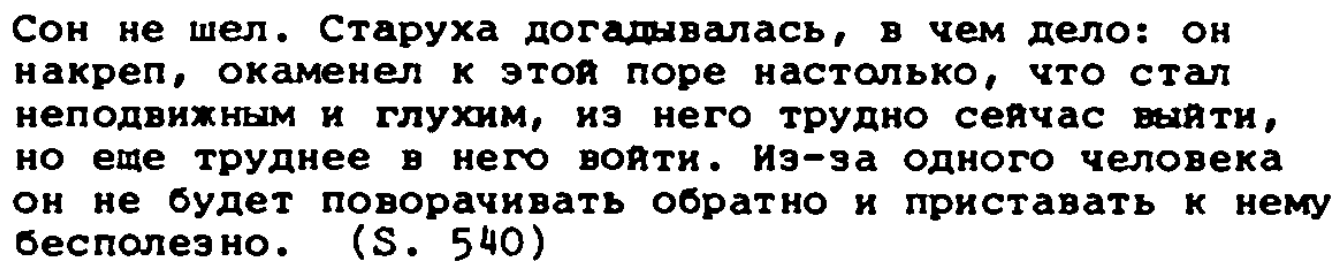
неподвижным и глухим, из него трудно сеячас вити, но еще труднее в него вояти. Иэ-за одного человека он не будет поворачивать обратно и приставать к нему бесполеэно. (S. 540)

Ganz in dieser volkstumlichen Vorstellungswelt bewegt sich auch die Haltung der Heldin zum Tod, zu Gott, zur Natur. Der Tod ist fur Anna wie ein lebendes Wesen, ein Zwilling ihrer selbst, der nichts Schreckliches an sich hat: 
его в себя, и они уже никому не отдадут друг друга. (S. 526)

Er, den sie ein Leben lang hinter sich her gefuhrt hat, ist ihr nah und vertraut wie eine Freundin:

За последние годы они стали подружкамн, старуха часто разговаривала с нея, а смерть, пристроивиись где-нибудь в сторонке, слушала ее рассудительныя wenoт и понимахmе взшыхала. Они договорились, что старуха отоидет ночью... (S. 525)

Der Gedanke an den Tod ist fur Anna nicht verbunden mit der Erwartung eines "Jungsten Gerichts", einer Instanz, vor der es gilt, Rechenschaft abzulegen, sondern mit der Erwartung der Offenbarung des letzten Geheimnisses des Lebens. Und in ihrer Vorstellung davon, wie sie sterben wird, tritt ganz in den Vordergrund das Geheimnisvolle und die Poesie dieses Geschehens:

\footnotetext{
Она уснет, но не так, как всегда, неэаметно для себя, а памятно и светло - словно опусхаясь по ступенькам куда-то вниз и на кахдоя ступеньке приостанавливаясь, чтобы осмотреться и различить, сколько ея еще осталось ступать. Когда она наконец соядет на земпо, похрытую сверху хелтоя соломоя, и поямет, что теперь полностьо уснула, навстречу ея с лестниub напротив спустится такая пе, как она, худая старуха и протянет руку, в которую она должна будет вручить своя ладонь. (S. 529)
}

Die Reflexionen Annas uber ihren Tod, die Bilder und Vorahnungen, die er in ihr hervorruft, ihre Vorstellung vor Akt des Sterbens und die Sorge, daB er wurdig vonstatter: gehe - das einzige, was sie an ihrem Tod beunruhigt -, nehmen breiten Raum ein und gehoren zu den starksten unc eindrucksvollsten Teilen der Erzăhlung. Fur das Verstăndnis des Charakters der Heldin, seiner Einbindung in die Tradition, sind sie uberaus wichtig.

In der Haltung der alten Anna zum Tod mit inren vielfaltigen Bezügen zu altem Volksglauben und Volkspoesie spiegelt sich die bewahrte, lebendige Beziehung inrer geistigen Welt zu uralten Vorstellungen des Volkes, die dem Ritual des Sterbens und dem Akt des Abschiednehmens groke 
Bedeutung beimessen. Am deutlichsten und unmittelbar kommt sie zum Ausdruck in der Episode, da Anna ihre Tochter Varvara bittet, sie nach inrem Tode nach alter sitte zu beweinen und inr sogar das Klagelied beibringt, mit dem Anna selbst schon ihre Mutter ins Grab geleitet hat ${ }^{213)}$. Auch die Religiositat Annas druckt sich in dieser Vorstellungswelt aus. Es ist ein quasi vorreflexives, ganz persönliches Verhältnis der Heldin zu "ihrem" Gott, das der Autor anschaulich wiedergibt. Annas Vorstellungen von Gott und seinem Wirken erinnern bisweilen an Volksmärchen und Legende:

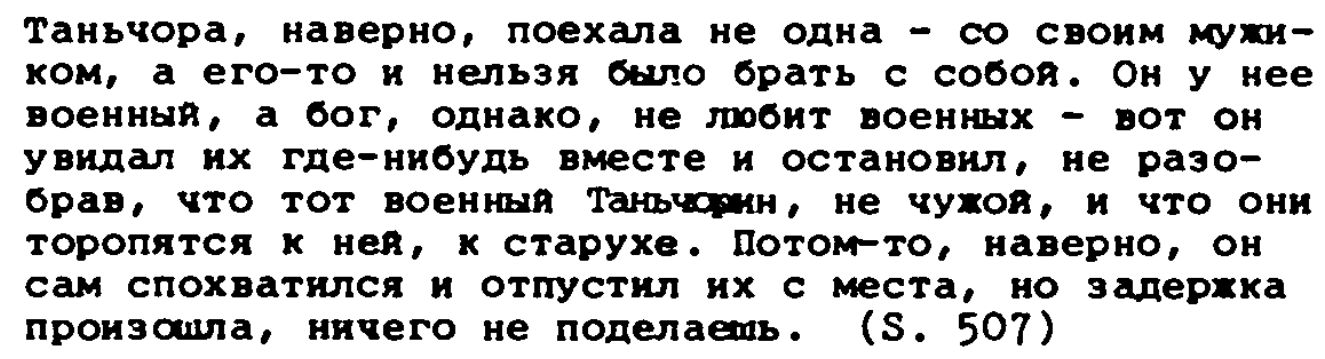

Gott ist fur Anna ein Synonym fur das Gute, Hoffnungsvolle, nirgendwo in ihrer Vorstellung tritt er auf als der furchtbare, strafende Gott und letzte Prufstein inres Gewissens.

Надехда идет от бога, думала старуха, потому что надехда робка, стеснительна, добра, а страхи, которые от черта, навязчивы и грубы... (S. 510)

So einfach und so unlosbar verbunden mit der Arbeit und der tăglichen Sorge um die Grundfragen der Lebenserhaltung das Leben Annas war, so einfach und ganz und gar bezogen auf das in diesem Leben Erfahr- und Erlebbare ist auch inre Betrachtungsweise. Die Gedanken Annas uber Leben und Tod bringen deutlich diese organische Einheit von Lebensanschauung und Lebenspraxis zum Ausdruck, auf der die innere Stabilitat ihres Charakters und Lebens berunt.

213) Vgl. Krivośćapova, Rol' fol'klora, Diss., a.a.0., S. $71 \mathrm{f}$. 
Zu dieser Lebenserfahrung gehort freilich ihr einfacher, aber starker Glaube. Er ist Ausdruck eines ungebrochenen, nicht reflektierten Verhaltnisses zur Transzendenz. Am Verhalten zum Tode bewahrt sich für Rasputin - ganz im Schillerschen Sinne die Wahrheit des Sittlichen in inrer letzten und nicht mehr aufhebbaren Konsequenz. 214)

Anna hat nicht nur keinerlei Furcht vor dem Sterben, ihrem Denken fehlt uberhaupt jegliche Polaritat von Leben und Tod. Der Tod ist fur sie Teil inres Lebens:

Не умирает только тот, кто не рохnается. (S. 539)

Und sie verhalt sich $z u$ ihm "gerade wie $z u$ einer Sache inres Lebens"215). Sehr anschaulich läbt Rasputin diese Auffassung Annas in ihrer Vorstellung von der Individualităt nicht nur eines jeden Lebens, sondern auch des Todes zum Ausdruck kommen:

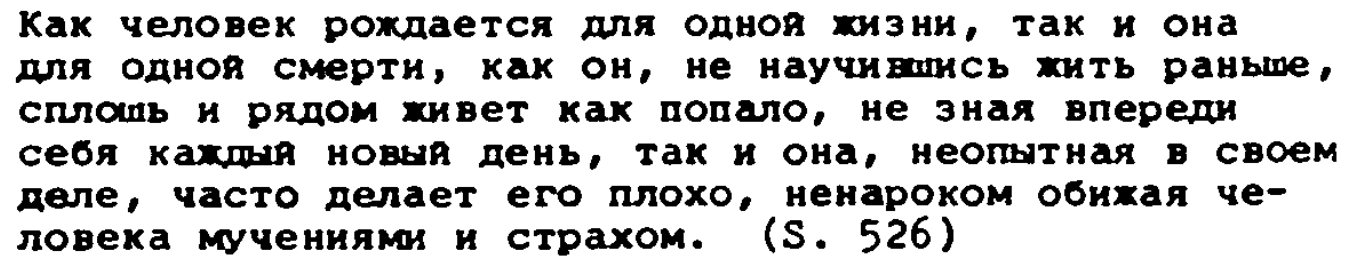
сплопь и рядом хивет ках попало, не зная впереди себя кахшыя новыя день, так и она, неотытная в своем деле, часто делает его плохо, ненароком обихая человека мучениямя и страхом. (S. 526)

Aus diesem Grunde kann Anna auch nicht begreifen, warum kleine Kinder sterben mulssen, und ihre Gedanken und der Hader mit Gott in dieser Frage geben die Emprindungen der Mutter wieder, die selbst funf Kinder ins Grab legen mubte.

Die Selbstverstăndichkeit und Gelassenheit, mit der die Heldin ihren Tod erwartet, wurde von der Kritik immer wieder besonders akzentuiert und war hăufig Anlab zum Vergleich der Erzăhlung mit anderen literarischen Darstellungen des Menschen an der Schwelle des Todes:

214) Rolf-Dieter Kluge, Valentin Rasputin. Zur Rezeption Cechovs und Dostoevskijs in der sowjetrussischen Dorfprosa, Manuskript im Druck

215) Sergej Zalygin, Povesti Valentina Rasputina, in: Rasputin, Povesti, a.a.0., S. 3-12, S. 5 
Dieses naturliche Ineinanderflieben von Leben und Tod als komplementare Erscheinungsformen des Seins ist schon bei Turgenev und Tolstoj als staunenswerte naturliche harmonie des russischen Bauern bewundert worden, aber die BewuBtseinsstadien der Vorbereitung und Erwartung eines solchen friedvollen Todes sind - soweit ich sehe - noch nie so einfuhlsam literarisch gestaltet worden. 216)

So sind Annas Gedanken Uber den Tod zugleich und vor allem Gedanken über das Leben und seinen Sinn, und die Frage, wie man sterben soll, wird zu einem Teil der Frage, wie man leben soll.

Annas Verstăndnis des Lebens beruht auf der uberaus wachen und geschärten Empfindung seiner Unendlichkeit und ununterbrochenen Kontinuitat, innerhalb derer das einzelne Menschenleben als Glied einer endlosen Kette begriffen und in dieser seiner Punktion bejaht wird. Am deutlichsten tritt diese "einfache Wahrheit" hervor in der Erinnerung Annas an die Geburt inres Enkels, die ihrem Sohn Michail die Erkenntnis brachte, als Vater "an der Fortfunrung des Menschengeschlechts" teilzuhaben:

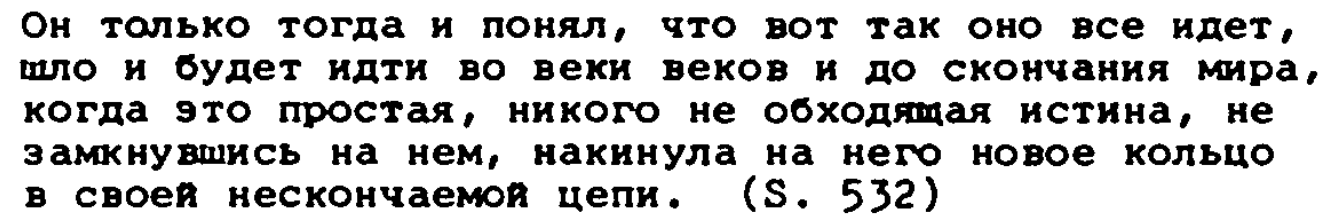
шло и будет идти во веки веков и до скончания мира, когда это простая, никого не обходящая истина, не замкнувияс на нем, накинула на него новое кольцо в своея нескончаемон цепи. (S. 532)

Und es ist von Bedeutung, daB im AnschluB an diese Erinnerung die Vision Annas folgt van dem alten, zerschlissenen Hăuschen mit den geschlossenen Fenstern, die die Erinnerungen an ihre Kinder enthalten, und die uberleitet $z u$ der von geheimnisvoller Poesie getragenen Passage:

Вся жизнь тут, в этих окошках. Растворяя их и гляди, чем ты, старуха, была богата, какие воспомннания, сохранивияс, пошевелят после тебя послушные ягодные кусты на берегу реки, ветки береэы на опушке леса или пахнут кому-то в лицо, вызвав в нем смутные и тревожные предчувствия, для которых в нем ничего не было... (S. 532)

216) Kluge, Zur Rezeption Čechovs, a.a.0.; vgl. auch Olga Gladyševa, Stariki, in: Volga, 1973, Nr. 1, S. 159-166, S. 162; Baranov, a.a.0., S. 67 
Dieses Traumbild Annas unterstreicht ein weiteres Mal die zentrale Bedeutung der Kinder fur die Heldin, denen fast alle ihre Gedanken vor dem Tode gelten und veranschaulicht die gleichsam aus dem Unterbewubtsein Annas hervorgeholte Auffassung und Sinngebung des Lebens. Das "alte, zerschlissene Hauschen" - das Leben Annas - erhalt seine Verbindung zur Welt durch die Penster - die Erinnerungen an die Kinder, in denen Anna weiterleben wird und in denen sie ihre Teilhabe an dem groben Ganzen des unendlichen Lebens betrachten und beurteilen kann. Mutterschaft und Mutterliebe erhalten hier fast die Bedeutung einer philosophischen Kategorie. Uber die Beziehung Annas zu ihrem eigenen Geschlecht, innerhalb dessen sie sich als Glied einer endlosen Kette begreift ("...sie hatte wen, den sie verlieb, und sie hatte wen, zu dem sie ging", S. 527f.), und aus der sich inre Vorstellung von Pflicht und Verantwortung ableitet ("Und inr Leben erschien ihr auf einmal gut, botmabig und glucklich. ...hatte sie es doch ganz den kindern gewidmet", S. 531f.), deckt der Autor das elementare Bewubtsein vom Zusammenhang des eigenen Lebens mit dem gesamten Erdenleben auf. Aus dieser Lebensauffassung resultiert auch die Selbstverstandlichkeit, mit der Anna ihr Leben und Schicksal angenommen hat und $z u$ ihm steht. In der geistigen Welt der Heldin Rasputins gibt es nicht die Sehnsucht nach einem anderen Leben, nicht die Suche nach einem tieferen, befriedigenderen Sinn als dem, den das reale Leben geboten hat, wie sie so charakteristisch sind für die Ubergangstypen und Sonderlinge Vasilij Šukšins. Anna steht voll und ganz zu ihrem Leben, so wie es sich ergeben hat, und sieht in dessen guten wie schlechten Seiten einen Sinn. Und bei der Wiedergabe aus der Perspektive Annas versteht es der Autor, vor allem die starken und stabilen züge hervortreten zu lassen, die diese Lebenshaltung, deren Kern darin besteht, "sein Leben zu besorgen", dem Charakter der Heldin verleint:

...но никогда ей не приходило в голову, что хорашо бы стать на чье-то месте, чтобы, как он, больше 
увидать или легче, как Он, сделать. Из своея шкуры не выскочишь - не змея... Справлять свою жизнь для нее было то радостьо, то мучением - мучительноя радостью, она не энала, где они сходились и где расходились и что из них для нее было полезнея, она принимала их в себя для себя, для своего продолхения, для того, чтобы озариться их потаяным огнем.

(S. 531)

Zweifellos handelt es sich bei dieser bewußten Identifikation mit dem eigenen, unverwechselbaren Schicksal um eine eindrucksvolle poetische Wiedergabe der aus praktischer Erfahrung geschopften Lebensauffassung einer Bauernschaft, "die inr schweres Schicksal ertragen und menschliche wurde unter unmenschlichen Verhaltnissen kraft dieses Wissens bewahrt hat"217). Aber starker als die traditionell mit dieser Lebenshaltung verbundene Schicksalsergebenheit und Demut, deren Poetisierung und Idealisierung dem Autor hăufig zum Vorwurf gemacht wird, tritt bei Anna ein anderes Moment hervor. In ihrer Aufassung vom Sinn des Lebens und der Pflicht des Menschen ist ein ausgeprăgtes Verstăndnis von der Individualitat und Einzigartigkeit eines jeden menschlichen Lebens enthalten, und aus der lebendigen Empfindung dieser Einzigartigkeit und Unwiederholbarkeit der eigenen Existenz bezieht sie wesentlich ihr Verantwortungsgefuhl und inre Kraft:

Но она не жаловалась на свою жизнь, нет. Как можно жаловаться на то, что било твоим собственным, болыше ничьим, и что выпало только тебе, больше никому? Как пропла, так и ладно, во второя раз не начнется. Потому-то и хватает человеку одноя жнзни, что она у него одна, - двух бы не хватило. (S. 530f.)

Die Lebensauffassung der heldin ist verankert in einer festen, uber Generationen hinweg weitergegebenen Ordnung mit stabilen sittlichen Orientierungen, deren Kriterien aus der unmittelbaren praktischen Lebenstatigkeit des Menschen geschopft sind. Von essentieller Bedeutung für die philosophische Position Rasputins ist die Idee des Zusammenhangs dieses traditionellen Wertesystems mit der hoheren Ordnung der Natur, ihrem "ewigen Kreislauf".

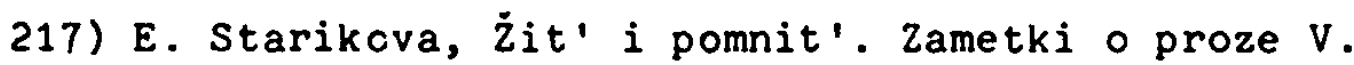
V. Rasputina, in: Novyj mir, 1977, Nr. 1 Hejid SVüst2963954791231 248, S. 241 
Uber die gelassene Haltung seiner Heldinnen zum Tod auberte der Autor:

Ich glaube, daB die lange Lebenserfahrung sie diese Ruhe gelehrt hat. Vor inren Augen wechselten Saat und Ernte, der Winter wurde vom Frunling abgelost, der Herbst nahm das Laub von den Baumen... 218)

Galina Belaja beschreibt diese Art der Lebenserfahrung năher:
Alles in dieser Welt war naturlich, die Geburt wie der Tod, alles in ihr hatte seinen erkennbaren An- rang und muste folglich auch sein in der Natur so oft beobachtetes Ende haben. Der Tod verlor seine Dramatik angesichts der ewigen Fortdauer dieser Er- scheinung, die fulr alle gleichermaben Gultigkeit be- $s a B$, sowie auch durch die ganz offensichtliche Tat- sache, dab das Leben naturlicherweise verschiedene Stadien aufwies: Das Stadium des Werdens, der Blute und des Vergehens. 219)

Den Naturdarstellungen kommt in allen Erzăhlungen Rasputins wesentliche Bedeutung zu. Auch wenn sie in "Poslednij srok" weniger auffaliig und nicht so umfassend begegnen wie in den beiden folgenden Novellen, ist ihre Funktion hier doch bedeutsam und vielfaltig. In Bezug auf die Gestalt Annas wird die Beschreibung der Natur zum Mittel der Poetisierung und psychologischen Charakterisierung. Das wenige, was von der Natur $z u$ ihr durchs Penster dringt, wird von Anna besonders intensiv wahrgenommen und weckt zartliche Vertrautheit:
на полу рядом со старухоя играло солнце, не боясь худобы, прннялось гладить и пригревать косточки, ея стало совсем хорошо и снова захотелось заплакать, будто она начала С ног подтанвать н оседать. Она осмелилась и отцепила от кровати руки, сняв с ннх тяхесть и размпиля, что если она упадет, то упадет на солнце и пристанет к нему... (S. 487)

Die Natur, deren Beschreibung in Gestalt der Sonne, des Morgens, des voranschreitenden Tages hăfig an volkspoe-

218) Rasputin, Das Leben ist das Wichtigste, a.a.0., S.154

219) G. Belaja, Vecnoe i prechodjašcee, in: Literaturnoe obozrenie, 1979, Nr. 2, S. 11-16, S. 16 
tische Motive anklingt 220), prăsentiert sich daruberhinaus in "Poslednij srok" in ihrem ewigen, sich wiederholenden Kreislauf:

В своя черед засветилось утро, стало проясняться, но еще до солнца с реки нанесло такого густого и непроглядного тумана, что все в нем утонуло, потерялось. (S. 406)

... - день был мягкия и легкия и ровно сошелся над самоя деревнея, а то и над само старухиноя избоя.(S.416)

Светлия вечер подходил к концу, в нзбе, да и не только в избе - везде, выстывало, смежалось. (S. 431)

In dieser Weise wird der gesamte Gang der Erzăhlung begleitet von der unaufhorlichen Tatigkeit der Natur, die gleichsam als Leitmotiv zu dem langsamen Sterben Annas den Gedanken vom ewigen Kreislauf des sich erneuernden und vergehenden Lebens wachhalt.

Die Greisin nahert sich vor ihrem Tode selbst der Erkenntnis des Zusammenhangs ihres eigenen Lebens mit dieser höheren Ordnung der Natur, den sie vor allem sinnlich und emotional wahrnimmt. Ihre Gedanken an das letzte Geheimnis des Lebens sind eng damit verbunden:

\footnotetext{
Она боялась гадать об этом и все-таки в последние годы все чаме и чаме думала о солнце, земле, траве, - птичках, деревьях, дожде и снеге - обо всем, что жнвет рядом с человеком, давая ему от себя радость, и готовит его к концу, обещая свою помощь и утешение. И то, что все это останется после нее, успокаивало старуху: не обязательно быть здесь, чтобы слишать их повторяющияся, зовущия голос - повторяющияся для того, чтобы не потерять красоту и веру, и зовуиия одннаково к жизни и смерти. (S. 488)
}

Auch die Erinnerungen Annas, die in der Erzăhlung breiten Raum einnehmen, sind fur den Charakter der Heldin von wesentlicher Bedeutung. Die Retrospektive Annas ermoglicht nicht nur einen Einblick in die Vorgeschichte der Hauptgestalt und der Kinder sowie in die Kontinuitat des Charakters in der Zeit bei engstem Zeitrahmen der Erzăhlhandlung. Das Erinnern selbst, die Fahigkeit Annas, lebendig im Gedăchtnis zu bewahren, was ihr Leben ausgemacht

220) Vgl. Judalevic, Avtoref. diss., a.a.0., S. 19 
hat, tritt als wesentliches Merkmal ihres Charakters hervor, dem gerade im Kontrast $z u$ der weitgehenden Erinnerungslosigkeit der Kinder erhohte und selbstăndige Bedeutung zukommt.

Sich erinnern bedeutet fur Anna nicht gegenwartsvergessenes Verweilen in der Vergangenheit. In ihren an emotionalen und seelischen Momenten reichen Ruckblicken spiegelt sich der Inhalt ihres Lebens, dessen sie sich, ganz unter dem Aspekt der Gegenwart und der von ihr aufgeworfenen Fragen, vergewissert. Anna lebt mit ihren Erinnerungen, an ihnen richtet sie sich auf und aus innen schopft sie Kraft. Etwa, wenn es uber ihre Erinnerungen an die Zärtlichkeiten der Tochter Tan'čora heiBt:

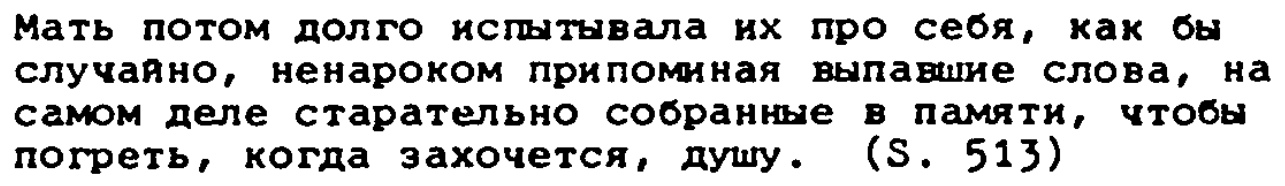

Ohne die "lichten und teuren Freuden" und die "teuren Traurigkeiten", die sie lebendig im Gedăchtnis bewahrt, "hătte sie sich längst in der Geschăfigkeit und im Gewimmel verloren" (S. 531).

Das Gedachtnis, die Erinnerung des Menschen an das, was war, ist bei Rasputin eng verbunden mit dem Grad an BewuBtheit und Verantwortungsgefuhl in Bezug auf das eigene Leben wie das Leben insgesamt sowie mit der Erkenntnis seiner selbst als zeitlichem Kontinuum. Eine Erkenntnis, die auch das Bewubtsein der Kontinuitzt des eigenen Ich nach dem Tode - in den Nachkommen und im Gedăchtnis der Menschen - einschliebt.

In allen drei Novellen des Autors kommt dem Problem der Erinnerung innerhalb der philosophischen Thematik der Wechselbeziehung von Mensch und Zeit und des Zusammenhangs der Zeiten grobe Bedeutung $z u^{221)}$. Es steht bei Rasputin in engem Zusammenhang mit dem Motiv des Abschieds, das in "Poslednij srok" die ganze Erzăhlung durchzieht

221) Vgl. hierzu besonders A.A. Dyrdin, Dialektika pamjati. Ċelovek $i$ vremja $v$ povesti V. Rasputina "Zivi $i$ pomni", in: Sovremennyj sovetskij roman. Filosorskie aspekty, Leningrad 1979, S. 178-193 
und die Situation der handelnden Personen prăgt. Fur Anna ist es der Abschied vom Leben und dem, was sie hinterlassen hat, fur die kinder ein Abschied von der Mutter. In Rasputins Prosa bezeichnet Abschied nicht nur den Umstand der Trennung von etwas als wesentlich und wertvoll Empfundenem, sondern er ist immer zugleich verbunden mit einem Zustand besonderer geistiger Anspannung und Empranglichkeit. Es ist eine Situation der verstarkten Reflexion und des Bilanzziehens, in der mit besonderer Schärfe die Alternative aufgeworfen wird: erinnern und damit bewahren oder vergessen und verlieren.

Diese gedankliche Intention des Autors realisiert sich in "Poslednij srok" in der Gegenuberstellung des Charakters der alten Anna und der Charaktere der Kinder.

\subsubsection{Der moderne Mensch}

- Die Charaktere der Kinder -

Der moralische Konflikt der Romanerzählung erwăchst aus der Gegenuberstellung des traditionellen, ganz in der volkstumlich-bauerlichen Lebensweise und Vorstellungswelt begrundeten Charakters der alten Anna und der von modernen Lebensformen und Denkhaltungen geprägten Charaktere der Kinder. Auch bei inrer Darstellung bleibt der Autor seinem Prinzip der "Selbstaufdeckung" der Gestalt treu. Einen Einblick in die Charaktere der Kinder erhalt der Leser vor allem durch deren Gesprache und Handlungen ihr Verhalten gegenuber der Mutter und untereinander sowie die Beschaftigungen, mit denen sie jeweils die Zeit des Wartens ausfullen. Auch hierbei mischt sich der Erzahler nicht kormentierend ein, sondern konstatiert und registriert, allerdings nuchterner und distanzierter als bei der Darstellung Annas, das Verhalten der Helden.

Die Kinder treten vorrangig im Dialog auf. Bewubtseinsdarstellung mit Hilfe der "erlebten Rede" oder des "nesobstvenno-avtorskoe povestvovanie" findet nur begrenzt Anwendung und dient - im Unterschied zur Darstellung 
Annas - nicht der umfassenden Aufdeckung der geistigen Welt der Helden, sondern lediglich der Wiedergabe momentaner Befindlichkeiten des Bewubtseins. Das fur die Gestalt Annas kennzeichnende Bemulhen des Autors um ganzheitliche Darstellung des Charakters fehlt in Bezug aur die Kinder. Rasputin zeigt sie nicht in ihrem gewohnten Lebensbereich, der weitgehend im Dunkeln bleibt, da der Erzăhler nur spärliche Pakten uber das eigentliche Leben der Kinder liefert: Il'ja und Ljusja leben in der Stadt. Ersterer hat zehn Jahre im Hohen Norden gearbeitet und ist unglucklich verheiratet. Ljusja ist kinderlos geblieben, Varvara dagegen, die im nahen Rayonzentrum lebt, hat wie die Mutter viele kinder zur Welt gebracht, erfăhrt aber an ihnen wenig Preude.

Annas Kinder werden in einer Ausnahmesituation gezeigt, die einen Einblick in ihren Charakter und dessen Bewertung vorrangig unter zwei Aspekten ermoglicht: Unter dem Aspekt des Abschieds von der sterbenden Mutter und dem der Wiederbegegnung nach langer zeit mit dem Ort ihrer Herkunft und den nächsten Verwandten. Das gilt auch fur Michail, der sich zwar in seinem gewohnten Milieu bewegt, aber durch den erwarteten Tod der Mutter und die Anwesenheit der Geschwister ebenfalls aus seinem gewohnlichen Alltag und Betatigungsfeld herausgehoben ist.

Die Unterschiede in Charakter und Personlichkeit der Geschwister sind groß. DaB es zwischen ihnen nach all den Jahren kaum noch Gemeinsamkeiten gibt, wird bereits im ersten Gespräch beim Abendbrot und im folgenden vor allem in den Spannungen zwischen der gebildeten Ljusja und der etwas einfaltigen Varvara deutlich. Vorlăufig eint sie jedoch noch der gemeinsame AnlaB ihrer zusammenkunft und das Gefuhl, das der bevorstehende Tod der Mutter in ihnen hervorruit.

Dieser Tod kam nicht uberraschend, und auch im BewuBtsein der Kinder bildet er den gesetzmäBigen und würdigen $A b-$ schlub eines langen, rechtschaffenen Lebens. Schmerz und Trauer sind dementsprechend gemessen, aber aufrichtig. Doch die Konfrontation mit dem Tod ruft bei den Kindern eine Betroffenheit anderer Art hervor, die im Dialog der beiden Brilder von Michail formuliert wird: 
- Скажи все же, а, - начал опять разговор миханл.

- ведь знали, что вечно жить не будет, что близко уж. Вроде привыкнуть долхны, а не по себе.

- А как иначе, - подтвердил илья. - Мать.

- Мать... это правильно. Oтца у нас нет, а теперь мать переедет, и все, и одни. Не маленькие, а одни. Скажем, от нашея матери давно уж никакого толку, а считалось, первая ее очередь, потом наша. Вроде загораживала нас, можно било не бояться. А теперь живи и думая. (S. 416甲.)

Es ist die verstărkt ins Bewubtsein getretene Erkenntnis der eigenen Sterblichkeit und das Gefuhl der Hilflosigkeit und Angst vor dem eigenen Tod, das sie auslost. Rasputin erfabt diese psychologische Situation der Kinder am Bett der Mutter, indem er den Charakter dieser Furcht und den Versuch inrer Verdrängung wiedergibt:

Они стояли вокруг матери, со страхом смотрели, не зная, что думать, на что надеяться, и этот страх совсем не походил на все прехние страхи, которые выпадали им в городскоя и деревенскоя хизни, потому что он был всего страннее и шел от смерти - казалось, теперь она заметила всех их в лино и больше уже не забудет. Страшно было еше и вндеть, как это пронсходит: когда-нибудь это должно было произоити и с ними, а они считали, что это то самое, и не хотели смотреть, чтобы не помнить о нем постоянно, и все-таки не могли отояти или отвернуться. (S. 417)

Und noch einmal dringt der Autor in die Psychologie seiner Helden vor, wenn er in ihnen den Anflug von Selbstmitleid und ein aus dem Unterbewußtsein hervordrăngendes dumpfes Gefuhl der Pflicht, beim Sterben der Mutter dabei zu sein, beschreibt:

Они ждали, особенно близко чувствуя, что они сыновья и дочери этоя старухи, и жалея ее, а ене больше жалея себя, потому что после ее кончины им останется горе, навязанное смертью, которое кончится не скоро. и еiце кахпыя из них по-своему чувствовал новое, не былавее прежде в нем горькое удовлетворение собоя оттого, что он здесь, при матери, в ее последния час, как и полохено сыну или дочери, и тем самым заслужил ее процение - какое-то другое, не человеческое промение, мало имеюмее отношение к матери, но все же необходимое в жнзни. (S. 418) 
Die Bedrückung löst sich, sobald Anna erste Anzeichen der Besserung zeigt, was sich deutlich im Verhalten der Helden widerspiegelt: In der hektischen Geschartigkeit der Frauen beim Kochen des Breis fur die Mutter und in der spübaren Erleichterung, die sich im scherzhaft-prahlerischen Gesprăch der Brüder Luft macht.

In dem Maße, wie sich der Zustand Annas bessert, weicht die Betroffenheit der Kinder, kehren sie zu inrer "normalen", gewohnten inneren Haltung zurück. Die Emprindungen am Sterbebett scheinen vergessen, an ihre Stelle treten Arger und Verdrossenheit uber die mibliche situation, in der man sich befindet. Diese machen sich in zunehmenden Spannungen zwischen den Geschwistern Luft, die sich am letzten Abend in einem fur alle peinlichen Auftritt Michails am Bett der Mutter entladen, und fuhren schlieblich zur vorzeitigen Abreise Ljusjas, Il'jas und Varvaras. Das Versagen der Kinder angesichts dieser "letzten Frist" und die sich daraus ergebende moralische Bewertung inrer Charaktere treten nicht so sehr in ihren konkreten Handlungen zutage - etwa darin, daB Michail und Il'ja sich an dem für die Trauergäste gekauften Schnaps betrinken oder daB Ljusja das Kleid zur Beerdigung am Bett der Mutter năht -, sondern vielmehr in der inneren Haltung der Helden, die der Autor in der Gesamtheit ihrer Gespräche und Verhaltensweisen aufdeckt und deren Konfrontation mit der geistigen Welt Annas die Darstellung zu einer Diskussion uber Lebensweise und Sittlichkeit schlechthin ausweitet.

Die Haltung der Kinder zum Tod der Mutter und allem, was damit verbunden ist, ist durch eine formale, an gesel1schaftlicher Etikette und Konvention orientierte Einstellung zu diesem Vorgang und der eigenen Pflicht dabei bestimmt. Diese Pflicht zu erfullen, sind sie bereit. Sie lassen Arbeit und Familie im Stich, um der Mutter den letzten Dienst $z u$ erweisen, und jeder trifft die in seinen Augen notwendigen Vorbereitungen: Ljusja năht ihr Kleid, die Bruder besorgen den Schnaps fur die Trauerfeier, und die koprlos umherlaufende Varvara bejammert die Mutter. 
Diese Haltung ist durchaus verbunden mit aufrichtiger Trauer, obgleich das letzte Wiedersehen fur die Kinder nicht von derselben Bedeutung ist wie fur Anna. Aus der Perspektive der beiden Bruder gibt der Autor eine ausgezeichnete Charakteristik dieser inneren Einstellung:

Братья понимали, что сеячас все главное для них состонт в том, чтобы ждать, но и ждать тоже мохно поразному и они исподволь ухе науали тревохиться, так ли ждут, как надо, не теряют ли даром время. Напоминание об умирающе матери не отпускало, но сильно и не мучило их: то, что надо было сделать, они сделали - один дал известие, другоя приехал, и вот водку вместе принесли - все остальное зависело от само матери или от кого-то там еще, но не от них - не копать же в самом деле могилу неготовому человеку! всегда у них была работа, а тут вдруг ее не стало, потому что перед бедоя, которая заступила за порог, справлять посторонню работу считалось нехороно, а от самоя беды никакого дела больше не шло. (S. 416)

Eine Wertung oder gar Verurteilung dieser haltung erfolgt hier nicht, und sie ergibt sich auch für den Leser erst im folgenden, nach der unerwarteten Wende im 2 ustand der alten Frau. Durch diese Wende wird die vorwiegend auf Wahrung der auberen Form und gesellschaftlichen Gepflogenheit gerichtete Haltung der Kinder bedeutungslos. Sie erfullt keine Punktion mehr. Der unreflektiert erlebte rituelle Vorgang des Abschiednehmens ist gestort, und statt Freude und Erleichterung ruft die Aussicht auf Gesundung der Mutter eher Verwirrung und Arger hervor. Past als ob die Mutter sie betrogen und gezwungen habe, umsonst zu kommen.

Die entstandene Situation deckt auf, wie wenig die Kinder in ihrem jetzigen Leben noch mit dem ort ihrer Herkunft und Kindheit, mit ihrer Familie und dem Beziehungssystem, aus dem sie hervorgegangen sind, verbindet. Die Darstellung unterstreicht die Fremaheit, mit der sie sich im Elternhaus bewegen. Zwischen ihm und ihrem gewohnten Leben scheint es keinen Bezug zu geben. Am deutlichsten kommt diese Fremaheit in der Gestalt Ljusjas zum Ausdruck, die als gebildete Städerin auch daruber reflektiert:

Очень уж не хотелось оставаться дома, не хотелось

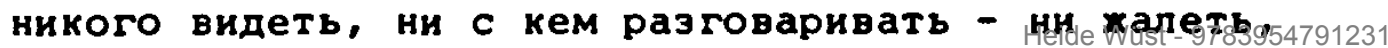


ни подбадривать. Родня, блиэкая родня, с котороя надо вести себя как-то по-другому, чем со всемн остальнымя людьми, а она вовсе не чувствовала особоя, кровноя близости мехду собоя и ею, только знала ○ нея умом, и это вызывало в нея раэдражение...(S.462f.)

Vom Verstand und weniger von echtem Gefuhl bestimmt ist auch der Umgang der Geschwister miteinander. Die Erinnerungen des ersten Abends an die gemeinsame Jugend und Kindheit bleiben eine Episode, und in den Vordergrund tritt zunehmend das Pehlen einer gemeinsamen Sprache, was besonders plastisch in den ständigen Wortwechseln zwischen Ljusja und Varvara zum Ausdruck kommt. Diese Fremdheit im Verhalten der Kinder untereinander, gegenuber der Mutter und uberhaupt am Ort ihrer Herkunft tritt als bestimmendes Merkmal ihrer inneren Welt hervor und läbt diese im Vergleich zur geistigen Welt Annas, die mit alledem durch eine lebendige und inhaltsreiche Beziehung verbunden ist, arm und durftig erscheinen. Es ist wesentlich dieses Moment der Fremaheit, auf dem der Eindruck von Gefülskălte und Herzlosigkeit im Verhalten der Kinder beruht und das das Wesen des Konflikts in "Poslednij srok" ausmacht.

Das "Fremde" tritt in Rasputins Prosa häufig auf als Symbol fir ein besonderes geistiges und ethisches Verhaltnis des Menschen zur Welt.

Das Fremde ist bei Rasputin ein hăufig gebrauchtes und mehrfach abgewandeltes Wortsymbol fur alles Widernaturliche, der Bestimmung des Menschen und seiner Verantwortung gegenüber der Gemeinschaft $2 u-$ widerlaufende. Nicht Entfremdung von sich selbst in einer Welt, die einen anderen Zustand nicht zuläBt, sondern Absonderung von den Menschen, die inrerseits das Fremdwerden des anderen schnell herausspuren und verurteilen. 222)

Grundlage und Ursache fur diese, den modernen Charakter in "Poslednij srok" auszeichnende Haltung versucht der Autor aufzudecken, indem er zwei dieser Charaktere năher ausfürt: Die Stadterin Ljusja und den bei der Mutter im Dorf lebenden Michail.

222) Thun, Dialog mit Rasputin, a.a.0., S. 202 
Die Gestalt Ljusjas hebt sich am meisten von allen anderen Gestalten der Erzăhlung ab. Sie wirkt besonders fremd, geradezu deplaziert in diesem Milieu, das auch der Erzăhler nie anders als "Haus der alten Frau" (staruchinaja izba) nennt. Deutlich zeigt sich dieses Fremde in Ljusjas Sprache. Wie uberhaupt die Repliken der Dialoge auch ohne besonderen Hinweis des Erzăhlers aufgrund ihrer stilistischen Merkmale muhelos die Gestalt zu erkennen geben, der sie zuzuordnen sind, so fällt die geschliffene, grammatikalisch einwandrreie, aber farblose Rede Ljusjas sofort ins Auge. So wie Ljusja spricht niemand in der ganzen Erzăhlung, und die von ihr gebrauchten stereotypen Wendungen sind im Munde der anderen Helden nicht vorstellbar:

... поямя, похалуяста, это. (S. 429)

Неужели ты не понимаешь, что маме не до них? (S.444) Неужели ты не видишь, на каких простынях лехит у вас мама?... Разве мохно больному и старому человеку, твоея матери, спать на таких простьнях? (S. 431)

Gegenuber der unbeholfeneren und umstandlicheren Ausdrucksweise der Geschwister und Annas hat Ljusja stets rhetorische Forme In vom Typ "daB du dich nicht schämst", "was erlaubst du dir nur", "begreifst du das wirklich nicht" parat, die die Unnaturlichkeit ihres Wesens und das Gezwungene ihres Verhaltens unterstreichen. In der Kritik wurde an "Poslednij srok" gerade die Gestalt Ljusjas bemängelt. Sie sei gewollt und konstruiert und kunstlerisch nicht uberzeugend 223 ). Die Einseitigkeit dieser Gestalt resultiert jedoch vor allem daraus, dab sie nicht in ihrem eigentlichen Milieu und kaum in ihrer wirklichen Innenwelt gezeigt wird, daß es dem Autor vielmehr auf bestimmte, diesem Bewubtseinstyp eigene Zuge ankam, die in dem dargestellten Zusammenhang extrem fremd und unnaturlich erscheinen muBten.

Wăhrend in Annas Sprache das Gesagte mit dem Gedanken und dem Gerühl eine reste Einheit bildet, ist bei Ljusja hier

223) Vgl. Pankin, Proščanie, a.a.0., S. 67; Zabelin, a.a.0., s. $82 \mathrm{r}$. 
eine tiefe Kluft festzustellen. Inre Worte, etwa wenn sie die Mutter zurechtweist, weil diese vom Sterben spricht, sind nicht die naturliche Auberung eines tatsăchlichen Gefuhls, sondern lassen die Orientierung ihres Denkens an abstrakten, lediglich intellektuell reflektierten Verhaltensnormen erkennen. Die Xußerungen Ljusjas maskieren hăufig das, was wirklich in ihr vorgeht. So sind ihre Vomurfe an Michail wegen seines unwurdigen Verhaltens gegenuber der Mutter nicht von echter Sorge und Mitgefuhl für Anna getragen, sondern Ausdruck inrer Gereiztheit und Uberheblichkeit gegenuber den Geschwistern und dem Milieu, in dem diese sich bewegen.

Der Autor widmet der Heldin ein eigenes Kapitel, das ihren Spaziergang in den Wald gestaltet und einen Einblick in ihre Innenwelt gibt. Es ist jedoch weniger die Innenwelt der eigentlichen Stadterin Ljusja, die hierbei aurgedeckt wird, als vielmehr ein spezifischer, ganz an die momentane Situation gebundener, psychischer und bewubtseinsmäbiger Zustand der Heldin, der fur diese selbst uberraschend ist.

Die von fruher her vertraute Natur und Ortlichkeit lost in Ljusja Erinnerungen an ihre Kindheit und Jugend aus. Indem der Autor in ausfuhrlicher Gedankenwiedergabe diese Erinnerungen und die an sie gebundenen Reflexionen gestaltet, verfolgt er den Vorgang und die Bedeutung des sich Erinnerns an einer Gestalt, der - im Gegensatz zu Anna das Gedachtnis fehlt, um sich als zeitliches Kontinuum zu begreifen.

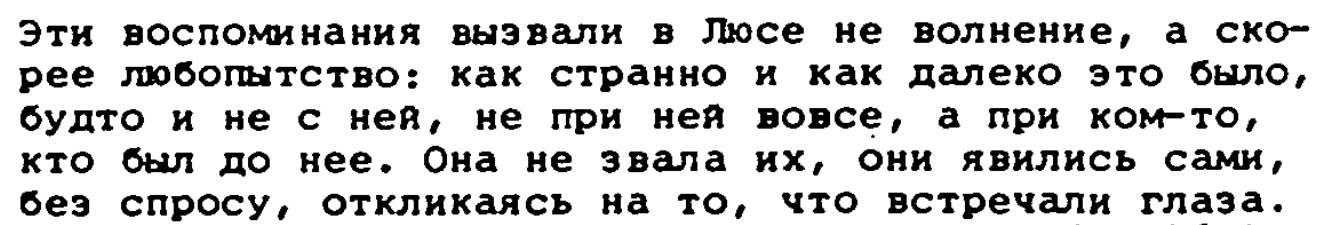

(S. 465)

Die anfangliche Neugier wird jedoch von anderen, tieferen Emprindungen abgelost, sobald Ljusja die verbdeten, seit der Auflosung des Kolchoses nicht mehr besteliten Felder des Dorfes erblickt: 
Она подумала, что ея долхно быть горько, гораздо горше того, что она чувствует, потому что видит эту заброшенную, запушенную земшо впервые после того, как знала ее другои. Но горечи или боли не было - была растерянность, постепенно переходямая в непонятную, пугаюшуо тревогу, которая, казалось, передавалась от земли, оттого, что земля помнит ее и, как окончательного суда, ждет ее решения - ведь она, Люся, не один раз бывала здесь прежде и дате parorara. (S. 469)

Der zunehmenden Betroffenheit, die die Heldin verspurt und den sie gefangenhaltenden Erinnerungen haftet etwas Ratselhaft-Bedeutsames und zugleich Bedrohliches an, das weniger in den Erinnerungen selbst als vielmehr im Vorgang des Erinnerns begrüdet liegt:

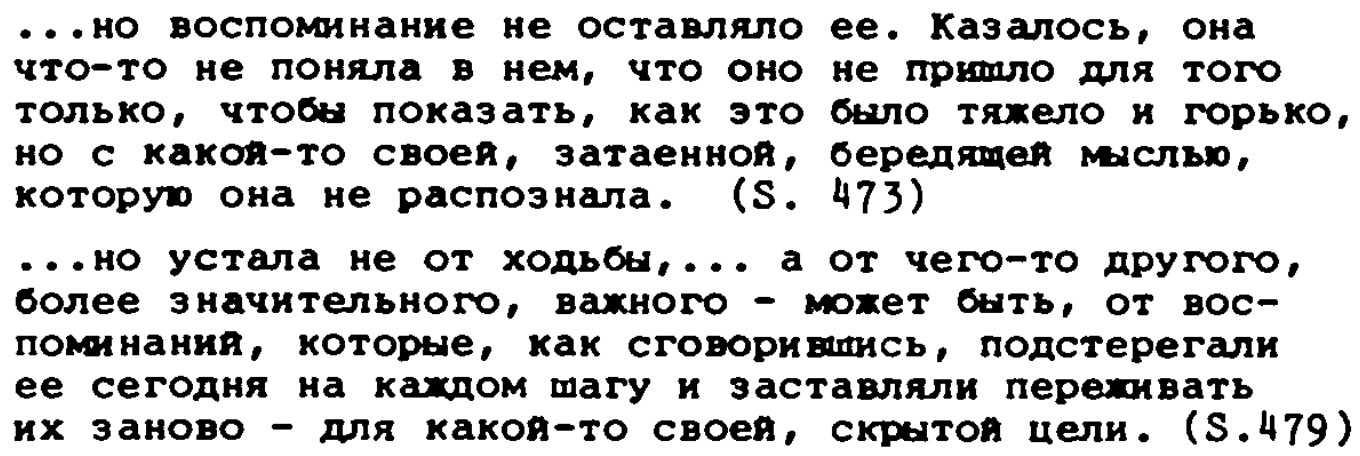

Rasputin zeigt Ljusja in einem psychologischen Zustand, in dem - hervorgerufen durch die außere situation - Verdrangtes und Unverarbeitetes aus dem Unterbewubtsein hervordringt und Macht uber die Heldin gewinnt, die sich in vagen Vorahnungen, unbestimmten Kngsten und in zermurbendem Grubeln uber etwas nicht Greifbares, RatselhaftBedeutsames niederschlăgt. Für Ljusja wird hier die Begegnung mit dem Dorf $z u$ einer Konfrontation mit ihrer eigenen Vergangenheit, mit einem Teil ihrer selbst, den sie in sich unterdruckt und aus ihrem Leben bereits verwiesen hatte. Doch es ist für die Heldin eine beunruhigende Enthullung, da sie Empfindungen auslost, die ihr Verstand nicht unter Kontrolle bringen kann. Der Gedanke einer Schuld gegenuber dem Dorf und seinen Menschen sowie eines Wertverlustes durch die Loslosung von ihnen klingt hier an: 
Казалось, жизнь вернулась назад, потому что она, Люся, здесь что-то забыла, потеряло что-то очень ценное и необходиме для нее, без чего нельзя.. (S.479)

Und das Ratselhaft-Bedeutsame eroffnet sich schlieblich in der Erkenntnis Ljusjas:

\begin{abstract}
Забыла... Вот оно наконец то, что, не открываясь, почти с самого начала сегодня изводило ее какоя-то молчаливоя давнея виноя, за которую придется держать ответ. в самом деле, там, в городе, в своея новоя жизни, Люся все забыла - и воскресники по весне, когда заготавливали дрова, и поля, где работала, и заваливиегося игреньку, и случая у черемухового куста, и многое-многое другое, что бывало еме раньше, - забыла совсем, до пустоты. (S. 480)
\end{abstract}

Das Wort "vergessen" bezeichnet den volligen Bruch Ljusjas mit dem Dorf und das heiBt mit inrem fruheren Leben und den Wurze In ihrer Identitat. Die Erinnerungslosigkeit der Heldin geht einher mit einem Identitats- und Wertverlust, der die Frage nach der geistigen und moralischen Grundlage ihrer Existenz aufwirft. Worauf baut das neue Leben Ljusjas in der Stadt auf, wenn sie all das, aus dem sie hervorgegangen ist, "unterschiedslos aus ihrem Gedachtnis hinausgeworfen hat" ( . 480)? Von der Heldin selbst wird dieses Problem nicht reflektiert. Sie bemulht sich, es zu verdrängen, indem sie ihren psychischen $\mathrm{Zu}-$ stand auf ihre angegriffenen Nerven zuruckfuhrt und sich entschliebt, inm durch die vorzeitige Abreise $z u$ entfliehen.

In der Kritik wurde dieses Kapitel und die in dem Wort "vergessen" sich offenbarende Erkenntnis Ljusjas als entscheidendes Urteil des Autors uber seine Heldin aufgefabt, in dem man eine Verabsolutierung der băuerlichen Traditionen als allein gultiges moralisches Fundament zu erkennen glaubte.

Die einzige Erklărung für die innere Unzulănglichkeit der Helden... sieht der Autor in ihrer Loslösung von jenem natürlichen Boden, auf dem der Charakter Annas gewachsen ist und seine innere Stabili- 
tät erlangt hat, in der Loslbisung vom băuerlichen Boden. 224)

Die im Ljusja-Kapitel aufgeworfene Identitatsproblematik ist kennzeichnend fur die gesamte jungere Generation in "Poslednij srok" und verdeutlicht und vertieft dieses auch auf einer anderen Ebene des Textes hervortretende Moment der Charaktere. Das Bild der Kinder, wie es in den Erinnerungen Annas und Ljusjas entsteht, zeichnet vor allem die schwere und entbehrungsreiche Kindheit und $J u-$ gend der Nachkriegszeit, den Schmerz der Trennung vom Elternhaus und ist ein ebenso poetisches und sympathisches wie das Bild der alten Anna. Der Kontrast zwischen diesem Bild und den Kindern, wie sie sich zum Zeitpunkt der Handlung darstellen, zieht sich durch die ganze Erzăhlung und läbt einen Bruch, eine schroffe Bezugslosigkeit zwischen den früheren und den gegenwartigen Charakteren deutlich werden, die die Kinder als abgeschnitten von einem wesentlichen Teil ihres Lebens erscheinen lassen. Ganz im Unterschied zur Gestalt Annas fehlt den Charakteren der Kinder diese Kontinuitat in der Zeit.

Den Gegenpol zu Ljusja unter den Kindern und die nach Anna am meisten ausgefunrte und interessanteste Gestalt der Erzahlung stellt Michail dar. Die Darstellung vermeidet dabei jedoch den Schematismus einer Gegenuberstellung von "unnaturlichem" stadttypus einerseits und "naturlichem" Menschen des Dorfes andererseits, der dem Autor bisweilen vorgeworfen wird. In Michail den "Bewahrer der familiăren Traditionen" und "Trăger der positiven sittlichen Werte" sehen zu wollen, wie L.S. Sepeleva es tut, ist sicher verfehlt 225). Der Charakter Michails, in dem sich "Zartgefuhl und Grobheit, Selbstlosigkeit und Mangel an Kultur"226) gleichermaben vereinen, ist gerade in sei-

224) Feliks Kuznecov, Proza Valentina Rasputina, in: ders., Pereklička èpoch, Moskva 1980, S. 298-311, S. 305

225) L.S. Sepeleva, Sovremennaja povest' o derevne, in: Voprosy istorii i literatury, Celjabinsk 1974, vyp. 12 , S. $3-21, \mathrm{~S} .18$

226) Pankin, Proščanie, a.a.0., s. 66 
ner Ambivalenz uberzeugend gestaltet und erweitert und differenziert das Bild des Dorfes in "Poslednij srok". Michails Hang zum Vodka und sein skandaloses Verhalten, wenn er betrunken ist, werden ohne Beschonigung dargestellt. Er ist der Urheber der unwurdigen Szene am Bett Annas, der den Geschwistern die Kuh als Zugabe anbietet, wenn sie die Mutter zu sich nehmen. Aber Michail ist es auch, der, um der Mutter Leid zu ersparen, die Schuld auf sich nimmt, als sich erweist, dab Tan'cora nicht kommen wird. Und in seinen Worten, mit denen er nach Abreise der Geschwister Anna un Verzeihung bittet, spiegelt sich ebenfalls diese andere Seite seines Charakters:

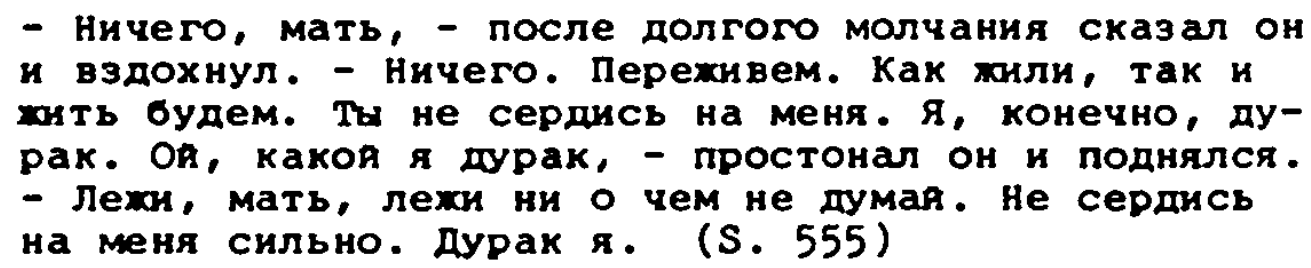

Die Grunde fur diese Doppeldeutigkeit im Charakter des Helden sind in der Zwiespaltigkeit seiner Existenz angedeutet, die der Autor in den Gesprăchen der beiden Bruder im Badehaus aufzudecken sucht. Eine zwiespaltigkeit, die durch die "erbarmungslose Komik"227), mit der die Badehausszenen dargeboten sind, eindringlich unterstrichen wird.

Der ganzen Situation, in der Michail und II'ja im funften und achten Kapitel gezeigt werden, haftet etwas Groteskes an. Die Zecherei auf dem Hintergrund der im Sterben liegenden Mutter, der fur die Trauergăste bestimmte Vodka, das Badehaus, das gar "kein richtiges", sondern ein Badehaus "auf Zeit" ist, als Ort des geselligen Treibens. Doch die Darstellung ist so treffend und authentisch, daB das Ungew $b$ nnliche der Situation vom Leser kaum wahrgenommen und die Aufmerksamkeit vor allem auf die Charaktere gelenkt wird.

Dies gilt bereits fur den Anfang des funften Kapitels, der mit fast naturalistischer Detailtreue den Leser in das jămmerliche Befinden Michails nach dem abendichen

227) Starikova, Žit'i pomnit', a.a.0., S. 220 
Rausch einfuhrt und treffend den psychischen Vorgang charakterisiert, den die Erinnerung an die im Haus vorhandenen Vodka-Vorrate in ihm aus lost:

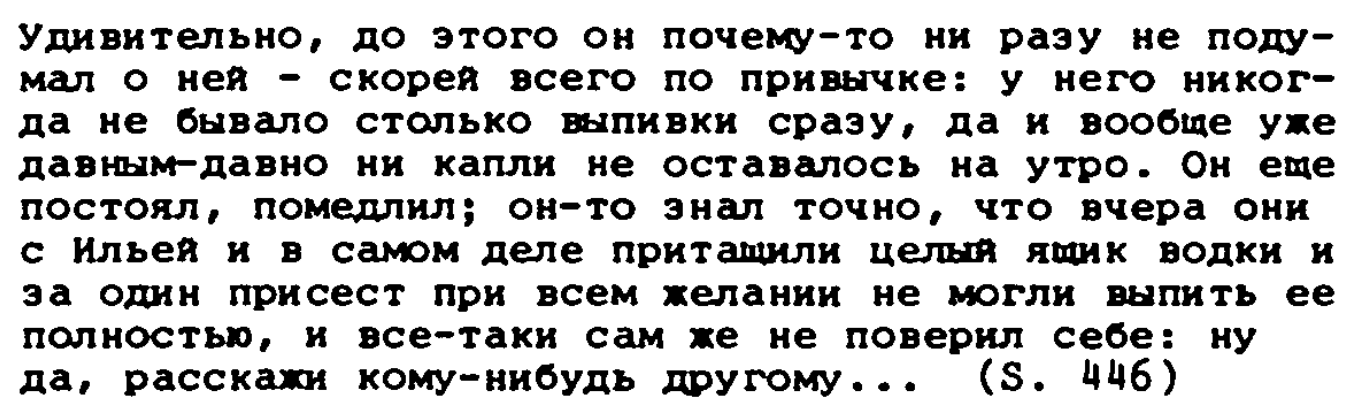

Der ganze Anfang des Kapitels läbt die zwiespăltige Bedeutung, die der Alkohol fur Michail hat, erkennen, und ohne daB die Darstellung erklärend oder verallgemeinernd Uber die Wiedergabe der momentanen Situation und Befindlichkeit des Helden hinausgreift, wird bereits hier in der Haltung zum Alkohol ein wesentliches Moment dieses Charakters aufgedeckt. In der Philosophie des Trinkens, die Michail im Gesprăch mit dem Bruder darlegt, wird es năher ausgefuhrt. Uberall sieht Michail aubere Zwánge und eine Fremabestimmtheit seiner situation, in der das Trinken zum Teufelskreis wird, der allein Befreiung bringen kann, aber selbst wiederum einen zwang darstellt.
А выпил - как на волю попал, освобохденье насту- пило, и ты уж ни холеры не долхен, все сделал, что надо. А что не сделал - не надо было делать, и пра- вильно сделал, что не делал. И так тебе хорспо бы- вает, а кто откахется от того, чтобы хорошо бело, какоя дурак? Выпивка, она ведь вначале всегда как праздник. (S. $453 \mathrm{f.})$

Und die Ursachen fur diese seelische Problematik des Helden sind angedeutet in Michails Erzăhlung uber die Verănderungen im Dorf nach der Auflosung des Kolchoses, in der zerstorung der alten sozialen Strukturen des Dorfes und dem verănderten Charakter der Arbeit und der daraus resultierenden sozialen und bkonomischen Entfremdung.

Теперь что, теперь краны. Подиепил - отцепил, смотри только, чтоб не придавило. И везде так, кругом машины вместо людея, техника. (S. 454) 
A теперь каштың по себе. Что ты хочешь: свон уехали, чужне понаехали. Я теперь в родноя деревне многих не знаю, кто они такие есть. Вроде н сам чужоя стал, в незнакомую местность переселился. (S. 455)

Die gedankliche Intention des Autors ist hier offensichtlich, doch sie bleibt unaufdringlich, weil eingebettet in die authentische Darstellung der Charaktere, die hier fast ausschlieblich mit Hilfe inrer eigenen "Stimmen" im Dialog aufgedeckt werden. Auch werden die Erbrterungen der Bruder wiederholt durch den Einschub humorvoller Episoden - das Erscheinen Varvaras und vor allem die Episode mit Ninka - unterbrochen, was ironische Distanz des Autors zu seinen helden bezeugt. Ungeachtet der beschamenden Situation und der charakterlichen Unzulänglichkeiten der Helden erzeugen die Dialoge und besonders die Gestalt Michails eine gewisse Sympathie. Der ironische "podtekst", der das ganze Kapitel auszeichnet, schafft Distanz des Autors, aber er enthalt keine Verurteilung der Helden, die gleichsam von zwei Seiten dem Leser vorgefunrt werden. Im Charakter Michails gibt es eine Orfenheit und Aufrichtigkeit, die der Autor besonders in der Sprache des Helden zum Ausdruck kommen labt. Es ist. eine Sprache, in der sich eine lebendige Beziehung zwischen Wort und Gedanke widerspiegelt und in der sich das tatsăchliche Emprinden des Helden ausdrückt. Wenn Michail uber die Mutter spricht, so klingt das v8liig anders als die geradezu austauschbaren Phrasen Ljusjas:

\footnotetext{
- А я тебе так скаху, илья: зря она это. Лучие бы она сеячас померла. И нам лучие, и ея тоже. Я это тебе только говорю - чего уж мы будем друг перед дружкоя танться? Все равно ведь помет. А сеячас самое время: все собрались, приготовились. Раз уж собралась, ну надо было это дело до конца довести, а не вводить нас в заблуждение. (S. 457)
}

Die Dialoge im Badehaus und der in den Helden aufgedeckte Bewubtseinstyp lassen an die Ubergangstypen Sukšins erinnern. Mit der Gestalt Stepans, der im achten Kapitel sich dem Besaufnis der Bruder zugesellt, erweitert Rasputin diesen Ausschnitt des modernen russischen Dorfes, und in der voller Humor dargebotenen Unterhaltung der drei 
fängt der Autor typische Zeiterscheinungen in den Charakteren seiner Gestalten ein: Die im Zuge des soziorkonomischen Wandels durcheinandergeratenen Wertvorstellungen und die bewubtseinsmäbigen und psychologischen Reflexe dieses Prozesses. Die Einteilung der Frau in "baba" und "ženščina", die Michail und Stepan treffen, zeigt anschaulich, wie die Auflossung der alten patriarchalischen Strukturen und die Aufweichung der traditionellen Rollenzuweisung zwischen den Geschlechtern dem Bewustsein der Mănner zu schaffen macht. Die Eindringlichkeit der Problematik, die hier angesprochen ist, beruht darauf, dab sie aus einem bestimmten Bewubtsein heraus gegeben wird, das authentisch, mit der inm eigenen Sprache dargestellt ist und das zugleich, durch den ironischen "podtekst", selbst kritisch dargeboten wird.
- Если на то пошло, сильно много в ней женщнны стало, от бабы ничего ух не осталось. А с нея не только в кино ходить, С нея хить надо. Для хизни мне, к примеру, баба болыне подходит. Она на любую рабо- ту способна, не будет хдать, когда мухнк придет со смены и принесет ведро воды. Она все сама мохет. И терпеливая, по всякому пустяку не будет взбрыкивать. мало ли что по домашности пронсходит - почему об этом долхна знать вся деревня, а если в городе, то весь город? (S. 500)

Die Darstellung legt auf diese Weise nicht etwa den Gedanken einer Ruckkehr zur patriarchalischen Lebensweise nahe. Sie deckt allerdings auf, dab jene alten, zu ihrer Zeit in sich geschlossenen Strukturen, die einem Leben wie dem Annas Stabilitat und Sinn verliehen haben, im modernen Leben der Helden noch nicht durch etwas Adăquates ersetzt werden konnten.

\subsubsection{Zusammenfassung}

"Poslednij srok" erschien 1970, als der Streit um die Dorfprosa und die Stadt-Land-Problematik seinen Hohepunkt erreicht hatte, und die meisten Rezensionen des Buches bewegten sich um die Frage, inwieweit die Bestands- 
aufnahme des Autors hinsichtlich Verlust und Gewinn sittlicher Werte die Anerkennung einer moralischen Uberlegenheit des alten Dorfes und der băuerlichen Kultur zum Ausdruck bringe. Tatsăchlich bleibt dieser Dorf-Stadt-Gegensatz in der Romanerzahlung sehr unaufdringlich und tritt hinter der authentischen Gestaltung und feinen psychologischen Zeichnung der Charaktere zurulck. So hat auch Elena Starikova in ihrem fur die Dorfprosa-Diskussion wichtigen Aufsatz Rasputins Buch betont vom Bekenntnischarakter anderer Darstellungen abgegrenzt und auf das hervorstechende erzahlerische Merkmal dieser Prosa hingewiesen:

In der Erzăhlung "Die letzte Frist"... versetzt sich der 1938 (richtig: 1937, H.W.) geborene Schriftsteller in seiner vorstellung so vollig in die achtzigjăhige Băuerin Anna..., daB die Todesvision der Alten und die eigene Beziehung ineinanderflieben und keinerlei Raum mehr bleibt für das lyrische "Ich". Rasputin gibt den Charakteren gleichsam vollige Freiheit, sich selbst zu entwickeln und $z u$ of fenbaren, vor allem dem naiven, fast mythologischen Bewubtsein der sterbenden Băuerin, in dem die nulchterne und klare Weltsicht und die demutige, sozusagen fast konfliktlose Hinnahme der Welt, wie sie ist, mit den hochpoetischen, marchenhaft-wunderbaren und in ihrer asthetischen und moralischen Geschlossenheit schonen Vorstellungen von Leben und Tod verschmelzen. 228)

Ungeachtet der Poesie dieses traditionellen dorflichen Charakters verfallt die Darstellung nicht in eine Idealisierung der Gestalt Annas. Das Bild einer ganz gewohnlichen, in ihrer Schwache und Hinfalligkeit deutlich gekennzeichneten alten Frau bleibt im gesamten Verlauf der Erzăhlung ebenso gegenwärtig wie die Begrenztheit des geistigen Horizontes der Heldin, derer sich diese angesichts der Tochter Ljusja sogar schämt (S. 425) und die sie gegenuber der Freundin Mironicha gelassen konstatiert:

M с тобоя, однако уж две последние старинные старухи на свете остались. Боле нету. После нас и старухи другие поядут - грамотные, толковые, с пон-

228) Starikowa, Der soziologische Aspekt, a.a.0., S. 56f. 
ятием, че к чему в мире деется. А ма с тобоя эаблудились. Теперечи другоя век идет, не наш. (S. 544)

Das Bild Annas wird immer wieder, vor allem in den Dialogen, auf diese "nuchterne Realităt" einer achtzigjahrigen Băuerin, fur die auch der Erzăhler stets lediglich die Bezeichnung "starucha" (alte Frau, Alte) verwendet, zurulckgefuhrt. Von Bedeutung ist in diesem Zusammenhang auch das Mironicha-Kapitel (Kap. 7), das nicht nur einen besonderen Reiz aufweist durch die lebendige und bilderreiche Sprache des Dialogs. In inm wird die Unterhaltung zweier alter Prauen ohne jede Beschonigung oder Erhohung vorgefuhrt, und der durch die etwas verschrobene Gestalt Mironichas erzeugte Humor bewirkt eine distanzierte Darbietung der Hauptheldin.

In der Romanerzăhlung "Die letzte Rrist" besticht vor allem die uberaus feine psychologische Zeichnung, die komplizierte, meisterhaft ausgefunrte Verbindung von Humor und tiefer Trauer, von lyrischphilosophischen Passagen und ausdruckvollen Genrebildern. 229)

Der durch diese Verbindung bewirkte Wechsel von Annăherung und Distanz des Autors gegenuber seinen Personen kann als wesentliches Moment fur die kunstlerische Authentizitat der Darstellung angesehen werden.

Die Konfrontation der Charaktere in "Poslednij srok" stellt eine Konfrontation unterschiedlicher Bewubtseinshaltungen und Einstellungen zum Leben dar, die Grundrragen menschlichen Seins aufwirft, wobei die Art der Darstellung weniger auf Beantwortung als vor allem auf Bewubtmachung gerichtet ist. Nyota Thun spricht von der "Suggestivkraft" des Erzahlens in Rasputins Prosa, die "das Geschriebene als Provokation an sich selbst" emprinden lasse 230). Gerade in der Spannung zwischen der Geschlossenheit des Charakters der alten Anna, uber den

229) Surganov, Celovek na zemle, a.a.0, s. 549

230) Thun, Dialog mit Rasputin, a.a.0., S. 204 
alles gesagt ist, und der offenheit der Charaktere der Kinder - verstärkt noch durch das rătselhafte Bild der nicht erscheinenden Tan'cora - wird eine Betroffenheit des Lesers erzeugt, die weit uber den dargebotenen Wirklichkeitsausschnitt und die vordergrundige Dorf-StadtProblematik hinausreicht.

3.2. Das Dorf und sein Charakter in der kunstlerischphilosophischen Konzeption Valentin Rasputins - Die Novelle "Prošcanie s Matëroj" -

Die ausgezeichnete Kenntnis des sibirischen Dorfes, seiner Menschen, Traditionen und Lebensformen, uber die Rasputin verfugt, sowie die hohe Authentizitat der Darstellung weisen den Autor als einen der genauesten Beobachter und differenziertesten Beschreiber des russischen Dorfes in der modernen Literatur aus. Doch ungeachtet dieser Besonderheit seines erzăhlerischen Talents tritt Rasputin in seinen großen Erzahlungen vor allem als philosophischer Schriftsteller hervor, der "nicht als Schilderer des Alltagslebens, sondern eher als ein sozialphilosophischer Kunstler vor uns Fragen aufwirft"231) und zeigt sich die Bedingtheit des Dorfthemas in dieser Prosa uberaus deutlich. Nur dem Anschein nach, so Galina Belaja, handle diese Prosa von "alten Frauen, ihren Kindern und Enke ln", von "zu uberflutenden Dorfern und dem Schicksal ihrer Bewohner". Hinter der Einfachheit der Sujets und der Helden verberge sich eine weitere, von der Kritik lange nicht bemerkte Schicht der Rasputinschen Prosa, die den Eindruck eines "symbolischen Realismus" hervorrufe ${ }^{232)}$. Die Eigenart der philosophischen Thematik des Autor berunt darauf, dab sie eng mit der Konzeption des traditio-

231) J. Selesnjow, Erde oder Territorium?, in: Kunst und Literatur, 1977, Nr. 10, S. 1038-1047, S. 1039

232) Galina Belaja, Kol'co v neskončaemoj cepi... o Valentine Rasputine, in: Moskovskij Komsomolec, 15.1 .1982 , S. 4 
nellen Charakters in seiner Prosa verknupft ist und ihre kunstlerische Gestaltung vorrangig uber die Lebensanschauung und praktische Seinserfahrung der einfachen dorflichen Helden erfolgt.

\begin{abstract}
"Unbemerkte" Menschen in den endlosen sibirischen Weiten bringen Gedanken vor uber das Leben, uber den Tod, uber Schuld, über Schicksal...,
\end{abstract}

stellt Barbara Hiller fest, und sie verweist auf den spezifischen Charakter der hierbei dargebotenen Lebensvorstellungen, "die auf einem anderen als dem uns ublichen Boden entstanden sind"233) und den modernen Leser mit dem - fur das ausgehende zwanzigste Jahrhundert beinahe exotischen - Reiz einer vorwiegend an die Natur gebundenen und aus ihren Gesetzen hergeleiteten Lebenshaltung konfrontieren.

Der traditionelle Charakter zeichnet sich bei Rasputin nicht so sehr durch umfassende Individualisierung aus, sondern, wie Anna in "Poslednij srok", verkorpern auch die zentralen Heldinnen der beiden rolgenden Novellen vornehmlich einen bestimmten Bewubtseinstyp. Stärker als die individuellen Zuge des Charakters und der Lebensformen interessieren den Autor dabei die Lebenshaltung und besondere seelische Verfassung, die die dorfliche Lebensweise in diesem Typus hervorgebracht hat. Die Heldinnen können als verschiedene varianten eines Charakters und Bewubtseinstyps bezeichnet werden, wobei auch Problemstellungen, Motive und sogar Aussagen der Personen sich in den drei Romanerzahlungen wiederholen und auf eine Rulckkehr des Autors zu fur inn zentralen Fragen verweisen, die er unter neuen Aspekten beleuchtet und vertieft. Es sind Grundfragen menschlichen Seins, die den gesamten Komplex der Beziehung von Mensch und Welt und das Problem seiner Sittlichkeit in einer sich gefahrlich schnell verăndernden Gegenwart umfassen. Der traditionelle dorfliche Cha-

233) Barbara Hiller, Valentin Rasputin: Leb und vergiB nicht, in: Weimarer Beitrăge, 1978, $\mathrm{Nr} .9, \mathrm{~S} .133-$ 139, S. 135 
rakter und uberhaupt die Welt des alten Dorfes fungieren dabei nicht nur als positives Gegengewicht zu negativ gewerteten Erscheinungen der Epoche, sondern erhalten eine vielfaltige ideelle und ăsthetische Funktion als Medium fur einen Dialog zwischen Vergangenheit und Gegenwart und fur eine umfassende Befragung des Lebens nach Sinn und ziel menschlicher Existenz.

Das hinsichtlich seiner storflichen Vorlage aktueliste und gleichzeitig das umstrittenste Buch Rasputins ist seine vorlaufig letzte grobere Erzahlung, die 1976 in "Naš sovremennik" erschienene Novelle "Prošcanie s Matèroj". Das Problem der Uberflutung und Umsiedlung ganzer Dorfer fur die Elektrifizierung Sibiriens hat Rasputin bereits in der autobiographische zuge tragenden Reiseskizze "Vniz i vverch po tečniju" (Stromab- und -aufwärts, 1972) aufgegriffen. In "Abschied von Matéra" bildet es die aubergewohnliche Grundsituation, in die der Autor seine Figuren stelit und die zum auslosenden Moment ihres Denkens und Handelns wird.

Matëra, Insel und Dorf gleichen Namens im sibirischen Strom Angara, muB dem Bau eines gewaltigen Wasserkraftwerks weichen. Die Umsiedlung in eine neue, eigens fur die Bewohner der zu uberflutenden Dorfer errichtete siedlung ist zum Teil schon vollzogen. Aur Matëra zuruckgeblieben sind nur noch wenige, in der Hauptsache alte Menschen, die Haus, Garten und Vieh versorgen, solange diese noch notwendig sind.

Die Novelle schildert den letzten Sommer der Insel vor ihrer Uberflutung, die Tatigkeit ihrer Natur und das Leben der noch im Dorf verbliebenen Bewohner, ihre Gespräche und Gedanken, die sich rast ausschlieblich um den bevorstehenden Untergang Matëras bewegen. Schlieblich die letzten Vorbereitungen zur Uberflutung, die schrittweise erfolgende Zerstorung der Insel: die Einebnung des Friedhofes, die Vernichtung der Vegetation, das Niederbrennen der Hauser. Rasputin zeigt diesen letzten Sommer aus der Sicht der Bewohner Matëras, aus der Perspektive eines in alten Traditionen fest verankerten und uber Jahrhunderte 
hinweg kaum veränderten Lebens. Fur die Alten des Dorfes ist der Gedanke an die Umsiedlung unvorstellbar. Das unbekannte Neue schreckt und angstigt sie, der bevorstehende Verlust der Heimaterde ruft Trauer und Schmerz hervor, die Art und Weise, wie der Untergang Matëras vollzogen wird, lost Emporung und Scham aus. Vor allem fur die achtzigjăhrige Dar'ja Pinigina, um die sich die Alten zusammenschließen, wird der Abschied von Matëra zum Anlab, ihr Leben und das ihrer vater zu uberdenken und darin nach Antwort zu suchen auf Fragen, die sich um den Sinn des Daseins, um Schicksal, Schuld und Verantwortung bewegen. Gegenuber der jungen Generation, die ganz gerne von Matëra fortgeht, dem Enkel Andrej, der am Bau des Kraftwerks mitarbeiten will sowie gegenuber den Premden, die die sanităren Mabnahmen fur die Uberflutung durchruhren, tritt Dar'ja als Huterin des Alten und unbeugsame Verfechterin seiner Werte auf. Von Matëra verabschiedet sie sich wie von einem sterbenden Menschen. Sie putzt und weibt inr haus und schmuckt es wie zu einem hohen Feiertag, bevor sie es den fremden Arbeitern zum Anzunden uberläbt.

Rasputin labst die Alten um Dar'ja bis zum Schlub auf Matëra ausharren. Die Prage ihrer endgultigen Umsiedlung bleibt offen. Die Novelle endet in einem apokalyptischen, allegorisch an Sintflut und Weltenbrand anknüpfenden Bild: Die Alten sitzen auf der vollig niedergebrannten Insel und blicken in die vorbeiziehenden undurchdringlichen Nebelschwaden, wahrenddessen ein zu ihrer Evakuierung ausgeschickter Kutter sich auf der Angara verirrt und weder die Insel noch das Festland wiederfinden kann. "Prośćanie s Matëroj" nimmt im bisherigen Werk Rasputins eine gewisse Sonderstellung ein, die nicht nur auf der Aktualitat und Brisanz des gewahlten Stoffes und der aubergewohnlichen Schäre, mit der der Autor sein Problem aufwirft sowie der bisweilen geradezu provokativen $\mathrm{Zu}$ spitzung der Darstellung beruht, sondern auch auf der ungewohnlichen Struktur des Werks, mit der Rasputin seiner vielschichtigen philosophischen Thematik kunstlerisch Gestalt $z u$ verleihen sucht. Elena Starikova spricht von 
einem "ungew⿰̆nnlichen Genre", fur das die Bezeichnung "Novelie" (povest') nicht so recht passe. In "Prošçanie $s$ Matëroj" gebe es vielmehr etwas, das an "alte Sagen und Mythen" erinnere 234 ).

Die teilweise recht heftigen Diskussionen, die Rasputin mit seinem Buch provozierte 235 ), lassen sich vor allem auf diese Besonderheiten der Novelle zurükfunren und spiegeln sie deutlich wider. Aurfallend ist dabei nicht nur das Vorliegen extrem gegensatzlicher Wertungen, sondern auch die Hăufigkeit der Einschrănkungen, mit denen selbst sehr positiv wertende Kritiker gerade dieses Werk belegen. Vorgeworfen werden dem Autor und seinem Buch Einseitigkeit der dargebotenen Weltsicht, Idealisierung der Vergangenheit und Fortschrittsfeindlichkeit, die einfache Wiederholung bereits gestalteter Themen, Konflikte und Charaktere sowie eine widerspruchliche kunstlerische Konzeption, ein Ubergewicht der Idee des Autors uber die authentische Darstellung, die Uberfrachtung des Textes mit Symbolik und eine weitschweifige Erzahlweise.

In einem von der Zeitschrift "Voprosy literatury" unmittelbar nach Erscheinen der Novelle veranstalteten Rundtischgesprăch grenzte der Kritiker Salynskij "Proßzanie s Matëroj" als Mißerfolg des Autors von dessen vorangegangenen literarischen Leistungen $a b$. Die gedankliche Konzeption sei gewollt und kunstlerisch nicht uberzeu-

234) Starikova, Żit' i pomnit', a.a.0., S. 244; zum Gattungscharakter des Werks vgl. Rolf-Dieter Kluge, Walentin Rasputin. Abschied von Matjora, in: Die russische Novelle, hrsg. v. Bodo Zelinsky, Dusseldorf 1982, S. 274-284; zu Besonderheiten und Entwicklung der Gattung der "povest'" bei Rasputin vgl. auch Ju.A. Dvorjaślin, Russkaja sovetskaja povest. 60-ch - nacalo 70-ch godov. Evoljucija zanra $v$ trorcestve V. Belova, V. Lipatova, V. Rasputina, Avtoref. diss...kand. fil..., Leningrad 1976

235) Neben vielen Rezensionen und kritischen Beitrăgen in den fuhrenden sowjetischen Literaturzeitschriften ist hier besonders zu verweisen auf das Rundtischgesprach der Zeitschrift "Voprosy literatury": Proza Valentina Rasputina, 1977 , Nr. 2, S. 3-81 (deuts ch auch in: Kunst und Literatur, 1977, Nr. 9, S. 918$948, \mathrm{Nr} .10, \mathrm{~S} .1038-1057$ ) sowie auf die Diskussion um "Abschied von Matjora" in: Weimarer Beitrăge, $1980, \mathrm{Nr} .11$, S. 130-150 
gend, die "Intensitat des philosophischen Denkens" habe gegenuber den fruheren Werken merklich nachgelassen ${ }^{236)}$. Der Kritiker Oskockij sieht darin ebenfalls "kunstlerische Fehlleistungen" und eine "Besessenheit" des Autors, "aus der trotz allem nicht tragischen Situation um jeden Preis eine Tragodie 'herauszupressen'"237). Auch Starikova hebt in derselben Diskussion die letzte Erzăhlung Rasputins aus dessen Gesamtwerk hervor, allerdings als "bedeutendes Werk", das "Probleme von gesamtnationaler Bedeutung" aufwerfe:

Bei "Abschied von Matëra" haben wir es zweifellos mit einer umfassenderen Verallgemeinerung zu tun als bei den fruheren Werken des Schriftstellers...; das ist in der Tat eine Erzahlung nicht nur uber die alten Frauen von Materra, sondern auch uber uns alle, uber unsere zeit und uber die komplizierten Fragen, vor denen heute der Mensch und die Menschheit stehen, uber unsere Einstellung zur Erde, zur Natur insgesamt, uber unser Vorwätsschreiten und unser verspatetes Zuruckblicken, uber den Preis des Fortschritts und uber die Gerechtigkeit bei der verteilung seiner Segnungen. 238)

Die ungew onnliche Schărfe, mit der in "Proščanie s Matëroj" diese Problematik aufgeworfen wird und ihre dramatische Zuspitzung resultieren aus der Begrenzung des gesamten Erzăhlvorgangs auf eine Perspektive, die in der Lebenswelt Materras begrundet liegt. Dabei handelt es sich nicht nur um die Bewohner und die Zentralfigur Dar'ja, aus deren Warte die Vorgange beurteilt werden. Dorf und Insel selbst treten hierbei als besondere, in sich geschlossene Welt auf, als eine Art Mikrokosmos mit seiner eigenen, seit Jahrhunderten bewahrten Ordnung, in den sich die Gestalten der Alten organisch einfügen.

In sehr viel umfassenderer Weise als in den vorangegangenen Erzăhlungen entwirft Rasputin in Matëra das Bild des abgelegenen sibirischen Dorfes an der Angara, seiner Natur und Lebensform, seiner Traditionen und geistigen

236) 0. Salynski, Das haus und die Wege, in: Kunst und Literatur, 1977, Nr. 9, S. 918-938, S. 938

237) W. Oskozki, Dauert dieser Abschied nicht zu lange?, ebenda, S. 938-948, S. 944

238) J. Starikowa, Wenden wir uns dem Leben zujide biendæa954791231 Nr. 10, S. 1053-1057, S. 1054 via free access 
Werte 239), wobei sich eine verstarkte Hinwendung des Autors zu historischem und ethnologischem Material, vor allem aber zu den Elementen und kunstlerischen Moglichkeiten der Volksdichtung und Volksmythologie feststellen last.

Die Verwendung von Sujets und Motiven aus histori$s$ chen und toponymischen Sagen, die Beschreibung von Brauchen, Ritualen, aberglaubischen Vorzeichen und volkstülichen Uberlieferungen, die traditionell mit der dorflichen Lebensweise verbunden sind und uralte Vorstellungen der alteingesessenen Bewohner zum Ausdruck bringen - all dies dient der eigentumlichen Charakterisierung Matëras sowie der Verdeutlichung des tragischen Konflikts in der Novelle. 240)

Rasputin zeigt diese Welt der Vergangenheit in "Bildern von eindringlicher Schbnheit" 241), und der Blick, der von inr aus auf die Gegenwart erfolgt, last diese in einem wenig vorteilhaften Licht erscheinen. Die Kritiker Rasputins sehen hinter diesem Perspektivprinzip eine antizivilisatorische Grundhaltung des Autors:

Alle menschlichen Werte, alle Schonheit und wüde hat Rasputin der Matera zugedacht, dem Leben der

239) Von einem eigentlichen Bild des Dorfes mit eigenständiger - konkreter und symbolischer - Bedeutung im Textaufbau kann man in Rasputins Prosa erst seit "Zivi $i$ pomi" sprechen. Wahrend in "Den'gi dlja Marii" und "Poslednij srok" Milieu und Atmosphăre des Dorfes nur durch wenige Details und vorwiegend uber die Figuren charakterisiert sind und weder das Dorf noch seine geographische Lage naher bezeichnet werden, fuhrt Rasputin in "źivi $i$ pomni" erstmals toponymische Besonderheiten in groberem Umfange ein und erhalten Legenden, Sagen und volksmythologische Symbole als Ausdruck des "Volksbewubtseins" erhohte Bedeutung fur die Gestaltung der dorflichen Lebenswelt. Vgl. hierzu Dyrdin, a.a.0.; Krivošcapova, Idejno-chudożestvennye funkcii fol'klora, a.a.o.; E.G. Slabovskaja, Celovek $i$ priroda v povesti V. Rasputina "Źivi i pomni", in: Literatura i fol'klor Vostočnoj Sibiri, Irkutsk 1978, S, 82-90

240) Krivoscapova, Rol' fol'klora, Diss., a.a.0., S. 50

241) Karin Hirdina, Beitrag zur Diskussion um "Abschied von Matjora", in: Weimarer Beitrăge, 1980, Nr. 11, S. 137-138, S. 138 
Vergangenheit. Auf der Seite des Neuen: die gedanken- und gewissenlos hingebaute Siedlung, Menschlichkeit zerstorendes Hasten und Jagen, Verlust der Bindungen an das eigene Gewordensein, entwurzelte Existenz...

Die Widerspruche des gesellschaftlichen Portschritts ... erscheinen so nur als Bedrohung von Poesie, Menschlichkeit, Integritat der Personlichkeit.. 242)

Die Einseitigkeit dieser Perspektive in "Prošcanie s Matëroj" ist evident, und der Vorwurf einer verklărendidealisierenden Betrachtung des alten Dorfes und seiner Traditionen wăre berechtigt, gabe es nicht hinter der vordergrundigen Ebene der geschilderten Ereignisse und vorgefuhrten Schicksale in der Erzăhlung eine zweite, nach umfassender kunstlerischer Verallgemeinerung strebende, die sich nicht in den thematischen Rahmen von Staudammbau und uberflutetem Inseldorf einfugt. Diese zweite Ebene tritt jedoch in "Prošcanie s Matëroj" deutlich in den Vordergrund und verbietet eine blob wortliche Lesart des Textes: In Dorf und Insel Matera schafft Rasputin nicht nur ein poetisches Bild der dorflichen Vergangenheit und dessen, was er an Wertvollem in Kultur und Moral der russischen Bauernschaft zu sehen glaubt, sondern Matëra wird zugleich zur kunstlerischen Metapher fur die zentrale Idee des Autors von der organischen Einheit des Weltgebaudes und seiner "ewigen Ordnung".

3.2.1. Die Einheit des Weltgebaudes und der Gedanke der "hoheren Ordnung"

\subsubsection{Die St8rung des "ewigen Kreislaurs"}

Tat'jana Krivošçapova sieht in Dorf und Insel Matëra "die hauptsachliche tragische Gestalt der Novellen"243), und auch Jurij Seleznev hat zu Recht bemerkt, dab zentraler "Held" der Erzăhlung nicht Dar'ja sei, sondern Matëra selbst, und in diesem Zusammenhang auf den Symbolgehalt

242) Hirdina, ebenda, S. 137,138

243) Krivośçapova, Rol' fol'klora, Diss., a.a.O. S. 43 
des Namens Matëra (vom Stamm "mat" - Mutter) hingewiesen 244). Bereits der Anfang der Novelle - die poetische Beschreibung des auf Matëra anbrechenden Frühlings und des Dorfes in seinem halbverlassenen Zustand unterstreicht die zentrale Rolle des Inseldorfes im Verlauf der kommenden Ereignisse und deckt in seinem Schicksal die Ursachen fur den sich im folgenden entspannenden dramatischen Konflikt auf. Der Erzahler zeigt Matëra eingereint in den Kreislauf der Natur, deren gesetzmảige Ordnung von steter Verănderung und wiederholung, betont durch die anaphorische, den Rhythmus der Jahreszeiten und ihren inneren Zusammenhang gleichsam nachvollziehende Gestaltung der Passage, ganz den Grundtenor der Einleitung bildet:

И опять наступила весна, своя в своем нескончаемом ряду, но последняя пля Матёры, для острова и деревни, носяинх одно название. Опять с грохотом и страстью пронесло лед, нагромоздив на берега торосы, н Ангара освобожденно открылась, вытянувитсь в могучую сверкающую течь. Опять на верхнем мысу бояко эашумела вода, скатываясь по релке на две стороны; опять запиала по земле и деревьям зелень, пролились первые дожди, прилетели стрижи и ласточки и лобовно к жизни заквакали по вечерам в болотие проснувшеся лягушки. Все это бывало много раз, и много раз Матёра была внутри происхолящих в природе перемен, не оставая и не забегая вперед каждого дня. 245)

Doch fur Matëra ist dieser Kreislauf unterbrochen, seine Ordnung gestort, und die folgende Passage geht uber zur Beschreibung dieses Zustandes, der charakterisiert wird in der wiederholten Gegenuberstellung:

Вот и теперь посадили огороды - да не все... Как всегда, посеяли хлеба - да не на всех полях... та Матёра и не та... Все на месте, да не все так... (S. 15)

Die Darstellung betont das herausgehobensein der jetzigen Matëra aus dem allgemeinen Kreislauf, die Storung der

244) Selesnjow, Erde oder Territorium, a.a.0., S. $1038 \mathrm{f}$. 245) Valentin Rasputin, Proścanie s Materoj, in: ders., Povesti, a.a.0., S. 15; im folgenden alle Zitate ${ }_{1783954791231}$ nach dieser Ausgabe 
gewohnten - nicht sozial determinierten, sondern aus den höheren Gesetzen der Natur hergeleiteten - Ordnung sowie die Unnaturlichkeit und beklemmende Ungewibheit dieses Schwebezus tandes:

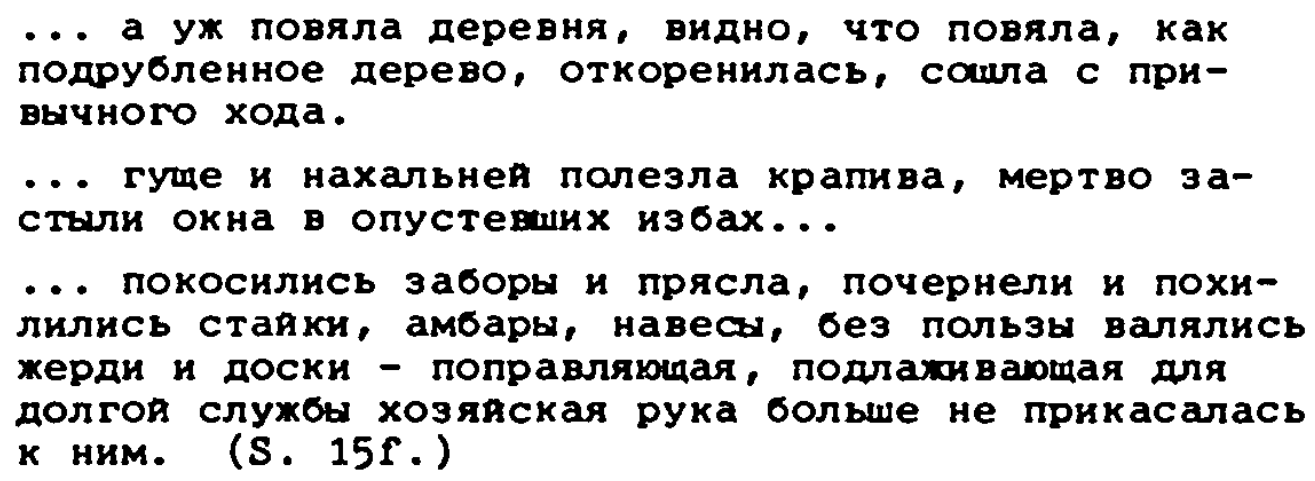

Der Gedanke der storung der hoheren Ordnung der Natur und der Unterbrechung der organischen Entwicklung des Lebensprozesses von Insel, Dorf und Bewohnern bildet die Grundlage des Sujets in "Prošcanie s Matëroj". In diesem Sinne wird das Geschehen um das Inseldorf von seinen alten Bewohnern und vom Autor emprunden, und dieser Grundgedanke durchzieht die ganze Erzăhlung in den Reflexionen der Helden und den vom Autor geschaffenen Bildern.

Die in ihrer ganzen Vielfalt und Schbnheit dargestellte Natur Matëras bildet nicht den Hintergrund der Ereignisse, sondern tritt vor allem in ihrer Aktivitat und gesetzmăbigen Bewegung auf, die dem gesamten Leben auf Matëra zugrunde liegt:

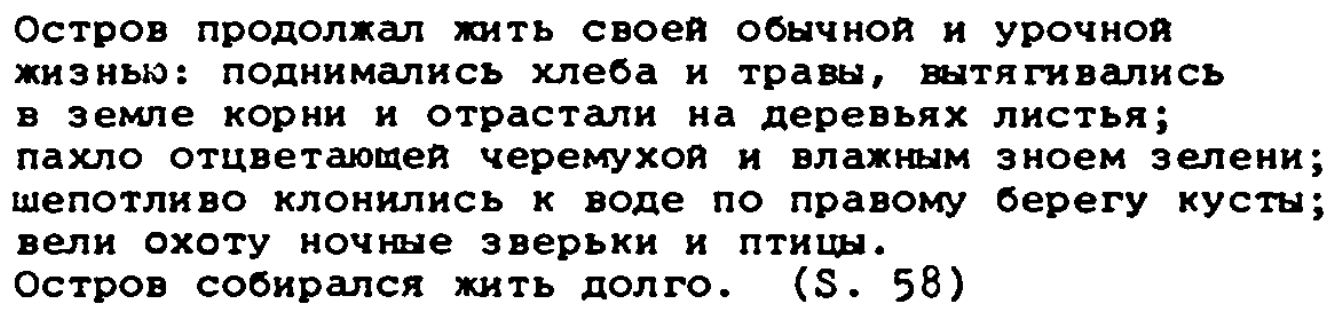

In den Beschreibungen der Natur Materas läbt der Autor immer wieder das Bild der reichen, fruchtbaren, schonen und dem Menschen so bedeutsamen Erde entstehen, das seinen Hohepunkt in den Tagen der letzten Ernte erreicht und setzt es in Kontrast $z u$ den Bildern der schrittweisen 
Zerstorung der Insel in den letzten Kapiteln.

Der dem Gedanken der Storrung des ewigen Kreislaufs zugrundeliegenden Naturaufrassung, die sich auch bei anderen modernen Autoren findet, hat Galina Belaja eine bemerkenswerte studie gewidmet, in der sie feststellt:

Das Besondere an der Position solcher Schriftsteller, wie V. Astaf'ev, S. Zalygin, V. Rasputin, G. Troepol'skij, V. Belov, E. Nosov, C. Ajtmatov besteht - bei aller individuellen Verschiedenheit darin, dab sie nicht auberhalb der Natur stehen, sondern gewissermaßen innerhalb derselben, daB die Natur fur sie nicht Objekt der Unterwerfung oder Umgestaltung ist, auch nicht eine dem Menschen verhängnisvoll entgegenstehende Kraft. Ihre Prosa ist durchdrungen von der Emprindung, das beider Schicksal aufs engste miteinander verknupft ist. 246)

Verbunden mit dieser Position, die den Menschen als integralen Bestandteil der Natur und somit als deren hoheren Gesetzen unterworfen begreift, ist "das stete Empfinden der organischen Einheit der Welt und des wechselseitigen Zusammenhangs inrer Teile", auf dem nach Elena Starikova die Hauptidee des Autors sowie das zentrale poetische Prinzip in "Proścanie s Matëroj" beruhen 247).

Die Einleitung der Novelle gestaltet diesen Grundgedanken der Einheit von Mensch und Natur und der Verknupfung inres Schicksals. Die unmittelbar, ohne Absatz, vom anbrechenden Fruhling zum Zustand des Dorfes und schlieblich zu seinen Bewohnern und den allabendlichen Gesprăchen uberleitende Darstellung gibt gleichsam den inneren Zusammenhang des Geschehens und der Erscheinungen wieder, den mit dem Rhythmus der Natur verschmelzenden Rhythmus des menschlichen Lebens. Dem Einsetzen des Fruhlings entspricht die Aussaat auf den Feldern und Bestellung der Garten, von denen die Rede ist, der bevorstehenden Unterbrechung des natürlichen Kreislaufs für Matëra die Storrung der Ordnung und die Auflosungserscheinungen im Leben des Dorfes. Dabei wird die feierliche, poetische, die Erha-

246) Belaja, Večnoe i prechodjašcee, a.a.0., S. 13

247) Starikova, Żit'i pomnit', a.a.0., S. 245 
benheit der Natur und der sich in ihr vollziehenden Prozesse unterstreichende Lexik und Intonation der einleitenden Passage abgelost von der mehr nüchternen, der Sprache und Betrachtungsweise der Bewohner angenăherten Darstellung des Dorfes, in die selbst Wendungen des "prostorečie" Eingang finden ("I kartošku, markošku v ogorodach tykali nynçe ne $v$ odin srok...", S. 15). In der Beschreibung der leerstehenden Hăuser, der schiefen zăune, der Hoftore, die "irgendein boser Geist immer wieder aufstieb", spiegeln sich zugleich die Reflexe dieser auberen Unordnung in BewuBtsein und Psyche der Dorfbewohner.

Diese in der gesamten poetischen Struktur der Einleitung sich ausdrückende Einheit von Natur, Inseldorf und Bewohnern bestimnt das Bild Matëras, wie es in der Novelle entsteht. Seinen Kulminationspunkt erreicht es in der Darstellung der letzten Heuernte, die alle Bewohner noch einmal in gemeinsamer Arbeit im Dorf vereint. Rasputin schildert sie als berauschendes, alle begeisterndes Fest, das den Menschen im Einklang mit der Natur die vollkommene Harmonie seiner selbst mit der Welt und ihren Erscheinungen empfinden labt.

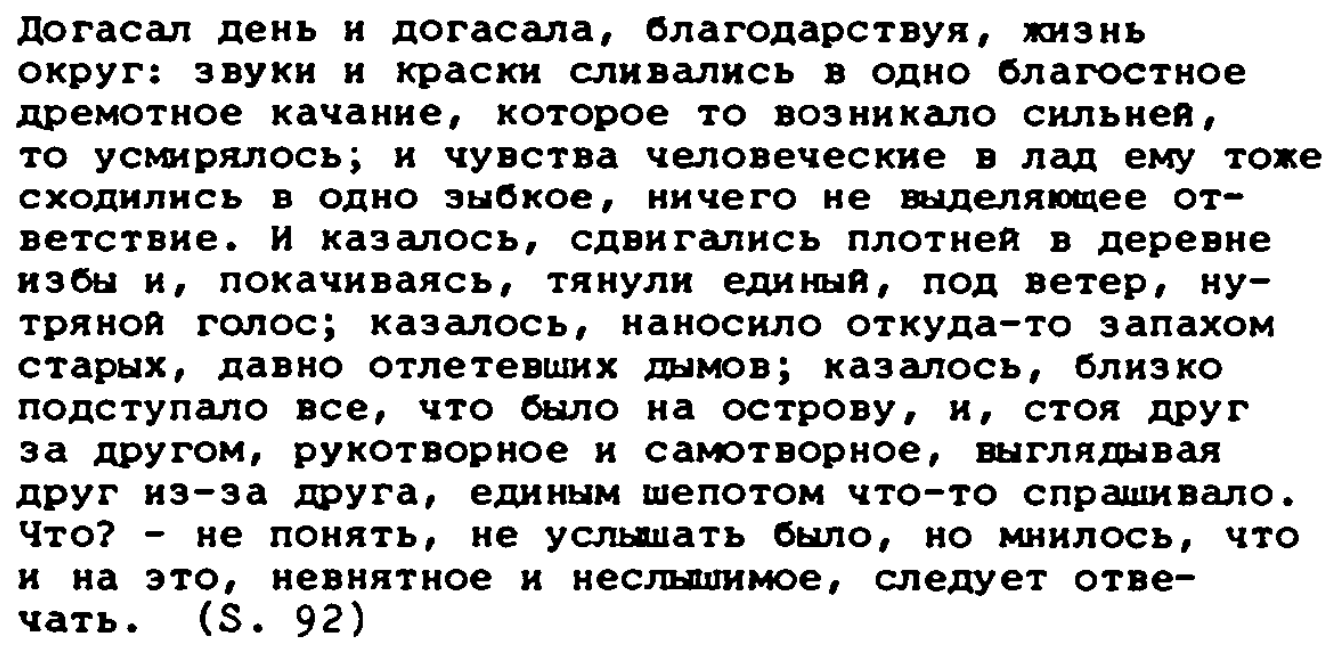

Die letzte gemeinsame Anwesenheit und Arbeit auf Matera versetzt die Inselbewohner in die charakteristische Rasputinsche Abschiedssituation, die sie Uber den Inhalt des bisherigen Daseins nachdenken und in ihm das Besondere und Bedeutungsvolle wahrnehmen 1abt. Und der Erzăh- 
ler, gleichsam die Gespräche und Reflexionen der Inselbewohner begleitend, gibt den Gedanken wieder von der Einheit des Menschen mit der Welt, als deren Teil er geschaffen ist und sich zu begreifen hat und deren Schonheit und Unversehrtheit $z u$ empfinden und $z u$ bewahren $z u m$ Sinn seines Daseins wird:

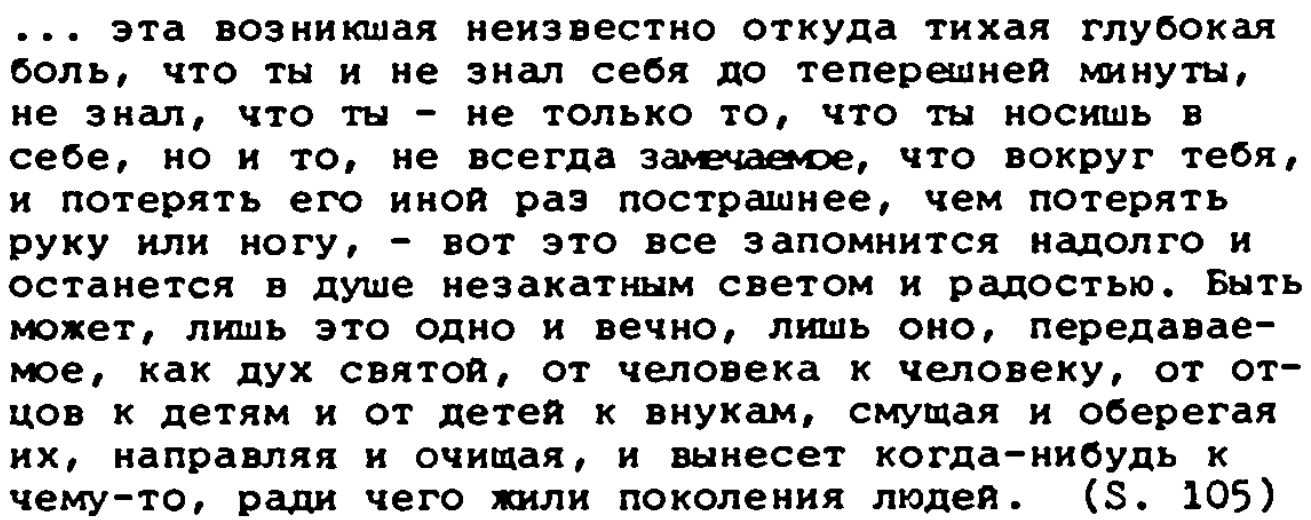

Die Heuernte wird zum eigentlichen Abschied von Matëra. Auf sie folgt bereits Schritt um Schritt die Zerstorung der Insel und der Untergang ihrer Symbole - der Brand der Muhle und der Kampr mit dem "Königslärch" -, uberlagert von der an den Leser weitergegebenen Frage der Bewohner und des Autors:

Почему, почему при них, кто живет сеячас, ничего этого не станет на этои эемле? - не раньше и не позже. Спроста ли? Хорошо ли? Чем, каким утешением унять душу? (S. 106)

\subsubsection{Das Bild Materas}

Das Bild Materas entsteht in der Novelle gleichsam auf zwei Ebenen: Auf der realen als Bild des alten sibirischen Dorfes und seiner der Vergangenheit angehorenden Lebenswelt und auf einer verallgemeinernd-symbolischen Ebene als Metapher für die Einheit des Weltgebăudes. Bereits der im AnschluB an die Einleitung erfolgende Blick in die Geschichte Matëras läBt diese beiden Ebenen und die ihnen zugrundeliegenden erzählerischen Verfahren 
erkennbar werden. Der Erzăhler betont die vorzuglichen natürlichen Bedingungen Matëras und verweist damit auf die reiche und fruchtbare Landschaft, in der das Dorf gelegen ist. Doch die an Form und Sinngebung der Volkssage anklingende Erwăhnung "jenes ersten Mannes", der klug und weitblickend erkannte, "dab er ein besseres Stuck Erde nicht finden wüde" (S. 16), verleiht dieser Eigenschaft Matëras zugleich einen tieferen Sinn, der an anderer Stelle vom Erzahler erneut aufgegriffen wird:

и тихо, покояно лехал остров, тем паче родная, самоя судьбоя назначенная земля, что имела она четкие границы, сразу за которыми начиналась уже не твердь, а течь. Но от края до края, от берега до берега хватало в нея и раздолья, и богатства, и красоты, и дикости, и всякоя твари по паре всего, отделивись от материка, держала она в достатке - не потому ли и назвалась громким именем Maтёpa? (S. $43 f$.

Das Bild der in sich abgeschlossenen, von Wasser umgebenen Erde, die alles in sich vereinigt, was den Reichtum und Fortbestand des Lebens gewahrleistet, erhält hier durch den Anklang an die Arche Noah ("...und von jeder Kreatur ein Părchen") und die besondere Hervorhebung des Namens Matëra deutlich Symbolcharakter.

Matëra ist gedanklich-bildhaft gewiB mit solchen Stammbegriffen verbunden wie Mutter (russ. mat'), Mutter Erde, Mutter Heimat, Kontinent (russ. materik) - Erde, die von allen Seiten vom Ozean umgeben ist (die Insel Materra ist gleichsam ein "kleiner Kontinent"). Und schlieblich dringt in das Bewubtsein des Menschen von heute nicht zufallig immer mehr das Bild unseres Planeten ein, der Erde als einer "kleinen Insel" im großen kosmischen Ozean... 248)

Die vom Erzăhler angefunrten Ereignisse aus der uber dreihundertjăhrigen Geschichte des Dorfes zeigen Matëra eingebunden in die Geschichte und Geschicke des ganzen Landes. Die Bewohner dieses Ortes

verabschieden sich nicht von einer bedeutungslosen Vergangenheit, nicht von einem kärglichen Boden, 
auf dem Generationen von Menschen aufgewachsen sind, sondern von uralter, bewohnbar gemachter, an Erfahrung reicher Erde, die jahrhundertelang ihre Bewohner ernahrt hat. 249)

Und wieder erscheint Matëra hier inmitten des ewigen Kreislaufs:

\begin{abstract}
Вот так худо-бедно и жила деревня, дерхась своего места на яру у левого берега, встречая и провожая годы, как воду, по котороя сносились с другими поселениямн и возле котороЯ извечно кормились. И как нет, казалось, конца и края бегушея воде, нет и веку деревне: уходили на погост одни, нарождались другие, заваливались старые построяки, рубились новые. Так и жила деревня, перемогая любые времена и напасти, триста с лишним годов... (S. 17)
\end{abstract}

Wie diese in Bau und Intonation dem Stil des Volksmărchens angenăherte Passage ist der ganze Exkurs des Erzahlers in Geschichte und Geschicke Matéras durchsetzt mit Benennungen und Wertungen, die der dorflichen Lebensweit bzw. der Betrachtungsweise des einfachen Volkes entstammen und diese veranschaulichen. So etwa, wenn es von der Mühle, die Matëra besitzt, heibt:

... с помолом хоть и некорыстным, да не заемным, на своя хлебушко хватало. (S. 17)

Oder wenn der Erzăhler volkstumliche Aphorismen einstreut, wie: "Je wunderlicher die Sprache, um so lieber ist sie bekanntlich den Menschen" (S. 16). In seinem gesamten Bau und Kolorit zeigt der Erzăhlertext hier eine Anlehnung an die volkstumliche Art des epischen Erzăhlens, an die ihm eigene Bildhaftigkeit der Darstellung, Neigung zum Abschweifen und Liebe zum Detail:

Ниже по Ангаре строят плотину для электростанции, вода по реке и речкам поднимется и разольется, затопит многие земли и в том числе в первую очередь, конечно, Матёру. Если даке поставить друг на дружку пять таких островов, все равно затолит с макушкоя, и места потом не показать, где там селились люди. Придется переезжать. (S. 17) 
Diese Annăherung des Erzăhlers an die Perspektive und Vorstellungswelt des Volkes ist grundlegend fur die gesamte poetische Struktur der Novelle, die das Bild Materas nicht durch Beschreibung von auBen entstehen läbt, sondern - analog zur Selbstaufdeckung des Charakters von innen, aus der ihr eigenen geistigen welt heraus und mit ihren Formen der Wahrnehmung aufdeckt.

Eine gegenuber "Poslednij srok" quantitativ und qualitativ erhohte Bedeutung erhalten die "Stimmen" des Dorfes, die in "Prośçanie s Matëroj" immer wieder in den Erzăhlertext eingefuhrt werden. Im zweiten Kapitel, das die alten Frauen von Matëra im Gespräch zeigt, geht der Erzăhler ausfuhrlich auf das Schicksal Simas ein, die aus Tula zugereist ist und deshalb eine Sonderstellung im Dorf einnimmt. Sein Bericht dient dabei nicht nur der năheren Charakterisierung Simas, sondern gibt zugleich auch die Betrachtungsweise der Dorfbewohner wieder:
... она была пришлоя, занесенноя в Матёру случая- ным ветром меныше десяти лет назад,... и говорила, что два раза, до вояны и в вояну, видела Москву, $x$ чему в деревне по извечноя привычке не очень-то доверять тому, что нельзя проверить, относились со смешком. Как это Сима, какая-то непутевая стару- ха, могла видеть москву, если никто из них не ви- дел? Ну и что, если рядом жила? - в Москву, поди, всех подряд не пускапт. (S. 18)

Und auch die Wertung von Simas traurigem Schicksal ist deutlich an den Kriterien der Dorfler orientiert:

\begin{abstract}
Судьба ея, похоже, и верно досталась не сладкая, если столько пришлось мытариться, оставить в вояну родину, где выросла, родить едннственную и ту немую девчонку и теперь на старости лет остаться с малолетним внучонком на руках... (S. 19)
\end{abstract}

Ahnliches gilt für die Charakteristik Bogoduls, die der Erzăhler zu Beginn des vierten Kapitels gibt. Auch Bogodul ist ein Zugereister, von dem niemand weiB, woher er kommt und uber den Gerulchte umgehen, er sei wegen Mordes nach Sibirien verschickt worden. Er hat früher als Hausierer die Dorfer an der Angara befahren und sich schlieb- 
lich ganz auf Matëra niedergelassen, wo er im Winter abwechselnd bei den alten Frauen Unterschlupf findet und den Sommer uber in einer noch aus der Zeit des Bürgerkriegs stammenden Baracke haust. Die hervorstechenden Merkmale Bogoduls sind sein furchterregendes AuBeres und seine Kunst des Fluchens, mit der er seinen ansonsten sehr kärglichen Wortschatz vortrefflich zu kompensieren weiB. Letzterer verdankt Bogodul auch seinen Namen, den ihm die Dorfbewohner verliehen haben (von "bogochul'nik" - Gotteslästerer). Die ganze Beschreibung dieser merkwüdigen Gestalt ist durchsetzt mit den "Stimmen" des Dorfes und gibt auf diese Weise humorvoll und zugleich mit eigentümicher Poesie einen Einblick in das dörfliche Milieu und seine Denkstrukturen. So etwa, wenn es uber die unterschiedliche Einstellung der Frauen und Mănner in Matëra zu Bogodul heiBt:
А раз любили его старухи, ясное дело, не любили старики. Чужоя, да ене блажноя, подъедала-подпи- вала, ни побалакать с ним, ни вызнать ничего - черт его поямет, что за человек, этот старуиня приворотень. Она своему, родному на сто рядов, за- будет чая поставить, а ему нет, для нее он, про- хиндея, и верно как бог, сошедияя наконец на стра- дальную землю и истытуюини всех их своим греиным, христарадным видом...
... но терпели: и со старухами лучше не свяэываться, и он человек все-таки, не собака. (S. $34 \mathrm{f}$.)

Die Gestalt Bogoduls selbst gehort in ihrer Wunderlichkeit und Ambivalenz zum Bild Matëras, wie es in der Novelle entsteht und ist kennzeichnend fur den "besonderen Realismus" dieser Prosa. In der Forschung wurde das von den gesellschaftlichen Normen abweichende Verhalten dieser ratselhaften Gestalt als unmittelbar sozial und politisch motiviert gedeutet $\left.{ }^{250}\right)$. Eine solche Interpretation der Gestalt Bogoduls rindet jedoch kaum einen Rückhalt im Text und wird vor allem dem Symbolcharakter dieser Figur und inrer asthetischen Funktion nicht gerecht. In der Charakterisierung Bogoduls durch den Erzăhler sind Wendungen enthalten, die durch ihre Anlehnung an volks-

250) Vgl. Meichel, a.a.0., S. $181 \mathrm{fr}$. 
poetische Bilder und Vergleiche seiner Gestalt etwas Besonderes verleihen und ihre Existenz auf Matëra in geheimnisvoller Weise motivieren. So beginnt der Erzahler mit der Feststellung, dab sich kaum noch jemand an das erstmalige Auftauchen Bogoduls auf Matëra erinnert, vielmehr:

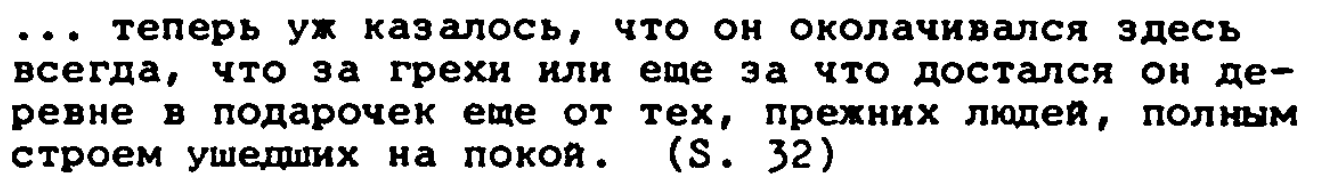

Und bei der Beschreibung seines AuBeren wird erwahnt, daB dieses in all den Jahren unverăndert geblieben sei,

... будто бог эадался целью провести хоть одного человека через несколько поколения. (S. 33)

Durch solcherart Charakterisierung wird Bogodul gewissermaBen der volkstümlichen Vorstellungswelt zugeordnet, die Matëra umgibt und die mittels seiner Gestalt eine weitere Konkretisierung erfahrt. Die besondere Beziehung und Sympathie der alten Frauen $2 u$ Bogodul, den sie "christoven'kij" (deutsch etwa: arme Seele, deren sich Christus er barme) und "svjataja dusa na kostyljach" (heilige Seele auf Krulcken) nennen, wurzelt denn auch im

Brauch der russischen Dbrfer, heimatlose Vagabunden, Notleidende und Waisen freundlich aufzunehmen, ihnen mit Mitleid und Zuneigung zu begegnen 251),

und ist Ausdruck dieser im Denken der alten Frauen noch lebendigen Tradition.

Die Gestalt Bogoduls gehort als "origineller Tribut des Schriftstellers an die folkloristische Exotikn252) ganz der in der Vergangenheit wurzelnden Vorstellungswelt an, die mit dem Bild Matëras verbunden ist. Seine Existenz

251) Nina Podzorova, Raznozvučie. Zlobodnevnoe i većnoe $\checkmark$ proze Valentina Rasputina, in: Nas̉ sovremennik, 1978, Nr. 10. S. $180-186$, S. 185

252) Krivošcapova, Rol' fol'klora, Diss., a.a.0., S. 67 
außerhalb Matëras ist unvorstellbar, und der Untergang der Insel bedeutet auch fur inn das Ende. So heibt es nicht zufälig im Text, daB Bogodul der einzige war, den die Gerüchte um den bevorstehenden Untergang Matëras "gewissermaben uberhaupt nicht zu betreffen schienen" (S. 35), und auch der "Herr der Insel" weiB:

... здесь, в Матёре, и достанет наконец Богодула смерть, что живет он, как и Хозяин тоже, последнее лето. (S. 56)

Mit Matëra zum Untergang verurteilt ist auch ein anderes Symbol dieser Welt: Der "carskij listven'", die gewaltige Larche, die "ewig, măchtig und herrisch" die Insel uberragt und die nach altem Volksglauben Matëra mit ihren Wurzeln am Grunde des Flusses festhălt. Alle Versuche der fremden Arbeiter, diesen "Königsläch" zu fallen oder $z u$ verbrennen, scheitern, und der Baum uberragt weiterhin die zerstorte Runde Matëras. Es ist inr Lebensbaum, inr Hüter und Beschützer und Symbol ihrer unbeugsamen Lebenskraft. Als solcher lebt der "Konigslarch" in den Vorstellungen der Bewohner, und aus diesem Grunde wurden inm in fruherer Zeit Gaben und Opfer dargebracht. Im Kampr zwischen Mensch und Baum bleibt die mächtige Lărche zwar Sieger, aber das Schicksal Matëras kann auch sie nicht abwenden. Die zerstorte Insel uberragend, wird der "Kठnigslarch" zugleich zum symbol rur das tragische Scheitern der Vorstellungswelt, die er repräsentiert.

Elemente der Folklore und inrer Poetik kennzeichnen durchgăngig die Darstellung der Natur in "Prošc̆anie s Matëroj", die somit gleichsam durch das Prisma des Volkes gezeigt wird und dessen Vorstellungen von der Natur und Beziehung zu ihr wiedergibt. Auffallend ist die Beseeltheit der Welt in dieser Prosa, in der "alles lebendig ist und sich alles in gleichermaßen aktiver Beziehung zueinander befindet"253). Die Erscheinungen der Natur sind mit menschlichen Eigenschaften und Empfindungen ausgestattet und zeigen ein dem des Menschen ahnliches Leben und Verhalten

253) Starikova, iit' i pomnit', a.a.0., S. 247 
auch dann, wenn sie nicht aus der Perspektive der Helden wahrgenommen werden. Da kreist der Himmel "in freudiger Ungeduld", und die Sonne "hat ihr Versprechen gehalten" (S. 122), das Feuer "seufzte befreit" und "fing an, sich im ganzen Haus zu vergnügen" (S. 75), und von Nacht und wind heibt es:

\begin{abstract}
Кочь будто остановилась и не стекала уже поперек Ангары в своN закатную сторону, а набравинсь до краев, творила над Матёрои слепое осторожное кружение. Слепо тыкался то с одноя, то с другоя стороны ветерок, и, не натянувиись, засыпая на ходу, опадал и застревал в траве. (S. 58)
\end{abstract}

Auch Pflanzen und Tiere verfugen in dieser welt uber ein Innenleben: Eine Birke "hatte es einst gewagt, sich neben dem gestrengen 'Konigslarch' zu erheben" und dieser "erbarmte sich ihrer und verscheuchte sie nicht" (S. 160). Die vogel jauchzen "vor Glück, daß sie leben durfen" und die Ferkel "nehmen schon einmal Mab" an den Pfützen, in die sie sich spater hineinlegen wollen (S. 122). Von der Angara heibt es:

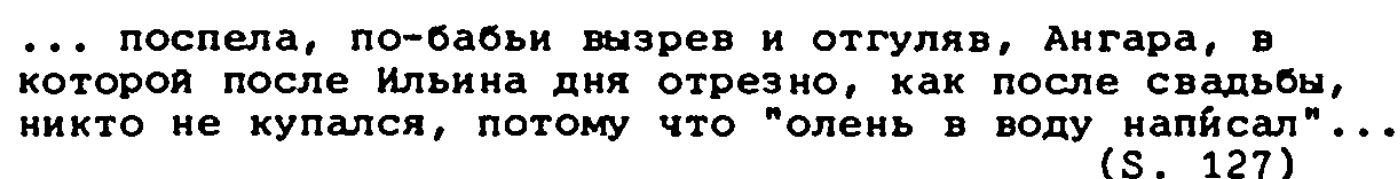
(S. 127)

Immer wieder werden auch in die Naturschilderungen Geschichten, Legenden und Sagen aus dem Bewubtsein der Inselbewohner eingeflochten, die dieser einen besonderen, geheimen Sinn verleihen und die enge Beziehung von Mensch und Natur bildhaft veranschaulichen, wie etwa die Erzăhlung Dar'jas von dem fremden Kaufmann, der sich auf dem Hochufer Matëras begraben ließ oder die Sage von dem Burschen Pronja, der dort als "Nixengemahl" umhergeht. Beseelt und mit den Eigenschaften eines lebenden Organismus ausgestattet erweisen sich auch die Hăuser auf Matëra und seine Muhle, die Dinge und Gegenstände des alltăglichen Gebrauchs, die den Menschen umgeben:

Das Prinzip der allgemeinen Beseeltheit der Welt geht naturlich und organisch in die Sprache des 
Schriftstellers ein und nahert die Poetik der Rasputinschen Erzăhlweise den poetischen Besonderheiten der Folklore an. 254)

Einen besonderen Platz in der ăsthetischen Struktur der Novelle nimmt die rătselhafte mythologisierte Gestalt des "Chozjain ostrova", des "Herrn der Insel" ein, die eigenartigste und in der Kritik am häufigsten angefochtene symbolische Erscheinung in "Prošcanie s Materoj". Das unerwartete Erscheinen des "Herrn", der beschrieben wird als "kleines Tierchen", kaum grober als eine Katze, wird dadurch motiviert, daB

Если в избах есть домовые, то на острове должен быть и хозяин. (S. 53)

Der Bezug zum "domovoj", dem meist fürsorglichen Hausgeist der russischen Folklore, unterstreicht die Funktion der Gestalt als Symbol der Einheitlichkeit der Materawelt und ihrer seit alters her festgefugten ordnung.

Diese Gestalt... zeugt davon, dab der Schriftsteller das ganze Dorf als ein einziges Haus auffabt, das die in Jahrhunderten herausgebildeten Sitten und Brăuche bewahrt. 255)

Doch von der Existenz des "Herrn" auf der Insel weiB keiner der Helden, und trotz der Anlehnung an die mythologische Gestalt des "domovoj" bleibt er eine phantastische Schopfung des Autors, die keinen unmittelbaren Bezug zum BewuBtsein der Helden aufweist. Der Kritiker Dedkov sieht in dem "Herrn der Insel" ein "sehr literarisches Wesen":

...diese Gestalt, die wahrscheinlich dazu bestimmt ist, die Beseeltheit Matëras noch zu verstärken, gibt dem Text, abgesehen von einer Vorwegnahme des Handlungs verlaufs, wenig. 256)

254) Starikova, Żit'i pomnit', a.a.0., S. 247

255) Krivoścapova, Rol' fol'klora, Diss., a.a.0., S. 46

256) I. Dedkov, Mei nebom i zemlej..., in: Druźba narodov, 1977, Nr. 3, S. 263-266, S. 266 
Der "Herr" erscheint erstmals im sechsten Kapitel, an einer Stelle im Text, an der der Leser bereits uber alles Wichtige informiert ist: Uber Matëra und die Helden, die Problematik der Ubergangssituation und die unterschiedlichen Reaktionen der Bewohner, die ungewisse Zukunft in der neuen Siedlung. Von Anfang an erscheint er als geheimnisvolles Wesen, mit dem auch geheimnisvolle Gedanken eingefuhrt werden:

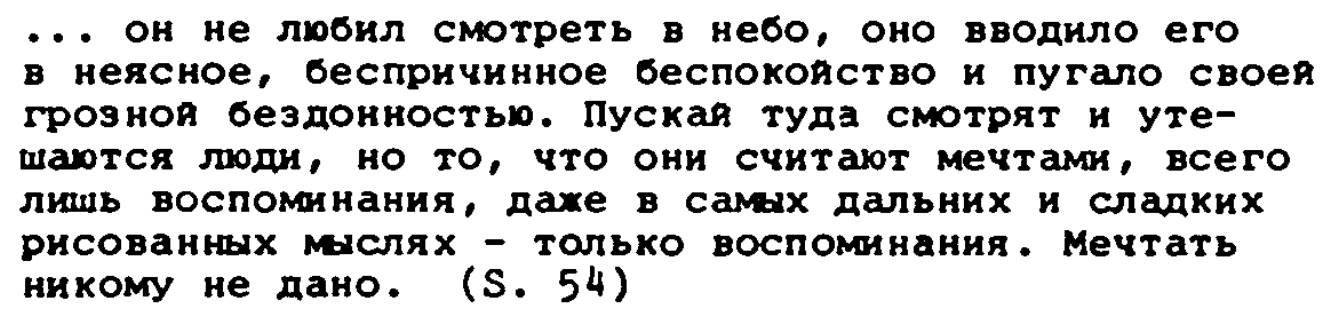

Der "Herr der Insel" weib und sieht alles, er vernimmt die feinsten Gerăusche und Gerulche, alle Bewegung und Verănderung in der Natur und im Dorf, er spurt die dem Holz der Hăuser entstromende Wäme und "jenen besonderen, ausschlieblich vom Herrn der Insel wahrnehmbaren fauligranzigen Geruch nach auslaufendem Schicksal" (S. 56). Den Untergang der Insel und die Art und Weise, wie er sich vollziehen wird, sieht er voraus, und gleich dem "Königslärch" versieht er seinen Dienst bis zum Ende, ohne sich den Ereignissen entgegenzustellen.

Die phantastische Gestalt des "Herrn der Insel" ermöglicht die Betrachtung Materas und inres Schicksals von einer besonderen, poetisch-geheimnisvollen Warte aus, mit der der Autor eigene Gedanken einfuhrt, ohne die allgemeine asthetische Struktur der Erzahlung zu durchbrechen. In ihr symbolisiert Rasputin seine zentrale Idee von der hoheren Ordnung der Natur und den Gefahren ihrer Verletzung durch den Menschen. In der sich in organischer Einheit mit dem "ewigen Kreislauf" entwickelnden Materawelt gibt es den "Herrn", und nur hier vermag dieser zu herrschen. Es ist eine uberaus bescheidene, fast demutige Herrschaft, die er ausubt:

На что он и был Хозяин, чтобы все видеть, все знать и ничему не мешать. (S. 54) 
Sein Inspektionsgang uber die Insel zeigt ihn ausschlieblich bei der aufmerksamen und teilnahmsvollen Wahrnehmung aller Nuancen der Erscheinungen und Veränderungen im Leben von Dorf und Insel. Dabei bevorzugt er das Sanfte, Unaufdringliche; die Unruhe im Dorf und die "lauten und groben" Gerăusche schrecken ihn. Sie storen die Harmonie, der sein besonderes Augenmerk gilt:

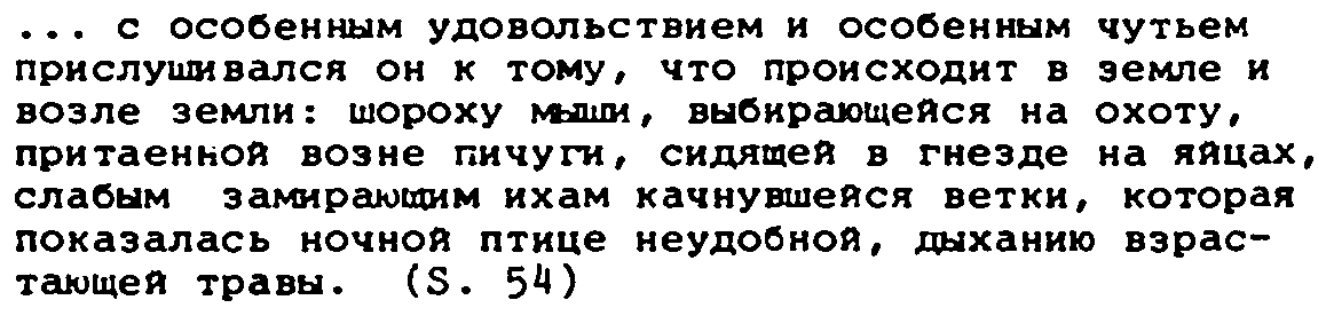

Besonders liebt er das Rauschen des flieBenden Wassers der năchtichen Angara:

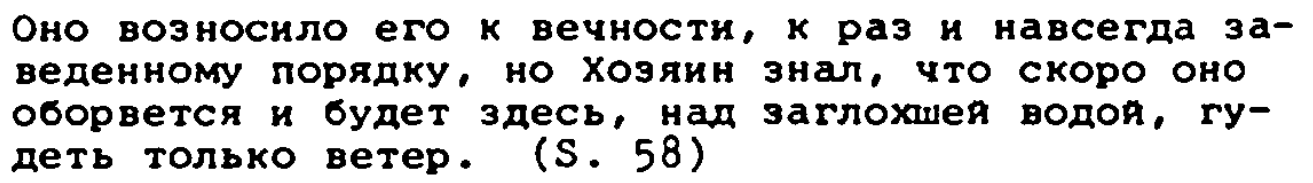

Voll einfuhlsamer Poesie gestaltet das Kapitel die Vorstellungen des Autors vom Wesen dieser Ordnung, in der alles auch angesichts des bevorstehenden Endes weiterhin seinen Dienst versieht. Dle Existenz des "Herrn der Insel" und der Sinn seines Dienstes sind untrennbar verbunden mit der "ein fur allemal eingefuhrten Ordnung" und inneren Harmonie der Matëraweit, und der "Herr" weiß, dab es nach ihm keinen Herrn mehr geben wird, dab er der letzte ist. DaB er gegenuber der Macht des modernen Menschen nichts ausrichten kann, bezeugt, daB dieser sich auberhalb der Natur und ihrer Gesetze gestellt hat und signalisiert zugleich dessen Verantwortung für das Geschehen und die Folgen.

Im Auftreten des Herrn der Insel in "Abschied von Matëra" aubert Rasputin den sehr aktuellen und alarmierenden Gedanken von der Bedrohung des Gleichgewichts in der Natur, das nach Kraften zu bewahren, das vernunftigste und daher hochste Prinzip mensch- 
lichen Verhaltens auf der Erde sei. 257)

Dieser symbolische Gehalt der phantastischen Gestalt des "Herrn" stimmt auch uberein mit der Bedeutung, die dem Wort "chozjain" (Herr, Hausherr) im Denken der Helden und in der im Bild Matëras sich ausdruckenden volkstümlichen Vorstellungswelt zukommt. Bezulglich des verwilderten und vermoderten Zustandes der von Bogodul bewohnten Baracke aus der Kolcakzeit heibt es im Text:

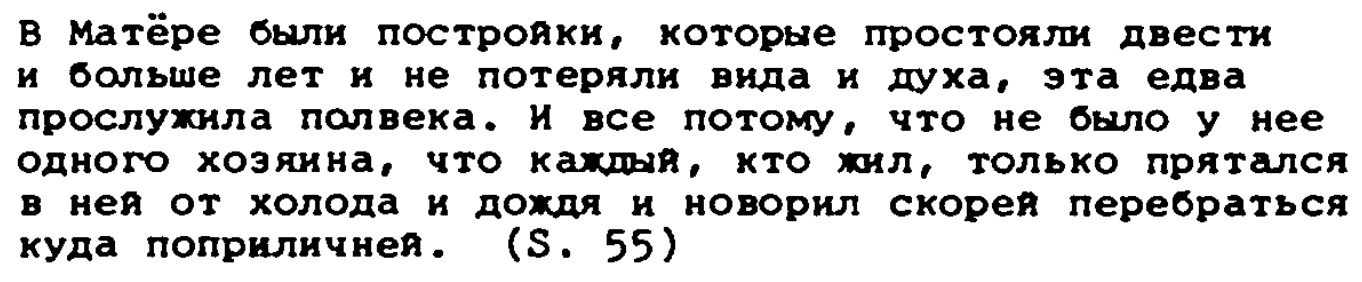

В Матёре были построякн, которые простояли двести и больше лет н не потеряли вида и духа, эта едва прослухнла полвека. И все потому, что не было у нее одното хозянна, что кахшы, кто жнл, только прятался куда поприличнея. (S. 55)

Und an anderer Stelle aubert die Heldin Dar'ja Uber den modernen Menschen und seine Einstellung zum Leben:

Он думает, что он хозяин над ея, а Он давн-о-о ух не хозяин. Давно из рук ее упустил. (S. 117)

"Herr", "Herr sein" bezeichnet in diesem Denken die Ste1lung des Menschen, der sein Leben auf der Grundlage einer umfassenden verantwortungsbewubten und füsorglichen Beziehung zu der inn umgebenden Welt organisiert. Sie steht in engem Zusammenhang mit der besonderen Einstellung der Helden zur "Erde", die in "Proščanie s Matëroj" erhorte konkrete wie symbolische Bedeutung erhălt und der entfremdeten Einstellung des Menschen zur Erde und zu sich selbst gegenubergestellt wird.

Barbara Hiller hat auf die Bedeutung des Widerspruchs von "Nicht-Beendbarkeit" und dennoch sich abzeichnendem Ende in der Konzeption der Novelle aufmerksam gemacht, der bereits in der Einleitung enthalten ist ("Und wieder brach der Fruhling an, ein neuer in der endlosen Reihe der Frühlinge, aber der letzte für Matëra...", S. 15) und den

257) Starikova, i̇t' i pomnit', a.a.0., S. 244 
auch die Symbole Matëras, der "Konnigs lärch" und der "Herr der Insel", zum Ausdruck bringen 258). Beide veranschaulichen Kriterien ewigen Seins: Der "Konnigslärch" als Symbol der Lebenskraft, des tiefen Verwurzeltseins, der Unbeugsamkeit und Beständigkeit, der "Herr" als Symbol organisch sich vollziehender Bewegung und Veränderung, als Symbol der Kontinuitat und des inneren Zusammenhangs in der Abfolge von Vergangenheit, Gegenwart und Zukunft. Auf Ewigkeit ausgerichtet, wie Matëra selbst, symbolisieren beide Prinzipien der Unendlichkeit des Lebens. DaB der Untergang der Insel auch fur sie das Ende bedeutet, signalisiert den Widersinn des Geschehens und muB

zwangs laufig zum Nachdenken uber Forsetzungsvarianten, die der Unbeendbarkeit Rechnung tragen, führen. Zwar ist diese Fortsetzung nicht mehr zu denken fur dieses konkrete Dorf Matëra und diese konkrete Insel, auch nicht fur diesen Insel-"Herrn" und diesen Beherrscher-Baum. Das bedeutet aber nur, das die Fortsetzung irgendwo anders liegen muB. 259)

\subsubsection{Die Darstellung der Helden und ihre Beziehung} zu Matëra

In diese vom Autor so eindringlich poetisierte Matëra und die sie umgebende geistige Welt organisch eingebunden erweisen sich die alten Bewohner des Dorfes. In inrem Verhaltnis zu Matëra werden auch alle anderen Gestalten der Erzăhlung charakterisiert.

Indem Rasputin die Alten in inrem gewohnten Milieu und ihren alltaglichen Lebenszusammenhangen, in für sie charakteristischen Verhaltensweisen und Gesprächen zeigt, deckt er in ihnen jenen Charakter und Bewubtseinstyp auf, der auch die alte Anna in "Poslednij srok" auszeichnet. Gegenuber dieser fruheren Erzahlung geht der Autor jedoch insofern weiter, als er die Charakterisierung und Poeti-

258) Barbara Hiller, Zur Poetik Rasputins. "Proścanie s Matëroj", in: Zeitschrift für Slavistik, 1983, Nr. 2, S. 187-193

259) Ebenda, S. 190 
sierung der geistigen Welt seiner Helden, vor allem in der Gestalt Dar'jas, aufs HuBerste zuspitzt und bis zu symbolischer Verdichtung fortfuhrt.

Auch die Darstellung des Charakters erfolgt in dieser Novelle auf zwei Ebenen, denen unterschiedliche erzahlerische Verfahren zugrundeliegen. Dort, wo der Autor seinem aus "Poslednij srok" vertrauten Prinzip des Wechsels von Annaherung und Distanz zu seiner Person treu bleibt, entsteht das detaillierte, einfuhlsame und authentische Bild des mit der alten bauerlichen Lebenswelt verwachsenen und ganz von ihr geprägten Charakters. Dort, wo Rasputin auf diesen Wechsel verzichtet, fuhrt die Annăherung zu einer eigentülichen Verschmelzung der geistigen Welt der Gestalt mit den Gedanken des Autors.

Der Wechsel von Annăherung und Distanz des Autors zu seinen Personen, dem die fur Rasputins Prosa so charakteristische Verknupfung von Humor und Trauer, Poesie und nuchtern-realistischer Darstellung zugrundeliegt, kennzeichnet vor allem die ersten Teile der Erzahlung. Das Gesprăch der drei alten Frauen, mit dem diese im zweiten Kapitel eingefuhrt werden, zeigt ganz gewohnliche Greisinnen mit ihren Eigenheiten und Schrullen, mit ihrer der Situation vollig angemessenen Trauer und Furcht. Es zeigt sie in ihrer farbenreichen, ausdrucksstarken Sprache, die zuge des Charakters und eine in inrer Urwuchsigkeit reizvolle, aber durch die Ruckstandigkeit des dorflichen Lebens deutlich begrenzte geistige Welt aufdeckt:

\footnotetext{
я у дочери в городе-то гостевала - дивля: тут тебе, с места не сходя, и Ангара, и лес, и уборна-баня, хошь год на улину не показываяся. Крант, так же от как у самовара, повернешь - вода бежнт, в одном кранту холодная, в другом горячая. И в плиту дрова не подбрасывать, тоже с крантом - нахмень, жар идет. Вари, парь. Прямо кушы тебе с добром!... (S. 22)
}

Auch der Erzahlertext, in dem immer wieder die "Stimmen" der Dorfbewohner anklingen, ist voller Humor, wenn zum Beispiel von Simas angeblichem Moskauaufenthalt und ihrer Freierschaft auf Matera die Rede ist, und bietet einen 
differenzierten Einblick in das Leben der Heldinnen und des Dorfes. Aber auch Trauer und Schmerz, die der Gedanke an den bevorstehenden Abschied von Matëra bei den Alten hervorruft, finden die Anteilnahme des Erzăhlers, wenn er poetisch die Natur der Insel und die von ihr ausgehende Ruhe beschreibt und dabei feststellt, daB "alles so beständig und ewig schien, daß man an keine Umsiedlung und Uberflutung, an keinen Abschied glauben mochte" (S. 20), ebenso wie die Furcht der Heldinnen vor dem ungewissen Schicksal:

у Симы не было свое собственности, не было родственников, и ея оставалось одна дорога - в дом престаревах... (S. 23)

Und die nach der Ankunft Bogoduls, der von der Einebnung des Friedhofes durch fremde Arbeiter berichtet, aus der Perspektive Dar'jas wiedergegebene Emprindung der gestorten Ordnung verbindet den Erzahler mit den Helden:

- Кого грабют? че ты мелешь?! - дарья налила чая, но насторожилась, не убрав стакан из-под крана. Такое теперь время, что и нельзя поверить, да приходится; скажи кто, будто остров сорвало и понесло как щепку - надо выбегать и смотреть, не понесло ли взаправду. все, что недавно еме казалось вековечным и неподатным, как камень, с такой легкостью помчало в тартары - хоть глаза закрывая. (S. 25)

Auch das anschliebende Kapitel, das die Vertreibung der Arbeiter vom Friedhof durch die alten Frauen und das Gespräch der Dörfler mit dem Vorsitzenden des Dorfsowjets, Voroncov, und der für Uberflutungsfragen zuständigen "offiziellen Personlichkeit", Žuk, schildert, ist nach diesem Prinzip gestaltet. Der zu Anrang und Ende des Kapitels distanzierte Erzăhler vollzieht eine Annăherung an die Haltung der Alten, wenn er Dar'jas Emprindungen angesichts des zerstorten Friedhofs wiedergibt:

Сиротливые, оголенные могилы, сведенные в одинаково немые холмяки, на которые она смотрела в горячечноя муке, пытаясь осознать содеянное и все больше 
помрачаясь от него, вновь подхлестнули ее свонм обезобрахенным видом. (S. 27)

Im Dialog mit Voroncov und Žuk labt der Autor zwei unterschiedliche Haltungen zusammenstoBen, wobei der Position der Dorfler deutlich der moralische Vorzug zukommt. Es sind vor allem zwei unterschiedliche Einstellungen zu der zu uberflutenden Erde, die hier aufgedeckt werden. Die im Kommandoton Voroncovs bzw. in der Verstăndnis heischenden, an offiziellen Schablonen orientierten Rede iuks vorgebrachte Haltung der Fremden, die durch Begriffe, wie "Territorium", "Uberflutungszone", "Touristen und Intouristen" gekennzeichnet wird. Und die Haltung der Bewohner, in deren Rede Worte, wie "Erde", "Matěra", "Hausherr" und "solange wir hier leben" anklingen. Die Repliken der Dorfler wecken Mitgefuhl, und selbst der in ihnen enthaltene Humor erzeugt eher eine gegen die Fremden gerichtete Ironie:

- А ехели он лицо, пушая ответит народу. М думали, оне врут, а он, вот он, лицо. Кто велел наше кладбиме с эемлея ровнять? там лоди лехат - не эвери.

Im funften Kapitel gibt der Erzahler mit der Ankunft von Dar'jas Sohn Pavel einen tieferen Einblick in das Leben der Heldin, die wie Anna aus "Poslednij srok" viele Kinder zur Welt gebracht und drei von innen fruhzeitig verloren hat, und beleuchtet zugleich die Problematik der Umsiedlung und des Ubergangszustandes, in dem sich die Helden befinden.

Aus der Perspektive der Dorfbewohner werdén die Verhälnisse in der neuen siedlung dargestellt und dabei die bewubtseinsmäbigen und psychologischen Reflexe aufgedeckt, die mit der Zerstörung der vertrauten Lebensstrukturen und der Konfrontation mit qualitativ neuen Lebensbedingungen verbunden sind.

Die modernen Wohnungen in der neuen "Siedlung städtischen Typs" entbehren, obwohl nach einheitlichem Standard gebaut, nicht des Reizes. Aber der Boden, auf dem die Sied- 
lung errichtet wurde, erweist sich als schlecht gewăhlt. In den Kellern steht Wasser, Wiesen oder viehweiden sind nicht vorhanden, so daB an das Halten einer Kuh nicht zu denken ist. Uberhaupt werfen die ganzen wirtschaftlichen Fragen ein Problem nach dem anderen auf.

Столько всего, что поневоле опустятся руки: пропади оно все пропадом. (S. 51)

Verbunden mit dem neuen Leben ist aber auch ein Identitätsverlust, der sich im Gefühl quălender Ungewibheit und in Furcht vor dem Kommenden niederschlagt, von denen auf Matera nur die Jungeren, wie Klavka Strigunova und der liederliche Sohn der alten Katarina, Petrucha, frei sind:

\begin{abstract}
Потом, ... когда очутятся они в новоя жизни и определится, кем им быть - крестьянамн ли, но какими-то другими, не теперешним, или столбовыми дворянамя, когда впрягнутся они в лямку этоя новоЯ жизни и потянут ее, станет, наверно, легче, а пока все впереди пугало, все казалось чухим и непрочньм, крутым, не для всякого-кахдого, вот как эти лесенки, по которым один поднимется шутя, другоя нет. (S. 51)
\end{abstract}

Die Zerstorung des gewohnten Lebenszusammenhangs bedeutet Verlust des inneren Gleichgewichts:

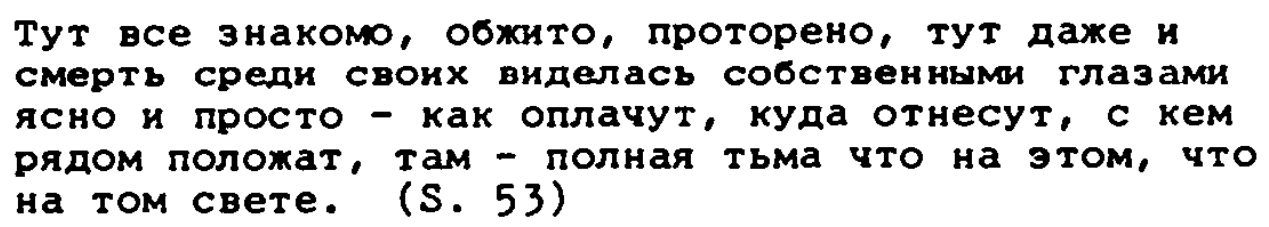

Diese innere Zerrissenheit deckt Rasputin vor allem in der Gestalt Pavels auf, der als Vertreter der mittleren Generation die Gruppe der Dorfbewohner reprăsentiert, der es zukăme, das Alte mit dem Neuen zu verbinden und seine als unabdingbar erkannten werte in das neue Leben zu tradieren. Pavel beurteilt die Ereignisse vom Standpunkt der Einsicht in die Notwendigkeit der modernen Veränderungen sowie der GewiBheit, trotz aller Schwierigkeiten auch mit dem neuen Leben zurechtzukommen. Doch die Brücke vom Alten zum Neuen vermag auch Pavel nicht zu 
schlagen. In den Reflexionen des Helden über das Leben in der neuen Siedlung und den Sinn der Verănderungen läbt Rasputin stattdessen scharfe Kritik an den sozialen und wirtschaftlichen Verhaltnissen im modernen sowjetischen Dorf deutlich werden: Pavel quălen die Unvernunft und Verantwortungslosigkeit, mit der fremde Bauleute und Planer die Siedlung errichtet und den neuen Sowchos organisiert haben, der trotz vielfaltiger Investitionen fur lange Zeit die zur Uberflutung bestimmte fruchtbare Erde nicht wird ersetzen konnen. Er beobachtet den geistigen und moralischen Utilitarismus, der sich unter den neuen Lebensbedingungen breit macht, das im Streben nach Xmtern und einem leichten Leben verlorengegangene soziale und okonomische Verantwortungsgefuhl. Die Art und Weise, mit der der technische Fortschritt im Falle Matëras durchgesetzt wird, weckt den Eindruck von Chaos und Widersinn der neuen Verhaltnisse und labt in Pavel nur Fragen und Zweirel entstehen, die ihn in eine Position der Ungewibheit und des Schwankens zwischen zwei verschiedenen Welten versetzen:

Мать живет в одноя уверенности, молодые в другоя, а тут и уверенности никакон нету. Ни туда, ни сюда, меж темн и другимя... Не успеен разгадать одну загадку, наваливается вторая, еще похитрея. (S. 79)

In Pavels Reflexionen spiege in sich die zermübende Unordnung und Ungewibheit der Verhaltnisse in der Siedlung, die in der Novelle in scharfen Kontrast zu der Welt Matëras treten. Die haltung des Helden zu dieser wird dagegen voll Poesie und lyrischer Wehmut wiedergegeben:

Приезжая в Матёру, он всякия раз поражался тому, с какоя готовностьо смыкается вслед эа ним время : будто не было никакого нового поселка, откуда он только что приплыл, будто никуда он из Матёры не отлучался... (S. 76)

Не больно терять это топько тем, кто тут не жил, не работал, не поливал своим потом кахную борозду. (S. 78)

Einen Höhepunkt erreicht die Darsteliung dieser Beziehung der Bewohner zu ihrem Dorf in der Beschreibung der Abreise 
Egors und Nastas'jas, die sich aus Trotz nicht für die neue Siedlung, sondern fur eine wohnung in der stadt entschieden haben und als erste aus dem Kreis der Alten Abschied nehmen mulssen.

Rasputin schildert minuziors und jedem Detail Aufmerksamkeit schenkend den Tag der Abreise der beiden Alten und hebt damit eine Seite der großen Veränderungen der modernen Zeit hervor und verleiht ihr Bedeutung, die im Denken des modernen Menschen meist wenig Beachtung erfährt. Der aufgewulhlte seelische Zustand und der Schmerz der Trennung von fast allem, was das bisherige Leben ausgemacht hat, wird nicht beschrieben, sondern im Verhalten und in den Worten der Helden aufgedeckt: Im ruhelosen Umherlaufen Nastas'jas, die in der schlaflosen Nacht vor der Abreise "unter lautem Wehklagen" immer wieder das leergeräumte Haus nach vergessen geglaubten Gegenständen absucht, in ihrer Haltung zum Haus, dessen nackten und bloben Anblick sie dadurch zu mildern zu sucht, daß sie die Gardinen wieder anbringt, zum ofen, den sie uberflussigerweise noch einmal anheizt, in den Gesprăchen, die sie mit den Dingen und Gegenständen fuhrt, die sie mitnimmt oder zurücklassen muB:

\footnotetext{
Потом достала старенькия половик и тоже вернула на прехнее место у порога с ласковым приговором: "Тебе ли, родненькия, в город ехать, жнэню менять? Оставаяся, где лежал, дома оставаяся. Тебе уж не мы с Егором нужны, тебе чтоб под свонм порогом находиться. Это уж так. И находись, никто тут тебя не тронет. ьудешь как на пенэии". (S. 59)
}

Auch Brauchtum und Aberglaube finden Eingang in die Darstellung und kennzeichnen die Situation des Abschiednehmens und die seelische Verfassung der Helden, wenn die alten Frauen bei Nastas'ja Abbitte leisten oder diese unbedingt an einem Mittwoch abreisen will, weil das die Aussichten auf eine Ruckkehr verbessert, und sie den Samowar nicht im Haus einpackt, "damit er sehen kann, wohin er zurückkehrt" (S. 66).

Naivität und Poesie dieser Weltsicht werden dabei ebenso aufgedeckt wie ein besonderer $z$ ug der geistigen welt die- 
ser Helden: Der hohe Grad an Aurmerksamkeit und Verantwortungsgefuhl, die sie allem und jedem in ihrer Umgebung entgegenbringen. $\mathrm{Zu}$ Haus und Hof, $z u$ den Tieren und den Dingen des alltăglichen Gebrauchs verhalten sich Nastas'ja und Egor wie zu einem nahen Menschen, und die Veränderungen des eigenen Lebens finden gleichsam eine Parallele im Schicksal der Dinge und Gegenstande:
Курятник, лавки, топчан, еще однн стол, русская печка, подполье, пвери оставались. Много чего оста- валось в амбарах, во дворе, в завоэне, погребе, стаиках, на сеновале, в сенях, на полатях - н все такое, что перешло еме от отиов и дедов, что позарез нужно было кақдую минуту здесь и что там сразу ока- зывалось без надобности. Ухваты, сковородник, кваш- ня, мутовкн, чугуны, туеса, кринки, ушаты, кадки, лагуны, щипцы, кросна... А еще: вилы, лопаты, грабли, пилы, топоры / нз четырех топоров брали только однн /, точило, железная печка, тележка, санки... А еме: капканы, петли, плетеные морды, лыжи, другие охот- ннчьн и рыбачьн снасти, всякия мастеровоя инстру- мент. Что перебирать все это, что сердие казнить!

Was in dieser Aufzăhlung zum Ausdruck kommt, ist nicht der Gram des Besitzers um den Verlust seiner Habe, sondern der Schmerz, der entsteht bei der Trennung von Dingen, $z u$ denen eine lebendige, traditions- und inhaltsreiche Beziehung existiert, die einen wesentlichen Teil des Lebens ausmacht. Auch die Natur hat ihren Platz in diesem Beziehungssystem des Menschen zur Welt und eroffnet sich diesem in der Stunde des Abschieds in inrer ganzen Schonheit und Bedeutung:

Под звонким, ярким солнцем с раннего утра все кругом звенело и сияло, всякая малость выступила на вид, раскинулась не таясь. Пьшно, богато было на матёринскоя земле - в лесах, полях, на берегах, буяноя зеленью горел остров, полнов статью катилась Ангара. Жить бы да жить в эту пору, поправлять, окрест глядючи, дуиу, прикндывать урожая - хлеба, огородноя большоя и малои разности, ягод, грнбов, всякоя дикоя пригодноя всячины. Ждать сенокоса, затем уборки, потихоньку готовнться к ним н потихоньку же рыбачить, поднимать до страдованья, не надсажаясь, подступающую день ото дня работу - так, выходнт, и жили многие годы и не знали, что это была за жизнь. (S. 61) 
Der reine, von der Distanz des Autors zu seinen Figuren und dem Milieu zeugende Humor, der das ganze Kapitel durchzieht, verbindet sich organisch mit der wiedergabe der Trauer und Verzweiflung, die diesen Abschied umgeben und auch vom Leser mitempfunden werden.

Trauer und Mitgeruhl des Autors kennzeichnen die Darstellung der Alten von Matëra und des Dorfes, mit dessen Untergang auch eine ganze, in jahrhundertealten Traditionen wurzelnde Lebenswelt unwiederbringlich dahingeht. Eine Lebenswelt, die fur Rasputin voller Poesie, Schonheit und Harmonie war und deren Ablosung durch die moderne Gegenwart von inm mit vielen Fragezeichen versehen wird.

Vor uns spielt sich nicht nur das individuelle Drama des alten Menschen ab, der des besonderen Schutzes bedarf und den man nicht einfach "verprlanzen" kann, es ist vor allem das soziale Drama der Aurlossung von traditionellen Bindungen und Werten, das Entstehen eines instabilen Zustandes "zwischen" den Werten, bei dem das eine Wertgeruge sich auflost und das andere noch nicht gerestigt ist. In - der alten Gemeinschaft hatte alles seinen Sinn, jedes Detail, auch das Leben als Ganzes...

Die unausgesprochene Frage Rasputins ist, ob sich der Mensch, der sich doch in der Ruhe, in der abgeschiedenen, abgeschlossenen und uberschaubaren Matëra-Welt als Gestalter seines Lebensprozesses bewăhrt hat, dies auch in der Dynamik der großen Welt vermag. 260)

Die Tragik der Situation in "Prošçanie s Matëroj" und des Konflikts, in dem sich die Helden erweisen und der vor allem von Dar'ja in seiner ganzen Tiefe durchlebt wird, entfaltet sich jedoch nicht auf dieser Ebene der Darstellung, sondern sie erwächst aus den geistigen Prozessen, die der Autor in seinen Gestalten stattrinden läbt und aus dem Symbolgehalt des Erzăhlten, der in vielfältigen Momenten der Novelle zum Ausdruck kommt.

260) Regina Hager, Beitrag zur Diskussion um "Abschied von ilatjora" in: Weimarar Beitrăge, 1980, $\mathrm{Nr} .11$, S. $133-136$, S. 136 


\subsubsection{Die Einheit von Mensch und Natur als Grundlage der organischen Entwicklung des Lebens}

Zentrales Moment in der Haltung der traditionellen dorflichen Helden Rasputins zum Leben ist in allen drei Novellen das elementare Empfinden einer unteilbaren Einheit von Mensch und Natur. Es zeichnet die alte Anna aus, die sich in den Tagen ihrer "letzten Frist" immer deutlicher als Teil des gewaltigen, ewigen Lebens funlt, und bildet die Grundlage für die Ruhe und Gelassenheit, mit der sie ihren Tod und inr gelebtes Leben annimmt. Wăhrend jedoch Rasputin in "Poslednij srok" diese Haltung in einer Gestalt aufdeckt, die ihr Leben im Einklang mit der Natur zu Ende fuhren konnte und vor dem Tode die harmonische Einbindung des eigenen $I \mathrm{ch}$ in das gesamte Erdenleben mit ganzer Intensitat empfindet, stellt er seine Helden in "Proścanie s Matëroj" in eine vollig andere situation.

Das Empfinden einer untrennbaren Einheit von Mensch und Natur beinhaltet die Forderung und das Bedürfnis, sich im Einklang mit dieser und inrer Ordnung zu befinden, als Grundlage und Voraussetzung der Harmonie von Mensch und Welt sowie des Menschen mit sich selbst.

Fur die Alten von Matëra wird dieser Einklang mit der Natur und inren Gesetzen auf tragische Weise gestort. Die bevorstehende tberflutung der Insel und die unausweichliche Umsiedlung versetzen sie in eine Situation, in der sie sich als auBerhalb der Natur stehend begreifen mulssen. Der Abschied von Matëra ist fur sie deshalb nicht nur ein Abschied von der gewohnten Umgebung, von der mit Erinnerungen und Traditionen behafteten Erde der Vater, der Trauer und Schmerz hervorruft, sondern er zerreibt den inneren Lebenszusammenhang der Helden und schneidet sie ab von dem geistigen und moralischen Fundament inres Lebens. Hierin liegt die eigentliche Tragik der Situation und hierin wurzelt auch die fast irrational anmutende Seelenqual Dar'jas, die das Schicksal der Insel als inr eigenes Schicksal erlebt, inr Gefuhl, verantwortlich zu sein fur das Geschehen und die Mobilisierung all ihrer sittlichen Kräte. 
Diesen im geistig-seelischen Bereich sich entwickelnden Konflikt gestaltet Rasputin in den Reflexionen, Monologen und Streitgesprăchen Dar'jas und zum Teil Pavels und verbindet dabei das, was er an wertvollem in Kultur und Moral der alten russischen Bauernschaft entdeckt, mit eigenen Vorstellungen von der Welt und der Bestimmung des Menschen und setzt es in Bezug zu unserem modernen Leben. Hieraus resultieren die eigentüliche "Vergeistigung" und Uberhohung der Gestalt Dar'jas und der băuerlichen Lebenswelt Matëras sowie die außerst zugespitzte, geradezu schematisch anmutende Aufteilung der Helden in "Eigene" (svoi), das heibt mit der Welt Matēras aurs engste Verbundene und "Fremde" (čužie), die dieser Welt fernstehen und ihren Untergang herbeifuhren. Auf dieser Besonderheit beruht auch der Vorwurf, der Autor gleite teilweise in einen publizistischen Stil $a b^{261)}$, und die Kritik an der Darstellung der Charaktere in "Prošcanie s Matëroj", wie sie etwa V. Sapośnikov erhebt:

Im Unterschied $z u$ allen vorangegangenen Novellen Rasputins ist "Abschied von Matëra" ärmer an vielseitigen und originellen Charakteren. Was die zentralen handelnden Personen anbelangt, so sind sie zwar nicht gerade konstruiert und schematisch, aber doch eher symbolisch. Es scheint, als nehme ihnen Rasputin absichtlich die Freiheit der inneren Entwicklung, indem er ihnen nicht die Bedingungen für eine volistăndige Selbstaurdeckung scharft. 262)

\subsubsection{Der fehlende Zusammenhang der Zeiten}

Das Gefuhl, herausgehoben zu sein aus dem ureigensten Lebenszusammenhang und seiner naturlichen ordnung entsteht in Dar'ja nach der Răumungsaktion auf dem Friedhof, und der Autor deckt in einem langen Monolog seiner hel-

261) Vgl. Starikova, $\dot{z}_{i t}$ i pomnit', a.a.0., S. 245; L.A. Terakopjan, Blagodarnaja pamjat'. Povesti V. Rasputira, in: Molodaja grardija, 1977, Nr.6, S. 250-271, S. 267

262) Sapośnikov, a.a.0., S. 56 
din und in ihrer Begegnung mit der Natur Matëras den aufgewühlten seelischen Zustand auf, den die Vorgănge in inf ausgelost haben.

Dar'ja quălen tiefe Schuldgefuhle gegenuber inren Toten, dab sie die Zerstorung der Graber nicht hat verhindern konnen, sowie die Empfindung, daß sie nicht untătig bleiben darf, daß ihr in dem Geschehen eine bestimmte Aufgabe zukommt, uber die sie sich aber nicht klar werden kann. Sie erinnert sich an die Worte inres vaters und formuliert die aus "Poslednij srok" bekannte Haltung zum Leben, die auch ihre eigene ist:

Тятька говорел...: живи, дарья, покуль живется. Худо
ли, хорошо - живи, на то тебе жить выпало. В горе,
в зле будешь купаться, из сил выбьешья, к нам за-
хочешь - нет, живи, шевелись, чтоб покрепче заиепить
нас с белым светом, занозить в ем, что мы были.(S.37)

Doch diese einfache und klare Auffassung vom Leben als einer endlosen Kette, innerhalb derer sich der einzelne als Bindeglied zwischen den Generationen und Zeiten begreift und aus der ebenso einfache und klare Vorstellungen von Sittlichkeit und Verantwortung erwachsen, hat bei Dar'ja durch die Ereignisse um Matēra eine Erschutterung erfahren. Sie haben in ihr einen Bewubtseinsprozeb in Gang gebracht, der qualende Fragen und Zweifel auslost. Dar'ja versteht das Leben nicht mehr. Die Welt erscheint inr in zwei Teile gespalten, zwischen denen es keine Verbindung mehr gibt: In die Welt der văter, der Vergangenheit, der sie sich selbst zugehorig fuhlt, und in die der modernen Gegenwart, in der alles nach anderen, unbegreiflichen Gesetzen zugeht:

Нонче свет пополам переломнля: евон че деется! И по нам переломился, по старикам... ни туды мы, ни сюды. Не приведи господь! Оно, может, по нам маленько и видать, какие в ранешнее время были люди, дак ить никто назадь себя не смотрит. Все сломя голову вперед бегут. (S. 37)

Das neue Leben hat alles', was in der Welt Dar'jas klar und verständlich war und seinen Sinn und seine Bedeutung 
hatte, uber den Haufen geworfen, und das Alte erweist sich plotzlich als nutzlos und lastig:

\begin{abstract}
Дерево еще туда-сода, оно упадет, сгниет и поядет земле на удобрение. А человек? Годится ли он хоть для этого? Теперь и подкормку для полея везут из города, всю науку берут из книг, песни запомннают по радио. К чему тогда терпеть старость, если ничего, кроме неудобств и мучения, она не дает? (S.45)
\end{abstract}

Der verlorengegangene Zusammenhang der Zeiten ruft in Dar'ja nicht nur Zweifel am Sinn des eigenen Lebens hervor, sie sieht auch die Gefahr, daß dieser Sinn im Tempo der modernen Zeit vollig abhanden gekommen ist:

Стоило жить долгую и мытарную жизнь, чтобы под конец признаться себе: ничего она в нея не поняла. Пока подвигалась к старости она, устремнлась куда-то и человеческая кизнь. Пускай теперь ее догоняют другие. Но и они не догонят. Им только чудится, что они поспеют за нея, - нет, и им суждено с тоскоя и немощью смотреть ея вслед, как смотрит сеячас она. (S. 46 )

Dar'ja sieht vor allem einen Wandel der moralischen MaBstabe, wenn sie uber das fehlende Gewissen beim modernen Menschen spricht:

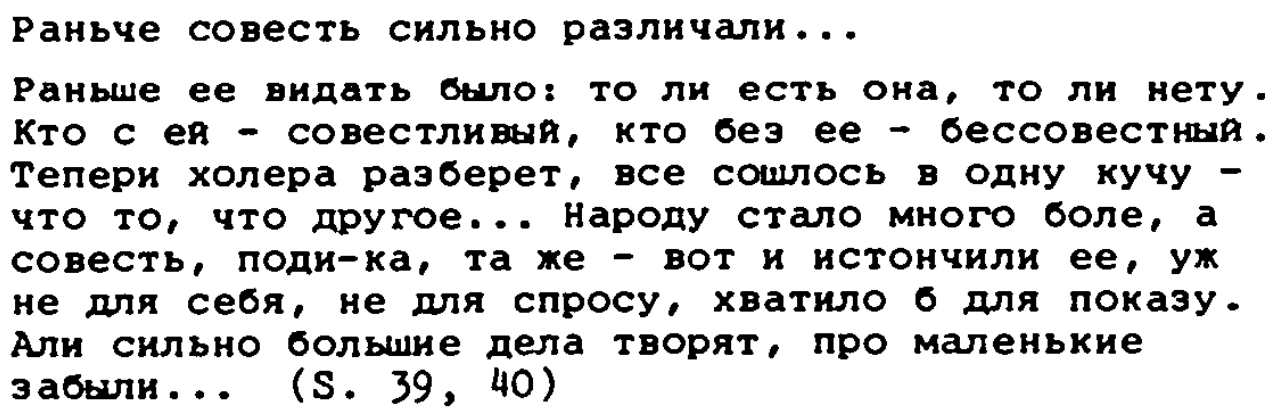

Gewissen und Schuld sind die beiden zentralen Begriffe, die Dar'jas Vorstellungen von Sittlichkeit bezeichnen. Auch diese Vorstellungen hat sie von ihrem Vater ubernommen, und ihnen liegt das hohe Maß an Verantwortungsbewußtsein zugrunde, das die moralische Grundhaltung der Heldin auszeichnet. Ein Verantwortungsbewubtsein, das nicht abstrakt in Dar'jas Denken existiert, sondern vom Autor als sehr konkrete, physisch und psychisch wahrge- 
nommene Empfindung dargestellt wird:

\begin{abstract}
Не об чем, люди говорят, твоему сердиу болеть. только пошто оно так болит? Хорошо, ехли об чем одном болит - поправить мохно, а ежли не об чем, обо всем вместе? Как на огне оно, христовенькое, горит и горит, ноет и ноет. Никакого спасу. Сильно, выходит, виноватая... (S. 145)
\end{abstract}

Rasputin hat in seinem Interview in der "Literaturnaja gazeta" diese Haltung naher beschrieben, als er auf die Frage nach den von inm am meisten geschatzten Charakterzugen antwortete:

Gute, Bedachtsamkeit, Gewissenhartigkeit und das Gefuhl der ungewollten Schuld und der Verantwortung fur alles, was in der Welt vor sich geht. Viele unserer Fehler entstehen aus einem mangelhaften Schuldbewubtsein. Leben heibt nicht nur Glück und Freude an allem, was das Leben ausmacht, sondern auch ständiges Empfinden dafür, daB man schlechter und schwächer lebt, als man eigentlich konnte, und daB andere an der eigenen stelle nutzlicher leben würden. 263)

Was hier als hoher ethischer Anspruch an den Menschen formuliert ist, wird von Rasputin in "Proščanie s Matëroj" in der Konfrontation mit modernen Lebenseinstellungen außerordentlich aktualisiert. Im Dialog zwischen Dar'ja und dem Enkel Andrej begegnen sich zwei Grundhaltungen, die beide vom Anspruch der Nüzlichkeit des einzelnen und der bewuBten Teilhabe an den Aufgaben der Menschheit ausgehen und die dennoch $z u$ diametral entgegengesetzten Aussagen gelangen. Andrej, beseelt vom Pioniergeist des jungen Sibirien, voller Begeisterung für das Neue und die Moglichkeiten des technischen Fortschritts, will am Bau des neuen Kraftwerks mitwirken. Dem auf Matëra beschrănkten Blickfeld der GroBmutter setzt er den erweiterten Horizont des modernen Menschen und sein Ideal eines mit der Bewegung der Zeit Schritt haltenden Lebens entgegen:

263) Rasputin, Ich muBte mich von Matjora verabschieden, a.a.0., S. 446 
- Пока молодоя, надо, бабушка, все посмотреть, везде побывать. Что хорошего, что ты тут, не сходя с места, всо жизнь прохнла? надо не подиаваться судьбе, самому распоряжаться над нея. (S. 95)

Сеячас время такое, что нельзя на одном месте сидеть... Сеячас время такое живое... все, как говорится, в движении. (S. 97)

Im Unterschied zu Petrucha und Klavka, deren Begeisterung für das Neue an vordergründigem materiellen Nutzen und dem Wunsch nach einem leichten Leben orientiert ist, liegt dieser bei Andrej das Bestreben zugrunde, dem Leben einen ideellen Sinn zu verleihen und der Menschheit Nutzen $z u$ bringen. Er will "an der vordersten Front" dabei sein, dort, "wo es am heiBesten zugeht, wo das wichtigste Bauvorhaben durchgefuhrt wird" (S. 99). Im Dialog zwischen GroBmutter und Enkel deckt Rasputin jedoch nicht nur den jugendichen Idealismus seines Helden auf, seinen Glauben, daB dem Neuen die Zukunft gehort und daB das Alte uberholt ist. Er läbt in dieser Lebenseinstellung Andrejs vor allem einen Verlust an grundlegenden ethischen Werten deutlich werden. Um seinem Leben einen Sinn zu geben, braucht Andrej das Besondere, Ungewbhnliche, etwas, worauf die allgemeine Aufmerksamkeit und das offentliche Interesse konzentriert sind:

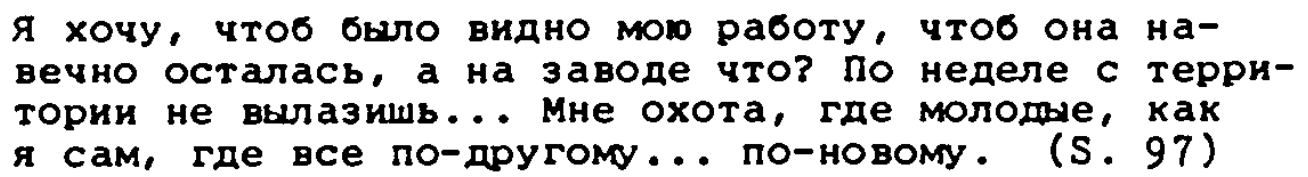

Hierin liegt der zentrale Unterschied zur Haltung Dar'jas, die ihre Aufgabe und den Sinn ihres Lebens in der verantwortungsvollen und gewissenhaften Ausrichtung der alltäglichen Dinge und Lebensfragen sieht und für die ihre Priichten untrennbar verbunden sind mit dem Platz, an den sie das Schicksal gestellt hat. Fü Andrej ist der Alltag und die gwohnliche Tatigkeit in der Fabrik oder im Sowchos uninteressant, und er unterscheidet und wertet bedeutende, wichtigere Aufgaben "im Maßstab sozusagen des ganzen Landes" und Aufgaben, "die leichter, gewohnter sind" (S. 101, 100). 
Andrejs Wunsch, der Menschheit Nutzen zu bringen, erweist sich so in erster Linie als Drang nach äuberlicher, zur Schau gesteliter Selbstbestatigung, und Rasputin deckt in der - in ihrem jugendlichen Idealismus durchaus nicht negativ gezeichneten - Gestalt jenes Moment der "Fremdheit" auf, das - wie schon bei den Kindern Annas in "Poslednij srok" - in seiner Prosa ein besonderes Verhaltnis des Menschen zur Welt charakterisiert.

3.2.3.2. Die negative Welt der "Fremden"

In "Proščnie s Matëroj" bilden die "Fremden" eine eigentümliche negative Welt.
Gemeinsam ist den "Fremden", daß sie dem naturli- chen Lauf des Lebens, seinem vernunftigen Sinn und seiner hoheren Ordnung entfremdet sind... Es sind diejenigen, die... alles im Handumdrehen entscheiden, die oberflächlich denken und blind sind in ihrer Anschauung und ihrem Verstăndnis vom Leben. 264)

"Fremde" - das sind in der Novelle die auswartigen Arbeiter, die den Friedhof einebnen, die offiziellen Vertreter, wie Voroncov und der zuständige fur Uberflutungsfragen, Zuk, die Erntehelfertruppe und die schuler aus der stadt, die durch ihr ausgelassenes Treiben die Bewohner von Matëra in Angst und Schrecken versetzen und die aus ubermut und zum Spaß die Mühle und das Kolchosbüro anzunden, schlieblich die "pożogściki", die "Zundler", die die endgultige Bereinigung der Insel vornehmen. Sie alle fuhren auf Matëra lediglich Anordnungen und Auftrăge durch, und ihre Haltung $z u$ ihr ist die gleichgultige Haltung von Fremden, für die Dorf und Insel nicht ihre eigenen sind.

Für jenen Žuk ist der See kein See, sondern das "Staubecken", die Insel keine Insel, sondern die "Uberflutungszone", die Erde keine Erde, sondern das "Territorium"... Daher sind auch die Menschen keine Menschen, sondern "zu uberflutende Burger"...

264) Belaja, Večnoe i prechodjaščee, a.a.0., S. 14 
Wir haben hier nicht den tragikomischen Konflikt zwischen dem kleinen żuk... und dem Volk..., sondern den $Z$ usammenstob von zwei verschiedenen Denkweisen, von zwei Weltanschauungen.

Wenn Erde nichts als ein Territorium ist, dann ist auch die Einstellung $z u$ inr dementsprechend. Die Erde - die Heimaterde, die Heimat - befreit man. Das Territorium besetzt man. Die Erde hat den Herrn; auf dem Territorium gibt es den Eroberer, den Okkupanten. Von der Erde, die "allen gehort - denen, die vor uns waren, und denen, die nach uns kommen werden", wird man nicht sagen: "Nach uns die Sintflut..." Den Menschen, der die Erde nur als "Territorium" ansieht, interessiert es wenig, was vor ihm war und was nach ihm sein wird. 265)

Die unterschiedliche Einstellung zur Erde, hinter der sich ein unterschiediches Verhältnis zur Natur und diametral entgegengesetzte Lebenseinstellungen verbergen, ist das zentrale, den Konflikt um Matëra weit ubergreifende Moment, das Rasputin in der Gegenuberstellung von "Eigenen" und "Fremden" aufdeckt. Für letztere ist die Erde passives objekt, dem Willen des Menschen unterworfen, der nach Gutdünken uber sie verfügt. "Der Mensch ist der Beherrscher der Natur" (S. 109), bemerkt der Enkel Andrej. Fur die Alten von Matëra ist die Erde Ernăhrerin und Wohltaterin, die Leben und Schönheit schenkt, von den Vorfahren anvertraute Heimaterde, die zu bewahren für die nachkommenden Generationen und den Erhalt des Lebens hochstes Gebot ist.

"Fremde", das sind in Rasputins Erzahlung deshalb auch diejenigen Bewohner Matëras, die, wie Petrucha und Klavka Strigunova, lieber heute als morgen in die neue siedlung ziehen und das eigene Haus vorzeitig anzunden, um die $A b-$ losesumme schneller zu erhalten. Für sie ist Matëra ein rúckstăndiges Nest, das längst in den Fluten der Angara hätte verschwinden mussen. Doch für wen nicht einmal der Ort, an dem er geboren und aufgewachsen ist, Heimat bedeutet, der wird sich auch allen anderen Orten gegenuber gleichgultig verhalten und sich nirgendwo und fur nichts verantwortich fülen:

265) Selesnjow, Erde oder Territorium, a.a.0., S. 1042 
... тут не припосли и нигде не прирастете, ниче вам не жалко будет. Такие уж вы есть... обсевки.

(S. 108)

So charakterisiert Dar'ja Gestalten wie Petrucha und Klavka. Die Frage nach der Beziehung des einzelnen zu seiner engeren Heimat, "in der der Mensch durch vielfaltige Faden sowohl mit der eigenen Vergangenheit und $\mathrm{Zu}-$ kunft als auch mit der seines Volkes verbunden ist"266), ist hier angesprochen. Fur den Autor ist diese Frage von wesentlicher Bedeutung. In der engen Verbindung zur heimatlichen Umgebung sieht Rasputin "einen moglichen Weg, um zu einer harmonischen Beziehung des Menschen zu sich selbst, zu seinen Mitmenschen wie zur Natur insgesamt zu finden"267).

\subsubsection{Die Beziehung zum Geschlecht}

Die "fremde" Einstellung zur Erde vergleicht Dar'ja mit der Haltung jenes Mannes aus der Legende, der die Stute, die rur sieben Brüder geprlügt hatte, für einen Rubel zwanzig an den $\mathrm{zigeuner}$ verkauft hat.

\footnotetext{
Эта земля-то рази вам однем принадлехит? Эта земля-то всем принаплежнт - кто до нас был и кто после нас придет. М тут в само мало доле на ея... Так и нам матёру на подержанье только дали... чтоб обихаживали м. ее с пользоя и от ее кормились. А вы че с ея сотворили? Вам ее старшие поручили, чтобы вы жисть прожили и младиим передали. Оне ить с вас спросют. (S. 109)
}

So kann von der Erde und von sich selbst auf ihr ("Unser Teil auf dieser Erde ist das allerkleinste") nur sprechen, wer sich intuitiv eingebunden sieht in das große, einheitliche Ganze des ewigen Lebens und wer den Sinn seines Daseins aus der bewußten Teilhabe an der Fortfuhrung und

266) B. Tesmer, Mensch, Natur, Gesellschaft in der Prosa Vasilij Belovs und Valentin Rasputins, in: Zeit267) Ebenda 
Mehrung des Menschengeschlechts bezieht. Das einzelne Menschenleben ist in diesem Weltempfinden dem Sinn und ziel des großen Ganzen und seiner hoheren Ordnung unterworfen und erhält hieraus seine Bedeutung auch uber den Tod hinaus.

Ein Mensch stirbt - ist das schrecklich? GewiB. Aber viel schrecklicher ist es, wenn das stirbt, was das menschliche Leben rechtfertigt. In dieses Koordinatensystem versetzt uns der Schriftsteller. Menschen kommen und gehen. Das Gesetz der Sterblichkeit ist unumst8Blich. Ein Mensch hat zwanzig Bücher geschrieben, zwei davon haben zur geistigen Entwicklung der Menschheit beigetragen. Das allein rechtfertigt. sicherlich schon den Autor. Aber ein einfacher Mensch, der lediglich Arbeitseinheiten verdient hat - was geht von seiner Existenz als integrierender Teil in die Unsterblichkeit ein? 268)

Bei den einfachen Helden Rasputins ist das Empfinden dessen, was das eigene Leben rechtfertigt, uberaus gescharft und untrennbar verbunden mit dem stets lebendigen Bewubtsein der eigenen Sterblichkeit. Die alte Anna aus "Poslednij srok" sah ihren Beitrag darin, das "Geschlecht zu erhalten", und selbst inr Sohn Michail hatte, als er Vater wurde, diese "einfache, niemanden auslassende Wahrheit" begriffen, "dab er sterblich ist, wie alles in der Welt sterblich ist, auber Himmel und Erde" (S. 532) und sich selbst als Glied der endlosen Kette erkannt. Die Beziehung zum Geschlecht ist auch in "Prošanie $s$ Matëroj" von zentraler Bedeutung für die Denkweise und sittliche Haltung der Helden. In Dar'jas Sorge um die Graber und das Schicksal der Toten in der uberfluteten Erde wird sie als lebendige geistige Beziehung zu den vergangenen Generationen und ihrem Vermăchtnis deutlich. In den Vorstellungen der Helden Rasputins haben auch die Toten ihren festen Platz im großen, einheitlichen Weltgebaude, von dem aus sie durch ein geistiges Band mit den Lebenden verbunden bleiben. Von dem schlafenden Dorf Matëra heibt es im Text:

268) A. Owtscharenko, Treu seinem Problem, in: Kunst und Literatur, 1977, Nr. 10, S. 1047-1053, S. 1052 
Старухам снились сухие тревожные сны, которые слетали к ним уже не по первои очереди, но старухи о том не знали. Только ночамн, отчалив от твердого бepera, сносятся живые с мертвымя, - приходят $к$ ним мертвые в плоти и слове и спрашивают правду, чтобы передать ее еше дальше, тем, кого помнили они. И много что в беспамятстве и освобохденности говорят живые, но, проснувшись, не помнят и ищут последним зряшным видениям случаяные отгадки. (S.57)

Und in ihrer Vision am Grabe der Eltern sieht sich Dar'ja eingereiht in ihr Geschlecht, an der Spitze eines "sich durch die Jahrhunderte ziehenden Keiles", der von ihr Rechenschaft fordert:

\begin{abstract}
Ея представилось, как потом, когда она соддет отсюда в свой род, соберется на суд много-много людеи - там будут и отец с матери, и деды, и прадеды - все, кто проиел свов черед до нее. Еи казалось, что она хорошо видит их, стоящих огромным, клином расходяюимся строем, которому нет конца... Они спрашивают о надежде, они говорят, что она, дарья, оставила их без надежшы и будушего. (S. 156f.)
\end{abstract}

Die Abtrennung vom Geschlecht und die Auflösung des geistigen Bandes zur Vergangenheit wird von Dar'ja als tragische Absonderung und Vereinzelung des Menschen emprunden:

Не помереть мне в спокое, что я от вас отказалась, что это на моем, не на чьем веку отрубит наш род и унесет. ОЯ, унесет, унесет... А я, клятая, отделюсь, другое поселенье зачну. Кто мне такое простих?! (S. 155)

Was kann das Dasein des Menschen rechtfertigen, wenn nicht diese Bindung an das Geschlecht, was kann inm Ruckhalt und Antwort auf die Frage geben, wie er zu leben und wie er zu sterben hat? Diese "ewigen" Menschheitsfragen werden von Dar'ja aufgeworfen angesichts des Untergangs von Matëra, der in Rasputins Novelle mehr ist als der Untergang einer kleinen Insel und eines alten Dorfes und der die Heldin in eine Position an der Nahtstelle zwischen den Zeiten versetzt, was dem Blick seine besondere Eindringlichkeit verleint: 
Вон сколько их было, прежде чем дошло до нее, и сколько будет после нее! Она находнтся сеячас на самом стибе: одна половина есть и будет, другая была, но вот-вот продернется вниз, а на сгиб встанет новое кольио. Где же их болыше - впереди или позади? И кто знает правду о человеке: зачем он живет? Ради жизни самоЯ, ради детея, чтобы и дети оставили детея, и дети детеи оставили детея, или ради чего-то епе? Вечным ли будет это движение? и если ради детеи, ради движения, ради этого беспрерывного продергивания - эачем тогда приходить на эти могилы? Вот они лехат здесь полнои матёринскоя ратью, молчат, отдав все свое для нее, для Дарьи, и для таких, как она, - и что нз этого получается? Что долхен чувствовать человек, радн которого жили многие поколения? Ничего он не чувствует. Ничего не понимает. И ведет он себя так, будто с него с первого и началась жизнь и им она навсегда закончится.

(S. 157f.)

Die Beziehung zum Geschlecht. - bei den Helden Rasputins Grundlage ihres intuitiven Empfindens fur die Einheit des eigenen Ich mit der Welt - erhät im philosophischen System des Autors umfassende Bedeutung für die Uberwindung der Polarităt von Persönlichem und Allgemeinem, Individuum und Gesellschaft, Ewigem und Vergănglichem.

"Geschlecht" ("rod") ist in der Auffassung des Schriftstellers ein auberordentlich umfassender Begriff, der sich nicht auf solche Begriffe, wie "Gemeinwesen" ("obšina"), "Dorfgemeinschaft" ("krest'janskij mir") oder "Volk" (noch weniger Patriarchalitat u.a.) reduzieren labt. Seinem Inhalt und Bedeutungsumfang nach chnelt er am ehester. jener Auffassung vom "Weltenprinzip" ("vselenskogo nacala"), die Dostoevskij der isolierten Persunlichkeit entgegensetzte. 269)

\subsubsection{Die Bedeutung der Erinnerung}

In einem engen Zusammenhang mit dem Begriff "rod" steht im künstlerisch-philosophischen Denken Rasputins der Begriff "pamjat" (Gedăchtnis, Erinnerung).

"Die Wahrheit liegt im Gedăchtnis. Wer kein Gedăchtnis hat, der hat auch kein Leben" (S. 158), erkennt Dar'ja

269) Belaja, Kol'co v neskončaemoj cepi, a.a.o. 
beim Abschiedsbesuch auf dem Friedhof, und auf diesem Verstăndnis des Gedăchtnisses, der Erinnerung als Bewegung des menschlichen Bewubtseins in der Zeit, als geistiges Band zwischen Vergangenheit, Gegenwart und Zukunft und Grundlage der Kontinuitat in der Abfolge der Zeiten und Generationen beruht auch das "philosophische Empfinden der Zeit"270), das Rasputins Helden auszeichnet und in Dar'jas Monologen und Reflexionen stets gegenwartig ist.

$\mathrm{Ob}$ und woran der Mensch sich erinnert, wird zum Kriterium seiner Sittlichkeit und geistigen Reife. Dar'jas Enkel Andrej braucht fur sein Gedächtnis vor allem die außerliche Selbstbestătigung, wenn er seinen EntschluB, am Staudamm mitzubauen, damit begrundet:

охота, пока молодоя, тохе участвовать... чтоб било, значит, потом что вспомнить... (S. 97)

Ganz anderer Art sind dagegen die Erinnerungen Dar'jas, die in inrem Leben außer Matëra nichts von der Welt ge sehen hat, und die Bedeutung, die die Heldin ihnen verleint. Fur Dar'ja bedeutet "pamjat'" Bewahrung der Tradition als lebendiges Bewubtsein des eigenen Gewordenseins und Anknupfen an die kollektive geistige Erfahrung der vorangegangenen Generationen, die dem Menschen Orientierung und halt gibt und ohne die er sich im Leben verrennt und seine Kraft sinnlos verzehrt. Die Heldin vergewissert sich dieser Erfahrung in ihrer Befragung der Vergangenheit, in ihren Reflexionen uber die Toten und ihr Vermachtnis, und sie kennzeichnet ihre gesamte geistige Welt, bei deren Wiedergabe Formen und Motive der Folklore, Brauchtum und alter Volksglaube als historisches Gedăchtnis des Volkes breiten Raum einnehmen.

Die grobe Bedeutung, die der Erinnerung, dem NichtVergessen in Rasputins Prosa zukommt, beinhaltet die Warnung vor einem Verlust des historischen Gedăchtnisses und den Gefahren, die der Gegenwart aus dem Fehlen eines

270) Zabelin, a.a.0., s. 70; vgl. auch Dyrdin, a.a.0, S. 190 . 
tradierten sittlichen Wertbewußtseins erwachsen:

Der technologische Fortschritt hat dieses Wertbewubtsein ignoriert, er ist in geschichtslosen Optimismus verfallen, sein Geschichtsbegriff verlor das Bewubtsein der Uberlieferung und Kontinuitat und verdunnte zur Leistungsbilanz wissenschaftlichtechnischer und politisch-sozialer Errungenschaften. Dieser Geschichtsverlust ist ein Metaphysikverlust, oder: Die literarische Modellierung der Bewubtseinsvorgange alter, religios empfindender Menschen entbI8Bt das sittiliche Defizit moderner konformistischer materialistischer Denkungsart. 271)

\subsubsection{Organisches Leben und Integritat der Personlichkeit}

Der Lebenshaltung Dar'jas, die eine hochstehende, das Bewubtsein von der Stellung und Verantwortung des Menschen in der endlosen Kette von Vergangenheit, Gegenwart und Zukunft beinhaltende Sittlichkeit begrundet, und die der Heldin ermöglicht, auch in der Tiefe des seelischen Konflikts ihre Personlichkeit zu bewahren, stellt Rasputin ein Bild des modernen Menschen gegenuber, der sich von der Bindung an das Geschlecht gelost und dem naturlichen Gang des Lebens entfremdet hat.

Der Mensch sei stolz geworden und vermessen, stellt Dar'ja gegenuber dem Enkel Andrej fest, angesichts der Macht und der gewaltigen Mrglichkeiten, die inm in der heutigen zeit gegeben sind. Er habe vergessen, dab er trotz alledem nur Mensch geblieben ist, und statt seine Sache $z u$ tun, strebe er nach Dingen, die seine kräfte uberfordern und seinem Wesen widersprechen:

наклашывая на воз столь, сколь кобыла увезет, а то не на чем возить будет... загордел человек, ох, загордел. Гордея, тебе же хуже. Тот малахольныя, которыя под собоя сук рубил, тоже много чего об себе думал. А шмякнулся, печенки отбил - дак он об землю их отбил, а не об небо. Никуды с земли не деться.

271) Kluge, Zur Rezeption Ćechovs, a.a.o. 
Че говореть - сила вам нонче большая дадена. Oх, болышая!.. И отсель, с Матёры, видать ее. Да как бы она вас не поборола, сила-то эта... Она-то большая, а вы-то как были маленькие, так и остались. (S. 96)

Die globalen Gefahren einer mit der Entwicklung von Wissenschaft und Technik nicht Schritt haltenden Sittlichkeit des mit seinen Bestrebungen in Gegensatz zur Natur geratenen Menschen sind hier angesprochen. Doch Rasputin beunruhigen auch die seelischen Resultate einer sich nicht organisch vollziehenden Entwicklung von Mensch und Gesellschaft.

Der "stolz gewordene", hochmutige, selbstgefallige Mensch begibt sich in eine gefahriiche Position, denn er gerat in Widerspruch zum Geschlecht, zum Volk, zur Menschheit. Und deshalb kann er im Grunde auch nichts, auBer "Verwirrung" ("rasterjannost" ") (ein von Rasputin hăufig verwendetes Epitheton), empfinden. 272)

In den Erklärungen Dar'jas, warum ihr der Mensch leid tue, labt der Autor seine Heldin ein hartes Urteil uber den modernen Menschen fălien. Er habe, von Sachzwăngen beherrscht und sich selbst entfremdet, in der Hektik und Eile seines Lebens dessen Sinn und Zweck langst aus den Augen verloren. Er tue immer das, was er eigentlich nicht morchte, und statt das eigene Leben mit wurde und Anstand zu besorgen, strebe er standig nach einem anderen und fuhre damit sich selbst und andere in die Irre:

И он не сам собоя на люди выходит, кого-то другого иэ себя корчит. Чем он, другоя-то, лутше тебя? Пошто ты, какоя есть, не живешь, а все норовишь притвориться... Человек сотворен, жить пущен, а ему, ишь, другого себя подавая. Запутался, ох, запутался, вконец заигрался. (S. 120)

Das moderne Leben, wie es in der Novelle im Verhalten der "Fremden" und in den Verhaltnissen in der neuen siedlung zum Ausdruck kommt, stellt sich gegenuber der in sich geschlossenen, geordneten, in segensreichem Wechselbezug mit der Natur sich entwickelnden Lebenswelt Matèras 
als ungeordnet, verworren, widerspruchsvoll und den Menschen innerlich zerstorrend dar. Der sein neues Leben in der Siedlung reflektierende Pavel vermibt bei all der äußeren Erleichterung, die es bietet, den erforderlichen seelischen Ruckhalt:

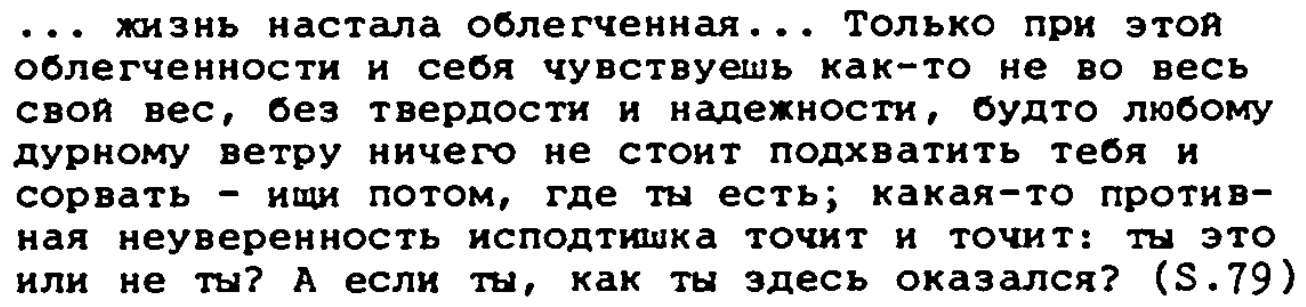

Und das letzte Kapitel, das einzige der Novelle, in dem die neue Siedlung in Erscheinung tritt, die nun die Nachfolge der bereits in Flammen aufgegangenen Matëra antritt, zeigt ein dusteres und fragwurdiges Bild und einen innerlich zerrissenen und erschopften Pavel, dem das neue Leben Aufgaben und Probleme aufburdet, die inn kaputtmachen. Er ist nicht mehr "sein eigener Herr", wie Dar'ja sich ausdrückt :

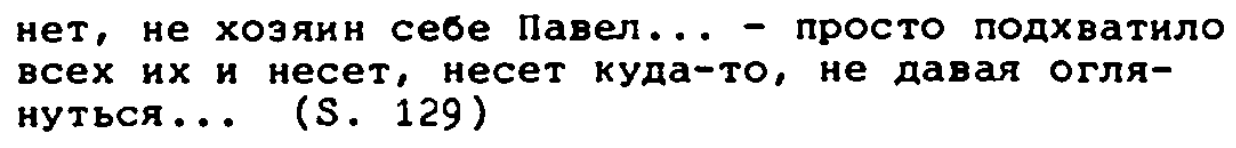

Wieder tritt hier die besondere, die Stellung des Menschen $z u$ der inn umgebenden Welt und den Zustand der Persönlichkeit bezeichnende Bedeutung von "chozjain" entgegen. "Herr sein" uber sich selbst und sein Leben, vermag der Mensch nur, wenn er sich nicht auBerhalb der gesetzmäBigen Ordnung stellt, aus der er hervorgegangen ist, sondern innerhalb dieser den ihm zugewiesenen Platz einnimmt, der allein sein Leben rechtfertigt und ihm hilft, seine Persönlichkeit zu organisieren und $z u$ bewahren. In "Proščanie s Matëroj" gelingt dies nur der alten Dar'ja, die bei allen $Z$ weifeln und Fragen, in die sie der durchlebte Konflikt stürzt, uber ein festes, ihr Orientierung gebendes Fundament verfugt und gleich den Symbolen Matëras, dem "Königslärch" und dem "Herrn der Insel", diesem moralischen Fundament und damit sich selbst bis zum Ende treu bleibt. 
In dem Abschiedszeremoniell gegenuber ihrem Haus fand Rasputin einen uberzeugenden kunstlerischen Ausdruck fur jene "aus alter Zeit stammende ehrfurchtige Beziehung, wie man sie zu Gott hat" (S. 168), die die Heldin allem, was inr Leben betrifft, auch angesichts des sicheren Untergangs bis zur letzten Minute entgegenbringt ${ }^{273)}$. Mit ihren letzten Kräften weiBt Dar'ja ihr Haus und den russischen ofen, richtet und schmuckt die Wohnung und gibt ihnen wie einem nahen Verstorbenen das letzte Geleit, bevor sie es den "zundlern" zum Anzunden UberläBt.

In der Schonheit dieses tragischen Rituals wird der Vorrang utilitaristischer Zweckmäbigkeit als Existenzprinzip verworfen und inm eine Haltung entgegengesetzt, die auf der unerschutterlichen Einsicht beruht, daB es der wurde des Menschen mehr entspricht, in kritischen Augenblicken einem eng gefabten "Nutzen" und sogar dem, was vernunftig erscheint, zu entsagen, um der eigentlichen Bestimmung des Menschen treu zu bleiben: Namlich kraft eigenen Willens seine bewuste Einheit mit der groberen Welt, von der man hervorgebracht und die einem gegeben wurde, zu bekrätigen. 274)

\subsubsection{Zusammenfassung}

Den in der Gegenuberstellung von Inseldorf und "Außenwelt" beabsichtigten Kontrast zwischen zwei Lebenssphären habe Rasputin literarisch nicht bewaltigt, konstatiert Nyota Thun:

wăhrend er fur "drinnen" seine Handschrift, die Menschen und Dinge zu sehen und zu beschreiben, ausgebildet hat, fehlt die kunstlerische Reife bei

273) Kluge sieht im letzten Dienst, den Dar'ja ihrem Haus erweist, eine an christlichem Gebot orientierte Handlung und verweist auf Jesaja 38,1: "Bestelle Dein Haus, denn Du wirst sterben und nicht lebendig bleiben", vgl. Kluge, Abschied von Matjora, a.a.0., s. 278. Zur Bedeutung der Religion in der Weltsicht der Helden sowie zum Problem des Transzendenten bei Rasputin vgl. auch ebenda, S. 284 sowie Kluge, Zur Rezeption Cechovs, a.a.0.

274) Starikova, Żit' i pomnit', a.a.0., S. 244 
der Darstellung von Menschen und Erscheinungen aus der Welt von "drauben". 275)

Diese Auffassung und der Vorwurf des Schematismus in der Konfrontation von Vergangenheit und Gegenwart in "Prošcanie s Matëroj" wären berechtigt, bestunde der Sinn dieser Gegenubersteliung darin, im Untergang der bauerlichdorflichen Lebenswelt Materas die tragische Dimension des Geschehens aufzudecken. Was den Autor beunruhigt, ist indessen nicht die Tatsache der Abkehr des modernen Rubland von seiner bauerlichen Vergangenheit, bei aller Trauer und Poesie, mit der dieser Abschied in seinem Buch dargestellt ist. Nicht die Verănderungen und der technische Portschritt als solche werden von inm problematisiert, sondern die Art und Weise, wie sie sich durchsetzen, die Gefahren einer nicht organischen Entwicklung dieses Prozesses und die daraus resultierenden katastrophalen Folgen fur den einzelnen wie fur Erde und Menschheit insgesamt .

Das Leben der Nachkriegszeit mit seiner Anspannung und Intensitat, seinem wahnsinnigen Tempo und Rhythmus, die dem Menschen keine Zeit lieben, daruber nachzudenken, ob er auch, wie die alte Dar'ja sagt, in die richtige Richtung laufe, mit seinem Phanomen der personlichen Selbstbestatigung und dem sich darin ausdruckenden mablosen Hochmut - all dies bildet die objektive Voraussetzung fur jene sittlichsoziale Erscheinung, die Rasputin beunruhigt und die inn veranlabt, uns zum Thema der fur die Menschheit bedeutsamen "ethischen Grundsatze" zuruckzufunren. 276)

Das Problem einer Sittlichkeit, die der Stellung und Verantwortung des Menschen in einer durch Vielfalt und Komplexitat der Erscheinungen und Widerspruche gekennzeichneten und sich gefahrlich schnell verăndernden Welt gerecht wird, bewubt $z$ machen, und die Suche nach einer Grundlage zu seiner Losung kennzeichnen das kunstlerischphilosophische Bestreben des Autors in "Prošcanie s Materroj". Die Einseitigkeit der auf die geistige Welt des

275) Thun, Dialog mit Rasputin, a.a.0., S. 198 276) Belaja, Kol'co v neskonđaemoj cepi, a.a.o. 
alten Dorfes begrenzten Perspektive und die ăußerste $\mathrm{Zu}$ spitzung des Kontrastes in der Gegenuberstellung von "Eigenen" und "Fremden", Inseldorf und Siedlung erweisen sich dabei als ăsthetisch motiviert. Mit ihrer Hilfe erreicht Rasputin "jene geistig-moralische Provokation" und Beunruhigung des Lesers, die es ermöglicht, găngige Anschauungen und Vorstellungen zu erschuttern und zur Uberprufung bestehender Wertesysteme $z u$ veranlassen ${ }^{277)}$. Zugleich dient diese Konfrontation dem Entwurf eines positiven sittichen Programms des Autors:

Rasputin projiziert die den Menschen umgebende Welt gewissermaben auf zwei Ebenen: eine ideale und eine reale. Die ideale benbtigt er, um seine Idee von der hohen Bestimmung und Verantwortung des Menschen $z u$ begrunden. Die Einheit von Himmel und Erde, der Lebenden und der Toten, das Empfinden seiner selbst als Glied in der "unendichen Kette", die intensive Wahrnehmung der Schonheit der Welt - all dies ist ein Unterpfand menschlicher Kraft. 278)

Die einfache und klare, in ihren Zusammenhängen uberschaubare und dem Menschen verstandiche Welt der Helden von Matèra gehort der Vergangenheit an. Nicht verschwunden sind jedoch in einer vollig veränderten Gegenwart das Bedurfnis des Menschen nach Erklärung dieser Zusammenhănge und sein Verlangen nach Harmonie mit der Welt und sich selbst.

Die Zeit der naiven und unreflektierten Vorstellungen ist verschwunden, nicht aber die Notwendigkeit der Vorstellungen selbst. Und irgendwer muB doch eine neue Geschichte der Seele schaffen? Die Kunst muB das tun' 279)

Ausgehend von dem, was er im realen Leben sieht und suchend in traditionellem Verständnis menschlichen Seins, entdeckt Rasputin den "ewigen Kreislauf" der Natur als unerschutterliche Realitat und Grundlage des einheitlichen Weltgebaudes, als dessen integraler Bestandteil der

277) Jurgen Engler, Beitrag zur Diskussion um "Abschied von Matjora" in: Weimarer Beitrăge, 1980, Nr. 11, S. $130-133$, S. 130

278) Belaja, Kol'co v neskončaemoj cepi, a.a \&. . ide Wüst-9783954791231

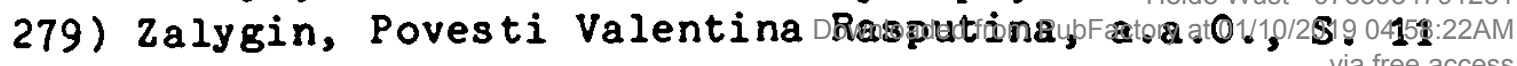


Mensch die höheren und ewigen Gesetze der Natur nicht ignorieren darf. In der Anerkennung dieser Ordnung liegt für Rasputin die Lösung des Geheimnisses von Leben und Tod begründet sowie die Moglichkeit einer Beantwortung der Grundfrage, wie der Mensch leben und wie er sterben soll.

Analog dem ewigen Werden und Vergehen in der Natur vollziehen sich auch Geburt und Tod im menschlichen Leben, und nur ausgehend von diesem Wissen um die Endlichkeit des eigenen Lebens vermag der Mensch, dieses würdig und sinnvoll zu gestalten. "Der Tod ist schrecklich", schreibt Rasputin, aber

она же, смерть, засевает в души живых медрыя и полезныя урожая, и из семени таяны и тлена созревает семя жизни и понимания. (S. 105)

"Kenne deine Frist", bemerkt Dar'ja (S. 86), und die besondere Bedeutung, mit der in allen drei Novellen Rasputins die Worte "Frist" wie auch "leb und vergib nicht" besetzt sind, ist in diesem Zusammenhang zu sehen. Wer vergibt oder zu verdrăngen sucht, dab ihm auf der Erde nur eine bestimmte Frist gegeben ist und, "stolz geworden", die Gesetze der Natur umgehen will, der handelt der Wurde und Verantwortung des Menschen zuwider und läuft Gefahr, sich in einer oberflachlichen und rücksichtslosen Jagd nach dem Leben sinnlos zu verzehren.

Indem Rasputin dieser "wilddiebhaften Beziehung zur Natur in uns und zur Natur auBerhalb uns selbst"280) die M8glichkeiten und die innere Kraft des in Einheit mit der Natur und in enger Bindung an das "Geschlecht" lebenden Menschen gegenuberstellt, zeigt er Ansatzpunkte fur einer. Ausweg aus dem sittlichen Dilemma der Gegenwart. Sie sind vor allem enthalten in dem Aufruf, das Tempo zu verlangsamen und Umschau $z$ halten, was an Wertvollem und Unverzichtbarem in dem von Generationen Geschaffenen zu bewahren ist, in der Bewußtmachung der Bedeutung des hi-

280) Belaja, Večnoe i prechodjašcee, a.a.0., s. 16 
storischen und sozialen Gedachtnisses des Menschen und der Forderung nach einem "Okologischen Bewubtsein", das den Raubbau an der Natur als Raubbau am Menschen und an der Zukunft der Menschheit begreift.

Die Position Rasputins ist nicht die einer Rückkehr zu dem Leben der Vergangenheit, zu einer Welt ohne Technik und zu der urwüchsigen Naturverbundenheit der băuerlichen Lebensweise, obwohl im Text bisweilen Gedanken anklingen, die eine solche Interpretation nahelegen:

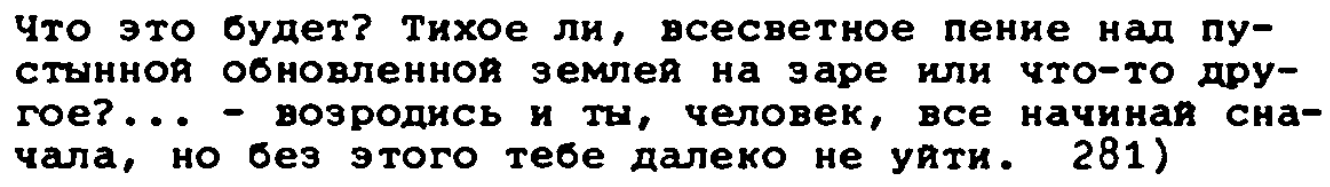

Es ist sicher kein Zurall, das Rasputin diese in der ersten Fassung der Novelle, die in "Naś sovremennik" erschien, enthaltene Passage für die Buchausgabe von "Prošcanie s Matëroj" gestrichen hat, denn

nicht in der Rulckkehr zur Legende und nicht in der Schafrung einer neuen besteht seine Stärke. ... Das Thema des menschlichen Gedăchtnisses, auf das die Welt sich gründet..., das in seinen Büchern allseitig und erschopfend ausgearbeitet ist, bezeugt, dab Rasputin an die Kontinuitat des menschlichen Geistes glaubt. Auf der Grundlage dessen, was er im Leben sieht (und er sieht... den Menschen durch reale Făden mit dem organischen Leben der Natur verbunden), macht Rasputin den Versuch, vor dem Leser eine Lebensphilosophie voll würde und BewuBtsein zu entwickeln, die dem Menschen seine Kraft und Stärke und die Moglichkeit, sie zu realisieren, zu zeigen vermag. 282)

281) Valentin Rasputin, Prošcanie s Matëroj, in: Nas sovremennik, 1976, Nr. 10, S. 60

282) Belaja, Kol'co v neskončaemoj cepi, a.a.o. 
Die Untersuchung des dorflichen Charakters in der Prosa Vasilij Sukśins und Valentin Rasputins hat die eingangs formulierte These bestătigt, nach der das Interesse der Autoren am dorflichen Helden in erster Linie ein Interesse an dessen Bewubtsein, an seiner besonderen Weltsicht und Art des Denkens darstellt. Sie war zugleich bemunt, die zentrale Bedeutung und vielfaltige Funktion aufzudecken, die diesen Helden als Bewustseinstypen im jeweiligen kunstlerischen System der beiden Autoren zukommt. An erster Stelle ist hier das neue Perspektivprinzip zu nennen, das in dieser Prosa durch die Einfuhrung der "Stimme" und des Blickwinkels des Helden auf breiter Ebene realisiert wird und $2 u$ neuen strukturmerkmalen fuhrt, die auf eine Ablossung des auktorial determinierten "monologischen Stils" des sozialistischen Realismus zielen.

Indem anstelle auktorialer Beschreibungen und Wertungen das Prinzip der Selostaufdeckung der Charaktere und Bewubtseinshaltungen in den Vordergrund tritt, zeigen sich zugleich neue Wirkungsintentionen, die auf eine Aktivierung und Emanzipierung des Lesers orientieren. Die Besonderheit der Erzahlperspektive und die daraus resultierende radikale Verănderung im Bezugssystem von Autor, Held und Leser zeigen die Prosa Śukšins und Rasputins eingereint in einen umfassenden InnovationsprozeB der modernen russischen Literatur, der nicht nur die Dorfprosa, sondern auch das Werk von "Stadtautoren", wie Jurij Trifonov und Andrej Bitov kennzeichnet und selbst im modernen Drama seinen Niederschlag findet ${ }^{283)}$.

283) Vgl. hierzu auch Rudolf Nelahauser, Wertung und Erzahlperspektive in der zeitgenossischen sowjetischen Erzăhlung. "Bytovaja proza", in: Slavistična revija. Ljubljana 1979, S. 417-429. Zu Gemeinsamkeiten in der Prosa Trifonovs, Sukšins und Rasputins vgl. auch Anatolij Bocarov, Kontrapunkt. Obscee i individual'noe $v$ proze Ju. Trifonova, V. Sukšina, V. Rasputina, in: Oktjabr', 1982, Nr. 7, S. 190-199 
Die Perspektive des dorflichen Helden und sein BewuBtsein erhalten darüberhinaus jedoch noch spezifische Bedeutung fur die Lobsung der in der untersuchten Prosa aufgeworfenen Fragen, wobei besonders dem volkstumlichnationalen Moment der geistigen Welt dieses Helden und seinem "außerliterarischen" Sprachmaterial eine zentrale Funktion zukommt.

Die in unterschiedliche Richtungen verlaufende Suche der beiden Autoren läbt von zwei verschiedenen küstlerischen Systemen mit jeweils eigenständiger Problematik sprechen. Wăhrend die besondere Verwendung der "fremden Stimme" in der Prosa Šukšins die Herausbildung eines Stilsystems bewirkte, das in der Polemik mit dem "kanceljarit" eine eigene künstlerische Auseinandersetzung mit modernen Geisteshaltungen funrt und in Anknupfung an die Poetik der karnevalistischen Lachkultur neue M8glichkeiten der asthetischen Aneignung von Wirklichkeit erschlob, sucht Valentin Rasputin in der Annăherung an die naive Vorstellungswelt seiner traditionellen dorflichen Gestalten und an das historische Gedăchtnis des Volkes nach kunstlerischem Ausdruck für seine philosophische Problematik. Beruhrungspunkte in der Prosa beider Autoren zeigen sich dabei in der Problematisierung aktueller Erscheinungen im geistig-seelischen Bereich des modernen Menschen: An formalen Konventionen orientiertes, durch Rollen und Funktionen determiniertes, dem realen Leben und dem menschlichen Wesen entfremdetes Denken und Handeln, geistiger Utilitarismus, der Drang nach auberlicher Selbstbestatigung werden von beiden Autoren unter BeschuB genommen. Vor allem aber bewegt Suksin wie auch Rasputin das Problem der fehlenden Harmonie von Mensch und Welt sowie des Menschen mit sich selbst als einer geistig-seelischen Grundbefindlichkeit der modernen Epoche mit ihren gewaltigen Verănderungen, ihrer Schnellebigkeit und Komplexităt der Erscheinungen. Für beider Prosa gilt, was Rasputin als zentralen Gegenstand seines künstlerischen Schaffens bezeichnete: 
Der Mensch in unserer sich wandelnden Welt, der Mensch unter anderen Menschen und mit sich allein, die sittlichen und psychologischen Veränderungen, die in inm vor sich gehen sowie die Ursachen und Folgen dieser Verănderungen. 284)

Interessant ist in diesem Zusammenhang die Idee von einem "anderen Leben", die als ernstes psychologisches Moment des modernen Menschen im Werk beider Autoren einen unterschiedlichen Niederschlag fand, aber auch Beruhrungspunkte aufweist.

Bei Rasputin tritt sie auf als illusorische und selbstbetrugerische Vorstellung des "stolz gewordenen" und "verwirrten" Menschen, der im Streben nach einem leichten Leben der Verantwortung gegenuber den ernsten Lebensfragen ausweichen will und im Drang nach auBerlicher Selbstbestătigung nach einer Befriedigung sucht, die er in den alltăglichen Lebenszusammenhăngen nicht finden kann. Diesem Wunsch nach einem anderen als dem gegebenen Leben stellt der Autor die bewubte Identifikation seiner Heldinnen mit dem unverwechselbaren und einmaligen eigenen Leben und Schicksal entgegen.

In Sukšins Prosa erscheint die Idee vom "anderen Leben" als widerspruchsvolles psychologisches Phănomen des Menschen der Gegenwart im Zusammenhang mit dem Bedurfnis nach selbstdarstellung und Selbstverwirklichung in einer den Menschen beengenden auBeren Welt, und der Autor deckt in inr die Sehnsucht nach einem Leben, wie es der Vorstellung nach moglich wăre, auf ${ }^{285)}$.

Der dorfliche Held als Bewubtseinstyp ermbglicht den Autoren, Vergangenheit und Gegenwart im geistig-kulturellen Bereich einander begegnen zu lassen und nach dem inneren Zusammenhang, auch im Hinblick auf die Entwicklung der Gesellschaft und des Menschen in der Zukunft, zu fragen. In dem Auftreten dieser - im jeweiligen Werk sehr unter-

284) Valentin Rasputin, Peredo mnoj ożivajut kartiny, in: Sovetskaja Kul'tura, 23.12.1977, zit. nach: Dyrdin, a.a.0, S. 178

285) Zur Polemik mit der Idee vom "anderen Leben" in der modernen russischen Prosa vgl. auch Belaja, Vecnoe i prechodjašcee, a.a.0., S. $13 \mathrm{f}$. 
schiedlichen - Bewußtseinstypen zeigt sich denn auch der Versuch, die Bewegung des menschlichen Bewußtseins im allgemeinen wie auch der sowjetischen Gesellschaft von ihrer geistig-kulturellen Seite her im besonderen $z u$ verstehen. Indem Šukšin diese Verănderungen in ihren vielfăltigen Verăs telungen und bizarren Verknupfungen in Bewubtsein und Psyche des Zeitgenossen aufspürt, untersucht er zugleich den heutigen Zustand des russischen Volkscharakters mit seinen widerspruchsvollen Neigungen und Schwankungen, aber auch mit seinen inneren Potenzen. Bei Rasputin tritt die Gefahr der Diskontinuitat geistiger Prozesse, des fehlenden Zusammenhangs der Zeiten in den Vordergrund, die in seiner Prosa umfassend und in ihren globalen Dimensionen problematisiert wird. Zugleich sucht der Autor nach einem "naturlichen Beweis" für den Sinn menschlicher Existenz mit dem Ziel, auch dem modernen Sein des Menschen zu einem stabilen geistig-moralischen Fundament zu verhelfen.

Der mit der Darstellung des dorrfichen Helden in der Prosa Vasilij Śukšins und Valentin Rasputins verbundene Fragenkomplex von Tradition und Fortschritt, Kontinuitat und Diskontinuităt, Gewinn und Verlust im System menschlicher Werte fuhrte im Werk beider Autoren zur Aktualisierung und Problematisierung von Grundrragen menschlichen Seins anhand grundlegender Erscheinungen der Gegenwart. Aktualitat und innovatorischer Gehalt dieser Prosa sind nicht zuletzt auch daran zu messen, daB es dabei gelang, nicht nur mächtige Klischeevorstellungen zu erschuttern, die lange Zeit Literatur und geistigen Uberbau der sowjetischen Geselischaft beherrschten, sondern auch Auffassungen und Strukturen zu durchbrechen, die fur das moderne Denken uberhaupt kennzeichnend sind. 


\section{LITERATURVERZEICHNIS}

I. Quellen

1. Vasilij Makarovic Śukšin: ausgewăhlte Textausgaben und publizistische Veroffentlichungen

Sel'skie ziteli, Moskva 1963

Ljubaviny, Moskva 1965

Tam, vdali. Rasskazy. Povest', Moskva 1968

Zemljaki, Moskva 1970

Charaktery, Moskva 1973

Besedy pri jasnoj lune, Moskva 1974

Izbrannye proizvedenija v dvuch tomach, Moskva 1975

Do tret'ich petuchov. Povesti. Rasskazy, Moskva 1976

Rasskazy, Moskva 1979

Rasskazy. Kniga dlja čtenija s kommentariem na russkom jazyke, Moskva 1979

Ja prišel dat' vam volju, Moskva 1982

Nravstvennost' est' pravda, Moskva 1979

Otvet na anketu "Voprosov literatury" "Literatura i jazyk", in: Voprosy literatury, 1967, Nr. 6, S. 148-150

2. Valentin Grigorevic Rasputin: ausgewăhlte Textausgaben und publizistische Veroffentlichungen

Kostrovye novych gorodov, Krasnojarsk 1966

Kraj vozle samogo neba, Irkutsk 1966

Čelovek s ètogo sveta. Rasskazy, Irkutsk 1967

Poslednij srok. Povesti i rasskazy, Moskva 1970

Vniz i vverch po tećeniju. Povesti, Moskva 1972

Povesti, Moskva ("Molodaja gvardija") 1976, 1978, 1980

Povesti, Moskva ("Sovetskaja Rossija") 1978

Żivi i pomni. Povest'. Rasskazy, Irkutsk 1978

Prošcanie s Matëroj, in: Naś sovremennik, 1976, Nr. 10, S. 3-78, Nr. 11, S. 17-70 
Byt' samim soboj, in: Voprosy literatury, 1976, Nr.9, S. $142-150$

deutsch (gekulrzt): Das Leben ist das Wichtigste, in:

Sowjetliteratur, 1978, Nr. 1, S. 150-157

Ne mog ne prostit'sja s Matëroj, in: Literaturnaja gazeta, 16.3 .1977

deutsch: Ich muBte mich von Matjora verabschieden...

Gespräch mit Valentin Rasputin, in: Valentin Rasputin,

Die Letzte Frist. Leb und vergib nicht, Leipzig (Reclam)

1980 , S. 444-446

Peredo mnoj ożivajut kartiny, in: Sovetskaja kul'tura, 23.12.1977

Irkutsk s nami, in: Sovetskaja kul'tura, 14.9.1979

Valentin Rasputin, Schriftsteller, in: Sowjetunion heute, 1983, Nr. 4, S. 36-38

II. Sekundărliteratur

1. Zur Dorfprosa und modernen russischen Literatur
Abramov, F.: Koe-čto o pisatel'skom trude, in:
Voprosy literatury, 1974, Nr. 3,
S. $180-195$
ders.: $\quad 0$ chlebe nasuścnom $i$ chlebe duchovnom, in: Naś sovremennik, 1976, Nr. 9, S. $170-172$

Ajtmatov, $\dot{C} .:$ Neizbeinost' garmonii, in: Literaturnaja gazeta, 1.1.1973

Anaschenkow, B.: Der "Mensch der Tat" und sein geistiges Potential, in: Kunst und Literatur, 1975, Nr. 3, S. 273-299

Anninskij, L.: Točka opory, in: Don, 1968, Nr. 7, S. 178-187

Arnol'dov, A.: Socialisticeskij kul'turnyj progress i naucno-techniceskaja revoljucija, in:

Voprosy literatury, 1981, Nr. 5, S. 3-33

Belaja, G.:

Iskusstvo est' smysl, in: Voprosy literatury, $1973, \mathrm{Nr} .7, \mathrm{~S} .62-94$

deutsch: Kunst ist Inhalt..., in: Kunst und Literatur, 1973, Nr. 12, S. 12111227 
dies.:

dies.:

Brown, D.B.:

Dedkov, I.:

Flaker, A.:

Granin, D.:

Gusarova, I.:

Gusev, V.:

Gutschke, I.:

Hiersche, A.:

ders.:

ders.:

Hildebrandt, G.:
Istorizm kak nravstvennaja $i$ chudozestvennaja pozicija pisatelja, in: Zanrovo-stilevye iskanija sovremennoj sovetskoj prozy, Moskva 1971, S.93-119

Slovo $v$ jazyke i slovo $v$ stile, in: Literaturnoe obozrenie, 1980, Nr. 2, S. 39-41

Soviet Russian Literature since Stalin, Cambridge 1978

Stranicy derevenskoj žizni. Polemiceskie zametki, in: Novyj mir, 1969, Nr. 3, S. 231-246

Él'sberg, Ja.E.: Izmenenija dejstvitel'nosti i razvitie stilej sovetskoj prozy, in: Problemy chudožestvennoj formy socialističeskogo realizma, t. 1, Moskva 1971, S.179-234

Modelle der Jeans-Prosa. Zur literarischen Opposition bei Plenzdorf im osteuropais chen Kontext, Kronberg/Ts. 1975

Wissenschaftlich-technische Revolution, Personlichkeit, Literatur, in: Kunst und Literatur, 1978, Nr. 11,

S. 1123-1140

Čuvstvo chozjaina zemli, in: Moskva, 1976, Nr. 2, S. 226-236

O proze, derevne $i$ cel'nych ljudjach, in: Literaturnaja gazeta, 14.2.1968

Das Verhaltnis von Mensch und Natur in der sowjetischen Gegenwartsliteratur, in: Zeitschrift fur Slavistik, 1975, $\mathrm{Nr} .4$, S. 526-531

Sowjetliteratur und wissenschaftlichtechnische Revolution, Berlin 1976

Sowjetische Dorfprosa - ein literarisches Phanomen des entwickelten Sozialismus, in: Weimarer Beitrăge, 1980, $\mathrm{Nr} .4, \mathrm{~S} \cdot$ 5-28

Die russische sowjetische Dorfprosa. Fragen ihrer Tradition, in: Zeitschrif: fur Slavistik, 1982 , Nr. 4, S. 568-575

Ein Beitrag zur sowjetischen Dorfprosa der Gegenwart, in: Die Welt der Slaven, 1973, S. 190-200 
$\begin{array}{ll}\text { Holthusen, J.: } & \text { Stilistik des "uneigentlichen" Erzah- } \\ \text { lens in der sowjetischen Gegenwarts- } \\ \text { literatur, in: Die Welt der Slaven, } \\ \text { 1968, S. 225-245 }\end{array}$

Jazykovye processy sovremennoj russkoj chudożestvennoj literatury. Proza, Moskva 1977

Klepikowa, J.: Fjodor Abramows Trilogie "Brüder und Schwestern", in: Kunst und Literatur, 1977, Nr. 6, S. 627-638

Koževnikova, N.A.: O nekotorych tendencijach razvitija jazyka sovremennoj russkoj prozy, in: Jazyk i stil' pisatelej v literaturnokritičeskom analize chudożestvennogo proizvedenija, Kišinev 1977, S. 36-57

dies.:

O sootnośenii reči avtora i personaža, in: Jazykovye processy sovremennoj russkoj chudożestvennoj literatury . Proza, Moskva 1977, S. 7-98

dies.:

O tipach povestvovanija $v$ sovetskoj proze, in: Voprosy jazyka sovremennoj russkoj literatury, Moskva 1971, S. 97-163

dies.:

Reçevye raznovidnosti povestvovanija $v$ russkoj sovetskoj proze, Avtoref. diss... kand. fil..., Moskva 1973

Kožinov, V.V.:

Golos avtora i golos personažej, in: Problemy chudožestvennoj formy socialističeskogo realizma, t. 2, Moskva 1971 , S. 195-235

Kusnezow, F.:

Auf der Suche nach dem kunftigen He 1den, in: Kunst und Literatur, 1973, $\mathrm{Nr} .8$, S. 778-792

ders.:

Literaturkritik: Mythos und Realitát der geistigen Werte, in: Kunst und $\mathrm{Li}$ teratur, 1974, Nr. 10, S. 1087-1114

Kuznecov, F.:

Sud'by derevni $v$ proze i kritike, in: Novyj mir, 1973, Nr. 6, S. 233-250

Lewis, $\mathrm{Ph}$.:

Peasant Nostalgia in Contemporary Russian Literature, in: Soviet Studies, XXVIII/4, 1976, S. 548-569

Metčenko, A. :

Večnyj zov i pozyvnye veka, in: Moskva, 1972, Nr. 4, S. 197-212

Napolova, T.: Nacional'naja samobytnost' pisatelja $i$ duchovnyj oblik geroja, in: Volga, 1972 , Nr. 10, S. 147-177 
Neuhăuser, R.: Wertung und Erzăhlperspektive in zeitgenössischen sowjetischen Erzăhlungen, in: Slavistična revija. Ljubljana 1979, S. 417-429

Perret-Gentil, Y.: Der Kolchosbauer in der heutigen russ:schen Dorf-Literatur, in: Osteuropa, 1978, Nr. 9, S. 794-810

Po trebovaniju zizni (S IV plenuma vsesojuznogo soveta po kritike), in: Voprosy literatury, 1971 , Nr. 8, S. 26-39

Protčenko, V.I.: Nekotorye voprosy razvitija "derevenskoj prozy", in: Problemy russkoj sovetskoj literatury 50 - 70-e gody, Leningrad 1976, S. 58-107

ders.: $\quad$ Povest' 60-ch - načalo 70-ch godov, in: Sovremennaja russkaja sovetskaja povest', Leningrad 1975, S. 161-223

Radov, G.: Na novom ètape. Sovremennoe selo v literature, in: Literatura i sovremennost', Nr. 11, 1970-71, Moskva 1972, S.247-274

Schaumann, G.: $\quad$ Cechov und die Sowjetliteratur der Gegenwart, in: Zeitschrift fur Slavistik, $1978, \mathrm{Nr} .1$, S. 84-92

Schmid, W.:

Thesen zur innovatorischen Poetik der russischen Gegenwartsprosa, in: Wiener Slawistischer Almanach, Band 4, 1979, S. 55-93

Sidorov, E.Ju.: $\quad K$ probleme stilevogo mnogoobrazija sovremennoj russkoj sovetskoj prozy (60 70-e gg.), Avtoref. diss... kand. fil..., Moskva 1974

Ssachno, H.v.: Der Aufstand der Person. Sowjetliteratur seit Stalins Tod, Berlin 1965

Starikova, E.: Sociologičeskij aspekt sovremennoj "derevenskoj prozy", in: Voprosy literatury, 1972, Nr. 7, S. 11-35

deutsch: Der soziologische Aspekt der heutigen "Dorfprosa", in: Kunst und Literatur, 1973, Nr. 1, S. 43-65

Strugackij, A.: Novye čelovečskie tipy, in: Voprosy literatury, $1976, \mathrm{Nr} .11$, S. 16-18

Surganov, V.: Čelovek na zemle, Moskva 1975

Surovcev, Ju.: $\quad$ o nacional'noj samobytnosti i "rantastičeski vyčurnoj ljubvi" $k$ nej, in: Literaturnoe obozrenie, 1973, Nr. 2, S.60-70 
Tampej, D.I.:

ders.:

Trefimova, G.:

vikulov, S.:

Witte, G.:

Zalygin, S.:

ders.:

ders.:
Idejno-èstetičeskie problemy sovremennoj prozy o derevne i literaturnaja kritika, Avtoref. diss... kand. fil..., Moskva 1975

Proza o derevne i sovremennaja literaturnaja kritika, in: Sovremennyj literaturnyj process $i$ kritika, Moskva 1975, S. 77-104

Vremja vybora. Chudožestvennoe osmyšlenie vzaimootnošenij človeka i prirody $v$ sovetskoj literature, in: Voprosy literatury, $1981, \mathrm{Nr} .12, \mathrm{~S} .7-48$

Ljubov' $k$ zemle? Da!, in: Naś sovremennik, 1969, Nr. 1, S. 110-115

Die sowjetische Kolchos- und Dorfprosa der funfziger und sechziger Jahre. Zur Evolution einer literarischen Unterreihe, Diss. München 1983

Rasskaz i rasskazcik, in: Literatura i sovremennost', $\mathrm{Nr}$. 11, 1970/71, Moskva 1972, S. 319-335

NTR i literatura. Razmyślenija i dogad$k i$, in: ders., Literaturnye zaboty, Moskva $1979^{2}$, S. $42-54$

Pisatel' i Sibir', in: ebenda, S. 19-41

2. Zu Vasilij Makarovič Śukšin

Andrianov, A.:

Anninskij, L.:

ders.:

ders.:

Balichin, A.E.:
Eśce raz o "strannych" gerojach Vasilija Šuksina, in: Molodaja gvardija, 1973 , Nr. 10, S. 308-312

Put' Vasilija Šukšina, in: Vasilij

Sukşin, Do tret'ich petuchov. Povesti. Rasskazy, Moskva 1976, S. 638-666

Šukšin-publicist, in: Vasilij šukßin, Nravstvennost' est' pravda, Moskva 1979 , S. 3-20

Śukšinskaja žizn', in: Literaturnoe obozrenie, 1974, Nr. 1, S. 50-55

Vasilij Makarovič Šukšin. Očerk žizni i tvordestva, in: V.M. Suksin, Rasskazy . Kniga dlja čtenija s kommentariem na russkom jazyke, Moskva 1979, S. 5-30 
Belaja, G.A.:

dies.:

dies.:

dies.:

Čalmaev, V.:
Antimiry Vasilija Šukšina, in: Literatura i sovremennost', Nr. 16, 1976-77, Moskva 1978, S. 269-279

Fars ili tragedija?, in: Literaturnoe obozrenie, 1979, Nr. 3, S. 58-60

Puti istinnye $i$ mnimye, in: Literaturnaja učeba, 1978, Nr. 4, S. 212-217

Roždenie novych stilevych form kak process preodolenija "nejtral'nogo" stilja, in: Mnogoobrazie stilej sovetskoj literatury. Voprosy tipologii, Moskva 1978, S. 460-485

Ukrepit'sja i žit'. Molodye geroi i novellisticeskoe iskusstvo Vasilija Šukšina, in: ders., Obnovlenie perspektivy, Moskva 1978, S. 113-164

Dragomireckaja, N.V.: Slovo geroja kak princip organizacii stilevogo celogo, in: Mnogoobrazie stilej sovetskoj literatury. Voprosy tipologii, Moskva 1978, S. 446-459

El'sberg, Ja.:

Smena stilej $\mathbf{v}$ sovetskom russkom rasskaze 1950 - 1960-ch godov. Sergej Antonov - Jurij Kazakov - Vasilij Sukšin, in: Smena literaturnych stilej, Moskva 1974 , S. 178-198

Emel'janov, L.: Vtoroe prodtenie: K 50-letiju so dnja rożdenija V.M. S̉ukšina, in: Naś sovremennik, 1979, $\mathrm{Nr} .7, \mathrm{~S} .162-170$

Ėventov, I.:

Nakazanie smechom. 0 sovremennom jumore, in: Zvezda, 1977, Nr. 1, S. 198-207

Frejlich, S.:

O stile Vasilija Śukśina, in: Voprosy literatury, 1982, $\mathrm{Nr} .9, \mathrm{~S} .57-66$

Gorn, V.:

Pereizdanijam V. Śukšina - podlinno naučnyj uroven', in: Voprosy literatury, 1977, Nr. 1, S. 248-252

Gromov, E.:

Poètika dobroty. K probleme nacional'nogo charaktera $v$ tvorcestve Vasili.ja Śukšina, in: Moskva, 1978, Nr. 12, S. 204-208

Gusev, V.:

Čechov i stilevye poiski sovremennoj sovetskoj prozy, in: V tvorceskoj laboratorii Cechova, Moskva 1974,

S. 354-366

ders.:

Imenno žizn', a ne čto drugoe...., in: Literaturnoe obozrenie, $1974, \mathrm{Nr} .1$, S. 50-55 
ders.:

Ivanov, I.P.:

ders.:

Kamyševa, O.A.:

Kantorovic̀, V.:

Kawerin, w.:

Korobov, V.:

Kuz'muk, V.A.:

ders.:

Marčenko, A.:

Ognev, A.V.:

Ossoveckij, I.A.:

Ovčarenko, Al.: Rasskazy Vasilija S̉ukšina, in: Don,
Dialektnaja leksika v proizvedenijach godov, in: Voprosy jazyka sovremennoj russkoj literatury, Moskva 1971, S. 301-385 1976, Nr. 1, S. 155-166

Prostranstvo slova. O dvuch stilevych tendencijach sovremennoj prozy, in: Literatura i sovremennost', $\mathrm{Nr} .17$, Moskva 1980, S. 121-130

Proza Vasilija Śukšina. Chudožestvennyj mir pisatelja, Diss... kand. Fil., Leningrad 1979

Idejno-chudożestvennoe svoeobrazie povesti i rasskaza $60-c h$ godov.

V. Astaf'ev, V. Sukšin, V. Rasputin, Avtoref. diss... kand. fil..., Irkutsk 1975

O rasskazach V. Śksina, in: Problemy literatury Sibiri, XVII - XX vv., Novosibirsk 1974, S. 221-238

Nekotorye osobennosti poétiki rasskazov Vasilija Sukśina, in: Problemy istorii kritiki i poètiki realizma, Kujbyšev 1977, vyp. 2, S. 163-176

Novye tipy, novyj slovar', novye otnošenija, in: Sibirskie ogni, 1971, Nr. 9, S. 176-180

Die Erzahlungen Wassili Schukschins, in: Kunst und Literatur, 1977, Nr. 12, S. $1283-1290$

Vasilij Šukšin: Trorčestvo. Ličnost', Moskva 1977

Svoeobrazie geroja rasskazov Vasilija Sukšina, in: Vestnik Moskovskogo Universiteta, 1978, ser. IX, filologija, Nr. 2, S. 14-24

V. Šukšin i rannij Čechov, in: Russkaja literatura, 1977, Nr. 3, S. 198-205

Iz knižnogo raja..., in: Voprosy literatury, $1969, \mathrm{Nr} .4, \mathrm{~S} .48-71$

O cechovskoj stilevoj tendenciiv sovremennom russkom rasskaze, in: Žanrovostilevye problemy $v$ sovetskoj literature, Kalinin 1978, S. 129-165 
Pavlikov, G.F.: Proza v. Śukšina. Tvorčeskaja individual'nost' i èvoljucija geroja, Diss... kand. fil..., Leningrad 1977

Pankin, B.:

Vasilij šukšin i ego "čudiki", in: Junost', 1976, Nr. 6, S. 74-80

Poljak, L.:

Tradicii Ċechova $v$ sovremennoj stilistike, in: Żanrovo-stilevye iskanija sovremennoj sovetskoj prozy, Moskva 1976 , S. 232-265

Pudożgorskij, V.K.: Priemy raskrytija avtorskoj pozicii $\checkmark$ rasskazach $v$. Sukšina, in: Problemy realizma, Vologda 1979 , vyp. 6 , S. $122-134$

Russkij sovetskij rasskaz. Očerki istorii żanra, Leningrad 1970

Salagaeva, L.L.: Funkcii narodno-razgovornych èlementov $\checkmark$ proze.V.M. Śukšina, in: Formirovanie stilistićeskich navykov ućašcichsja $v$ processe raboty nad grammaticeskoj temoj, Alma Ata 1977 , S. 62-67

dies.:

Vneliteraturnaja leksika v proizvedenijach V.M. Sukšina, in: Stilisticeskij aspekt izučenija russkogo jazyka v skole i vuze, Alma Ata 1978, S. 53-60

Seleznev, Ju.I.: Fantastičeskoe v sovremennoj proze, in: Moskva, 1977, Nr. 2, S. 198-206

ders.:

Večnoe dviżenie. Iskanija prozy $60-\mathrm{ch}$

- nac̉ala 70-ch gg., Moskva 1976

Śepeleva, L.: Rasskazy Śukšina, in: Voprosy istorii $i$ teorii literatury, vyp. 9-10, Celjabinsk 1972, S. 122-139

Solov'eva, I. / Śitova, V.: Svoi ljudi - cočtemsja, in: Novyj mir, 1974, Nr. 3, S. 245-250

Strelkova, I.: $\quad$ "So smechom mnogoe ponimaetșja..." Jumor $v$ proizvedenijach $V$. Sukśina $i$ V. Belova, in: Naš sovremennik, 1978 , Nr. 4, S. 170-178

Urban, A.: $\quad$ S podlinnym verno. V. Sukśin. Charaktery, in: Zvezda, $1974, \mathrm{Nr} .4$, S. 213-215

Zalygin, S.: Geroj v kirzovych sapogach. K tvorčestvu Vasilija Šukšina, in: ders., Literaturnye zaboty, Moskva 1979, S. $156-162$ 
3. Zu Valentin Grigorevič Rasputin

$\begin{array}{ll}\text { Baranov, V.: } & \begin{array}{l}\text { Formula tvorčestva. O tvorcestve pisa- } \\ \text { telja V. Rasputin, in: Literaturnoe } \\ \text { obozrenie, 1975, Nr. 12, S. 65-69 }\end{array} \\ \text { Belaja, G.A.: } \quad \text { Kol'co v neskončaemoj cepi... O Valen- } \\ \text { tine Rasputine, in: Moskovikij komso- } \\ \text { molec, } 15.1 .1982, \mathrm{~S} .4\end{array}$

Bočarov, A.: $\quad$ Kontrapunkt. Obščee $i$ individual'noe $v$ proze Ju. Trifonova, V. Sukšina, V. Rasputina, in: Oktjabr', 1982, Nr. 7, S. 190-199

Chvatov, A.: $\quad$ Poiski novych rešenij, in: $V$ načale semidesjatych. Literatura naśich dnej, Leningrad 1973, S. 24-54

Čudakova, M.: $\quad$ Zametki o jazyke sovremennoj prozy, in: Novyj mir, 1972, Nr. 1, S. 212-245

Dedkov, I.:

Méz nebom i zemlej..., in: Družba narodov, $1977, \mathrm{Nr} .3, \mathrm{~S} .263-266$

Dvorjaščin, Ju.A.: Russkaja sovetskaja povest' 60-ch načalo 70-ch godov. Evoljucija Zanra $v$ tvorćestve V. Belova, V. Lipatova, V. Rasputina, Avtoref. diss... kand. fil...,Leningrad 1976
Dyrdin, A.A.: $\quad$ Dialektika pamjati. Čeloyek $i$ vremja $v$ povesti V. Rasputina "Żivi i pomni", in: Sovremennyj sovetskij roman. Filo- sofskie aspekty, Leningrad 1979,
S. 178-193

Engler, J.:

Beitrag zur Diskussion um "Abschied von Matjora" von Valentin Rasputin, in: Weimarer Beitrăge, 1980, $\mathrm{Nr} .11$, S. 130-133

Gladyseva, 0.: Stariki, in: Volga, 1973, Nr. 1, S. 159-166

Hager, R.:

Beitrag zur Diskussion um "Abschied von Matjora" von Valentin Rasputin, in: Weimarer Beiträge, 1980, Nr. 11, S. 133-136

Hiller, B.:

Valentin Rasputin: Leb und vergib nicht, in: Weimarer Beitrăge, 1978, Nr.9, S. 133-139 
dies.:

Hirdina, K.:

ders.:

Kasack, W.:

Kluge, R.-D.:

ders.:

Kotenko, N.:

dies.:

Kuznecov, F.:

ders.:

Meichel, J.:
Kamjanov, V.:

Zur Poetik Rasputins. "Proscianie s Matëroj", in: Zeitschrift fur Slavistik, 1983, Nr. 2, S. 187-193

Beitrag zur Diskussion um "Abschied von Matjora" von Valentin Rasputin, in: Weimarer Beiträge, 1980, Nr. 11, S. $137-138$

Judalević, B.M.: Priroda konflikta v povesti V. Rasputina "Poslednij srok", in: Problemy Zanra v literature Sibiri, Novosibirsk 1977 , S. 139-150

"Dialektika duši" v rannich proizvedenijach Valentina Rasputina, in: Oćerki literatury i kritiki Sibiri (XVII XX vv.), Novosibirsk 1976, S. 255-273

Zemlja - èmpirei - obratno. Iz nabljudenij nad sovremennoj liriko-filosofskoj prozoj, in: Družba narodov, 1974, Nr. 3, S. 255-267

Walentin Rasputin, in: Osteuropa, 1975, $\mathrm{Nr} .7$, S. 489-490

Walentin Rasputin. Abschied von Matjora, in: Die russische Novelle, hrsg. v. Bodo Zelinsky, Dusseldorf 1982, S. $274-284$

Valentin Rasputin. Zur Rezeption Ċechovs und Dostoevskijs in der sowjetrussischen Dorfprosa, Manuskript im Druck

Preżde vsego - toc̉nost': 0 tvorčestve V. Rasputina, in: Literaturnaja učeba, 1978, Nr. 4, S. 127-133

Krivośçapova, T.V.: Idejno-chudożestvennye funkcii fol'klora $v$ tvorčestve Valentina Rasputina, in: Fol'klor i literatura Sibiri, vyp. III, Omsk 1978, S. 133-144

Rol' fol'klora $v$ sovremennoj russkoj proze o derevne, Diss... kand. Fil..., Moskva 1977

Proza Valentina Rasputina, in: ders., Pereklička èpoch, Moskva 1980, S.198-311

Samaja krovnaja svjaz'. Sud'by derevni v sovremennoj proze, Moskva 1977

Zur Entfremdungs - und Identitatsproblematik in der Sowjetprosa der 60er und 70er Jahre. Eine literatursoziologische Untersuchung, Diss. München 1981 


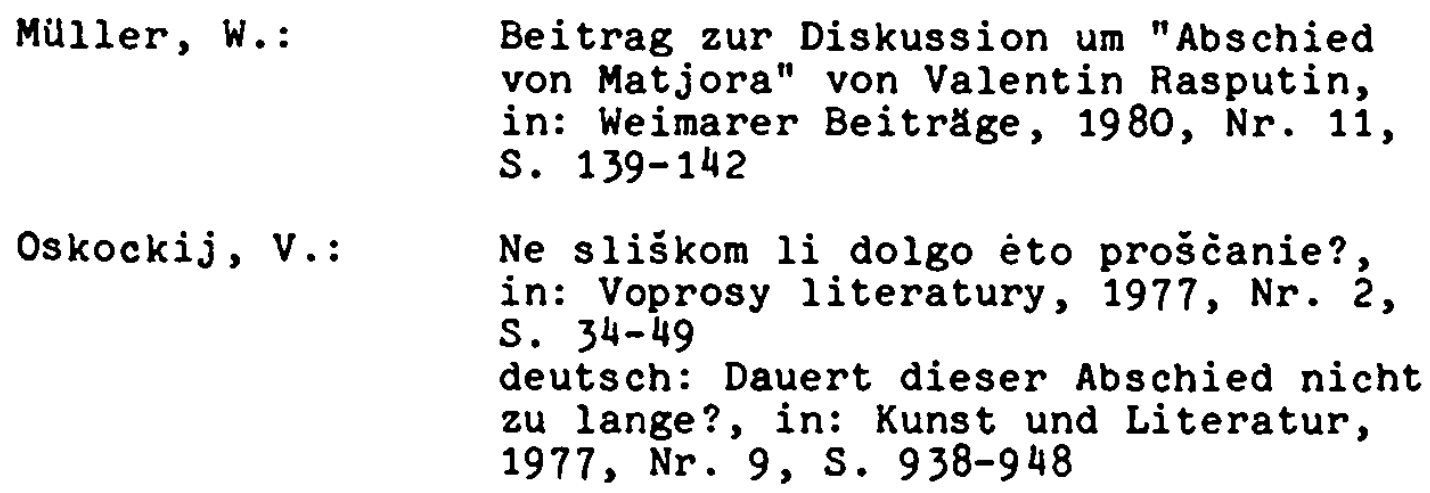

Oskockij, V.: Ne sliškom li dolgo èto prošc̀anie?, in: Voprosy literatury, 1977, Nr. 2, S. $34-49$

deutsch: Dauert dieser Abschied nicht zu lange?, in: Kunst und Literatur, 1977, Nr. 9, S. 938-948

Ovčarenko, A.: Vernost' svoej probleme, in: Voprosy literatury, 1977, Nr. 2, S. 63-72 deutsch: Treu seinem Problem, in: Kunst und Literatur, 1977; Nr. 10, S. 1047-1053

Pankin, B.:

Prośčanija i vstreči s Matëroj. Zametki o proze $V$. Rasputina, in: Drużba narodov, 1978, Nr. 2, S. 236-248

Plavius, H.:

Beitrag zur Diskussion um "Abschied von Matjora" von Valentin Rasputin, in: Weimarer Beitrăge, 1980, Nr. 11, S. $142-144$

Podzorova, N.: Raznozvućie. Zlobodnevnoe i većnoe v proze Valentina Rasputina, in: Naś sovremennik, 1978, Nr. 10, S. 180-186

Proza Valentina Rasputina. Rundtischgesprăch der Zeitschrift "Voprosy literatury", in: Voprosy literatury, 1977, $\mathrm{Nr} .2, \mathrm{~S} .3-81$

Salynskij, 0.: Dom i dorogi, in: Voprosy literatury, 1977, Nr. 2, S. 4-34 deutsch: Das Haus und die Wege, in: Kunst und Literatur, 1977, Nr.9, S. 918-938

Śapośnikov, V.N.: Valentin Rasputin, Novosibirsk 1978

Schaumann, G.: Beitrag zur Diskussion um "Abschied von Matjora" von Valentin Rasputin, in: Weimarer Beiträge, 1980, Nr. 11, S. 144-147

Seleznev, Ju.: Zemlja ili territorija?, in: Voprosy literatury, 1977, Nr. 2, S. 49-63 deutsch: Erde oder Territorium?, in: Kunst und Literatur, 1977, Nr. 10, S. 1038-1047

Šepeleva, L.S.: Sovremennaja povest' o derevne, in: Voprosy istorii i literatury, Celjabinsk 1974, vyp. 12 , S. 3-21 
Slabovskaja, E.G.: Ċelovek i priroda v povesti V. Rasputina "Živi $i$ pomni", in: Literatura $i$ rol'klor Vostočnoj Sibiri, Irkutsk 1978, S. 82-90

Starikova, E.G.: Obratimsja k iizni, in: Voprosy literatury, 1977 , Nr. 2, S. 72-80

deutsch: Wenden wir uns dem Leben $z u$, in: Kunst und Literatur, 1977, Nr. 10, S. 1053-1057

dies.: $\quad \dot{z}_{i t}{ }^{\prime} i$ pomnit'. Zametki o proze V. Rasputina, in: Novyj mir, 1977, Nr. 11, S. 236-248

Surowzew, J.: Zur multinationalen sowjetischen Prosa der siebziger Jahre, in: Kunst und $\mathrm{Li}-$ teratur, 1977, Nr. 8, S. 808-819

Tenditnik, N.S.: Otvetstvennost' talanta. 0 tyorcestve V. Rasputina, Irkutsk 1978

Terakopjan, L.A.: Blagodarnaja pamjat'. Povesti V. Rasputina, in: Molodaja grardija, 1977 , Nr. 6, S. 250-271

Teßmer, B.:

Mensch, Natur, Gesellschaft in der Prosa Vasilij Belovs und Valentin Rasputins, in: Zeitschrift fur Slavistik, 1983, Nr. 2, S. 194-203

Thun, N.:

Dialog mit Rasputin, in: Sinn und Form, 1980, Nr. 1, S. 197-207

dies.:

Beitrag zur Diskussion um "Abschied von Matjora" von Valentin Rasputin, in: Weimarer Beitrăge, 1980, $\mathrm{Nr} .11$, S. $147-150$

Ubersetzung im Disput. Rasputins "Prośc̆anie s Matëroj", in: Neue deutsche Literatur, 1980, $\mathrm{Nr} .7$, S. 102-117

Vasil'ev, V.: $\quad$ Sopricastnost' izizni, Moskva 1977

Zabelin, P.V.: Russkij ċelovek v proze V. Rasputina, in: ders., Literaturnyj raz-ezd. Razmyślenija o tvorćestve irkutskich pisatelej, Irkutsk 1974, S. 62-86

Zacharova, E.I.: Ėto stanovitsja tradiciej. Valentin Rasputin $v$ MGU, in: Vestnik Moskovskogo universiteta, 1977, ser. IX, filologija, $\mathrm{Nr} .3$, S. 79-86

Zalygin, S.: Povesti Valentina Rasputina, in: Valentin Rasputin, Povesti, Moskva ("Molodaja gvardija") 1978, S. 3-12 
4. Verschiedenes

Bachtin, M.M.: Probleme der Poetik Dostoevskijs, Munchen 1971

Belaja, G.A.: Zakonomernosti stilevogo razvitija sovetskoj prozy dvadcatych godov, Moskva 1977

dies.:

Stil' i vremja ("Avtoritetnyj" stil' i ego problematika), in: Mnogoobrazie stilej sovetskoj literatury. Voprosy tipologii, Moskva 1978, S. 231-256

dies.:

Gesetzmabigkeiten der Stilentwicklung der sowjetischen Prosa, in: Kunst und Li teratur, 1978, Nr. 7, S. 726-740

Bunin, I.: Das Leben Arsenjews, Berlin und Weimar 1979

Dunn, S.B. U. E.: Kulturwandel im sowjetischen Dorf, Berlin 1977

Lichačev, D.S.: Zametki $\circ$ russkom, in: Novyj mir, 1980, Nr. 3, S. 10-38

Vinogradov, V.V.: 0 teorii chudożestvennoj reči, Moskva 1971

ders.:

O jazyke chudožestvennoj literatury, Moskva 1959 
w

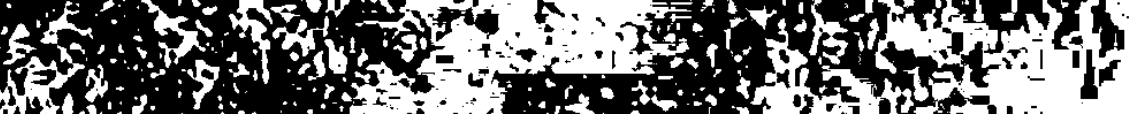

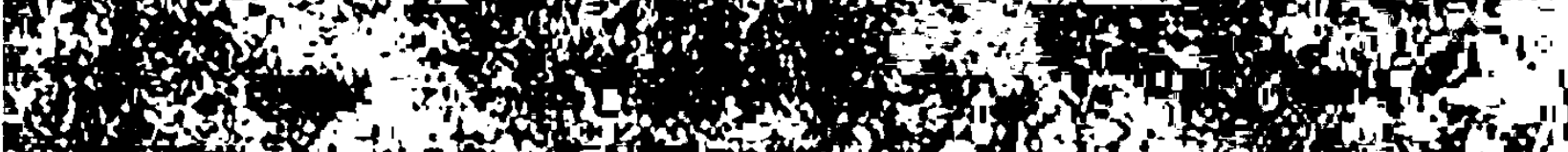

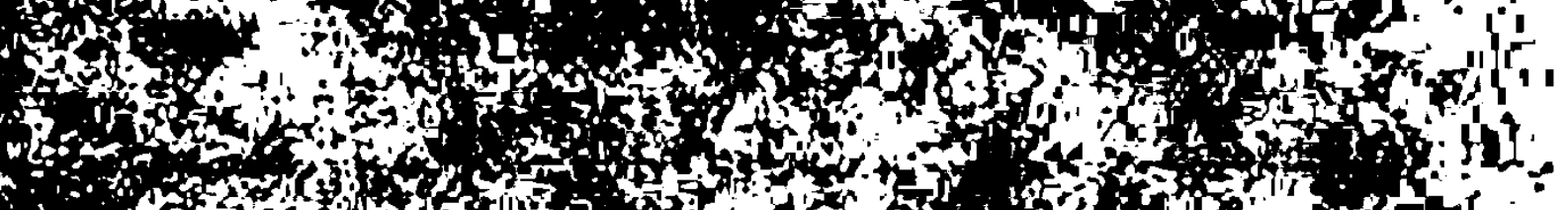
7.

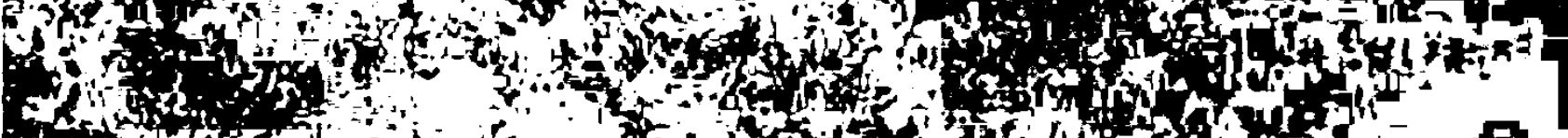

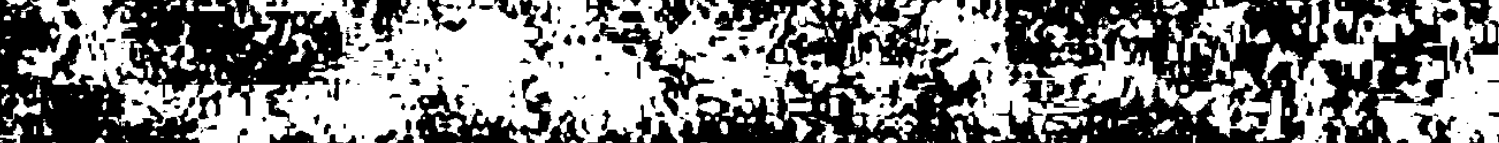

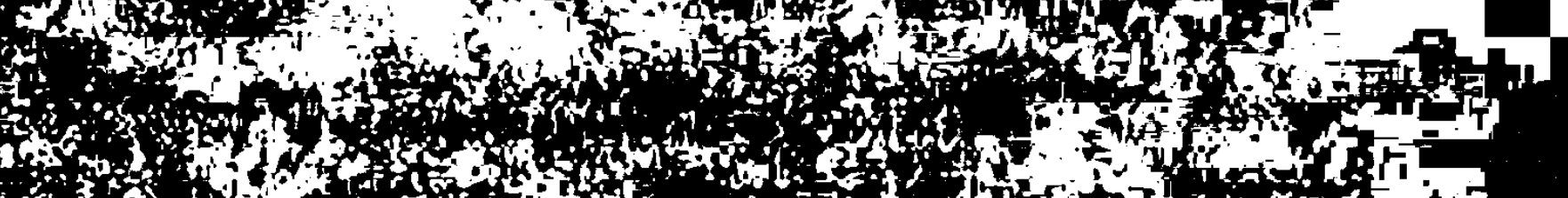

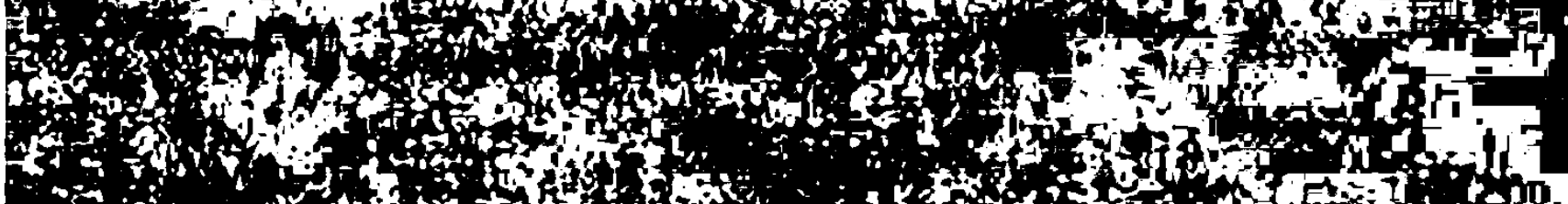

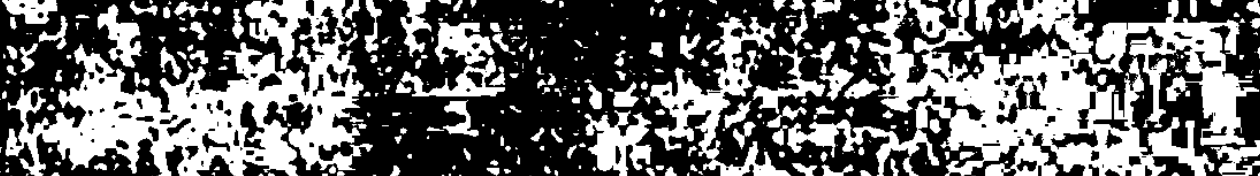

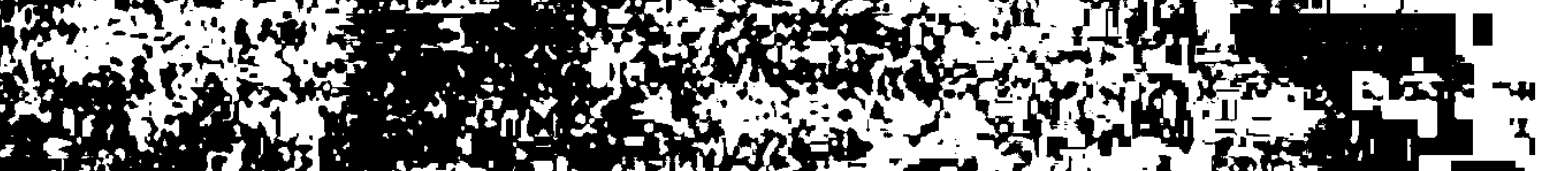

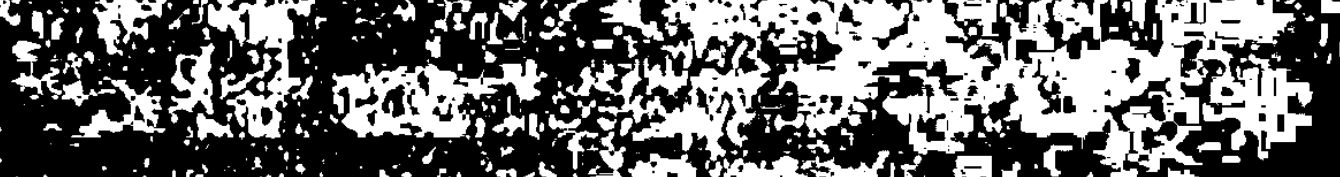

soly (1)

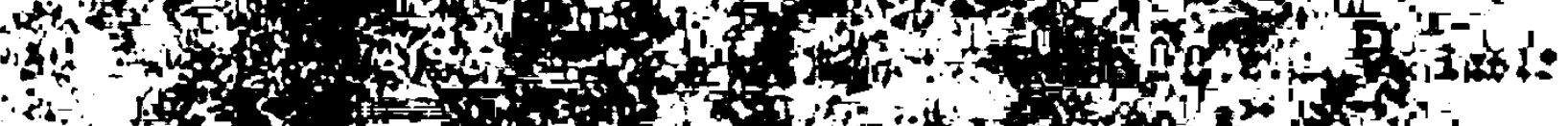

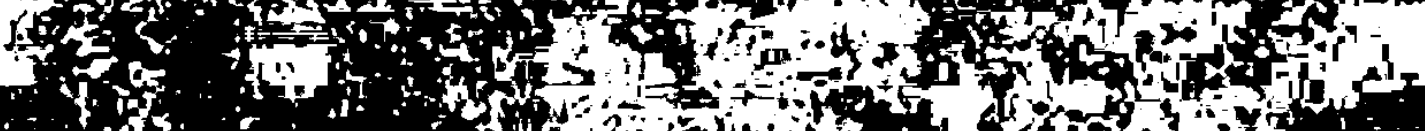

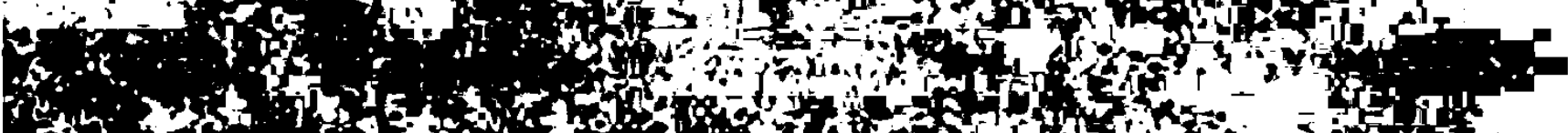

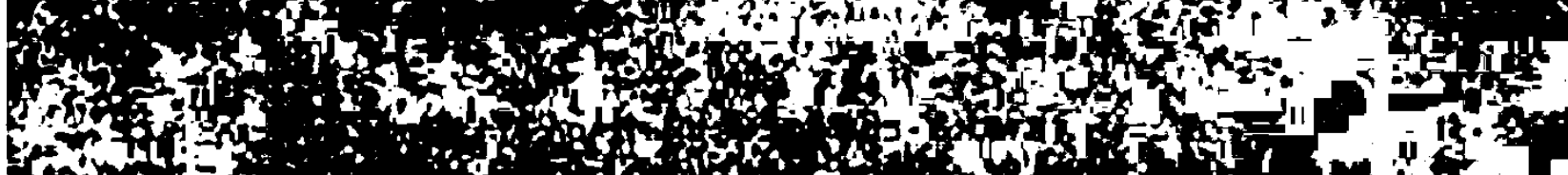
(and W (3)

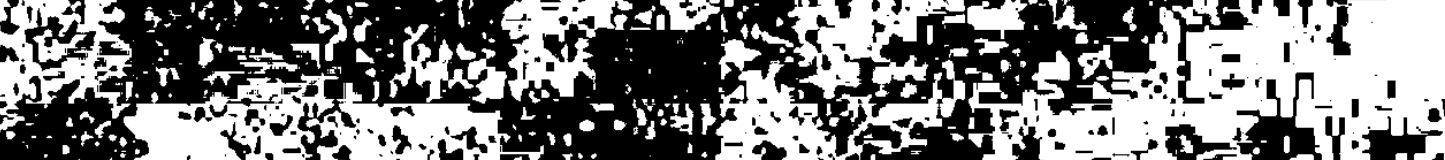

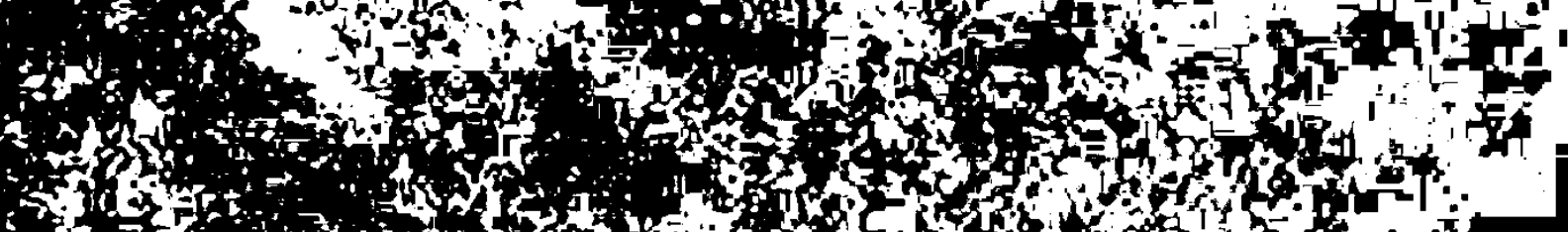

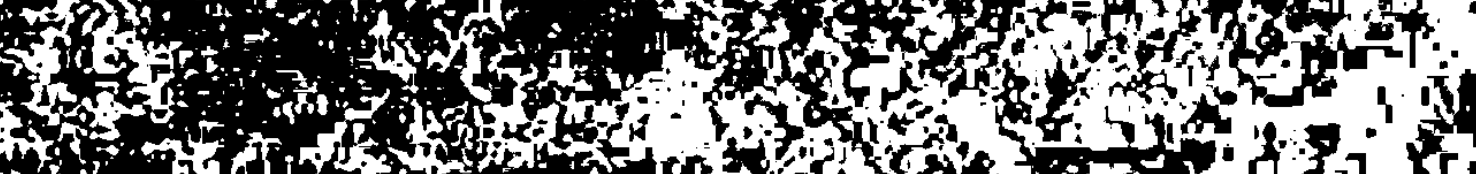
$\frac{1}{7}$

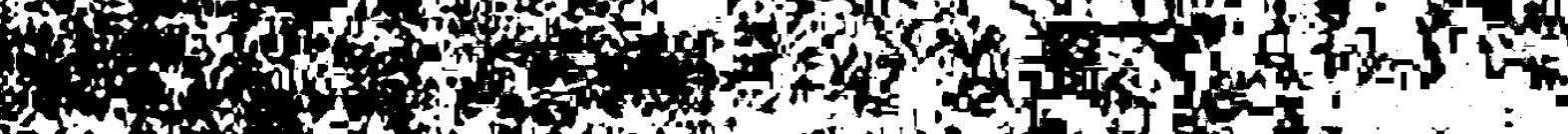

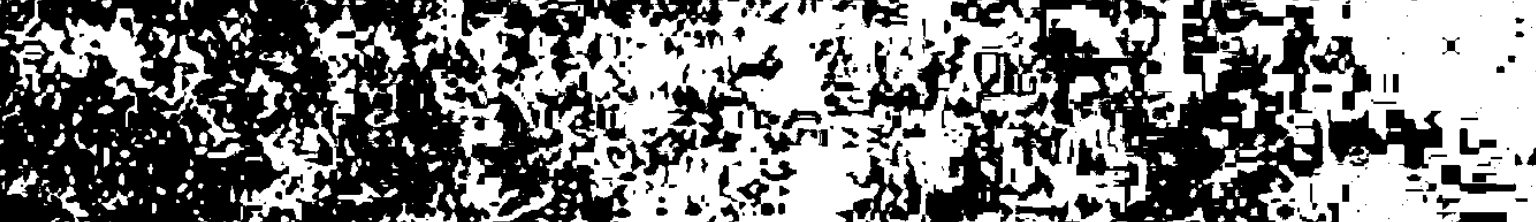

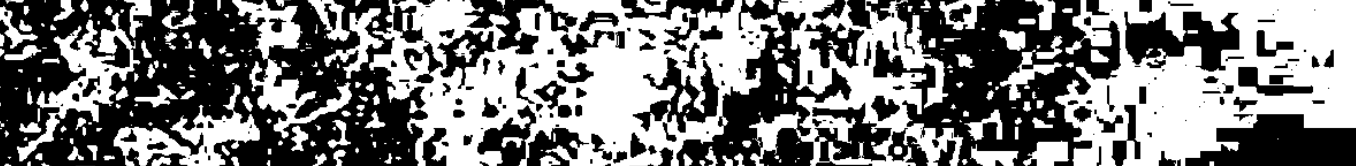

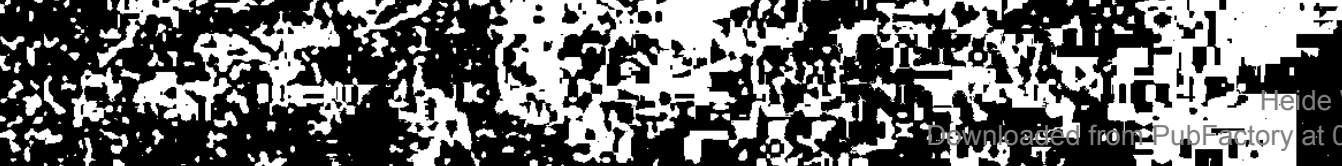

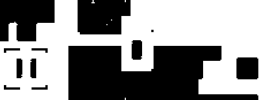




\section{SLAVISTISCHE BEITRAGE}

150. Deppermann, M.: Andrej Belyjs ästhetische Theorie des sch bpferischen BewuBtseins. Symbolisierung und Krise der Kultur um die Jahrhundertwende. 1982. X, $256 \mathrm{~S}$.

151. Meichel, J.: Zur Entfremdungs- und Identitatsproblematik in der Sowjetprosa der 60er und 70er Jahre. Eine Iiteratursoziologische Untersuchung. 1981. $217 \mathrm{~S}$.

152. Davydov, S.: "Teksty-Matreški" Vladimira Nabokova. 1982. VI, $252 \mathrm{~S}$.

153. Wallrafen, C.: Maksimilian Volos̄in als Künstler und Kritiker. 1982. IV, $273 \mathrm{~S}$.

154. Dienes, L.: Russian Literature in Exile: The Life and Work of Gajto Gazdanov. 1982. XII, 224 S., 7 Abb.

155. Bulgarien 1300. Referate der Sektion "Sprache und Iiteratur" des Symposiums "Bulgarien in Geschichte und Gegenwart", Hamburg 9.-17. Mai 1981. Herausgegeben von Peter Hill. 1982. $97 \mathrm{~S}$.

156. Bock, I.: Die Analyse der Handlungsstrukturen von Erzählwerken am Beispiel von N.V. Gogol's "Die Nase" und "Der Mantel". 1982. VIII, $168 \mathrm{~S}$.

157. Pihler, M.: Die ,Progres8ive, Form des englischen Verbs und ihre Ubersetzungsmöglichkeiten im Slowenischen. 1982. $170 \mathrm{~s}$.

158. Sesterhenn, R.: Das Bogostroitel'stvo bel Gor'kij und Lunačarskij bis 1909. Zur ideologischen und literarischen Vorgeschichte der Parteischule von Capri. 1982. VIII, $366 \mathrm{~s}$.

159. Kunstmann, H.: Vorläufige Untersuchungen uber den bairischen Bulgarenmord von $631 / 632$. Der Tatbestand. Nachklänge im Nibelungenlied. 1982. $104 \mathrm{~S}$.

160. Slavistische Linguistik 1981. Referate des VII. Konstanzer Slavistischen Arbeitstreffens Mainz 30.9.-2.10.1981. Herausgegeben von Wolfgang Girke. 1982. $264 \mathrm{~S}$.

161. Stobbe, P.: Utopisches Denken bei V. Chlebnikov. 1982. VIII, $157 \mathrm{~S}$.

162. Neureiter, F.: WeiBrussische Anthologie. Ein Lesebuch zur weibrussischen Literatur (mit deutschen Ubersetzungen). 1983. $230 \mathrm{~S}$.

163. Witte, G.: Die sowjetische Kolchos- und Dorfprosa der funfziger Jahre. Zur Evolution einer literarischen Unterreihe. 1983. X, $292 \mathrm{~S}$.

164. Timroth, W.v.: Russische und sowjetische Soziolinguistik und tabuisierte Varietäten des Russischen. 1983. VIII, $194 \mathrm{~S}$.

165. Christians, D.: Die Sprachrubrik in der Literaturnaja gazeta von 1964 bis 1978. Dokumentation und Auswertung. 1983. $266 \mathrm{~S}$.

166. Koschmal, W.: Das poetische System der Dramen I.S. Turgenevs. Studien zu einer pragmatischen Dramenanalyse. 1983. X, $453 \mathrm{~S}$. 
167. Hofmann, T.: Das Bauerntum in der sowjetrussischen Prosa der 20er Jahre. Konzeptionen, Konflikte und Figuren. 1983. $434 \mathrm{~S}$.

168. Morsbach, P.: Isaak Babel' auf der sowjetischen Bühne. 1983. X, 255 S.

169. Tutschke, G.: Die glagolitische Druckerei von Rijeka und ihr historiographisches Werk Knizice od zitiē rimskih arhierëov 1 cesarov. 1983. $373 \mathrm{~s}$.

170. Lam, A.: Mainzer Vorlesungen uber die polnische Iiteratur seit 1918. 1983. IV, $280 \mathrm{~S}$.

171. Pratt, S.: The Semantics of chaos in Tjutčev. 1983. VIII, $149 \mathrm{~S}$.

172. Slavistische Iinguistik 1982. Referate des VIII. Konstanzer Slavistischen Arbeitstreffens Kiel 28.9. - 1.10.1982. Herausgegeben von Hans Robert Mehlig. 1983. $262 \mathrm{~S}$.

173. Dingley, J.: The Peripheral Plural Endings of Nouns in Petrine Sermons. 1983. VIII, $388 \mathrm{~S}$.

174. Hoelscher-Obermaler, H.-P.: Das lyrische Werk Antoni Langes. Untersuchungen zur Dichtungssprache eines, jungpolnischen' Autors. 1983. $127 \mathrm{~s}$.

175. Bojle, V., W. Oschlies: Lehrbuch der mazedonischen Sprache. $1984.185 \mathrm{~s}$.

176. Roedel-Kappl, C.: Analogie und Sprachwandel im Vergleich zweier verwandter Sprachen: Russisch und Polnisch. 1984. $X, 246$ S.

177. Kattein, R.: Die Pronominalsysteme der slavischen Sprachen. 1984. IV, 142 S.

178. Wust, H.: Tradition und Innovation in der sowjetischen Dorfprosa der sechziger und siebziger Jahre. zu Funktion, Darstellung und Gehalt des dorflichen Helden bei Vasilij Sukzin und Valentin Rasputin. 1984. VIII, $249 \mathrm{~S}$. 